\title{
SISTEMATIZAÇÃO DAS CAUSAS DE INSUCESSO NA IMPLEMENTAÇÃO DE PROGRAMAS DE QUALIDADE: \\ UMA PROPOSIÇÃO DE AJUSTES AO PROGRAMA SEBRAE DE QUALIDADE TOTAL EM PEQUENAS EMPRESAS
}

Márcia Freire de Oliveira

Dissertação apresentada à Escola de Engenharia de São Carlos da Universidade de São Paulo, como parte dos requisitos para obtenção do título de Mestre em Engenharia de Produção.

ORIENTADOR: Prof. Dr. Edmundo Escrivão Filho

São Carlos

2002 


\section{DEDICATÓRIA}

Aos meus pais e irmãos 


\section{AGRADECIMENTOS}

$>$ À Deus, pela dádiva de viver, por ser guia de meus caminhos.

$>$ Ao meu orientador, Prof. Dr. Edmundo Escrivão Filho, pela orientação valiosa e fundamental, pelo empenho dispensado para a execução deste trabalho, pela amizade sincera e pela pessoa que és. Sem dúvida alguma você me proporcionou um grande crescimento profissional e humano, obrigada!

> Aos professores Carpinetti e Hermosilla pelas importantes contribuições feitas ao trabalho no exame de qualificação.

$>$ Aos professores e funcionários do Departamento da Engenharia de Produção que mesmo indiretamente contribuíram para a realização da pesquisa. Silvana, obrigada pela amizade!!!

> Ao Sebrae Franca, na figura de Gustavo, ao Sebrae Uberlândia, em especial à Luísa, e aos consultores do Programa Sebrae de Qualidade Total entrevistados, pelas informações repassadas.

> Aos proprietários/diretores e funcionários das empresas pesquisadas, pela atenção dedicada e informações cedidas.

> Aos meus pais, Maurisio e Cecília, pelo amor incondicional, por sempre terem acreditado em mim e apoiado as minhas decisões, vocês são a base da minha vida.

$>$ Aos meus irmãos Marcelo e Marcos, pelo apoio e amor.

> À Ana Cláudia e ao Maurício pela acolhida logo que cheguei em São Carlos e pela amizade construída ao longo desses anos.

> Aos amigos da pós-graduação, pelo auxílio no curso, na pesquisa, pelos momentos inesquecíveis de descontração que passamos juntos, pela amizade, pelo ombro amigo nas horas de lamentação e desabafo. Eu levaria no mínimo meia página para citar nomes...

$>$ Aos amigos do alojamento, fazendo um agradecimento especial ao Clayton e ao Lucas pela acolhida em Franca durante a Pesquisa de Campo.

> A todos os outros amigos que fiz aqui em São Carlos e aos que mesmo distantes, estarão sempre comigo.

$>$ Ao Serginho, pelo carinho, atenção e exemplo de pessoa, você vai sempre ser especial.

> À FAPESP, órgão financiador deste trabalho, por ter proporcionado recursos para a sua execução. 


\section{SUMÁRIO}

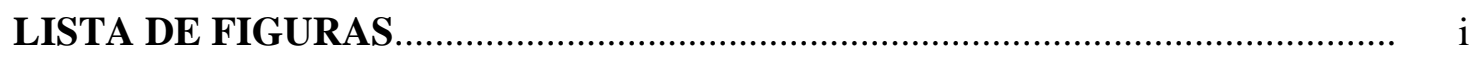

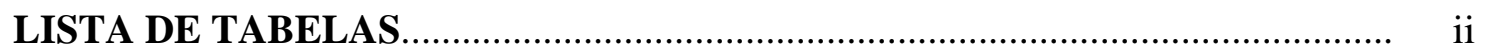

LISTA DE ABREVIATURAS E SIGLAS.......................................................... iv

RESUMO

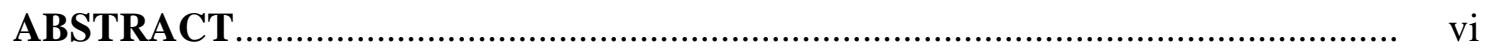

CAPÍTULO 1 - APRESENTAÇÃO........................................................................... 1

1.1 INTRODUÇÃO ............................................................................................ 1

1.2 CARACTERIZAÇÃO DO TEMA DA PESQUISA........................................ 2

1.3 FORMULAÇÃO DO PROBLEMA DA PESQUISA......................................... 3

1.4 DECLARAÇÃO DOS OBJETIVOS DA PESQUISA....................................... 4

1.5 RELEVÂNCIA DA PESQUISA EM ABORDAR O TEMA............................ 5

1.6 MOTIVAÇÃO PELO TEMA DA PESQUISA................................................... 6

1.7 ESTRUTURA DO TRABALHO................................................................... 7

CAPÍTULO 2 - GESTÃO DA QUALIDADE TOTAL (TQM) ............................... 9

2.1 SURGIMENTO DA GESTÃO DA QUALIDADE TOTAL............................... 9

2.2 QUALIDADE: CONCEITOS E ABORDAGENS........................................... 11

2.2.1 Conceitos de Qualidade.......................................................................... 12

2.2.2 Abordagens da Qualidade................................................................... 13

2.2.2.1 Joseph M. Juran......................................................................... 13

2.2.2.2 W. Edwards Deming................................................................ 14

2.2.2.3 Kaoru Ishikawa................................................................ 15

2.2.2.4 Philip Crosby ....................................................................... 17 
2.2.2.5 Armand V. Feigenbaum ....................................................... 18

2.2.2.6 Pontos Comuns aos Gurus da Qualidade................................... 20

2.3 DEFININDO A GESTÃO DA QUALIDADE TOTAL .................................. 20

2.4 PRINCÍPIOS DA TQM............................................................................ 22

2.5 SISTEMA DA QUALIDADE.................................................................. 24

2.6 FERRAMENTAS DA QUALIDADE......................................................... 26

2.6.1 Gráfico de Pareto................................................................................ 26

2.6.2 Diagrama de Causa e Efeito.............................................................. 27

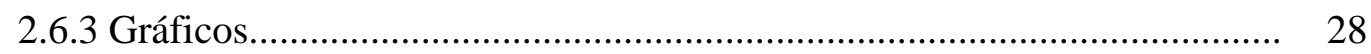

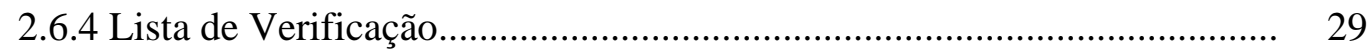

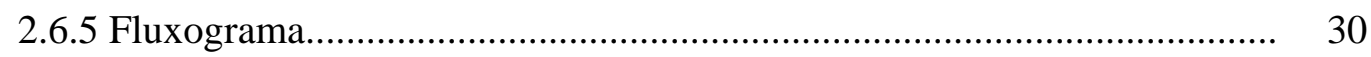

2.6.6 Matriz de Preferência......................................................................... $\quad 30$

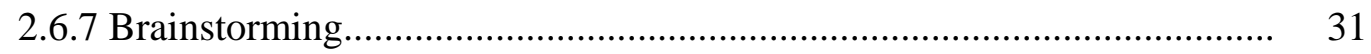

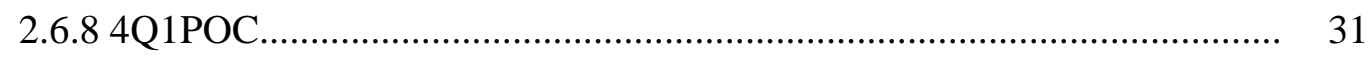

2.6.9 Matriz de Decisão............................................................................. 31

2.6.10 Técnica do Grupo Nominal................................................................. 32

2.7 MODELOS E PROGRAMAS DE IMPLEMENTAÇÃO DA TQM................ 33

CAPÍTULO 3 - CONTEXTO DAS PEQUENAS EMPRESAS.............................. 36

3.1 CLASSIFICAÇÃO DAS EMPRESAS....................................................... 36

3.2 IMPORTÂNCIA DA PEQUENA EMPRESA................................................ 39

3.2.1 Importância da Pequena Empresa em Algumas Economias Mundiais..... 40

3.2.2 Importância da Pequena Empresa no Brasil............................................. 41

3.2.3 Importância da Pequena Empresa no Estado de São Paulo....................... 42

3.3 GESTÃO DE PEQUENAS EMPRESAS...................................................... 43

3.4 CAUSAS DE SUCESSO E INSUCESSO DAS PEQUENAS EMPRESAS..... 44

3.5 GESTÃO DA QUALIDADE NAS PEQUENAS EMPRESAS........................ 47

3.5.1 Importância TQM nas Pequenas Empresas............................................. 48

3.5.2 Influência do Tamanho da Organização nos Resultados da TQM............ 48

3.5.3 Características da Pequena Empresa e Vantagens e Desvantagens na Utilização da TQM................................................................................... 50

CAPÍTULO 4 - PROGRAMA SEBRAE DE QUALIDADE TOTAL - PSQT..... 52

4.1 FILOSOFIA BÁSICA DO PSQT.............................................................. 53

4.2 HISTÓRICO DO PROGRAMA............................................................... 54

4.3 ESTRUTURA DO PROGRAMA.............................................................. 60

4.4 METODOLOGIA DO PROGRAMA........................................................... 66

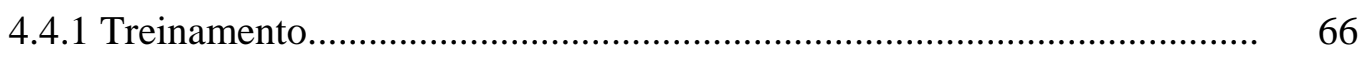

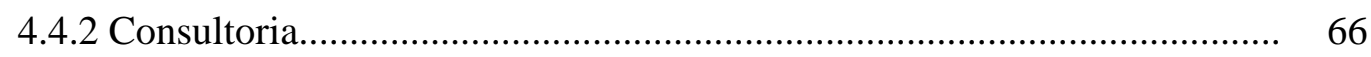

4.4.3 Implantação Orientada...................................................................... 66

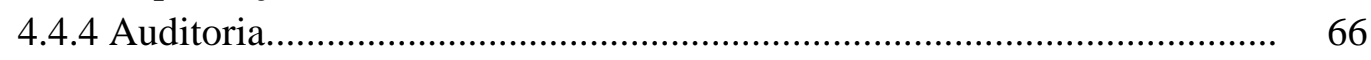


4.4.5 O Papel de Cada Um no Programa.

CAPÍTULO 5 - INSUCESSO DOS PROGRAMAS DE QUALIDADE..

5.1 CAUSAS DE INSUCESSO NA IMPLANTAÇÃO DE PROGRAMAS DE QUALIDADE.

5.2 CAUSAS DE INSUCESSO NA IMPLANTAÇÃO DE PROGRAMAS SEBRAE DE QUALIDADE TOTAL

CAPÍTULO 6 - TRABALHO DE CAMPO E DESCRIÇÃO DAS EMPRESAS .. 76

6.1 METODOLOGIA........................................................................................ 76

6.1.1 Caracterização da Pesquisa................................................................. 76

6.1.2 Questões da Pesquisa.............................................................................. 77

6.1.3 Variáveis da Pesquisa.......................................................................... $\quad 78$

6.1.4 Técnicas de Coleta de Dados............................................................... 78

6.2 DESCRIÇÃO DAS EMPRESAS.................................................................. 79

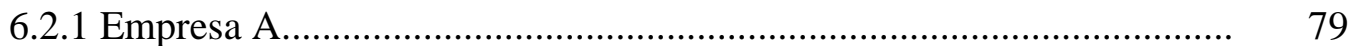

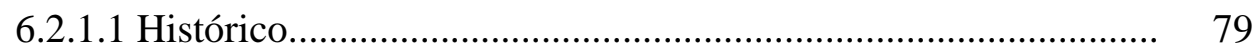

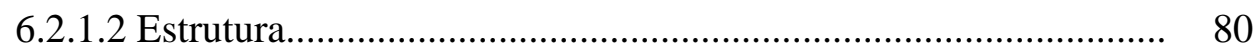

6.2.1.3 Mercado e Estratégia de Atuação................................................ 81

6.2.1.4 Recursos Humanos............................................................... 81

6.2.1.5 Situação Financeira.............................................................. 82

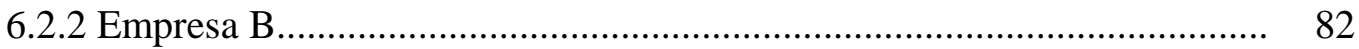

6.2.2.1 Histórico...................................................................... 82

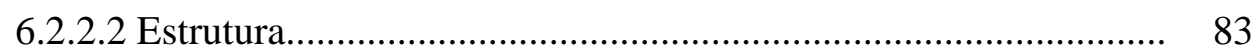

6.2.2.3 Mercado e Estratégia de Atuação.............................................. 84

6.2.2.4 Recursos Humanos............................................................... 84

6.2.2.5 Situação Financeira............................................................. 85

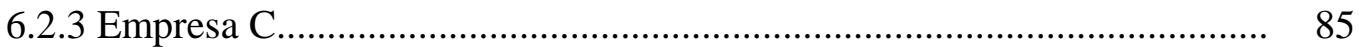

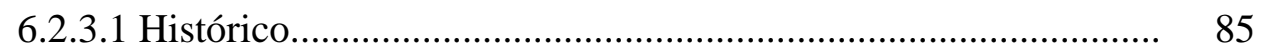

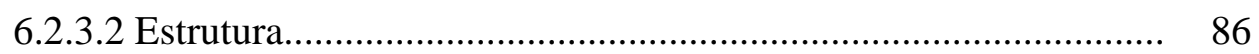

6.2.3.3 Mercado e Estratégia de Atuação.............................................. 87

6.2.3.4 Recursos Humanos............................................................... 87

6.2.3.5 Situação Financeira........................................................... 88

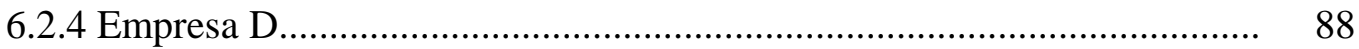

6.2.4.1 Histórico...................................................................... 88

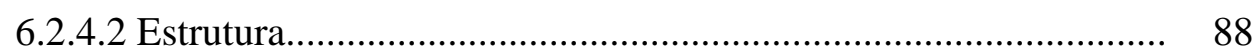

6.2.4.3 Mercado e Estratégia de Atuação.............................................. 89

6.2.4.4 Recursos Humanos................................................................... 90

6.2.4.5 Situação Financeira.............................................................. 90

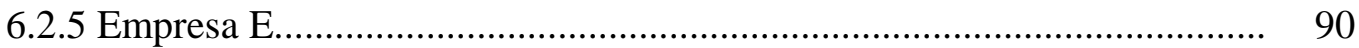

6.2.5.1 Histórico......................................................................... 90 


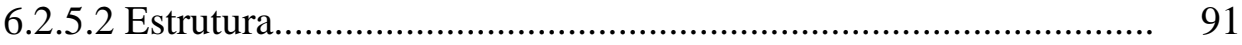

6.2.5.3 Mercado e Estratégia de Atuação............................................. 92

6.2.5.4 Recursos Humanos................................................................. 93

6.2.5.5 Situação Financeira................................................................. 93

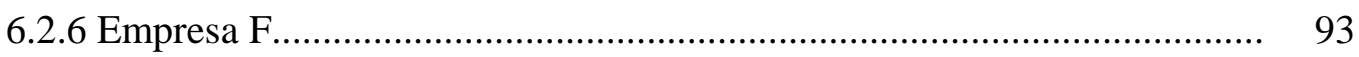

6.2.6.1 Histórico.............................................................................. 93

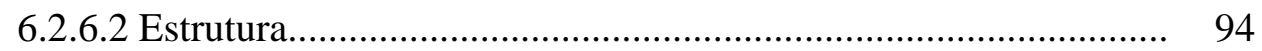

6.2.6.3 Mercado e Estratégia de Atuação.............................................. 95

6.2.6.4 Recursos Humanos.................................................................. 96

6.2.6.5 Situação Financeira................................................................ 96

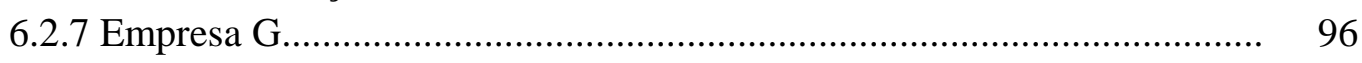

6.2.7.1 Histórico ........................................................................... 96

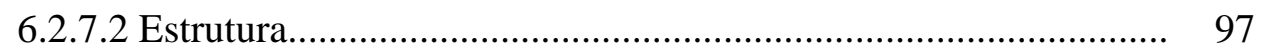

6.2.7.3 Mercado e Estratégia de Atuação.............................................. 98

6.2.7.4 Recursos Humanos.................................................................. 99

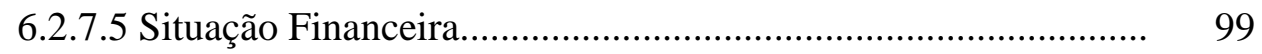

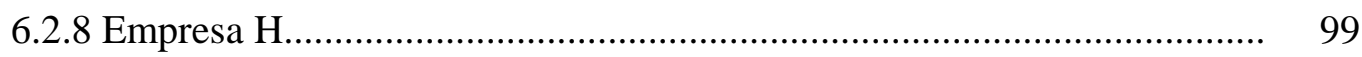

6.2.8.1 Histórico.............................................................................. 99

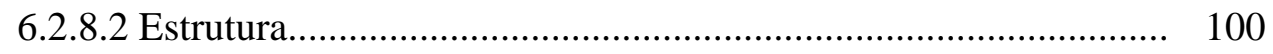

6.2.8.3 Mercado e Estratégia de Atuação............................................. 101

6.2.8.4 Recursos Humanos............................................................... 101

6.2.8.5 Situação Financeira............................................................... 102

6.2.9 Empresa I........................................................................... 102

6.2.9.1 Histórico.......................................................................... 102

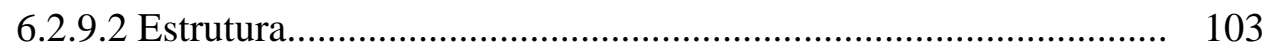

6.2.9.3 Mercado e Estratégia de Atuação............................................. 104

6.2.9.4 Recursos Humanos............................................................... 105

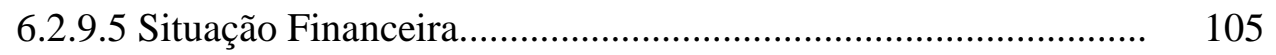

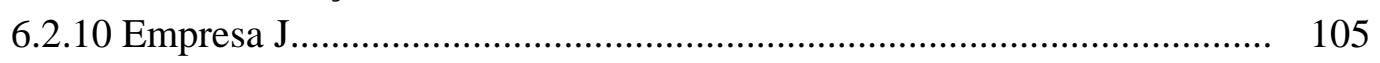

6.2.10.1 Histórico......................................................................... 105

6.2.10.2 Estrutura......................................................................... 106

6.2.10.3 Mercado e Estratégia de Atuação.......................................... 107

6.2.10.4 Recursos Humanos............................................................ 107

6.2.10.5 Situação Financeira.............................................................. 107

CAPÍTULO 7 - APRESENTAÇÃO DOS DADOS................................................. 109

7.1 ENTREVISTAS COM OS PROPRIETÁRIOS/PESSOAS-CHAVE............... 109

7.1.1 Empresa A............................................................................................... 109

7.1.2 Empresa B..................................................................................... 113

7.1.3 Empresa C................................................................................. 117

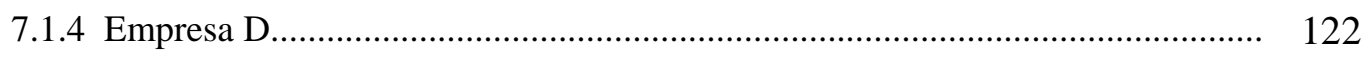




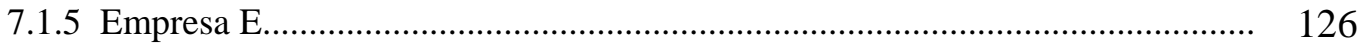

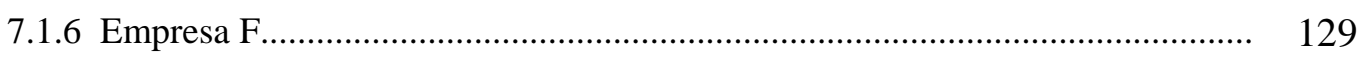

7.1.7 Empresa G........................................................................................ 133

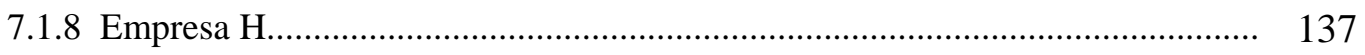

7.1.9 Empresa I............................................................................................ 141

7.1.10 Empresa J................................................................................... 145

7.2 ENTREVISTAS COM OS FUNCIONÁRIOS TREINADOS PELO PSQT... 148

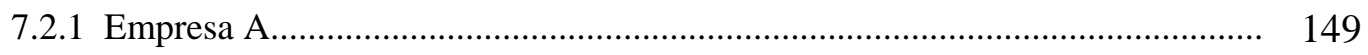

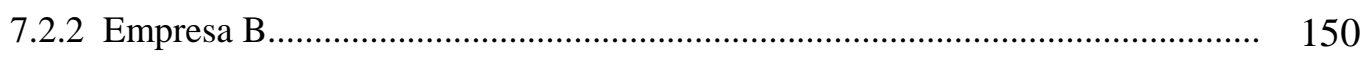

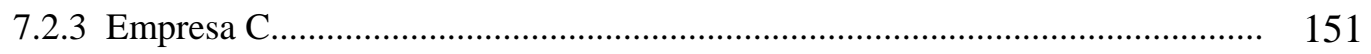

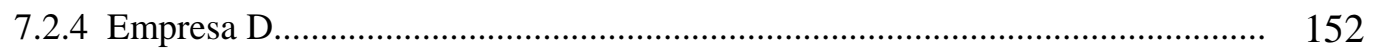

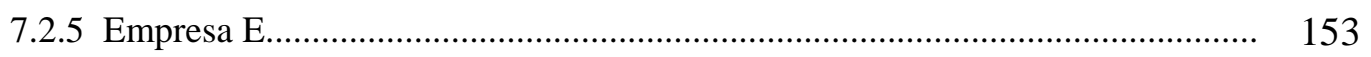

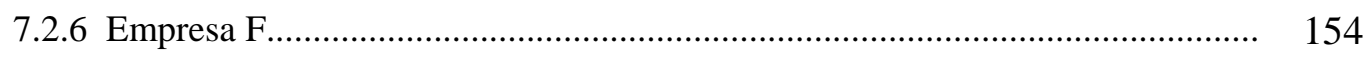

7.2.7 Empresa G...................................................................................... 155

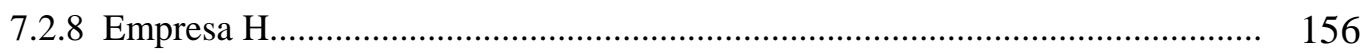

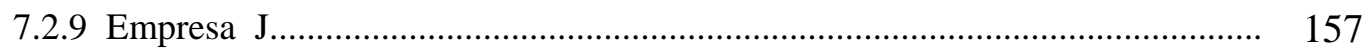

7.3 ENTREVISTAS COM OS CONSULTORES DO PSQT.............................. 158

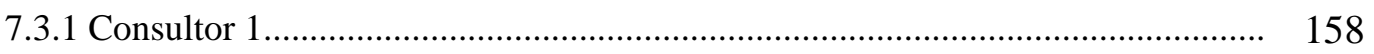

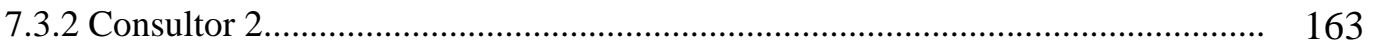

7.3.3 Consultor 3........................................................................................... 166

CAPÍTULO 8 - ANÁLISE DOS DADOS............................................................ 172

8.1 ANÁLISE DAS EMPRESAS............................................................................... 172

8.1.1 Empresa A............................................................................................ 172

8.1.2 Empresa B.................................................................................... 174

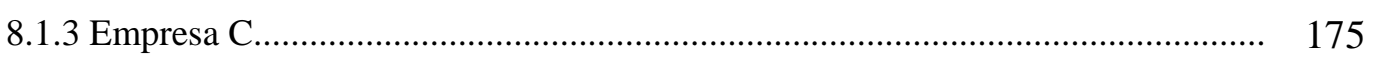

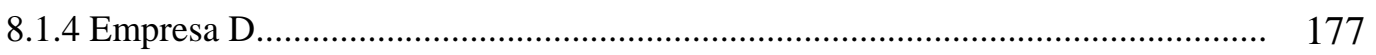

8.1.5 Empresa E....................................................................................... 179

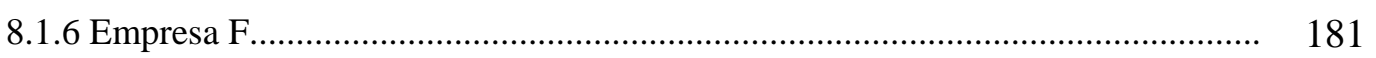

8.1.7 Empresa G......................................................................................... 183

8.1.8 Empresa H....................................................................................... 184

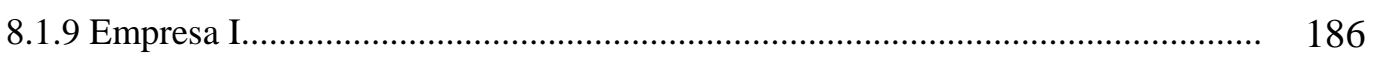

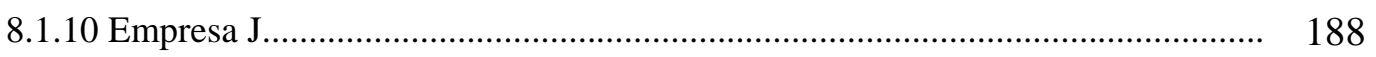

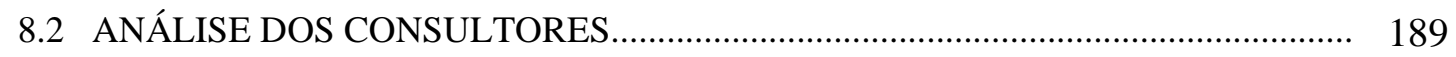

8.3 OBSERVAÇÕES DA PESQUISADORA................................................................... 192

8.4 CLASSIFICAÇÃO DAS CAUSAS DE INSUCESSO EM FATORES........................... 193

CAPÍTULO 9 - CONSIDERAÇÕES FINAIS................................................ 199

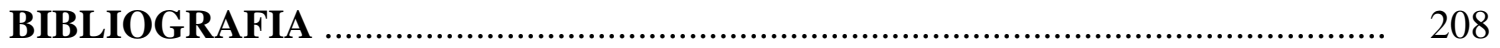

BIBLIOGRAFIA REFERENCIADA........................................................... 208 


\section{APÊNDICES}

APÊNDICE 1 Questionário de Caracterização da Empresa

APÊNDICE 2 Questionário (Proprietário/pessoa-chave)

APÊNDICE 3 Questionário (Funcionários treinados no PSQT)

APÊNDICE 4 Questionário (Consultor)

APÊNDICE 5 Informações Obtidas Através da Análise Documental

APÊNDICE 6 Nível de Implantação das Tarefas do PSQT por Bloco 


\section{LISTA DE FIGURAS}

FIGURA 2.1 - Ciclo PDCA …............................................................................. 15

FIGURA 2.2 - Ex. de Gráfico de Pareto para Defeitos de Lentes.......................... 27

FIGURA 2.3 - Diagrama de Causa e Efeito............................................................ 28

FIGURA 2.4 - Diagrama de Dispersão............................................................... 28

FIGURA 2.5 - Ex. de Histograma. Rendimento de uma reação para produção de uma substância química ................................................................ 29

FIGURA 2.6 - Ex. de Fluxograma................................................................. $\quad 30$

FIGURA 3.1 - Fatores condicionantes à taxa de mortalidade................................. 46

FIGURA 3.2 - Fatores de Sucesso..................................................................... 47

FIGURA 5.1 - Obstáculos à TQM .................................................................... 71

FIGURA 6.1 - Organograma da Empresa A....................................................... 80

FIGURA 6.2 - Organograma da Empresa B..................................................... 83

FIGURA 6.3 - Organograma da Empresa C..................................................... 86

FIGURA 6.4 - Organograma da Empresa D.................................................... 89

FIGURA 6.5 - Organograma da Empresa E......................................................... 91

FIGURA 6.6 - Organograma da Empresa F....................................................... 94

FIGURA 6.7 - Organograma da Empresa G.................................................... 97

FIGURA 6.8 - Organograma da Empresa H....................................................... 100

FIGURA 6.9 - Organograma da Empresa I.......................................................... 103

FIGURA 6.10 - Organograma da Empresa J........................................................ 106 


\section{LISTA DE TABELAS}

TABELA 2.1 - As Quatro Principais Eras da Qualidade......................................... 10

TABELA 2.2 - Elementos da TQM................................................................... 21

TABELA 2.3 - Ex. Lista de Verificação. Reclamação de defeitos na porta do carro.

TABELA 2.4 - Ex. Matriz de Preferência. Escolha de cargo de diretor executivo..

TABELA 2.5 - Ex. Matriz de Decisão. Atraso na entrega dos resultados dos exames

TABELA 2.6 - Modelos de Implementação da TQM............................................... 34

TABELA 3.1 - Classificação das empresas segundo a estrutura administrativa..... 38

TABELA 3.2 - Classificação das MPEs segundo o número de empregados........... 39

TABELA 3.3 - Classificação das empresas segundo o faturamento bruto anual..... 39

TABELA 3.4 - Participação das MPEs na economia brasileira.............................. 42

TABELA 3.5 - Pessoal Ocupado - MPEs - Estado de São Paulo............................... 42

TABELA 3.6 - Pontos fortes e fracos da pequena empresa...................................... $\quad 45$

TABELA 3.7 - Taxa de mortalidade das MPEs....................................................... 46

TABELA 4.1 - Estrutura do Programa Sebrae - $1^{\mathrm{a}}$ versão........................................ 56

TABELA 4.2 - Estrutura do Programa Sebrae - 2 $2^{\mathrm{a}}$ versão........................................ 57

TABELA 4.3 - Comparação entre as metodologias............................................... 57

TABELA 4.4 - Estrutura do Programa Sebrae - $3^{\mathrm{a}}$ versão..................................... 59

TABELA 4.5 - Sensibilização: Compromisso com o Êxito..................................... 60

TABELA 4.6 - Bloco I - A Conquista da Qualidade................................................. 61

TABELA 4.7 - Bloco II - D’Olho na Qualidade..................................................... 63

TABELA 4.8 - Melhoria de Processos.................................................................. 64

TABELA 5.1 - Causas de insucesso dos programas de qualidade........................... 72

TABELA 5.2 - Causas de insucesso do PSQT.......................................................... $\quad 75$

TABELA 6.1 - Características das empresas pesquisadas....................................... 108 
TABELA 7.1 - Mudanças nas práticas gerenciais - Empresa A.............................. 112

TABELA 7.2 - Mudanças nas práticas gerenciais - Empresa B.............................. 115

TABELA 7.3 - Mudanças nas práticas gerenciais - Empresa C.............................. 119

TABELA 7.4 - Mudanças nas práticas gerenciais - Empresa D............................... 124

TABELA 7.5 - Mudanças nas práticas gerenciais - Empresa E............................... 128

TABELA 7.6 - Mudanças nas práticas gerenciais - Empresa F.............................. 132

TABELA 7.7 - Mudanças nas práticas gerenciais - Empresa G............................... 135

TABELA 7.8 - Mudanças nas práticas gerenciais - Empresa H.............................. 139

TABELA 7.9 - Mudanças nas práticas gerenciais - Empresa I................................ 143

TABELA 7.10 - Mudanças nas práticas gerenciais - Empresa J.............................. 147

TABELA 7.11 - Avaliação do nível de implantação do PSQT - consultor 1.......... 160

TABELA 7.12 - Avaliaçao do nível de implantação do PSQT - consultor 2........... 164

TABELA 7.13 - Avaliaçao do nível de implantação do PSQT - consultor 3........... 168

TABELA 8.1 - Causas de Insucesso: Empresa A................................................. 173

TABELA 8.2 - Causas de Insucesso: Empresa B................................................ 175

TABELA 8.3 - Causas de Insucesso: Empresa C................................................ 177

TABELA 8.4 - Causas de Insucesso: Empresa D............................................... 179

TABELA 8.5 - Causas de Insucesso: Empresa E................................................... 180

TABELA 8.6 - Causas de Insucesso: Empresa F.................................................... 182

TABELA 8.7 - Causas de Insucesso: Empresa G................................................ 184

TABELA 8.8 - Causas de Insucesso: Empresa H.................................................. 185

TABELA 8.9 - Causas de Insucesso: Empresa I..................................................... 187

TABELA 8.10 - Causas de Insucesso: Empresa J................................................ 189

TABELA 8.11 - Avaliação dos Consultores: Pontos Específicos do PSQT .......... 190

TABELA 8.12 - Fatores de Insucesso: Avaliação dos Consultores........................ 192

TABELA 8.13 - Classificação das Causas de Insucesso em Fatores:..................... 194

TABELA 8.14 - Ocorrência das Causas de Insucesso............................................. 195

TABELA 8.15 - Causas de Insucesso: Avaliação dos Consultores......................... 198 


\section{LISTA DE ABREVIATURAS E SIGLAS}

CCQ - Círculo de Controle da Qualidade

CIPA - Comissão Interna de Prevenção de Acidentes

EVA - Etileno Acetato Vinil

ISO - International Standart Organization

JUSE - Union of Japanese Scientists and Engineers

MAMP - Método de Análise e Melhoria de Processos

MPE's - Micro e Pequenas Empresas

PNQ - Prêmio Nacional da Qualidade

PPDC - Process Decision Program Chart

PSQT - Programa Sebrae de Qualidade Total

SEBRAE - Serviço Brasileiro de Apoio à Micro e Pequenas Empresas

TQC - Total Quality Control

TQM - Total Quality Management 


\section{RESUMO}

OLIVEIRA, M. F. (2002). Sistematização das Causas de Insucesso na Implementação de Programas de qualidade: uma proposição de ajustes ao Programa Sebrae de Qualidade Total em pequenas empresas. São Carlos, 2002. 213p. Dissertação (Mestrado) - Escola de Engenharia de São Carlos, Universidade de São Paulo.

O objetivo principal desta pesquisa é compreender as causas de insucesso do Programa Sebrae de Qualidade Total (PSQT), por meio da sistematização dessas em fatores organizacional, comportamental e metodológico, e propor ajustes para melhorar os resultados de sua implantação. Através do levantamento bibliográfico realizado pode-se perceber que vários estudos apontam causas de insucesso na implantação de Programas de Qualidade Total, porém tais causas são apontadas de maneira dispersa, isolada e assistemática. Através dos resultados encontrados concluise que os fatores organizacional e comportamental foram os mais relevantes para o insucesso do Programa Sebrae de Qualidade Total. Já o fator metodológico foi o menos relevante no insucesso do referido Programa, apesar de as causas englobadas por este fator serem tratadas, na literatura pesquisada, como de alta representatividade. Espera-se com esta pesquisa contribuir com o SEBRAE, nos esforços de melhoria dos resultados do Programa Sebrae de Qualidade Total, com as pequenas empresas, sendo instrumento de informação e análise aos pequenos empresários, consultores e demais pessoas ligadas à área de qualidade em pequenas empresas e, particularmente, com o Grupo de Pesquisas em Pequenas Empresas da Engenharia de Produção - EESC/USP.

Palavras-chave: insucesso em Programas de Qualidade Total; Programa Sebrae de Qualidade Total; pequenas empresas. 


\begin{abstract}
OLIVEIRA, M. F. (2002). Sistematization of the causes of insuccess in the Implementation of Quality Programs: one proposition of adjustes to the Sebrae's Quality Total Programme in small business. São Carlos, 2002. 213p. Dissertação (Mestrado) - Escola de Engenharia de São Carlos, Universidade de São Paulo.
\end{abstract}

The main objective of this research is to comprehend the causes of insuccess of Sebrae's Quality Total Programme through the systematization of that causes in organizational, behavioural and methodological factors, and to propose adjustments to improve the results of your implantation. Through of the bibliographical survey realized it's possible to perceive that several researches show causes of insucces in the implantation of Quality Total Programmes, but that causes are showed in a disperse, isolate and assystematic way. Through the results found it's concluded that the factors organizational and behavioural were the most relevants for the insuccess of the Sebrae's Quality Total Programme. The methodological factor was the least relevant for the insuccess of the referred Programme, despite of the causes included into this factor are treated through the researched literature like causes with high representativeness. It's expected with this research to contribute with Sebrae, in his efforts of improvement of the of Sebrae's Quality Total Programme results; with the small business, being an instrument of information and analysis to the small managers, consultants and other people stand in with the quality area of the small business, and specifically with the Small Business Groupe Research of Engineer Production - EESC/USP.

Keywords: insucces of Quality Total Programmes; Sebrae’s Quality Total Programme; small business. 


\section{CAPÍTULO 1}

\section{APRESENTAÇÃO}

\subsection{INTRODUÇÃO}

A conceituação de qualidade utilizada nesta pesquisa pode ser resumida como a capacidade que as empresas devem ter de satisfazer as necessidades dos clientes, sejam eles compradores ou consumidores, através da oferta de bens e serviços adequados, tanto antes como durante e após a sua utilização (PANIGAS, 1998).

Qualidade existe desde os primórdios da humanidade, de acordo com BARÇANTE (1998) ao longo da história o homem sempre procurou o que mais se adequasse às suas necessidades. Diz o autor que a Qualidade evoluiu da Revolução Industrial até nossos dias através de quatro eras:

- Era da Inspeção - início do século XX - Taylor: qualidade igual em todos os produtos;

- Era do Controle Estatístico da Qualidade - entre 1930 e 1949 - Dodge, Roming, Edwards e Juran: Controle Estatístico de Processos e Deming: Gráfico de Controle de Processo;

- Era da Garantia da Qualidade - entre 1950 e 1960 - Juran, Feigenbaum, Crosby: Custos da Qualidade, Controle Total da Qualidade, Técnicas de Confiabilidade e Programa Zero Defeitos;

- Era da Gestão da Qualidade (TQM) - fim da década de 70 até os dias de hoje - Ishikawa, Crosby: valorização prioritária dos clientes e a sua satisfação como fator de preservação e ampliação da participação no mercado. 
JURAN (1997) diz que a Qualidade se tornará o elemento-chave do mundo empresarial no século XXI, quando provavelmente assistiremos à consolidação de duas superpotências da qualidade, EUA e Japão. No Brasil, o movimento em prol da Qualidade vem crescendo bastante e, de acordo com BARÇANTE (1998) a partir de 1990 teve um crescimento avassalador.

Para FEIGENBAUM (1997) à medida que a economia global cresce, fica absolutamente claro que a qualidade se torna a linguagem internacional dos negócios. Dessa forma, segundo LESSA (1995), enfrentar as exigências de uma mudança para a qualidade e a competitividade próprias à economia de mercado, requer muito mais do que uma técnica localizada de reduzir custos ou de melhorar a produção. Trata-se fundamentalmente de uma nova forma de pensar, de uma nova mentalidade gerencial, de uma nova ciência e educação, que devem fluir desde a cúpula da empresa até o mais simples colaborador, pois todos formam a empresa, fazem-na crescer e dela dependem.

\subsection{CARACTERIZAÇÃO DO TEMA DA PESQUISA}

De acordo com BARRETO et al.(1997), a qualidade é a base de qualquer sistema de produção e de trabalho. Não há como conceber uma atividade que seja executada sem a preocupação com a qualidade, pois ela terá uma influência decisiva na escolha e satisfação dos clientes e na rentabilidade e competitividade do negócio.

Conforme relatado em pesquisa realizada pelo SEBRAE (1998b), as mudanças que vêm ocorrendo na economia mundial têm sinalizado que o aumento da competitividade é o elemento-chave para a sobrevivência das empresas, o que vem exigindo crescentemente da indústria brasileira a adoção de ações de ajuste requeridas pelo processo de maior inserção no mercado mundial. A pesquisa ainda relata que o sucesso obtido, até agora, frente aos desafios mais imediatos é irrefutável, mas insuficiente se comparado à necessidade de se garantir maior competitividade nos próximos anos, sendo um dos desafios que ainda permanecem o adequado engajamento das empresas de menor porte, na busca por padrões de qualidade e produtividade.

A partir da percepção da necessidade da utilização da gestão da qualidade total também em pequenas empresas e da existência de metodologias apenas voltadas para grandes organizações, o Sebrae desenvolveu um programa para implantação da Gestão da Qualidade Total específico para as pequenas. O Programa tem como objetivo capacitar os empresários e suas equipes na auto-implantação dos conceitos, princípios e ferramentas da Gestão pela Qualidade Total. 
De acordo com CÂNDIDO (1998), observa-se que esta metodologia, através da sua abrangência, tem um papel fundamental para realizar consideráveis transformações num grande número de empresas, permitindo obter resultados num curto espaço de tempo. Mas, não é apropriado gerar expectativas de que apenas a execução das atividades definidas e implantadas irão resolver todos os problemas da empresa. Portanto, apenas o fato de buscar implantar a Gestão da Qualidade Total não é garantia de sucesso, inclusive muitas empresas não chegam a alcançar os resultados esperados.

Segundo WOOD JR. \& URDAN (1994), a prática do TQM vive um momento delicado. Evidências práticas demonstram uma lacuna entre as expectativas geradas pelos projetos de implantação e os resultados efetivamente alcançados.

De acordo com STEVANATO (1997) pode-se levantar a suspeita de que, no caso brasileiro, as mudanças organizacionais trazidas pelos programas de qualidade têm enfrentado problemas e resistências que muitas vezes tem resultado em fracasso. As dificuldades a enfrentar seriam de tal ordem que muitas empresas nacionais para fugir deste “inconveniente”, promoveriam apenas mudanças parciais ou superficiais.

TOLOVI JR. (1994) coloca as seguintes questões: o que está acontecendo com nossos programas de qualidade? Por que alguns funcionam maravilhosamente enquanto outros parecem apenas uma perda de tempo e dinheiro?

\subsection{FORMULAÇÃO DO PROBLEMA DA PESQUISA}

De acordo com MARTINS \& TOLEDO (1998), vários esforços têm sido feitos para implementar a Gestão pela Qualidade Total (TQM), entretanto muitos desses esforços têm falhado, trazendo decepção e desconfiança acerca da real efetividade da TQM.

As falhas na implantação de Programas de Qualidade Total ocorrem tanto em grandes quanto em micro e pequenas empresas que vêm buscando adotá-los.

No Brasil, micro e pequenas empresas de todo o país estão implantando o Programa Sebrae de Qualidade Total, voltado para a realidade e características de tais empresas. O Programa procura adaptar-se ao máximo às características das pequenas empresas, pois é certo que existem peculiaridades a esse tipo de empreendimento. Porém percebe-se que muitas micro e pequenas empresa ao tentar implantar o Programa, buscando a gestão pela qualidade, fracassam.

Segundo MARTINS \& TOLEDO (1998) vários estudos e pesquisas têm sido feitos no sentido de identificar as causas fundamentais das falhas e decepções com a implementação do TQM. Mas, ao mesmo tempo percebe-se que tais estudos encontram-se 
dispersos, sendo que as falhas identificadas têm sido tratadas de maneira assistemática, isolada e independente.

Em se tratando especificamente do Programa Sebrae de Qualidade Total, levantou-se através da bibliografia pesquisada, cinco estudos que identificam causas de insucesso do Programa. Porém, nota-se que a identificação de tais causas, também foi feita de modo disperso e isolado, o que dificulta não só a compreensão do insucesso do Programa como também a proposição de melhorias dos resultados de sua implantação.

A partir da bibliografia pesquisada, em uma análise preliminar, verificou-se que as causas de insucesso de Programas de Qualidade podem ser agrupadas em fatores organizacional, comportamental e metodológico. Acredita-se que a análise por fatores de insucesso (agrupamento de causas) permitirá propor de modo mais efetivo recomendações de ajustes ao Programa, reduzindo os casos de insucesso.

Desta forma, o enfoque da pesquisa, resume-se na seguinte questão:

As causas de insucesso do Programa Sebrae de Qualidade Total podem ser melhor compreendidas por meio de uma sistematização em fatores organizacional, comportamental e metodológico?

\subsection{DECLARAÇÃO DOS OBJETIVOS DA PESQUISA}

O objetivo principal da pesquisa é “compreender as causas de insucesso do Programa Sebrae de Qualidade Total, por meio da sistematização dessas em fatores organizacional, comportamental e metodológico, e propor ajustes para melhorar os resultados de sua implantação .”

Como objetivos secundários, tem-se:

1. Revisar a literatura sobre: gestão da qualidade total, gestão de pequenas empresas e insucesso dos programas de qualidade;

2. Avaliar a aplicação do Programa Sebrae de Qualidade Total , em um grupo de pequenas empresas e seus resultados;

3. Sistematizar as principais causas, agrupadas em fator organizacional, comportamental e metodológico do Programa Sebrae de Qualidade Total, e observar a possível existência de outras causas;

4. Propor medidas corretivas ao Programa Sebrae de Qualidade Total de acordo com a avaliação da aplicação do Programa em um grupo de pequenas empresas e da sistematização das causas de insucesso. 


\subsection{RELEVÂNCIA DA PESQUISA AO ABORDAR O TEMA}

Nos dias de hoje ter qualidade é uma questão fundamental para a competitividade e sobrevivência das organizações.

Segundo SANTINI et. al, (1998), as mudanças na economia mundial, caracterizadas pela globalização e rapidez tecnológica, vêm impondo a necessidade das empresas estarem cada vez mais comprometidas com a busca de maior competitividade, traduzida em ganhos de produtividade e melhoria da qualidade. Assim, coloca o autor, é constante a busca de técnicas, métodos e programas que incrementem a qualidade do negócio.

As pequenas empresas dentro do contexto econômico mundial, exercem papel de extrema importância, atuando principalmente como fornecedoras das grandes empresas e sendo fonte de geração de emprego. E, para que as pequenas empresas possam concorrer com as médias e grandes organizações elas também precisam utilizar mecanismos que incrementem a competitividade e auxiliem a sobrevivência, dentre eles a implantação de Programas que visem a adoção da Gestão da Qualidade Total.

Porém, segundo OLIVEIRA (1998), na maioria das empresas ainda predomina a falta de informação quanto ao objetivo e vantagens da implantação da Qualidade. Em geral imagina-se que é uma coisa complexa demais, aplicável apenas a grandes empresas.

Para desmistificar essa idéia é que o Sebrae, desde 1993, vem colocando à disposição das pequenas empresas um programa de gestão da qualidade denominado Programa Sebrae da Qualidade Total (PSQT). O Programa tem como público-alvo micro e pequenas empresas, assim foi elaborado com enfoque na realidade dessas, respeitando suas características e peculiaridades.

Muitas empresas buscam adotar programas de qualidade, mas a literatura mostra que em grande parte dessas empresas, independentemente do porte, há insucesso na tentativa de implantação desses programas.

De acordo com VALLE (1995), alguns programas de qualidade não são bem sucedidos e seus resultados ficam aquém do esperado. $\mathrm{O}$ autor ainda coloca a pergunta: Por que isto ocorre? Diz então que esta é uma pergunta que dá margens a inúmeras e diferentes respostas, resultantes da especificidade de cada empresa e do entendimento do que seja qualidade.

O Programa Sebrae de Qualidade Total não mostra realidade diferente em se tratando de insucesso na implantação de programas de qualidade. Estudos específicos sobre o Programa têm revelado um grande número de empresas que não alcançaram resultados satisfatórios com a sua implantação. 
De acordo com CÂNDIDO (1998), esta metodologia vem sendo conduzida com muito sucesso em um grande número de empresas, entretanto isto não é uma constatação geral, já que outro grande número vem obtendo resultados parciais ou resultados pouco significativos.

Percebe-se realmente que dentre os diversos estudos realizados para levantar as causas do insucesso na implantação de programas de qualidade, ocorrem algumas variações, e que as causas, apesar de apontadas, encontram-se dispersas, precisando de serem analisadas e sistematizadas para serem melhores compreendidas. Assim, através da análise, sistematização e melhor compreensão de tais causas será possível propor soluções mais efetivas para evitar a ocorrência de insucessos em programas de qualidade, melhorando os resultados da implantação dos mesmos.

Para tal análise e sistematização a ser feita buscou-se agrupar causas mais citadas, do fracasso da implantação de programas de qualidade, entre doze estudos realizados, apresentados na bibliografia, selecionando aqueles pertinentes à perspectiva da pequena empresa, pois esta que será estudada. Deve-se ressaltar que cinco desses trabalhos são pesquisas feitas com o objetivo de estudar os resultados alcançados com a implantação do Programa Sebrae de Qualidade Total, sendo um dentre esses uma pesquisa do próprio órgão fornecedor do programa. Dessa forma, tais causas foram agrupadas nos fatores organizacional, comportamental e metodológico.

Assim, a justificativa desta pesquisa está na busca da sistematização das causas de insucesso do Programa Sebrae de Qualidade Total e numa melhor proposição de soluções para essas causas. O reflexo dessa ação é extremamente relevante pois implica na melhoria do esforço do SEBRAE e, conseqüentemente, no ganho das pequenas empresas.

\subsection{MOTIVAÇÃO PELO TEMA DA PESQUISA}

A pesquisadora cursou graduação em Administração de Empresas durante cinco anos, de 1993 a 1997. Durante esse período dentre os conhecimentos repassados, trabalhos realizados e até mesmo visitas feitas para conhecer a realidade das empresas, muito pouco foi visto com enfoque nas pequenas organizações, ficando então uma lacuna a ser explorada, o que despertou o interesse de se trabalhar e conhecer um pouco mais tais empresas.

Aliada a isto, a motivação da pesquisadora pelo tema da pesquisa deve-se ao fato de ter trabalhado cerca de um ano, dos quatro que atuou no SEBRAE-MG, acompanhando o Programa Sebrae de Qualidade Total, vendo de perto casos de sucesso e insucesso na implantação do mesmo assim como inquietações, pontos satisfatórios e insatisfatórios apontados pelos pequenos empresários participantes do Programa. 
Como desde a graduação a pesquisadora demonstrava interesse na área acadêmica, ela buscou fazer o mestrado e neste realizar a pesquisa aliando o interesse em pequenas empresas despontado na graduação e reforçado pelo trabalho realizado no SEBRAE, somado à questão da adoção da Gestão da Qualidade Total nessas organizações.

\subsection{ESTRUTURA DO TRABALHO}

Este trabalho, contando com este capítulo de apresentação está dividido em seis capítulos, tendo ainda a Bibliografia ao final.

O capítulo 2, Gestão da Qualidade Total (TQM), apresenta um histórico, conceitos, sistema e ferramentas da qualidade, e também alguns modelos de implementação da TQM.

Já o capítulo 3, denominado Contexto das Pequenas Empresas, busca classificar as pequenas empresas, ressaltar a importância dessas a nível mundial, nacional e também no Estado de São Paulo, onde foi realizado o trabalho de campo. As peculiaridades desse tipo de empresa também são retratadas, assim como suas características de gestão e fatores de sucesso e insucesso. Também será enfocado neste capítulo a Gestão da Qualidade nas pequenas empresas.

No capítulo 4, Programa Sebrae da Qualidade Total (PSQT), descreve-se este Programa, fazendo um histórico do mesmo e detalhando todo o processo de implantação do Programa assim como a metodologia utilizada.

O capítulo 5, denominado Insucesso dos Programas de Qualidade, tem como objetivo levantar as causas apontadas por doze estudos a respeito das causas de insucesso dos Programas de Qualidade, sendo cinco deles específicos do Programa Sebrae de Qualidade Total.

No capítulo 6, Trabalho de Campo de Descrição das Empresas, é apresentada a metodologia utilizada na pesquisa, descrevendo-se a caracterização, questões e variáveis referentes ao trabalho de campo, bem como as técnicas de coleta de dados. Ë feito também neste capítulo uma caracterização geral das empresas selecionadas participantes da pesquisa de campo, sendo estas pequenas indústrias que implantaram o Programa Sebrae de Qualidade Total.

No capítulo 7, Apresentação dos Dados, descreve-se os dados coletados a partir das entrevistas e questionários aplicados como os proprietários/pessoas-chave e funcionários das empresas treinadas, e também com os consultores do Programa Sebrae de Qualidade Total.

No capítulo 8, Análise do Dados, faz-se a análise dos dados obtidos no trabalho de campo, buscando relacioná-los aos dados obtidos com a revisão bibliográfica. 
No capítulo 9, Considerações Finais, faz-se algumas considerações a respeito da pesquisa, assim como sugestões de futuros trabalhos a serem feitos ligados ao tema estudado

Após os capítulos descritos anteriormente é apresentada na parte final deste texto a Bibliografia, dividida em Bibliografia Referenciada, onde estão relacionadas as fontes de citações bibliográficas inseridas no texto, e a Bibliografia Complementar, onde estão relacionadas as fontes consultadas porém não citadas no texto.

Por último, após a Bibliografia, apresenta-se os apêndices do trabalho. 


\section{CAPÍTULO 2}

\section{GESTÃO DA QUALIDADE TOTAL}

Nos dias de hoje, com o crescente nível de competição do mercado global e uma maior sensibilidade e exigência dos consumidores, a qualidade passou a ser alvo de maior atenção das organizações. As pressões no sentido da melhoria intensificaram-se. A Gestão da Qualidade Total (TQM) vem sendo amplamente adotada em âmbito mundial, tendendo a evoluir e se expandir ainda mais no século XXI.

\subsection{SURGIMENTO DA GESTÃO DA QUALIDADE TOTAL (TQM)}

A Gestão da Qualidade Total corresponde à quarta etapa do movimento evolutivo da Qualidade, sendo precedida das etapas de Inspeção, Controle de Estatístico da Qualidade e Garantia da Qualidade. Tais etapas estão assim definidas de acordo com a abordagem de GARVIN (1992), podendo ser resumidas na tabela 2.1.

De acordo com BARÇANTE (1998), a Era da Gestão da Qualidade Total (TQM), iniciou-se no Ocidente a partir dos esforços de recuperação de mercado das grandes empresas americanas, em meio à invasão de produtos japoneses de alta qualidade no final da década de 70, prevalecendo até os dias de hoje. 
Tabela 2.1 - As Quatro Principais Eras da Qualidade

\begin{tabular}{|c|c|c|c|c|}
\hline \multicolumn{5}{|c|}{ ETAPAS DO MOVIMENTO DA QUALIDADE } \\
\hline Características & $\begin{array}{l}\text { Inspeção } \\
\text { (até 1920) }\end{array}$ & \begin{tabular}{|c|} 
Controle \\
Estatístico da \\
Qualidade (1920- \\
1950) \\
\end{tabular} & \begin{tabular}{|c|} 
Garantia da \\
Qualidade (1950- \\
1980)
\end{tabular} & \begin{tabular}{|c|} 
Gerenciamento \\
Estratégico da \\
Qualidade \\
(1980 em diante) \\
\end{tabular} \\
\hline $\begin{array}{l}\text { Preocupação } \\
\text { básica }\end{array}$ & Verificação & Controle & Coordenação & $\begin{array}{l}\text { Impacto } \\
\text { estratégico }\end{array}$ \\
\hline $\begin{array}{l}\text { Visão da } \\
\text { qualidade }\end{array}$ & $\begin{array}{l}\text { Um problema a ser } \\
\text { resolvido }\end{array}$ & $\begin{array}{l}\text { Um problema a ser } \\
\text { resolvido }\end{array}$ & $\begin{array}{l}\text { Um problema a ser } \\
\text { resolvido, mas que } \\
\text { seja enfrentado } \\
\text { proativamente } \\
\end{array}$ & $\begin{array}{l}\text { Uma oportunidade } \\
\text { de concorrência }\end{array}$ \\
\hline$\hat{\text { Enfase }}$ & $\begin{array}{l}\text { Uniformidade do } \\
\text { produto }\end{array}$ & $\begin{array}{l}\text { Uniformidade do } \\
\text { produto, com } \\
\text { menos inspeção }\end{array}$ & $\begin{array}{l}\text { Toda a cadeia de } \\
\text { produção, com a } \\
\text { contribuição de } \\
\text { todos os grupos } \\
\text { funcionais }\end{array}$ & $\begin{array}{l}\text { As necessidades } \\
\text { do mercado e do } \\
\text { consumidor }\end{array}$ \\
\hline Métodos & $\begin{array}{l}\text { Instrumento de } \\
\text { medição }\end{array}$ & $\begin{array}{l}\text { Instrumentos e } \\
\text { técnicas } \\
\text { estatísticas }\end{array}$ & $\begin{array}{l}\text { Programas e } \\
\text { sistemas }\end{array}$ & $\begin{array}{l}\text { Planejamento } \\
\text { estratégico, } \\
\text { estabelecimento } \\
\text { de objetivos e a } \\
\text { mobilização da } \\
\text { organização }\end{array}$ \\
\hline $\begin{array}{l}\text { Papel dos } \\
\text { profissionais } \\
\text { da qualidade }\end{array}$ & $\begin{array}{l}\text { Inspeção, } \\
\text { classificação, } \\
\text { contagem e } \\
\text { avaliação }\end{array}$ & $\begin{array}{l}\text { Solução de } \\
\text { problemas e a } \\
\text { aplicação de } \\
\text { métodos } \\
\text { estatísticos }\end{array}$ & $\begin{array}{l}\text { Mensuração da } \\
\text { qualidade, } \\
\text { planejamento da } \\
\text { qualidade e } \\
\text { projeto de } \\
\text { programas }\end{array}$ & $\begin{array}{l}\text { Estabelecimento } \\
\text { de objetivos, } \\
\text { educação e } \\
\text { treinamento, } \\
\text { trabalho } \\
\text { consultivo com } \\
\text { outros } \\
\text { departamentos e } \\
\text { delineamento de } \\
\text { programas } \\
\end{array}$ \\
\hline $\begin{array}{l}\text { Responsável } \\
\text { pela qualidade }\end{array}$ & $\begin{array}{l}\text { O departamento de } \\
\text { inspeção }\end{array}$ & $\begin{array}{l}\text { Os departamentos } \\
\text { de produção e } \\
\text { engenharia }\end{array}$ & $\begin{array}{ll}\text { Todos os } \\
\text { departamentos, } \\
\text { com o } \\
\text { envolvimento } \\
\text { periférico da alta } \\
\text { gerência }\end{array}$ & \begin{tabular}{|lr}
\multicolumn{2}{|}{ Todos na empresa, } \\
com a alta \\
gerência \\
exercendo forte \\
liderança
\end{tabular} \\
\hline $\begin{array}{l}\text { Orientação e } \\
\text { abordagem }\end{array}$ & $\begin{array}{l}\text { Inspeciona } \\
\text { qualidade }\end{array}$ & $\begin{array}{ll}\text { Controla } & \text { a } \\
\text { qualidade } & \end{array}$ & $\begin{array}{l}\text { Constrói } \\
\text { qualidade }\end{array}$ & $\begin{array}{l}\text { Gerencia } \\
\text { qualidade }\end{array}$ \\
\hline
\end{tabular}

Já WOOD Jr. \& URDAN (1994) colocam que o surgimento da TQM pode ser relacionado ao desenvolvimento dos modelos gerenciais e do próprio movimento da qualidade e explicado por uma seqüência didática de seis momentos, alguns quase simultâneos: 
- o da inspeção, o foco no controle do produto final, associado ao desenvolvimento do sistema de produção e consumo em massa;

- o surgimento do foco no processo, com uma coleção de técnicas estatísticas;

- a integração destas técnicas num modelo gerencial restrito, o Controle da Qualidade Total (TQC);

- a incorporação de elementos comportamentais e novas práticas gerenciais associadas ao acirramento da competição entre empresas, ao início da flexibilização da produção e ao aumento da fragmentação dos mercados. Consagração do termo TQM;

- a expansão para fora das fábricas, no setor de serviços e nas empresas públicas e;

- tendência de transformação do modelo e/ou sua difusão nas práticas gerenciais do dia-a-dia.

Atualmente, muitas empresas visando enfrentar uma situação, nacional e internacional, de concorrência acirrada, vêm adotando a Gestão da Qualidade Total. As empresas disputam a preferência de clientes cada vez mais exigentes, que esperam sempre mais de serviços e produtos de qualidade. Desta forma, a TQM contribui para alcançar a satisfação do cliente através da melhoria contínua da qualidade dos serviços e produtos da empresa (MEARS apud WOOD JÚNIOR \& URDAN, 1994).

\subsection{QUALIDADE: CONCEITOS E ABORDAGENS}

A Qualidade, devido a sua influência no campo do consumo, ocupa amplo espaço nos estudos organizacionais. Também está presente na área social, como nas instituições públicas, filantrópicas e educacionais porque é sinônimo de eficácia no cumprimento de metas. Porém, como toda matéria relevante, serve bem à utilização de resumos, chavões e distorções, na tentativa de ser levada a lugar comum. Assim, para qualquer apreciação sobre o tema, se faz mister a compreensão de suas base, de seus conceitos e abordagens (MOSSO, 2001).

\subsubsection{CONCEITOS DE QUALIDADE}

Segundo BARÇANTE (1998), várias abordagens sobre o tema qualidade foram surgindo gradualmente, ou seja, Qualidade é um tema em constante evolução, tornando necessário o conhecimento sobre as terminologias empregadas 
FEINGENBAUM (1983) diz que a qualidade é uma determinação do consumidor, levando em consideração as expectativas que ele possui em relação ao produto ou serviço utilizado. O cliente externo tem a palavra final.

CROSBY (1985) define a Qualidade como conformidade aos requisitos, sendo que a não-conformidade detectada é ausência de qualidade.

Já DEMING (1990) diz que Qualidade é sentir orgulho pelo trabalho bem feito, sendo que o aprimoramento da qualidade eleva a produtividade.

Para JURAN (1993) a Qualidade é definida de duas formas:

- orientada para as características do produto que atendam as necessidades dos clientes. Neste caso o principal efeito reside nas vendas e, geralmente, mais qualidade custa mais;

- orientada para a ausência de deficiências. Neste caso o principal efeito reside nos custos e, geralmente, mais qualidade custa menos.

Uma outra definição de Qualidade é estabelecida por ISHIKAWA (1993), que define Qualidade como adequação às exigências do consumidor.

De acordo com GARVIN (1992) os conceitos sobre Qualidade podem ser agrupados em cinco modos distintos de enfoque:

- Enfoque transcendental: Qualidade é sinônimo de "excelência nata”. Ela é absoluta e universalmente reconhecida. Esse enfoque é ligado às artes de maneira geral;

- Enfoque baseado no produto: Qualidade é definida como uma variável precisa e mensurável, e as diferenças na Qualidade refletem-se nas características de um produto;

- Enfoque baseado no usuário: Qualidade está nos olhos de quem observa, ou seja, o cliente. Ela está associada a uma visão subjetiva baseada nas preferências pessoais. Supõe-se que os produtos e/ou os serviços que mais e melhor preencham as expectativas e as necessidades do consumidor são aqueles de alta Qualidade;

- Enfoque baseado na fabricação: Qualidade é a “conformidade com as especificações”, seja para um produto ou um serviço. Uma vez que as especificações tenham sido estabelecidas, qualquer desvio significa perda de Qualidade;

- Enfoque baseado no valor agregado: um produto ou um serviço de Qualidade é aquele que apresenta desempenho esperado a um preço aceitável (para o cliente) e/ou conformidade às especificações a um custo aceitável (para o fornecedor). 


\subsubsection{ABORDAGENS DA QUALIDADE}

Alguns autores, denominados "gurus da qualidade" ficaram conhecidos mundialmente por seus estudos, e abordagens sobre a qualidade. Dentre esses autores e respectivas abordagens pode-se destacar: Joseph M. Juran; W. Edwards Deming; Kaoru Ishikawa; Philip Crosby e Armand Feigenbaum.

\subsubsection{JOSEPH M. JURAN}

Juran é considerado um dos arquitetos da Revolução da Qualidade no Japão, onde realizou várias confereências e consultorias a partir de 1954 (BROCKA \& BROCKA, 1994).

A abordagem de Juran considera que a administração da qualidade se faz com a utilização dos processos de planejamento, controle e melhoria. Tais processos são descritos através da Trilogia da Qualidade, que JURAN (1993) descreve de acordo com os seguintes passos:

1. Planejamento da Qualidade: é a atividade de desenvolvimento de produtos que atendam às necessidades do cliente. Envolve uma série de etapas que podem ser consideradas universais: determinar quem são os clientes; determinar as necessidades dos clientes; desenvolver características para o produto que atendem as necessidades dos clientes; desenvolver processos capazes de produzir as características dos produtos e; transferir o resultado do planejamento para os grupos operacionais;

2. Controle da Qualidade: processo usado pelos grupos operacionais como auxílio para atender aos objetivos do processo e do produto. Baseia-se no ciclo de controle e consiste nas seguintes etapas: avaliar o desempenho operacional real; comparar o desempenho com os objetivos e; agir com base na diferença;

3. Melhoria da Qualidade: maneira de elevar o desempenho da qualidade a níveis inéditos de inovação. A metodologia consiste de uma série de etapas universais: estabelecer a infraestrutura necessária para assegurar um melhoramento da qualidade anual; identificar as necessidades específicas para melhoramento - os projetos de melhoramento; para cada projeto estabelecer uma equipe que tenha claramente a responsabilidade de fazer com que o projeto seja bem sucedido e; fornecer os recursos, motivação e treinamento necessário às equipes para diagnosticar as causas, estimular o estabelecimento de uma solução e, estabelecer controles para manter os ganhos. 


\subsubsection{W. EDWARDS DEMING}

W. Edwards Deming é o mais conhecido de todos os gurus por colocar os negócios japoneses no caminho que os tornou número um em qualidade em todo o mundo (MIRANDA, 1994).

Deming revolucionou a gestão pois pregou transformações no relacionamento da empresa com seus funcionários, com seus gerentes, fornecedores e também chamou a atenção para a falsa ilusão quanto à facilidade do processo de qualidade, sendo este difícil e uma tarefa para longo prazo (REGINA, 1999).

Seus 14 princípios fundamentais para a administração, chamados 14 princípios de Deming, são mundialmente difundidos, reconhecidos e utilizados por inúmeras empresas como base para sua filosofia da qualidade (PANIGAS, 1998). Estes princípios são os seguintes (DEMING, 1990):

1. Estabeleça a consistência de propósitos no sentido de uma contínua melhoria de produtos e serviços como um plano para se tornar competitivo e permanecer no negócio;

2. Adote uma nova filosofia. Não aceito como inevitáveis os níveis comumente aceitos de atrasos, erros, materiais defeituosos e mão-de-obra;

3. Elimine a dependência da inspeção em massa;

4. Abandone a prática de selecionar fornecedores apenas pelo menor preço;

5. Encontre os problemas, descubra as causas;

6. Introduza métodos modernos de treinamento no trabalho;

7. Introduza métodos modernos de supervisão;

8. Afaste o medo para que todos possam trabalhar eficientemente em favor da companhia;

9. Elimine as barreiras entre departamentos;

10. Elimine metas numéricas, cartazes e rótulos que apenas pedem maiores níveis de produtividade para os trabalhadores, sem indicar métodos ou idéias para atingí-los;

11. Elimine padrões de trabalho que se apóiam em metas numéricas;

12. Institua um amplo programa de educação e treinamento para todos os empregados, incluindo a administração, a fim de eliminar o medo e as barreiras que impedem as pessoas de se orgulharem de seu trabalho;

13. Introduza um amplo programa para reciclar todos os funcionários em novos conhecimentos e novas técnicas, para que se atualizem com as mudanças de modelos, estilos, materiais, métodos e, quando necessário, novas máquinas 
14. Crie uma estrutura na alta administração para garantir num esforço cotidiano a aplicação dos 13 pontos anteriores.

Além dos princípios descritos anteriormente, Deming foi o principal responsável pela popularização do ciclo PDCA, desenvolvido por Walter Shewart. O ciclo consiste em um processo de desenvolvimento de melhorias contínuas. É representado por um círculo onde cada quadrante representa uma atividade gerencial para a busca de melhorias. O primeiro quadrante representa a atividade de Planejar (Plan), o segundo de Fazer (Do), o terceiro significa Verificar (Check) e o quarto representa a Ação (Act) na correção de eventuais distorções (SOARES, 1999). O ciclo PDCA é representado pela seguinte figura:

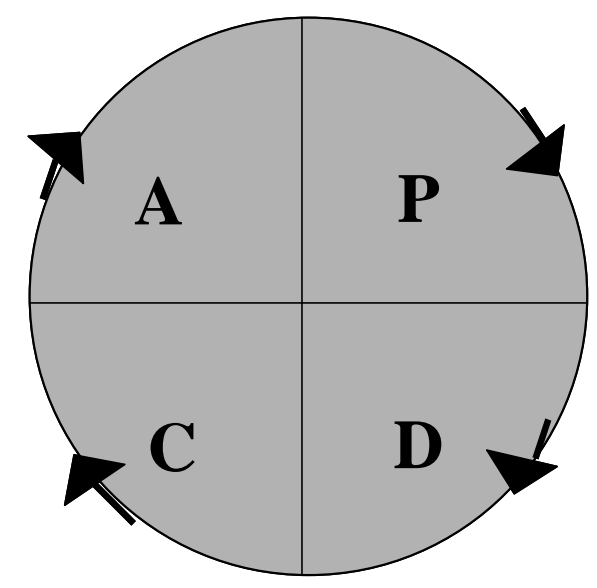

Figura 2.1: Ciclo PDCA (Fonte: DEMING, 1990: 66)

\subsubsection{KAORU ISHIKAWA}

Kaoru Ishikawa foi o primeiro pesquisador a usar o termo Controle da Qualidade Total (TQC) no Japão (BROCKA \& BROCKA, 1994), tendo iniciado suas pesquisas e trabalhos em tal assunto por volta de 1949.

Para ISHIKAWA (1986) o TQC no estilo japonês é uma revolução dentro da mentalidade administrativa, uma nova filosofia de gestão baseada em fatos e no respeito à humanidade.

ISHIKAWA (1986) coloca como características do TQC os seguintes tópicos:

1. controle da qualidade é fazer o que deveria ter sido feito em todas as indústrias;

2. um controle da qualidade que não apresente resultados não pode ser considerado como controle da qualidade;

3. o controle da qualidade começa e termina com a educação; 
4. para implementar o TQC é necessário conduzir a educação contínua em todos os níveis, desde o presidente até o último dos operários;

5. o controle da qualidade realça o melhor de cada um;

6. ao se implementar o TQC, os erros desaparecerão das empresas.

O autor ainda diz que a essência do TQC pode ser resumida nos seguintes pontos:

1. o primeiro passo em controle da qualidade é a detecção das exigências do consumidor;

2. o passo subsequente é saber o que os consumidores comprarão;

3. não se pode definir a qualidade sem considerar os custos;

4. atacar com antecedência os defeitos e as reclamações potenciais;

5. conduzir sempre as ações apropriadas. O controle da qualidade dissociado das ações é mera evocação;

6. um estágio ideal do controle da qualidade é aquele em que o controle não mais depende da verificação (inspeção) e;

7. a verdadeira essência do TQC é a efetividade do controle e a garantia da qualidade no desenvolvimento de novos produtos.

Uma contribuição muito importante de Ishuikawa foi a definição de sete ferramentas como instrumentos fundamentais de auxílio nos processos da qualidade (MOREIRA, 2000). Tais ferramentas, são denominadas como as Sete Ferramentas Básicas de Ishikawa, sendo elas: Gráfico de Pareto, Diagrama de Causa e Efeito; Histograma; Folhas de Verificação; Gráficos de Dispersão; Fluxogramas e Cartas de Controle (BROCKA \& BROCKA, 1994).

De acordo com BROCKA \& BROCKA (1994), talvez o alcance maior dessas ferramentas tenha sido a introdução dos Círculos de Controle da Qualidade (CCQ), elementos de extrema relevância nos trabalhos de qualidade feitos por Ishikawa.

O CCQ é um pequeno grupo de pessoas que trabalham em uma mesma área que, voluntariamente, desenvolve atividades de controle da qualidade, identificando problemas relacionados com a qualidade em seus trabalhos, gerando soluções possíveis para tais problemas.

Segundo ISHIKAWA (1986), a filosofia básica que rege o CCQ é constituída de:

1. contribuição para melhoria estrutural, organizacional e desenvolvimento da empresa;

2. criação de uma área de trabalho feliz, em que haja satisfação e respeito à natureza;

3. desenvolvimento das possibilidades infinitas de capacidade mental humana, permitindo sua aplicação. 


\subsubsection{PHILIP CROSBY}

De acordo com BROCKA \& BROCKA (1994), Philip Crosby é talvez a pessoa mais associada com a idéia de zero defeito, criada por ele em 1961. Zero defeito, de acordo com a abordagem do autor, não é um slogan, e sim um padrão de gerenciamento de desempenho.

Segundo CROSBY (1985), qualidade não custa dinheiro. Embora não seja um dom, é gratuita. Custam dinheiro as coisas desprovidas de qualidade - tudo o que envolve a nãoexecução correta, logo de saída, de um trabalho. $\mathrm{O}$ autor coloca ainda que a qualidade é um fator atingível, mensurável e lucrativo, que pode ser estabelecido desde que haja compromisso e compreensão, e que a pessoa esteja disposta a se empenhar no trabalho.

O autor afirma que a qualidade é de responsabilidade da cúpula e que temos que nos preocupar tanto com a qualidade quanto com o lucro.

De acordo com a abordagem de CROSBY (1985) existem 14 passos para a melhoria da qualidade, sendo eles:

1. Tornar claro que a cúpula está comprometida com a qualidade;

2. Formar equipes de melhoria da qualidade com representantes de cada departamento;

3. Determinar onde se encontram os problemas de qualidade atuais e potenciais;

4. Avaliar o custo da qualidade e explicar seu uso como ferramenta gerencial;

5. Aumentar a conscientização e a preocupação pessoal de todos os funcionários com a qualidade;

6. Agir para corrigir os problemas identificados nos passos anteriores;

7. Estabelecer um comitê para o programa zero defeito;

8. Treinar os supervisores para desenvolver ativamente a parte deles no processo de melhoria da qualidade;

9. Estabelecer um dia de zero defeito para que todos os empregados saibam que houve um mudança;

10. Encorajar os indivíduos a estabelecer metas de melhoria para si próprios e para seus grupos;

11. Encorajar os empregados a comunicar à gerência os obstáculos que eles enfrentam para atingir suas metas de melhoria;

12. Reconhecer e agradecer os que participam;

13. Determinar que os Conselhos de Qualidade se comuniquem regularmente e; 
14. Recomeçar tudo de novo para enfatizar que o processo de melhoria de qualidade nunca termina.

\subsubsection{ARMAND V. FEIGENBAUM}

Armand V. Feigenbaum foi quem introduziu o termo Controle da Qualidade Total (TQC) nos Estados Unidos e também, segundo SOARES (1999), foi o primeiro autor a estabelecer as bases científicas da qualidade, documentando-as.

FEIGENBAUM (1991) define o TQC como um sistema efetivo para integrar o desenvolvimento e a manutenção da qualidade, assim como os esforços de melhoria da qualidade nos vários grupos organizacionais em níveis mais econômicos, possibilitando a completa satisfação do consumidor.

O autor classifica dez princípios como fundamentais para o controle da qualidade total, sendo eles:

1. Qualidade é um processo extensivo a toda a empresa;

2. Qualidade é o que o consumidor julga ser;

3. Qualidade e custo são soma e não diferença;

4. Qualidade exige zelo individual e conjunto;

5. Qualidade é um modo de gerenciamento;

6. Qualidade e inovação são mutuamente dependentes;

7. Qualidade é ética;

8. Qualidade exige aperfeiçoamento continuado;

9. Qualidade é o caminho mais efetivo em custo e menos intensivo em capital no rumo à produtividade;

10. Qualidade é implementada como um sistema total associado a clientes e fornecedores.

De acordo com BARÇANTE (1998), a filosofia da qualidade de Feigenbaum pode ser resumida em três níveis:

1. A gerência deve perseguir qualidade como objetivo número um. Essa prioridade ou objetivo deve ser entendida por todos os empregados na organização.

2. As ações necessárias para atingir os objetivos devem ser implementadas por toda a empresa.

3. Motivação, avaliação dos resultados e comprometimento com a qualidade devem ser mantidos num alto nível todo o tempo na empresa. 
Um outro aspecto muito importante a destacar-se na abordagem de Feigenbaum é o fato de que com o trabalho do autor a qualidade passou a ter uma dimensão mensurável através dos custos da não-qualidade; ou seja dos custos de não fazer certo da primeira vez uma atividade ou processo (SOARES, 1999). Essa forma de definir os custos e medir a eficiência da qualidade sendo produzida ficou conhecida como custos da qualidade, possuindo a seguinte estrutura (FEIGENBAUM, 1991):

- Custos de Controle, divididos em

$>$ Custos de prevenção: representados pelos custos de atividades que têm por finalidade evitar que os defeitos ocorram tais como: treinamentos, manutenções preventivas, engenharia da qualidade, pesquisa e desenvolvimento etc.;

$>$ Custos de avaliação: caracterizados pelas despesas de manutenção dos níveis de qualidade atuais da companhia através de avaliações formais da qualidade do produto. Tais despesas envolvem elementos de custos como: inspeções, testes, verificações externas etc.;

- Custos de Falhas, divididos em:

$>$ Custos de falhas internas: são causados devido a materiais defeituosos que não estão de acordo com as especificações de qualidade da companhia para o produto. Eles incluem perdas como: retrabalho, sucata, materiais defeituosos etc.;

$>$ Custos de falhas externas: são os custos devidos aos danos que ocorrem fora da empresa, durante o funcionamento do produto. São por exemplo, os custos com consertos em garantia, queixas de clientes, recall, e até mesmo perda de mercado devido a danos na imagem do produto.

\subsubsection{PONTOS COMUNS AOS GURUS DA QUALIDADE}

Apesar de cada um dos gurus da qualidade, citados nos tópicos anteriores, ter desenvolvido sua própria abordagem, alguns pontos são comuns a todos eles, como os seguintes (BARÇANTE, 1998):

- comunicação interáreas na fase do projeto dos produtos, serviços e processos;

- qualidade é algo dinâmico, portanto envolve aprimoramento contínuo;

- é vital o envolvimento de fornecedores nos esforços em prol da qualidade;

- a maioria dos problemas relacionados à qualidade é de responsabilidade gerencial; 
- os gerentes devem ser os agentes de mudança;

- educação e treinamento devem ser um processo contínuo em todos os níveis da empresa, liderado pela alta administração.

\subsection{DEFININDO A GESTÃO DA QUALIDADE TOTAL}

A TQM, Total Quality Management ou Gestão da Qualidade Total, vem sendo estudada por um grande número de pesquisadores, possuindo uma série de conceituações. De acordo com LORENT et. al. (1998), apesar das divergências de visões existentes sobre o conceito de TQM, existem elementos comuns que tais conceitos englobam, dentre eles: suporte da alta direção, foco no consumidor, relacionamento com fornecedores e envolvimento dos empregados. A tabela 2.2 expõe os elementos englobados, de uma forma geral, pelos conceitos de TQM.

A ISO 8042, que trata do vocabulário da qualidade define TQM como sendo um enfoque gerencial de uma organização, centrado na qualidade, baseado na participação de todos os membros, com o objetivo de alcançar lucratividade de longo prazo, através da satisfação do cliente, incluindo benefícios para os membros da organização e para a sociedade (PURI, 1994).

MAIN (1995) diz que a TQM é uma forma de gerenciar uma organização que concentra esforços de forma sistemática e disciplinada na melhoria contínua da qualidade daquilo que faz 
Tabela 2.2. Elementos da TQM

\begin{tabular}{|c|c|}
\hline ELEMENTOS & DESCRIÇÃO \\
\hline Suporte da alta direção & $\begin{array}{l}\text { A alta gerência deve ser a primeira a estimular a adoção da TQM, } \\
\text { proporcionando a necessária liderança para motivar os empregados } \\
\text { e permitir a efetividade das ações em prol da qualidade total. }\end{array}$ \\
\hline Foco no consumidor & $\begin{array}{l}\text { As necessidades dos clientes e consumidores e a satisfação desses } \\
\text { tem que estar sempre na mente dos empregados. É necessário } \\
\text { identificar-se essas necessidades e o nível de satisfação dos clientes } \\
\text { e consumidores. }\end{array}$ \\
\hline $\begin{array}{l}\text { Relacionamento com os } \\
\text { fornecedores }\end{array}$ & $\begin{array}{l}\text { Relacionamentos de longo prazo com os fornecedores devem ser } \\
\text { estabelecidos e a empresa deve ajudar os fornecedores a melhorarem } \\
\text { a qualidade de seus produtos e serviços }\end{array}$ \\
\hline Treinamento & $\begin{array}{l}\text { Planos adequados de recrutamento de pessoal e treinamento devem } \\
\text { ser implementados para que os trabalhadores possam ter as } \\
\text { habilidades necessárias à participação desses nas atividades da } \\
\text { TQM. }\end{array}$ \\
\hline $\begin{array}{l}\text { Comportamento e atitudes } \\
\text { dos empregados }\end{array}$ & $\begin{array}{l}\text { As empresas devem estimular atitudes positivas, incluindo lealdade } \\
\text { à organização, orgulho do trabalho e foco nos objetivos } \\
\text { organizacionais. }\end{array}$ \\
\hline $\begin{array}{l}\text { Processo de design do } \\
\text { produto }\end{array}$ & $\begin{array}{l}\text { Todos os departamentos devem participar do design do processo e } \\
\text { trabalhar em conjunto para encontrar um design que satisfaça os } \\
\text { requisitos do consumidor, de acordo com as restrições tecnológicas, } \\
\text { técnicas e de custos da empresa. }\end{array}$ \\
\hline $\begin{array}{l}\text { Fluxo do processo } \\
\text { gerencial }\end{array}$ & $\begin{array}{l}\text { Emprego dos conceitos de } 5 \mathrm{~S} \text {. Instrumentos de melhoria estatísticos } \\
\text { e não estatísticos devem ser aplicados quando apropriados. Os erros } \\
\text { do processo devem ser evidenciados. As inspeções devem ser } \\
\text { realizadas de acordo com instruções claras. O processo deve ser } \\
\text { mantido sob controle estatístico. }\end{array}$ \\
\hline $\begin{array}{l}\text { Coleta e transmissão de } \\
\text { informações }\end{array}$ & $\begin{array}{l}\text { As informações devem ser avaliadas com prontidão e fazer parte do } \\
\text { sistema gerencial. Registros sobre indicadores de qualidade devem } \\
\text { ser mantidos, incluindo refugos, retrabalho e custo da qualidade. }\end{array}$ \\
\hline $\begin{array}{l}\text { Papel do departamento de } \\
\text { qualidade }\end{array}$ & $\begin{array}{l}\text { O departamento de qualidade deve ter autonomia e acesso à alta } \\
\text { gerência e também dividir o trabalho com outros departamentos. }\end{array}$ \\
\hline Benchmarking & A empresa deve estabelecer uma política de benchmarking. \\
\hline
\end{tabular}
Fonte: LORENTE et. al. (1998)

De acordo com FEIGENBAUM (1983), a TQM pode ser definida como um sistema efetivo para integrar o desenvolvimento, a manutenção e os esforços de melhoria para a qualidade dos vários grupos em uma organização, bem como para habilitar o marketing, a engenharia, a produção e o serviço em níveis mais econômicos que permitam a completa satisfação do cliente. 
Já JURAN (apud BROCKA \& BROCKA, 1994) define TQM como uma coleção de atividades relacionadas com a qualidade, como: a qualidade torna-se parte de cada agenda da alta gerência; os objetivos da qualidade entram no planejamento dos negócios; o enfoque está nos clientes e nos encontros competitivos; existem objetivos para melhorias anuais da qualidade; o treinamento é feito em todos os níveis; as medidas são estabelecidas em toda a parte; os altos gerentes revisam regularmente o progresso em relação aos objetivos; o reconhecimento é dado para o desempenho superior e; o sistema de prêmios é revisado.

Pela variedade de conceitos de TQM, vê-se necessário adotar um que mais se adeque ao enfoque desta pesquisa, sendo utilizada então a conceituação de MEARS (1993): a Gestão da Qualidade Total é um sistema permanente e de longo prazo, voltado para a satisfação do cliente através de um processo de melhoria contínua dos produtos e serviços gerados pela empresa, sendo fundamental a participação de todos os membros da empresa nesse processo.

\subsection{PRINCÍPIOS DA TQM}

De acordo com BROCKA \& BROCKA (1994), os princípios da TQM ou os elementos primários da filosofia do Gerenciamento da Qualidade variam de autor a autor. Suas quantidades podem também variar, mas sua medula é a seguinte:

- Visão organizacional: fornece a forma de trabalho que direciona as crenças e os valores da empresa. A essência da visão corporativa deve ser simples como um lema, de tal modo que todo o empregado a conheça e acredite nela;

- Remoção de barreiras: esforços gastos para superar resistências por parte de pessoas diretamente envolvidas com as mudanças relacionadas à TQM;

- Comunicação: elo que solidifica a filosofia, técnicas e práticas da TQM, podendo ser escrita, verbal ou não-verbal.;

- Avaliação contínua: compreende uma série de mecanismos de realimentação para que a empresa possa saber se os objetivos propostos estão sendo bem direcionados. Tal avaliação deve ser feita de modo que seus resultados possam ser repassados a tempo de permitir o início da ação corretiva. Esses mecanismos de realimentação podem ser, por exemplo, relatórios orais ou escritos, sistemas de informação, análise estatística integrada, entre outros ;

- Melhoria contínua: pequenas melhorias feitas continuamente, envolvendo todos na organização e permitindo uma maior facilidade de gerenciamento; 
- Relacionamento cliente/fornecedor: melhoria das relações da empresa com clientes e fornecedores através de estratégias como: tornar a visão organizacional voltada para a satisfação do cliente, premiar os fornecedores, minimizar a multiplicidade de fornecedores, identificar clientes internos e externos, estabelecer rotinas de diálogo com os clientes e, envolver os clientes no planejamento e desenvolvimento;

- Autonomia do empregado: fornecer autonomia aos empregados significa habilitá-los a alcançar o seu potencial mais elevado, proporcionando a condução de sua própria rotina diária, reconhecendo que o posicionamento das gerências é de auxiliar os empregados na solução de problemas, e não para colocar obstáculos no caminho. Autoridade e responsabilidade devem ser delegadas aos trabalhadores seja em uma tarefa, projeto ou divisão, inclusive aos que ocupam os níveis mais baixos na organização, valorizando as contribuições e opiniões de todos;

- Treinamento: todos os empregados precisam de treinamento para compreender e aplicar corretamente a TQM, suas técnicas e ferramentas, sendo que tanto as necessidades como os resultados do treinamento devem ser avaliados com o empregado para que ele ganhe entendimento.

COSTA NETO \& FERNANDES (1996), descrevem mais alguns princípios da TQM, importantes de serem citados, sendo eles:

- Satisfação Total do Cliente: para ser competitiva a empresa precisa exceder em qualidade aos olhos dos clientes e para prosperar no longo-prazo e perenizar sua sobrevivência ela precisa prever suas necessidades. As implicações do significado de satisfação do cliente em uma empresa orientada para a qualidade total são:

$>$ os processos gerenciais e de negócios devem estar alinhados para satisfazer as necessidades dos clientes;

$>$ a melhoria contínua dos processos só tem sentido se agregar valor para o cliente, em termos dos atributos críticos da qualidade, como percebidos por ele;

> a empresa deve, constantemente, comparar-se com referenciais de excelência;

$>$ o planejamento estratégico e os objetivos de aperfeiçoamento devem se pautar pelas necessidades atuais e latentes dos clientes e pela comparação do desempenho relativamente aos competidores;

> a satisfação do cliente deve ser constantemente medida; 
$>$ os requisitos dos clientes devem ser incorporados ao projeto dos produtos e serviços.

- Orientação para Resultados: estabelecimento de objetivos quantitativos no que diz respeito a atributos de projeto e processo, visando redução de custo e conseqüente aumento dos lucros, acompanhado de aumento da qualidade. A orientação para resultados estabelece os parâmetros quantitativos de melhoria dos processos, implicando nos fatores:

$>$ objetivos de melhoria podem ser planejados;

$>$ objetivos de melhoria devem ser desdobrados por toda a organização;

> sistema de medição de desempenho deve ser introduzido, visando medir até que ponto os objetivos são atingidos;

$>$ objetivos de melhoria devem estar vinculados aos objetivos estratégicos da organização.

- Foco nos Processos: aperfeiçoamento sistemático dos processos sendo que os resultados e suas causas são analisados e a partir daí desencadeadas ações corretivas no sentido de melhorar os processos. As implicações para as organizações acerca do significado de foco nos processos são:

$>$ a redução da variabilidade nos processos está associada à redução de custos;

$>$ atenção deve ser dada aos processos relacionados com clientes, desenvolvimento de novos produtos, fornecedores e fabricação, considerados críticos para qualquer tipo de empreendimento;

$>$ a melhoria contínua dos processos deve estar relacionada com as necessidades dos clientes;

- Comprometimento de Todos: participação das pessoas de todos os níveis da organização no aperfeiçoamento contínuo dos processos e na rotina diária de trabalho. As pessoas devem estar motivadas. A alta administração deve comunicar os objetivos de melhoria, a visão e a missão da organização, reforçar a constância de propósito e fornecer feedback do desempenho dos empregados, visando o maior envolvimento possível desses.

\subsection{SISTEMA DA QUALIDADE}

O sistema da qualidade é composto pela estrutura organizacional, responsabilidades, procedimentos, processos e recursos para implementação da TQM (CERQUEIRA NETO, 1992). 
O sistema da qualidade pode assumir muitas formas. Portanto, é melhor definí-lo em termos de suas funções ou tentativas, e não em termos de como ele é implementado. Os sistemas da qualidade são específicos às organizações que os implementam. Porém, a maioria deles têm algumas características comuns (HARRINGTON, 1997):

- eles cobrem um amplo escopo de atividades da organização. A qualidade é definida em termos amplos e inclui não somente as características de desempenho do produto, mas também as características de qualidade do atendimento que os clientes exigem;

- como a consistência dos resultados é fundamental, os sistemas da qualidade concentram-se na consistência do processo de trabalho. Isso frequentemente inclui certo nível de certificados para padronizar o trabalho;

- os sistemas da qualidade enfatizam a prevenção de erros em vez de recorrer à detecção de reação aos erros;

- reconhecendo-se que nem todos os sistemas serão 100\% eficazes na prevenção, há também ênfase na ação corretiva dos problemas encontrados. Os sistemas da qualidade incluem deteç̧ão, retorno (feedback) e correção;

- a maioria dos sistemas de qualidade inclui elementos de medição para aumentar sua eficácia e/ou identificar problemas.

Segundo MARTINS \& TOLEDO (1998), as ações do sistema da qualidade devem ter como objetivo principal a formalização dos procedimentos de garantia da qualidade, da organização, para a manutenção dos padrões de desempenho esperados, visando a previsibilidade da qualidade dos processos e dos produtos ou serviços.

Os autores ainda colocam que o sistema da qualidade é um dos pontos básicos da Gestão da Qualidade Total, uma vez que só é possível pensar em melhoria de uma atividade ou processo que já esteja formalizado e em andamento.

CERQUEIRA NETO (1995) diz que a sistematização hoje mais comum nas empresas e seus negócios é aquela realizada adotando-se as normas da série ISO 9000. Segundo o autor, tais normas permitem às organizações demonstrar o nível adequado da qualidade dos produtos e serviços que ela apresenta no mercado. Elas estabelecem um referencial para que sobre ele, e na sua expansão, seja construído todo o processo de asseguramento da qualidade do negócio na empresa. 


\subsection{FERRAMENTAS DA QUALIDADE}

Segundo PALADINI (1997) define-se "ferramentas" como os dispositivos, procedimentos gráficos, numéricos ou analíticos, formulações práticas, esquemas de funcionamento, mecanismos de operação, enfim, os métodos estruturados para viabilizar a implantação da Qualidade Total. Cada ferramenta refere-se a uma área específica de funcionamento do Sistema da Qualidade, de seu projeto ou da avaliação de seu desempenho. Elas dispõem, também, de ênfase específica, que pode dizer respeito a uma análise prática do processo produtivo para fins, por exemplo, de determinar previsões acerca de seu desenvolvimento ou então, priorizam a análise da ação de concorrentes (produtos ou serviços) em uma mesma faixa de mercado ou podem referir-se às formas de melhor atender a um grupo de consumidores.

Ë grande o número de ferramentas que podem ser utilizadas na Gestão da Qualidade Total, variando a classificação, dependendo do autor e da finalidade a que se destinam.

Uma forma comum de classificação de ferramentas é a denominada como As Sete Ferramentas Ishikawa, sendo elas Gráfico de Pareto; Diagrama de Causa-Efeito; Histogramas; Folha de Verificação; Gráficos de Dispersão; Fluxogramas e Cartas de Controle. Ishikawa organizou dessa forma tais ferramentas para aperfeiçoar o Controle de Qualidade (Brocka \& Brocka, 1994).

Já Moura (1994) expõe em seus estudos a classificação das Ferramentas Gerenciais da Qualidade, compilada pela JUSE entre 1971 e 1978, que compreende as seguintes ferramentas: Diagrama de Relações, Diagrama de Afinidades; Diagrama em Árvore; Matriz de Priorização; Matriz de Relações; Diagrama PDPC (Process Decision Program Chart) e; Diagrama de Atividades.

Por ser muito grande o número de ferramentas da qualidade tornando muito extensa o detalhamento de todas, explicitar-se-á neste trabalho apenas as ferramentas adotadas para a implantação do Programa Sebrae de Qualidade Total, sendo elas: Gráfico de Pareto; Diagrama de Causa e Efeito; Gráficos; Lista de Verificação; Fluxograma; Matriz de Preferência; Brainstorming, 4Q1POC; Matriz de Decisão e Técnica do Grupo Nominal.

\subsubsection{GRÁFICO DE PARETO}

O Princípio de Pareto estabelece que poucas causas são responsáveis pela maior parte dos efeitos. O Gráfico de Pareto torna claro que os problemas poucos mas vitais (causas) devem ser 
tratados primeiramente. Ë um gráfico de barras dispostas em ordem decrescente, com a categoria de maior frequência de ocorrência à esquerda. Cada barra representa uma causa. O gráfico exibe a contribuição relativa de cada causa em relação ao efeito total. Uma linha representando o efeito acumulado é freqüentemente acrescentada ao gráfico (BROCKA \& BROCKA, 1994: 350-351).

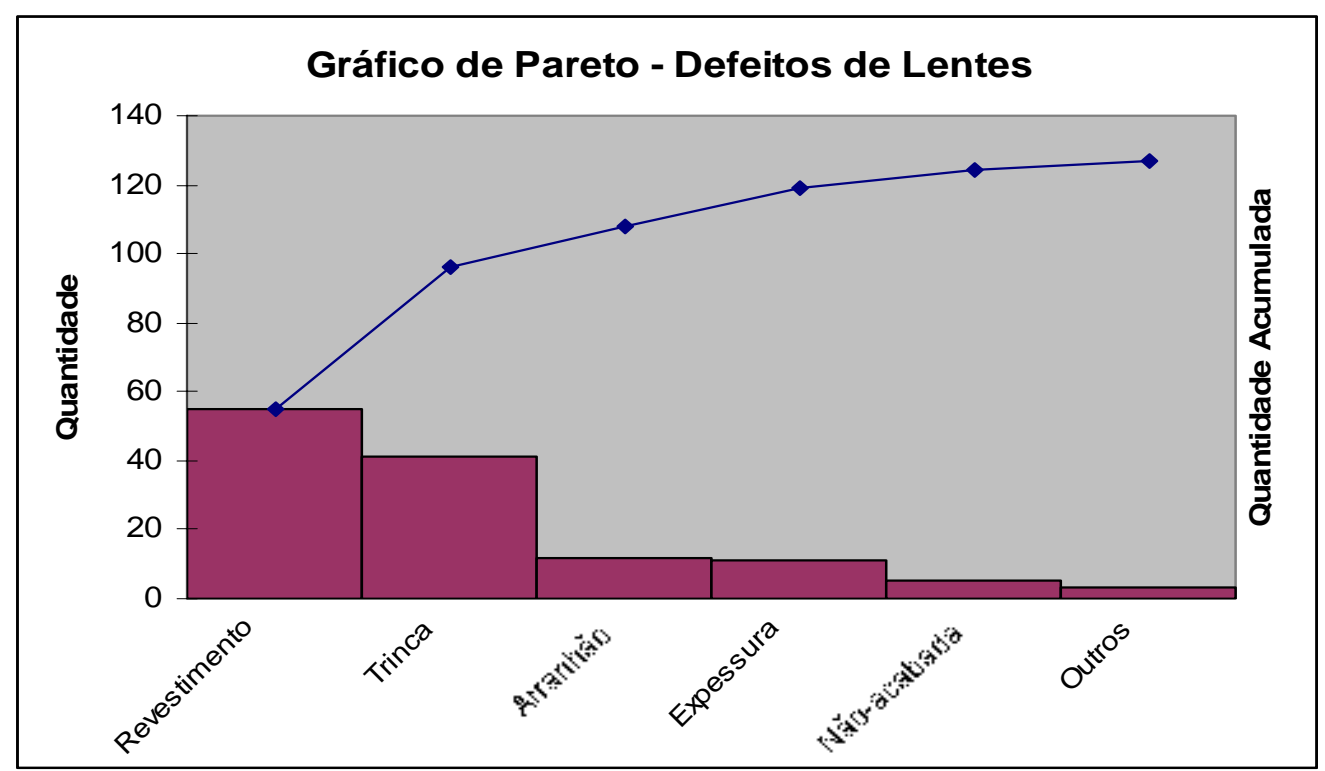

Figura 2.2: Ex. de Gráfico de Pareto para Defeitos de Lentes. (Fonte: WERKEMA, 1995: 78)

\subsubsection{DIAGRAMA DE CAUSA E EFEITO}

O Diagrama de Causa e Efeito é uma ferramenta utilizada para apresentar a relação existente entre o resultado de um processo (efeito) e os fatores (causas) do processo que possam afetar o resultado considerado (WERKEMA, 1995).

As principais categorias, frequentemente consideradas no diagrama, são os 6M: métodos, mão-de-obra, material, máquinas, moeda e medidas. As causas são classificadas nessas categorias, ou outras, conforme o caso. Quando apropriado as causas podem ser subdivididas (BROCKA \& BROCKA, 1994). 


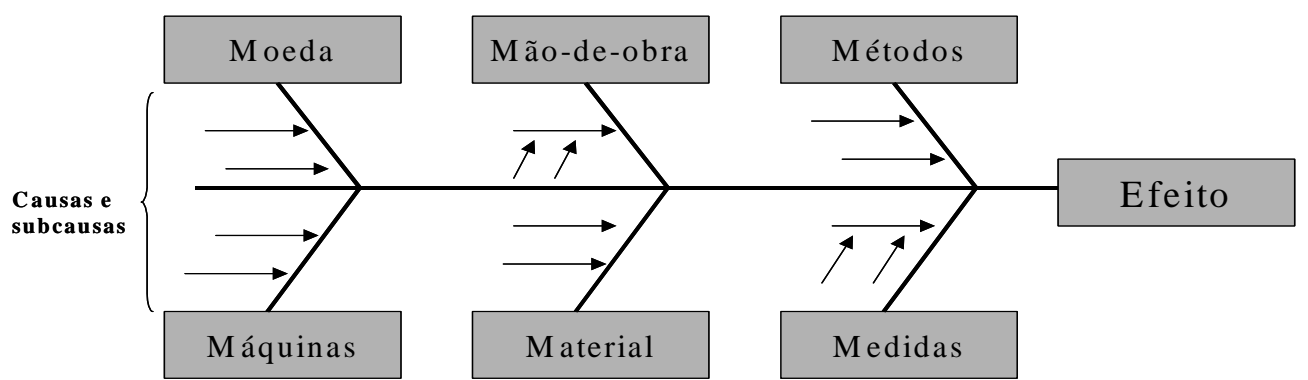

Figura 2.3: Diagrama de Causa-Efeito (Fonte: adaptado de BROCKA \& BROCKA, 1994)

\subsubsection{GRÁFICOS}

Os gráficos são instrumentos utilizados para visualizar dados númericos,, tornando mais evidente e compreensível a apresentação de dados (SEBRAE, 1999x).

De acordo com BROCKA \& BROCKA (1994) existe um vasto número de opções de gráficos, sendo os mais referenciados como ferramentas da qualidade os seguintes:

- Diagrama de Dispersão: gráfico utilizado para a visualização do tipo de relacionamento existente entre duas variáveis, verificando qual alteração deve-se esperar em uma variável em consequência das alterações ocorridas na outra variável (WERCKEMA, 1995).

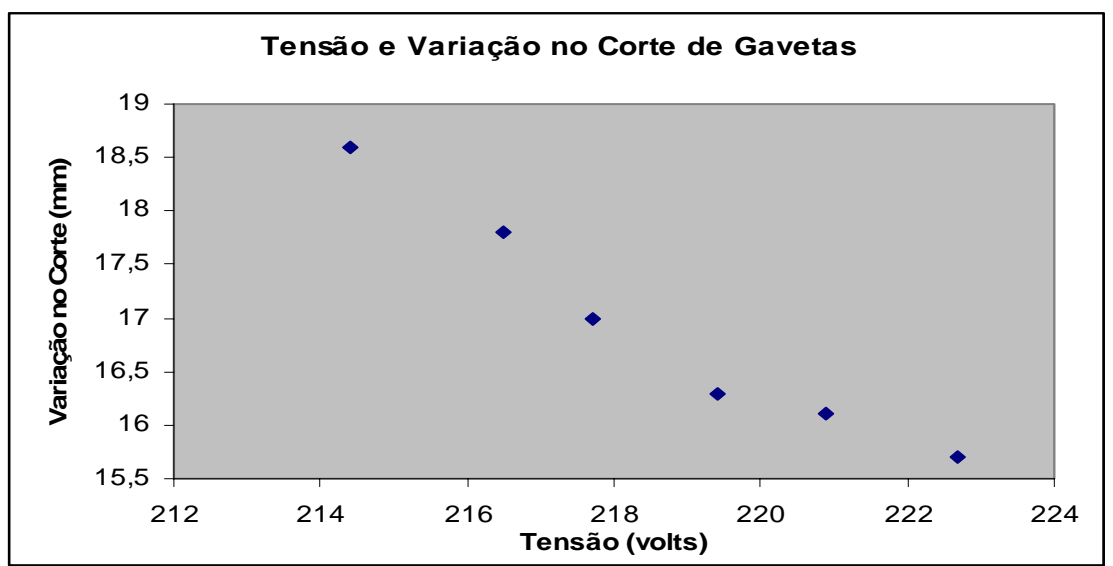

Figura 2.4: Ex. de Diagrama de Dispersão. (Fonte: WERCKEMA, 1995: 181)

- Histograma: é um gráfico de barras no qual o eixo horizontal, subdividido em vários pequenos intervalos, apresenta os valores assumidos por uma váriável de interesse. O histograma dispõe as informações de modo que seja possível a visualização da forma da distribuição de um conjunto de dados e também da percepção da localização do valor central e da dispersão dos dados em torno deste valor central (WERCKEMA, 1995). 


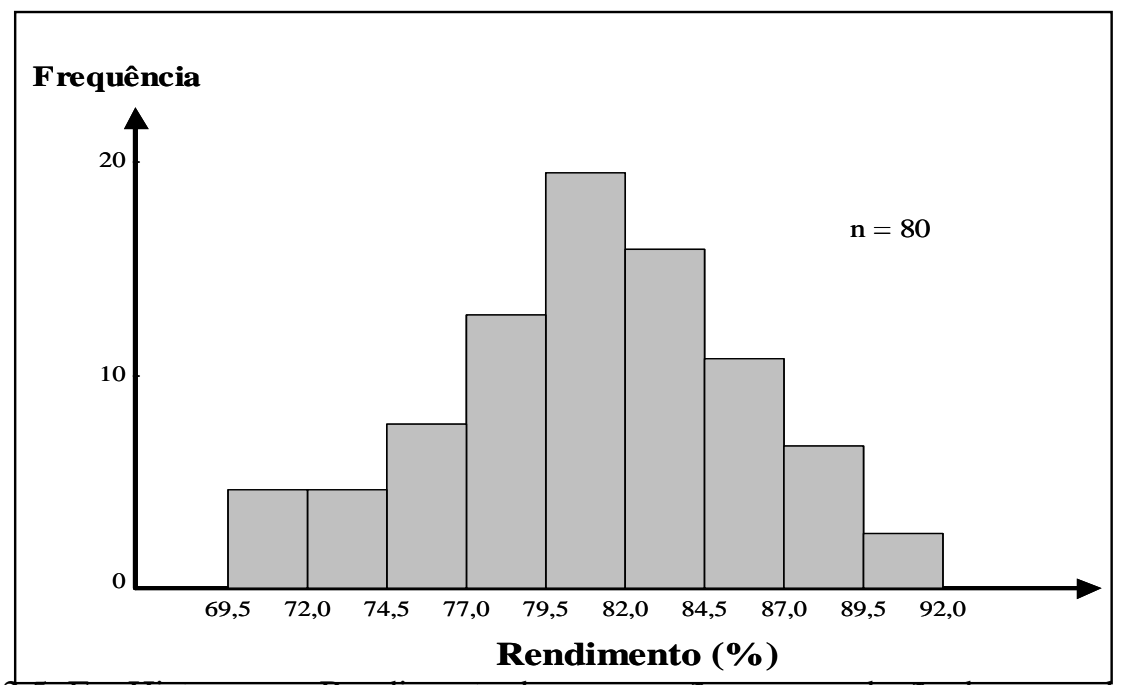

Figura 2.5: Ex. Histograma. Renđimento đe uma reação para prođução đe uma substância química. (Fonte: WERCKEMA, 1995: 126)

\subsubsection{LISTA DE VERIFICAÇÃO}

A Lista de Verificação é usada para determinar com que frequência ocorre um evento ao longo de um período determinado (SEBRAE, 1999b). Segundo BROCKA \& BROCKA(1994) a Lista de Verificação simplifica o processo de coleta de dados por meio de um formulário bem planejado no qual os dados são preenchidos, ajudando a diminuir o erro e a confusão.

Tabela 2.3: Ex. Lista de Verificação. Reclamação de defeitos na porta do carro

\begin{tabular}{|c|c|c|}
\hline \multicolumn{3}{|c|}{ PROCESSO: Fabricação de porta de carro } \\
\hline PERÍODO: 01/09/96 A 30 & $96 \quad$ TOTAL DF & ITENS PRODUZIDOS: 480 \\
\hline TIPO DE DEFEITO & FREQUÊNCIA & \begin{tabular}{|c|} 
TOTAL \\
\end{tabular} \\
\hline Mancha na porta & 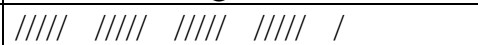 & 21 \\
\hline Risco & |l/I/I & 30 \\
\hline Defeito na tranca & 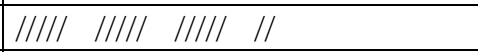 & 17 \\
\hline Folga & 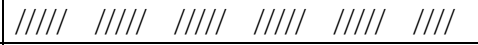 & 29 \\
\hline Amassado & $/ / /$ & 03 \\
\hline Defeito no vidro & $\| / / / /$ & 05 \\
\hline TOTAL & & 105 \\
\hline
\end{tabular}

Fonte: SEBRAE (1999b: 45)

\subsubsection{FLUXOGRAMA}

O fluxograma é a representação gráfica da sequência de atividades de um processo. Além da sequência das atividades o fluxograma identifica objetivos e entradas assim como saídas ou resultados do processo (SEBRAE, 1999b). 

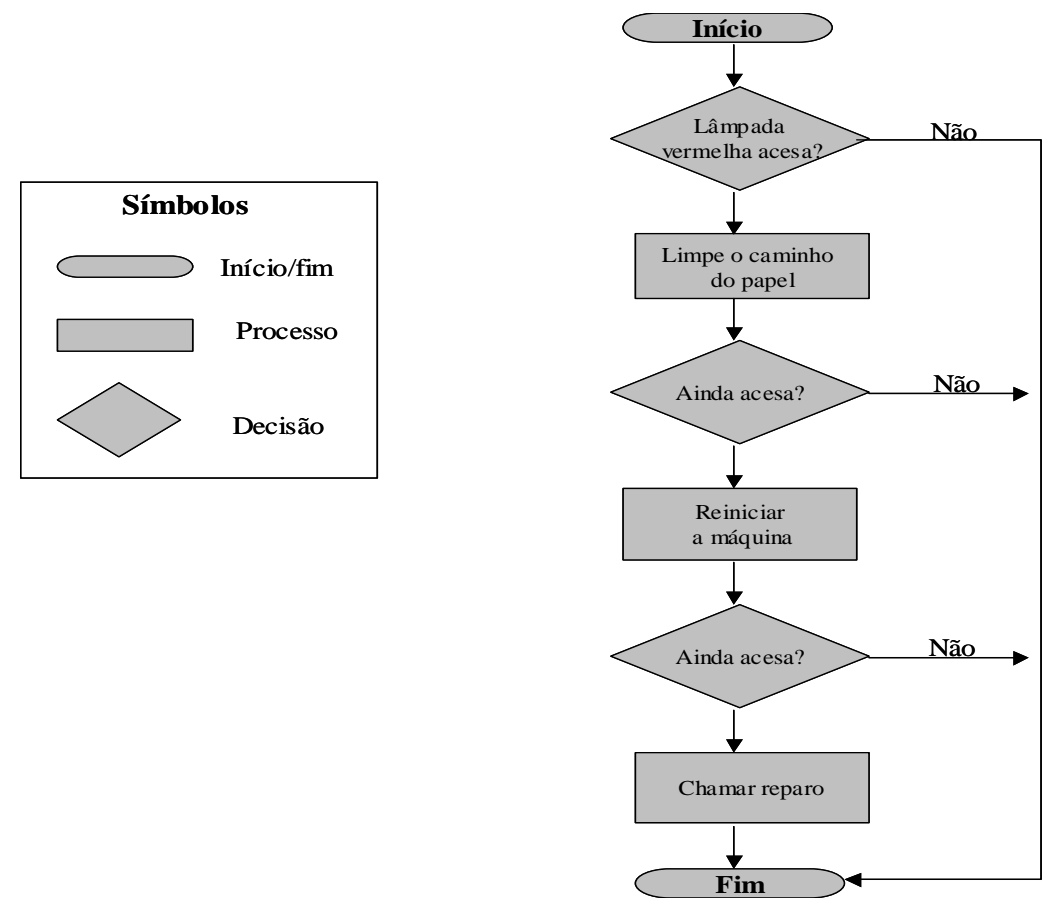

Figura 2.6: Ex. de Fluxograma. (Fonte: SEBRAE, 1999b: 34)

\subsubsection{MATRIZ DE PREFERÊNCIA}

A Matriz de Preferência é uma tabela que permite a organização de idéias ou alternativas segunda uma certa ordem ou grau de preferência, sendo usada para escolher e priorizar alternativas de forma rápida e precisa (SEBRAE, 1999b)

Tabela 2.4: Ex. Matriz Preferência. Escolha de cargo de diretor-executivo

\begin{tabular}{|l|c|c|c|c|}
\hline ALTERNATIVA & $\begin{array}{l}\text { Gerente } \\
\text { Industrial (GI) }\end{array}$ & $\begin{array}{l}\text { Gerente } \\
\text { Comercial (GC) }\end{array}$ & $\begin{array}{l}\text { Gerente de RH } \\
\text { (GRH) }\end{array}$ & $\begin{array}{l}\text { Membro do } \\
\text { Conselho (MC) }\end{array}$ \\
\hline GI & $\mathrm{X}$ & - & - & - \\
\hline GC & 2 & $\mathrm{X}$ & - & - \\
\hline GRH & 3 & 2 & $\mathrm{X}$ & - \\
\hline MC & 4 & 2 & 4 & $\mathrm{X}$ \\
\hline Frequência & 0 & 3 & 1 & 2 \\
\hline Priorização & $\mathbf{4}^{\mathrm{a}}$ & $\mathbf{1}^{\mathbf{a}}$ & $\mathbf{3}^{\mathrm{a}}$ & $\mathbf{2}^{\mathbf{a}}$ \\
\hline
\end{tabular}

Fonte: SEBRAE (1999b)

\subsubsection{BRAINSTORMING}

O Brainstorming é uma técnica pela qual um grupo de pessoas cria idéias originais em uma atmosfera sem inibições, envolvendo a contribuição espontânea dos participantes. Inicialmente, enfoca-se a quantidade de idéias geradas. Depois é feito o exame dessas idéias, garantindo que todos as compreenderam. Em seguida, um exame adicional elimina as 
redundâncias, questões sem importância e idéias inviáveis. As sessões de brainstorming ajudam todos os membros do grupo a contribuírem criativamente para a solução de problemas (WHITELEY, 1992).

\subsubsection{Q1POC}

Tradução para o português da sigla americana 5W2H (who, what, when, where, why, how e how much), o 4Q1POC, de acordo com o SEBRAE (1999b) é utilizado para planejar a implementação de uma solução. Tal planejamento deve ser feito em resposta a tais questões:

- Que: que ação será desenvolvida?

- Quando: quando a ação será realizada?

- Quem: quem será o responsável pela sua implantação?

- Por que: por que foi delineada esta solução (resultado esperado)?

- Onde: onde a ação será desenvolvida (abrangência)?

- Como: como a ação vai ser implementada (passos da ação)?

- Quanto: quanto será gasto ou quanto tempo gastará?

\subsubsection{MATRIZ DE DECISÃO}

A Matriz de Decisão é uma ferramenta que possibilita tomar decisão entre algumas alternativas, ponderando diferentes critérios de avaliação. Forma-se então uma matriz de decisão que vai revelar os pontos fortes e fracos de cada alternativa. Esta ferramenta é utilizada na empresa por quem tem o poder para tomar decisão sobre alguma situação (SEBRAE, 1999b) 
Tabela 2.5: Ex. Matriz de Decisão. Atraso na entrega dos resultados dos exames.

PROBLEMA: Atraso na entrega dos resultados dos exames

ALTERNATIVAS DE SOLUÇÃO:

1 - Contratar mais um funcionário para ajudar no preenchimento dos resultados

2 - Treinar equipe de auxiliares de laboratório 3 - Informatizar emissão de resultados.

\begin{tabular}{|l|c|c|c|c|c|c|c|}
\hline \multicolumn{2}{|c|}{ CRITÉRIOS } & \multicolumn{2}{c|}{ ALTERNATIVA 1 } & \multicolumn{2}{c|}{ ALTERNATIVA 2 } & \multicolumn{2}{c|}{ ALTERNATIVA 3 } \\
\hline Descrição de & Peso & Nota & Ponderação & Nota & Ponderação & Nota & Ponderação \\
\hline $\begin{array}{l}\text { Rapidez de } \\
\text { implantação }\end{array}$ & 3 & 2 & 6 & 4 & 12 & 1 & 3 \\
\hline $\begin{array}{l}\text { Possibilidade de } \\
\text { teste preliminar }\end{array}$ & 2 & 4 & 8 & 3 & 6 & 4 & 8 \\
\hline $\begin{array}{l}\text { Boa relação } \\
\text { lusto - benefício }\end{array}$ & 4 & 3 & 12 & 5 & 20 & 2 & 8 \\
\hline $\begin{array}{l}\text { Existência de } \\
\text { Know-how }\end{array}$ & 5 & 1 & 5 & 3 & 15 & 4 & 20 \\
\hline $\begin{array}{l}\text { Reação } \\
\text { mudança }\end{array}$ & 1 & 3 & 3 & 5 & 5 & 3 & 3 \\
\hline Total & & & $\mathbf{3 3}$ & & $\mathbf{5 3}$ & & $\mathbf{4 2}$ \\
\hline
\end{tabular}

Fonte: SEBRAE, 1999b

\subsubsection{TÉCNICA DO GRUPO NOMINAL}

A Técnica do Grupo Nominal é orientada para a decisão e adequada aos problemas especializados que requerem certo grau de perícia. Essa técnica pode ser classificada como uma composição de um brainstorming silencioso com um processo de análise de decisão. A estrutura abre linhas de comunicação e assegura (e requer) participação de cada membro (BROCKA \& BROCKA, 1994).

De acordo com o SEBRAE (1999b), o processo para se realizar a Técnica do Grupo Nominal consiste nas seguintes etapas:

1. Cada um do grupo escreve (ou fala) sobre o problema ou alternativa para a resolução de um problema que julgar mais importante;

2. Os problemas/alternativas relatados são colocados onde todos do grupo possam ver;

3. Verificação da duplicidade nos problemas/alternativas relatados. Se sim, esses devem ser combinados em um só. Discute-se brevemente as explanações das razões de cada problema/alternativa relatado;

4. Os problemas/alternativas são priorizados. 


\subsection{MODELOS E PROGRAMAS DE IMPLANTAÇÃO DA TQM}

A implementação da TQM por uma organização exige que esta adote algum modelo de referência como base para gestão (MARTINS \& TOLEDO, 1998). Segundo SOARES (1999), os modelos de implementação da qualidade total baseiam-se em geral nas diversas linhas de pensamento dos gurus da qualidade, podendo-se citar as seguintes (SOARES, 1999):

1. JUSE: linha de pensamento que orientou a implementação no Japão. Caracterizada principalmente pelos autores Ishikawa, em nível internacional; e Campos, no Brasil. Tem um forte apelo educacional procurando, através do treinamento popularizar as ferramentas estatísticas da qualidade e soluções coletivas de problemas;

2. Deming: caracterizada pela obra de Deming, basicamente a sua proposta dos 14 princípios;

3. Juran: caracterizada pela metodologia original do TQC, baseada pela obra do próprio autor;

4. Crosby: caracterizado pelo programa Zero Defeito, proposto pelo autor como opção ao TQM tradicional.

FERNANDES \& COSTA NETO (1996), apresentam os modelos de implementação do TQM preconizados por Merli, Shiba e Kaplan através da tabela 2.6.

Muitas organizações, buscando implantar a TQM, adotam os chamados Programas Qualidade Total. Segundo MOSSO (2001), o termo programa de qualidade significa um esforço concentrado e planejado, retratado através de etapas distintas, no término das quais serão feitas as correções das falhas e normalização dos procedimentos, para que os processos sejam sistematizados e jamais esquecidos.

MARTINS \& TOLEDO (1998) colocam que o Programa de Qualidade Total tem como pressuposto básico o aumento da capacidade competitiva da organização, e para que esse pressuposto seja atingido o Programa deve conter as ações necessárias dispostas de uma forma que direcione a organização a introduzir ou consolidar a orientação para a satisfação total do consumidor, para a gerência dos processos e para a melhoria contínua, de forma a fornecer produtos ou serviços com a qualidade desejada pelos clientes.

MOSSO (2001) coloca que a implantação de Processos e Programas de Qualidade tradicionalmente têm sido implementados por intermédio das normas internacionais ISO (International Standart Organization) da série ISO 9000 e, principalmente, pelos critérios de avaliação do Prêmio Malcom Bridge, que no Brasil se materializou pela criação do PNQ (Prêmio Nacional da Qualidade) . 
Tabela 2.6: Modelos de Implementação da TQM

\begin{tabular}{|c|c|c|}
\hline \multirow[t]{2}{*}{ Modelo } & \multicolumn{2}{|c|}{ Características dos Modelos } \\
\hline & $\begin{array}{r}\text { Fases } \\
\end{array}$ & \begin{tabular}{|l} 
Linhas Mestras \\
\end{tabular} \\
\hline \multirow[t]{4}{*}{ Merli } & - abordagem convencional & - qualidade do produto \\
\hline & $\begin{array}{lll}\text { organização } & \text { para } & \text { o } \\
\text { aperfeiçoamento } & & \\
& & \end{array}$ & $\begin{array}{l}\text { - } \quad \text { controle de processos } \\
\text { - } \quad \text { equipes de melhoria } \\
\text { - } \quad \text { ênfase em educação } \\
\text { - } \quad \text { equipes multifuncionais }\end{array}$ \\
\hline & - gerência por processos & $\begin{array}{l}\text { - } \text { ênfase na prevenção } \\
\text { - } \text { políticas anuais } \\
\text { - } \text { empowerment } \\
\text { - desdobramento de políticas } \\
\text { - } \text { gerências por processos } \\
\text { - benchmarking }\end{array}$ \\
\hline & $\begin{array}{l}\text { - implementação completa do } \\
\text { TQM }\end{array}$ & $\begin{array}{ll}\text { - } & \text { policy deployment } \\
\text { - } & \text { daily-routine-work } \\
\text { - } & \text { análise de custos globais } \\
\text { - } & \text { gestão do tempo de ciclo } \\
\text { - } & \text { desdobramento da qualidade } \\
\end{array}$ \\
\hline \multirow[t]{3}{*}{ Shiba } & - orientação & $\begin{array}{l}\text { - } \quad \text { visão e missão da empresa } \\
\text { - } \quad \text { objetivos da qualidade } \\
\text { - } \quad \text { infra-estrutura da qualidade }\end{array}$ \\
\hline & - empowerment & $\begin{array}{l}\text { - } \text { educação e capacitação } \\
\text { - } \text { emprego de equipes } \\
\text { - } \text { ferramentas da qualidade }\end{array}$ \\
\hline & - alinhamento & $\begin{array}{l}\text { - desdobramento de políticas e } \\
\text { objetivos } \\
\text { - gerência por processos } \\
\text { - gestão visual } \\
\text { - daily-routine-work }\end{array}$ \\
\hline \multirow[t]{4}{*}{ Kaplan } & - conscientização & $\begin{array}{l}\text { - } \text { reprodutibilidade dos processos } \\
\text { - } \quad \text { promoção do trabalho em equipe }\end{array}$ \\
\hline & - embasamento & $\begin{array}{l}\text { - } \text { educação e capacitação } \\
\text { - } \text { inspeção em projeto e fabricação } \\
\text { - } \text { prevenção de defeitos } \\
\text { - } \quad \text { redução de tempos de ciclos }\end{array}$ \\
\hline & - gerência & $\begin{array}{l}\text { - } \text { planejamento estratégico } \\
\text { - } \text { trabalho em equipes } \\
\text { - gerência dos processos } \\
\text { - equipes multifuncionais } \\
\text { - desdobramento da qualidade }\end{array}$ \\
\hline & - integração & $\begin{array}{l}\text { - estratégia como foco no cliente } \\
\text { - daily-routine-work } \\
\text { - benchmarking }\end{array}$ \\
\hline
\end{tabular}

Fonte: FERNANDES \& COSTA NETO (1996:183) 
SOLER (1997) coloca que o intercâmbio criado entre as instituições de fomento e manutenção dos Prêmios Nacionais da Qualidade (Prêmio Deming, Prêmio Malcom Bridge e PNQ) permite estabelecer-se referenciais de excelência, fortalecendo e substanciando as modificações anuais propostas em cada um deles para manter-se atuais os conceitos abordados. Assim, coloca o autor, a implantação da qualidade baseada nesses critérios se aproxima do processo dinâmico de busca contínua pela excelência organizacional vivenciada atualmente.

De acordo com ROTHMAN (apud GUIMARAES, 1998), as pessoas que apoiam os programas de qualidade argumentam que estes podem ajudar empresas de qualquer tamanho, independente se é uma empresa iniciante, uma esforçada jovem empresa, ou uma antiga empresa enxergando a possibilidade de galgar um degrau em termos de competitividade.

Um Programa de Qualidade que vem sendo muito difundido no país é o Programa Sebrae de Qualidade Total, criado pelo SEBRAE em 1993 para atender ao segmento das micro e pequenas empresas. O Programa tem como requisito básico ser autoimplantável, ou seja, os empresários, através de treinamento e o apoio de um consultor na empresa, devem, após finalizado o processo de capacitação no método de implantação, poder "caminhar com suas próprias pernas”, continuando eles próprios o processo. O consultor exerce, neste caso, um papel de facilitador, com a função de repassar a metodologia e apoiar o processo de implantação do PSQT na empresa durante o repasse dos módulos (PANIGAS, 1998). 


\section{CAPÍTULO 3}

\section{CONTEXTO DAS PEQUENAS EMPRESAS}

A pequena empresa exerce, mundialmente, um papel de extrema importância tanto econômico como social, difundindo e gerando riqueza, fornecendo novos empregos, introduzindo inovações, auxiliando as atividades das grandes empresas, entre outros.

Os pequenos negócios são indispensáveis no desenvolvimento e riqueza das nações, na disseminação da tecnologia e na intensificação da eficiência e eficácia de toda a atividade econômica. A busca da modernização e a promoção de um desenvolvimento integrado e global são fatores que passam a compor os critérios de modernidade e integração dos países ao meio produtivo internacional. E isto passa, necessariamente, pela ação das pequenas empresas. (PANIGAS, 1998)

\subsection{CLASSIFICAÇÃO DAS EMPRESAS}

Existem diversas formas de classificar as empresas na categoria de pequenas, tanto quantitativa como qualitativamente, não havendo como dizer se esta ou aquela forma é a mais correta de ser empregada. Pois, como diz MORIYAMA (2000), sem entrar no mérito dos critérios que têm sido utilizados para a caracterização das pequenas empresas, parece que o mais correto realmente é de se fixar a definição em função do objetivo a que ela se destina, utilizandose o parâmetro mais compatível com o mesmo. 
Segundo PINHEIRO (1996), os aspectos qualitativos estão relacionados ao cunho gerencial ou social, sendo portanto fácil de compreender porém difícil de se estabelecer critérios de divisão, do tamanho das empresas, mais precisos. Um exemplo de classificação qualitativa das empresas é a estabelecida por DRUCKER (1981), que classifica o tamanho das empresas de acordo com a estrutura administrativa, o que pode ser visualizado na tabela 3.1.

DRUCKER (1981) coloca que o parâmetro mais comum de classificação das empresas é o número de funcionários. Mas, diz o autor, o número de funcionários não é em si determinante. A estrutura administrativa, especialmente a estrutura da alta administração, é portanto o único critério de confiança para medir-se o tamanho de uma empresa, sendo uma empresa do tamanho da estrutura administrativa que necessita.

Em se tratando de critérios quantitativos, eles estão relacionados à ordem econômica e contábil da empresa. A literatura especializada aponta como critérios usualmente mais utilizados internacionalmente para a caracterização das pequenas empresas alguns parâmetros quantitativos como: mão-de-obra empregada, capital registrado, faturamento, quantidade produzida, dentre outras (MORIYAMA, 2000).

Um exemplo de classificação quantitativa utilizada no Brasil é a estabelecida pelo IBGE (Instituto Brasileiro de Geografia e Estatística), que é a mesma adotada pelo SEBRAE (2000a). Em tal classificação o porte das empresas é definido de acordo com o número de funcionários combinado com o setor ao qual a empresa pertence, o que é exposto na tabela 3.2.

O estatuto da Micro e Pequena Empresa também utiliza um critério quantitativo, classificando as empresas de acordo com a Receita Bruta Anual. A tabela 3.3 mostra esta classificação.

Pelo fato de os critérios qualitativos serem mais subjetivos e de difícil precisão, incorrendo em um tempo maior para a classificação do porte da empresa, neste projeto será utilizada a classificação do SEBRAE (2000a), que combina o número de funcionários com o setor econômico ao qual a empresa pertence. Assim serão utilizados critérios fixos e concretos para seleção das empresas a serem pesquisadas. 
Tabela 3.1 - Classificação das empresas segundo a estrutura administrativa

\begin{tabular}{|l|l|}
\hline Porte & \multicolumn{1}{|c|}{ Características } \\
\hline Micro & $\begin{array}{l}\text { Não existe separação de níveis } \\
\text { hierárquicos; } \\
\text { O dirigente da empresa ocupa a } \\
\text { maior parte do tempo em tarefas } \\
\text { operacionais e do empreendimento. }\end{array}$ \\
\hline Pequena & $\begin{array}{l}\text { Exige um nível administrativo entre } \\
\text { o chefe e os trabalhadores; } \\
\text { Dirigente ocupa a maior parte do } \\
\text { tempo nas áreas funcionais (finanças, } \\
\text { vendas, compras etc.), dedicando algum } \\
\text { tempo na função de direção e pouco } \\
\text { tempo em tarefas operacionais }\end{array}$ \\
\hline Média & $\begin{array}{l}\text { Dirigente ocupa a maior parte do } \\
\text { tempo em funções de direção, } \\
\text { coordenando níveis médios e } \\
\text { estabelecendo objetivos. Ele dedica } \\
\text { pouco tempo às áreas funcionais, que } \\
\text { são delegadas à gerência } \\
\text { capacidade de uma pessoa dividindo-se } \\
\text { em: coordenação de níveis médios e } \\
\text { estabelecimento de objetivos }\end{array}$ \\
\hline Arande
\end{tabular}

Fonte: Elaboração própria a partir de DRUCKER (1981) 
Tabela 3.2 - Classificação das empresas segundo o número de empregados

\begin{tabular}{|c|c|c|}
\hline Porte & $\mathbf{N}^{\mathbf{0}}$ Funcionários (indústria) & $\mathbf{N}^{\mathbf{0}}$ Funcionários (comércio) \\
\hline Micro & $0-19$ & $0-9$ \\
\hline Pequena & $20-99$ & $10-49$ \\
\hline Média & $100-499$ & $50-99$ \\
\hline Grande & Acima de 500 & Acima de 100 \\
\hline
\end{tabular}

Fonte: SEBRAE (2000a)

Tabela 3.3 - Classificação das MPEs segundo o faturamento bruto anual

\begin{tabular}{|c|c|}
\hline Porte & Receita Bruta Anual (R\$) \\
\hline Micro & até $244.000,00$ \\
\hline Pequena & acima de $244.000,00$ até $1.200 .000,00$ \\
\hline
\end{tabular}

Fonte: Lei Federal n ${ }^{\circ} 9841$ - Estatuto da Micro e Pequena Empresa (apud SEBRAE, 2000a)

\subsection{IMPORTÂNCIA DA PEQUENA EMPRESA}

Segundo LONGENECKER, MOORE \& PETTY (1997), como parte da comunidade empresarial, as pequenas empresas contribuem inquestionavelmente para o bem-estar econômico da nação. Elas produzem uma parte substancial do total de bens e serviços e oferecem condições excepcionais, na medida em que fornecem novos empregos, introduzem inovações, estimulam a competição, auxiliam as grandes empresas e produzem bens e serviços com eficiência.

CHER (1991) coloca que a importância das pequenas empresas pode ser verificada através de alguns aspectos, citando os seguintes:

- a significativa contribuição na geração do produto nacional;

- a absorção de mão-de-obra, principalmente a menos qualificada; 
- flexibilidade locacional;

- caráter majoritariamente nacional, havendo predominância do capital privado do país;

- o desempenho de atividades de auxílio às grandes empresas, realizando tarefas que muitas vezes essas não poderiam realizar ou realizariam com pouca eficácia, como distribuição e fornecimento.

\subsubsection{IMPORTÂNCIA DA PEQUENA EMPRESA EM ALGUMAS ECONOMIAS MUNDIAIS}

O SEBRAE (apud PANIGAS, 1998) relata a importância das pequenas empresas em algumas economias mundiais, sendo elas:

- Estados Unidos: nos Estados Unidos as pequenas empresas são responsáveis por 65\% da mão-de-obra em atividade no setor privado, $50 \%$ da produção e $54 \%$ das vendas. Assim, fica claro os motivos que levam tal país a considerar o fortalecimento das pequenas empresas como um permanente objetivo estratégico para o desenvolvimento de sua economia;

- Japão: as pequenas empresas no Japão representam cerca de 90\% das indústrias e empregam mais de $80 \%$ da força de trabalho. O Japão dedica-se intensamente à atividade de pesquisa e desenvolvimento de novos produtos, buscando a máxima terceirização e subcontratação na sua linha de produção através da compra, contratação e treinamento das pequenas empresas. Além disso, o governo nacional japonês, as províncias, cidades e instituições públicas e de economia mista, proporcionam apoio financeiro com deduções e créditos fiscais para aplicação nas áreas de pesquisa em novos métodos de operação, gerenciamento e desenvolvimento de mercados, principalmente em setores chave para a expansão da economia como: software, biotecnologia, eletrônica avançada, robótica e bens de capital;

- Itália: nesse país, as pequenas empresas são responsáveis por mais de $70 \%$ do PIB e garantem, em muitos setores, mais de $90 \%$ da produção regional. É intenso o apoio do governo e da iniciativa privada italiana aos pequenos negócios, através de incentivos financeiros, que subsidiam despesas de até $60 \%$ dos custos de implantação e aparelhamento, além de empréstimos e contribuições no primeiro triênio de operação da empresa. O governo garante isenção fiscal parcial e assistência técnica na fase de implantação, além de consultoria gratuita e cursos de qualificação;

- Alemanha: na Alemanha as pequenas e médias empresas são a base da cadeia produtiva e de toda a atividade econômica. O país fornece um tratamento diferenciado para as pequenas 
empresas em concorrências públicas e encomendas governamentais e proporcionam subsídios que incluem ajuda na formação do capital, garantias oficiais para exportação, crédito a juros baixos, e assessoria tributária e de gerenciamento;

- Coréia do Sul: é o país mais agressivo dos Tigres Asiáticos, possuindo um sistema produtivo semelhante ao japonês, onde as pequenas empresas operam por trás de grandes corporações no fornecimento de subcomponentes, peças e serviços, servindo de base ao sucesso exportador coreano. O governo adota como prioridade o fortalecimento dos pequenos negócios através de instituições como a Corporação para a Promoção da Pequena e Média Empresa, que promove a reestruturação, modernização e o acesso das pequenas empresas aos contratos do setor público.

\subsubsection{IMPORTÂNCIA DA PEQUENA EMPRESA NO BRASIL}

No Brasil o papel da pequena empresa é bastante significativo, tendo em vista a contribuição do pequeno empresário para a redução das desigualdades inter-regionais e interpessoais de renda. As micro e pequenas empresas brasileiras constituem um universo de aproximadamente 4,5 milhões de unidades, correspondendo a 98\% dos estabelecimentos e sendo responsável por cerca de 59\% dos empregos urbanos no Brasil, incluindo neste cálculo empregados e empresários de micro e pequenas empresas e os "Conta Própria” (indivíduo que possui seu próprio negócio mas não tem empregados). O número de MPEs industriais exportadoras se aproxima de 4.000 empresas, que exportam anualmente cerca de US\$ 800 milhões (SEBRAE, 1998a)

A tabela a seguir demonstra os dados percentuais da participação das MPEs na economia brasileira: 
Tabela 3.4 - Participação das MPEs na Economia Brasileira

\begin{tabular}{|l|c|}
\hline \multicolumn{1}{|c|}{ Variável } & As MPEs no Brasil (em \%) \\
\hline Número de Empresas & $98 \%$ \\
\hline Pessoal Ocupado & $59 \%$ \\
\hline PIB & $20 \%$ \\
\hline Número de Empresas Exportadoras & $29 \%$ \\
\hline Valor das Exportações & $1,7 \%$ \\
\hline
\end{tabular}

Fonte: SEBRAE (2000a). Elaboração a partir de dados do IBGE, FUNCEX, PNAD e

RAIS/MTE (1994, 1995 e 1996)

\subsubsection{IMPORTÂNCIA DA PEQUENA EMPRESA NO ESTADO DE SÃO PAULO}

No estado de São Paulo, de acordo com o SEBRAE (2000b), existem cerca de 1,3 milhão de micro e pequenas empresas, sendo $43 \%$ no comércio, $31 \%$ nos serviços, $14 \%$ na agropecuária e $12 \%$ na indústria, representando cerca de $97 \%$ do total de empresas do estado.

De acordo com o SEBRAE (2000c), o pessoal ocupado nas micro e pequenas empresas paulistas é de 7,4 milhões de pessoas, correspondendo a $67 \%$ do total do estado. A tabela 3.5 demonstra a distribuição da ocupação no Estado de São Paulo.

Tabela 3.5. Pessoal Ocupado - MPEs - Estado de São Paulo

\begin{tabular}{|l|r|r|r|}
\hline Posição na ocupação & \multicolumn{3}{|c|}{ Pessoal ocupado (1999) } \\
\hline & \multicolumn{2}{|l|}{$\begin{array}{l}\text { Micro e Pequena } \\
\text { Empresa }\end{array}$} & $\begin{array}{l}\text { Grande e Média } \\
\text { Empresa }\end{array}$ \\
\hline $\begin{array}{l}\text { Empregados com } \\
\text { carteira }\end{array}$ & $2.700 .960,00$ & $2.869 .203,00$ & $5570.163,00$ \\
\hline $\begin{array}{l}\text { Empregados sem } \\
\text { carteira }\end{array}$ & $1.267 .397,00$ & $761.727,00$ & $2.029 .124,00$ \\
\hline $\begin{array}{l}\text { Conta-própria } \\
\text { Empregador }\end{array}$ & $2.743 .486,00$ & - & $2.743 .486,00$ \\
\hline Total & $674.857,00$ & $3.638 .436,00$ & $11.025 .136,00$ \\
\hline Total (\%) & $7.386,700,00$ & $33 \%$ & $100 \%$ \\
\hline
\end{tabular}

Fonte: SEBRAE (2000c). Elaborado a partir da PNAD e RAIS 


\subsection{GESTÃO DE PEQUENAS EMPRESAS}

As pequenas empresas, em comparação com as grandes corporações, apresentam aspectos gerenciais peculiares, e muitas vezes limitantes.

De acordo com MORIYAMA (2000), a equipe gerencial das pequenas empresas passa por restrições que não constituem problema para as grandes empresas. Elas não têm dinheiro suficiente nem pessoas devidamente capacitadas, limitando seu poder de atuação, e muitas vezes elas não se disponibilizam a gastar dinheiro em pesquisas, propagandas, análises financeiras etc.

Os gestores de pequenas empresas são muito suscetíveis de sofrer de perspectivas limitadas e de constrição de seus contatos externos. Isso poderá tornar os conhecimentos e competências retrógrados tecnológica e economicamente, comprometendo o sucesso ou a sobrevivência da empresa. Talvez sequer chegarão a perceber que haja problemas de organização administrativa, relegando a necessidade de reflexão ou planejamento, tentando administrar intuitivamente (DRUCKER, 1981).

RATTNER et. al (1985) enumeraram alguns aspectos qualitativos característicos à gestão das pequenas empresas:

- sistemas de organização e administração tradicionais, concentrados nas funções do proprietário/gerente ou de membros da família;

- restrita especialização dos diversos cargos administrativos e relação interna e externa da empresa do tipo pessoal. O elemento humano é pouco qualificado, o que resulta em programação pouco eficaz da produção e falta de integração desta com outros setores ou departamentos da empresa, refletindo-se também na ausência de um sistema de informações para tomada de decisão na organização;

- referentes à administração financeira-contábil, destacam-se as dificuldades para obtenção de financiamentos, agravadas pela falta de recursos próprios. Na impossibilidade de ter acesso ao mercado de capitais, a empresa busca crédito a curto prazo, pagando altas taxas de juros;

- referentes à administração mercadológica, constituem aspectos e características fundamentais, o tipo de participação e controle de mercado, a forma e o grau de concorrência, o número de produtos comercializados, tanto na compra de insumos e matérias-primas, quanto na venda de produtos acabados. 


\subsection{CAUSAS DE SUCESSO E INSUCESSO DAS PEQUENAS EMPRESAS}

Na literatura sobre pequenas empresas pode-se encontrar pesquisas e estudos feitos demonstrando fatores de sucesso, insucesso, pontos fortes e fracos das pequenas empresas. Alguns dos resultados obtidos com tais pesquisas serão citados a seguir.

De acordo com CÂNDIDO (1998), as pequenas empresas apresentam pontos fortes e fracos, que são condicionantes à sua competição e sobrevivência. Tais pontos podem ser resumidos e visualizados na tabela 3.7.

Segundo RESNIK (1990), percebeu-se que a boa administração é o fator determinante da sobrevivência e sucesso de uma pequena empresa. Ao contrário do que muitos empresários afirmam, é a má administração e não a instabilidade econômica, os juros altos, a concorrência, a inconstância dos clientes ou o azar que é o fator determinante do fracasso.

ZIMMERER \& SCARBOROUGH (1994) relatam que em grande parte dos pequenos negócios a inexperiência gerencial e a inabilidade na tomada de decisões são os problemas principais no declínio desses. Segundo os autores, outros fatores, embora em menor importância, também contribuem para tal declínio, sendo eles: controle financeiro inadequado; ausência de planejamento estratégico; expansão não planejada; localização inadequada e dificuldades de acesso a crédito.

CHER (1991) diz que as causas de fracasso de uma pequena empresa são as seguintes:

- falta de experiência anterior no ramo do negócio, e falta de gosto pelo mesmo;

- falta de conhecimento do instrumento de administração (marketing, contábil-financeiro, recursos humanos, produção, informática);

- falta de recursos e dificuldade de obtenção de créditos e financiamentos;

- falta de profissionais qualificados, treinados e motivados;

- burocracias legais (aspectos tributários, fiscais e trabalhistas);

- imposição de preços por parte de grandes fornecedores e grandes clientes;

- obsolescência de métodos, equipamentos e mentalidade gerencial;

- falta de competitividade para enfrentar a concorrência;

- não utilização de orientação técnica profissional;

- falta de organização empresarial, política e econômica na empresa;

- desinformação acerca dos acontecimentos políticos e econômicos do país e;

- falta de comunicação entre patrões e funcionários. 
Tabela 3.6 - Pontos fortes e fracos da pequena empresa

\begin{tabular}{|c|c|}
\hline Pontos Fortes & Pontos Fracos \\
\hline $\begin{array}{l}\text { - Arrojo, crença e obstinação pelo trabalho; } \\
\text { - Agilidade nas ações e na tomada de decisões; } \\
\text { - Informações internas circulam com mais } \\
\text { facilidade; } \\
\text { - Funcionários mais próximos dos clientes; } \\
\text { - Melhor entendimento da organização pelos } \\
\text { - } \text { - Mancionários; } \\
\text { - Funcionários mais generalistas; } \\
\text { - Adaptabilidade maior em relação às } \\
\text { - } \text { mudanças de mercado; }\end{array}$ & $\begin{array}{l}\text { - Gerência autoritária e centralizadora; } \\
\text { - Individualismo por medo da concorrência; } \\
\text { - } \text { Dificuldade de comunicação com o meio } \\
\text { ambiente; } \\
\text { - Visão distorcida dos recursos humanos; } \\
\text { - Pouco profissionalismo no atendimento aos } \\
\text { - clientes; } \\
\text { - Empregos menos vantajosos para os } \\
\text { - } \text { trabalhadores; } \\
\text { - } \text { Palta de pessoal qualificado; } \\
\text { - Baixa disponibilidade de recursos; } \\
\text { - Baixo poder de barganha em relação à } \\
\text { contratação de empréstimos; } \\
\text { - Capacidade de produção limitada. }\end{array}$ \\
\hline
\end{tabular}

Fonte: CÂNDIDO (1998)

RESNIK (1990) diz que a eficácia gerencial está ligada ao empreendedor pois, na maioria das empresas este é quem desempenha o papel gerencial.

No Brasil, as micro e pequenas empresas, apesar de numerosas apresentam uma taxa de mortalidade bastante elevada. O SEBRAE (1999) demonstra, através de uma pesquisa realizada no período de agosto de 1998 a junho de 1999 em doze unidades da Federação, que a taxa de mortalidade variou, em cada estado, conforme exposto na tabela 3.8: 
Tabela 3.7 - Taxa de mortalidade das MPEs

\begin{tabular}{|c|c|}
\hline Ano de existência da empresa & Taxa de mortalidade (\%) \\
\hline $1^{\circ}$ & $30-61$ \\
\hline $2^{\circ}$ & $40-68$ \\
\hline $3^{\circ}$ & $55-73$ \\
\hline
\end{tabular}

Fonte: Elaboração própria a partir de dados fornecidos pelo SEBRAE (1999)

Esta pesquisa realizada pelo Sebrae procurou também identificar os fatores condicionantes à taxa de mortalidade demonstrada na tabela anterior. A pesquisa foi feita tanto em empresas extintas quanto em empresas em atividade. No estado de São Paulo os principais fatores encontrados foram:

- falta de capital de giro;

- recessão econômica e;

- carga tributária elevada.

Tais resultados podem ser visualizados, em termos percentuais em relação ao número total de empresas pesquisadas. Na figura 3.1.

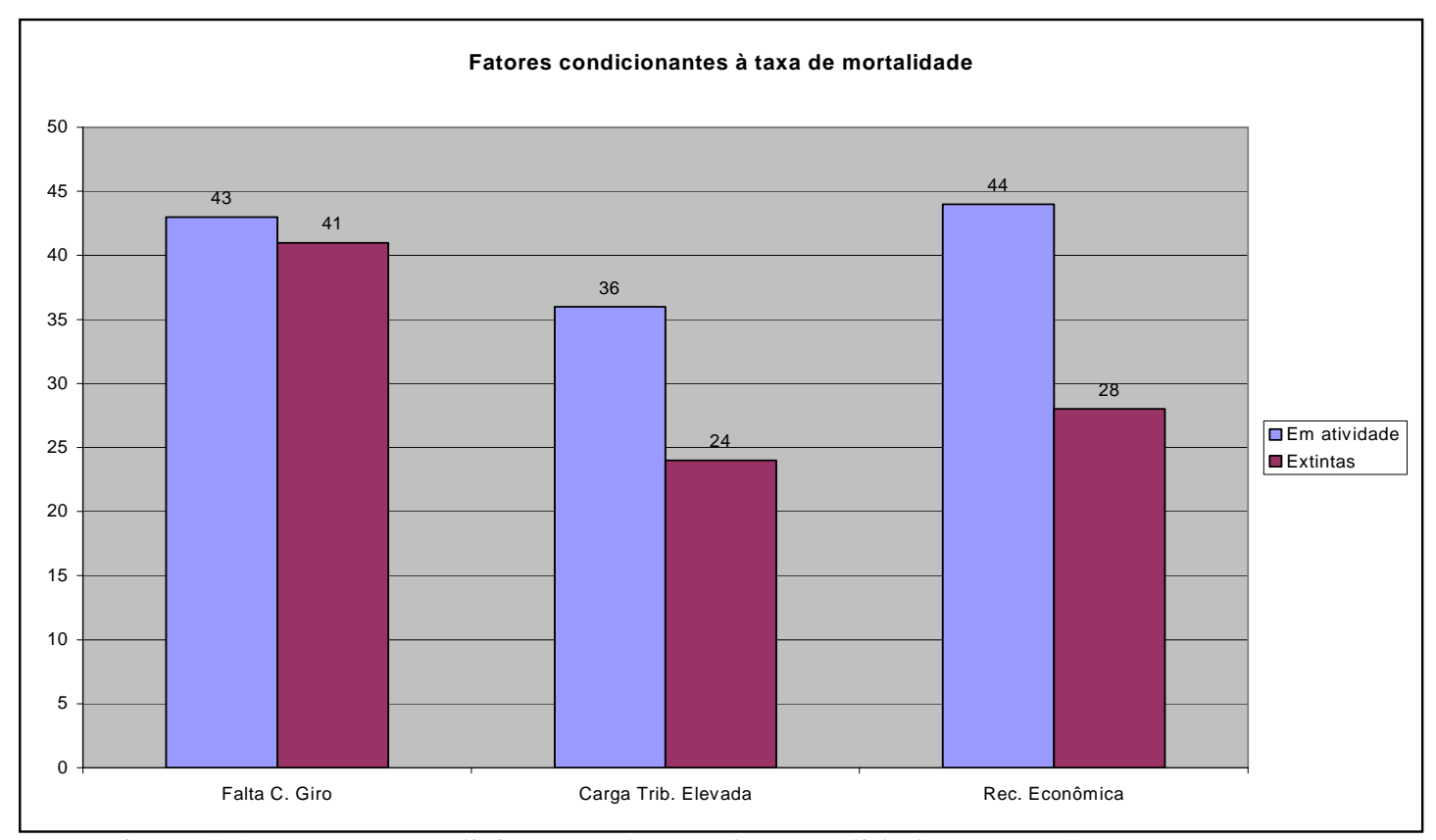

Figura 3.1 - Fatores condicionantes à taxa de mortalidade (Fonte: SEBRAE, 1999) 
Já em relação aos principais fatores, que uma empresa deve possuir para ter sucesso, os pequenos empresários, do estado de São Paulo, entrevistados pelo SEBRAE (1999) dizem ser:

- conhecimento do mercado onde atua;

- $\quad$ ter um bom administrador e;

- fazer uso do capital próprio.

Esses resultados estão demonstrados percentualmente em relação ao número total de empresas pesquisadas na seguinte figura:

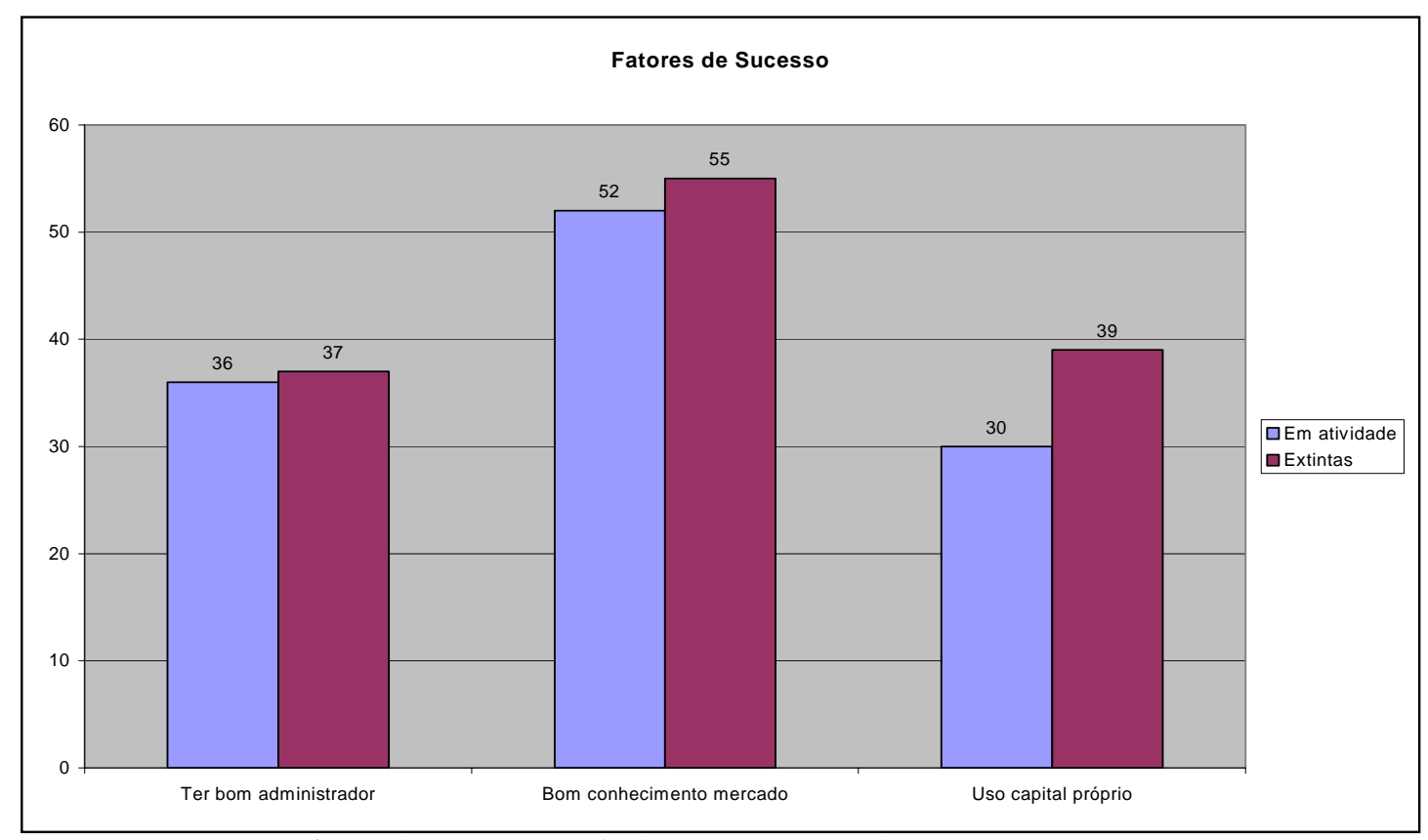

Figura 3.2 - Fatores de Sucesso (Fonte: SEBRAE, 1999)

\subsection{GESTÃO DA QUALIDADE TOTAL NAS PEQUENAS EMPRESAS}

As pequenas empresas, frente a um ambiente mundial de constante mudança e a cada dia mais competitivo, passaram a buscar e continuam buscando caminhos e alternativas para sobreviver e crescer.

Dentro desse contexto, a Gestão pela Qualidade Total (TQM) tem um papel fundamental para o aumento da eficiência e competência das pequenas empresas, pois como coloca PANIGAS (1998), a larga utilização da TQM em todo o mundo, por todos os segmentos empresariais e por empresas de todos os tamanhos, demonstra que ela tem muito a contribuir 
para a melhoria dos níveis de qualidade dos bens e serviços ofertados e na busca constante pela melhoria dos processos empresariais.

\subsubsection{IMPORTÂNCIA DA TQM NAS PEQUENAS EMPRESAS}

De acordo com GHOBADIAN \& GALLEAR (1996), cinco proposições chave revelam a importância de as pequenas empresas a adotarem a TQM:

- o alto nível de qualidade é um fator chave para a obtenção de uma posição competitiva, pois as pequenas empresas podem melhorar tal posição aplicando os conceitos da TQM;

- o emprego dos conceitos de TQM facilitam a sustentabilidade da alta qualidade de produtos e serviços;

- o flutuante setor das pequenas empresas é vital para a prosperidade econômica;

- o sucesso dos esforços de melhoria da qualidade nas grandes empresas muitas vezes dependem de que seus fornecedores também ofereçam produtos e serviços de qualidade, sendo grande parte destes fornecedores pequenas empresas.

Sabendo da importância em se utilizar a Gestão da Qualidade Total, muitas pequenas empresas vêm adotando Programas de Qualidade. Segundo PANIGAS (1998), uma das justificativas para que as pequenas empresas demonstrem interesse em Programas de Qualidade e se mostrem dispostas a uma reestruturação, é que seus dirigentes estão entendendo que o mercado está passando por um processo muito rápido de mudança e que a sobrevivência de suas empresas depende da capacidade em tornarem-se competitivas em um período de tempo cada vez mais curto.

\subsubsection{INFLUÊNCIA DO TAMANHO DA ORGANIZAÇÃO NOS RESULTADOS DA TQM}

TAYLOR (1997) diz que relativamente poucas pesquisas têm sido escritas sobre a influência do tamanho da organização nos resultados da TQM; por outro lado, muito do que tem sido publicado sobre a implementação da TQM visa identificar as melhores práticas incorporadas pelas organizações que vêm obtendo prêmios de qualidade, ou as utilizadas pelas grandes organizações.

O autor realizou uma pesquisa em 113 empresas do Reino Unido, sendo 56 pequenas e 57 grandes objetivando compreender se o tamanho da organização influencia no desempenho do gerenciamento da qualidade total, obtendo os seguintes resultados: 
- compreensão dos executivos a respeito da importância da TQM: a análise revelou que pequenas organizações tem uma visão mais restrita em relação às grandes sobre o propósito da Qualidade Total. A compreensão dos executivos seniores tende a melhorar quanto maior for a organização. Em particular, o entendimento da dimensão do consumidor é significantemente mais pobre nas práticas de qualidade utilizadas em pequenas empresas;

- compreensão da relação entre TQM e performance organizacional: não observou-se diferenças na compreensão da relação entre TQM e performance organizacional entre executivos de pequenas e grandes empresas;

- gerenciamento da qualidade como uma questão estratégica: neste aspecto, 86\% (oitenta e seis por cento) das pequenas responderam que consideram a qualidade como uma questão estratégica e 91\% (noventa e um por cento) das grandes também. Porém, quando as respostas foram comparadas com as questões sobre o entendimento do significado do gerenciamento da qualidade, percebeu-se que, nas pequenas empresas a estratégia era focada mais em questões internas, referentes às equipes de trabalho e à resolução de problemas do que em questões externas, ligadas aos consumidores;

- razões para dedicar-se ao TQM: houveram diferenças significantes entre as razões apontadas pelas pequenas empresas e o restante das organizações. Pequenas empresas deram respostas mais focadas em custo e eficiência ou na aspiração de ser o melhor, e menos em questões ligadas ao consumidor ou vantagem de marketing;

- nível de envolvimento dos empregados nas atividades de TQM: quando os pequenos empresários foram questionados sobre o envolvimento dos seus empregados nas atividades de qualidade, grande maioria deles disse que há o envolvimento, mas na prática, verificou-se menos envolvimento dos empregados do que o relatado devido a menos recursos disponíveis para treinamento ou mais pressões de tempo. 


\subsubsection{CARACTERÍSTICAS DAS PEQUENAS EMPRESAS E VANTAGENS E DESVANTAGENS NA UTILIZAÇÃO DA TQM}

Segundo GHOBADIAN \& GALLEAR (1996), as pequenas empresas possuem características peculiares que representam vantagens e desvantagens para o gerenciamento da qualidade total.

As vantagens levantadas pelos autores são as seguintes:

- pequenas empresas têm uma vantagem distinta a respeito da liderança do(s) proprietário(s)/altos executivos, o que é essencial na TQM, porque normalmente o principal executivo da pequena empresa consegue envolver os funcionários sem muito esforço organizacional, podendo rapidamente enfatizar e demonstrar a todos a importância da qualidade. Em grandes organizações isso já demora mais tempo;

- times de melhoria têm uma melhor visibilidade tanto horizontal como verticalmente em pequenas empresas. Assim, o nível de comprometimento e suporte, gerado pelos times de melhoria da qualidade podem direta e indiretamente influenciar a mudança de cultura, fator chave para o sucesso no gerenciamento da qualidade;

- em um ambiente de TQM, cada pessoa da organização precisa estar atento aos consumidores e suas necessidades. Em pequenas empresas os funcionários tendem a ter maior proximidade com os clientes, facilitando o foco no consumidor;

- empresas menores possuem menos níveis hierárquicos e menos pessoas a serem mobilizadas em prol da qualidade. Assim, mudanças culturais podem acontecer mais rapidamente porque o esforço requerido para reunir as pessoas e iniciar o processo de mudança é normalmente modesto;

- é mais fácil para as empresas pequenas a criação de uma atmosfera que auxilia o crescimento pessoal, mostrando aos funcionários como seu trabalho contribui para o alcance dos objetivos organizacionais, encorajando-os a dar idéias para melhoria ou expansão do negócio;

- em empresas pequenas as pessoas podem visualizar seus esforços de qualidade traduzirem-se em resultados tangíveis de maneira mais rápida;

- o processo de tomada de decisão é mais simples nas pequenas empresas porque há menos níveis gerenciais;

- a resistência à mudança tende a ser maior nas grandes organizações devido a fatores como: existência de muitos grupos com diferentes interesses, presença de um significante grau de diversidade cultural, alto grau de padronização e formalização, e dificuldades no processo de 
comunicação. Além disso as grandes empresas podem ter filiais ou outras unidades em locais diferentes, aumentando a complexidade da implantação e gerenciamento da qualidade. As pequenas empresas no entanto, normalmente operam em um único local, o que facilita e simplifica tais pontos.

Em se tratando das desvantagens, GHOBADIAN \& GALLEAR (1996) colocam os seguintes pontos:

- em empresas muito pequenas a personalidade do proprietário ou do executivo chefe, em geral, domina a cultura. Muitos proprietários possuem pouco treinamento gerencial formal, o que pode resultar em inflexibilidade e rigidez do ponto de vista desses, prejudicando o gerenciamento voltado para a qualidade total, que exige uma grande mudança de cultura;

- o tamanho limitado da equipe gerencial faz com que os indivíduos sejam responsáveis por um grande número de atividades e funções. Frequentemente, eles estão ocupados com o gerenciamento de tarefas rotineiras tendo pouco tempo para outras atividades, não dedicando tempo suficiente para questões relativas à qualidade;

- as pequenas empresas sofrem com a ausência de conhecimento específico e técnico, o que muitas vezes dificulta a adoção de técnicas e ferramentas da qualidade;

- restrições de tempo e pessoal muitas vezes impedem a organização de aplicar programas de incentivo e recompensa e também de esquematizar e operar um sistema efetivo de medida de performance. 


\section{CAPÍTULO 4}

\section{PROGRAMA SEBRAE DE QUALIDADE TOTAL - PSQT}

A evolução e mudança nos conceitos de qualidade e a forma como eles são gerenciados tornam essenciais que as organizações se direcionem para o futuro utilizando programas de gerenciamento da qualidade que sejam suficientemente bons, dando resultados positivos, para que funcionem frente à nova era dos negócios, ao invés de continuar a trabalhar com sistemas que foram eficientes no passado (FEIGENBAUM, 1998).

Programas de gerenciamento da qualidade têm sido largamente empregados a nível mundial, sendo que no Brasil a adoção de tais programas também tem sido crescente. Isso vem ocorrendo, segundo OLIVEIRA (1994) por motivos como:

- exigência de maior qualidade pelos clientes;

- constatação de que o crescimento atual da empresa exija que ela atinja novos patamares de qualidade e produtividade;

- níveis significativos de exportação dos produtos, exigindo alto padrão de qualidade;

- concorrência acirrada; e

- retração de mercado.

Observa-se que tais programas são adotados no país por empresas de vários setores e ramos organizacionais, sendo essas empresas grandes, médias e até pequenas e micros. Sendo que nestas duas últimas, destaca-se a utilização do Programa Sebrae de Qualidade Total (PSQT), com metodologia elaborada pelo Serviço Brasileiro de Apoio à Micro e Pequena Empresa (SEBRAE) nacional. 


\subsection{FILOSOFIA BÁSICA DO PSQT}

O Programa Sebrae de Qualidade Total, através de uma metodologia adaptada à realidade das micro e pequenas empresas, de fácil implantação, busca promover uma nova cultura de participação, colaboração e iniciativa, direcionada para a satisfação das expectativas e necessidades dos clientes.

O SEBRAE adota como filosofia básica para a implantação do PSQT dez princípios da Qualidade Total, apresentados no próximo parágrafo. Segundo PANIGAS (1998) para o SEBRAE existe a pressuposição de que uma empresa que conseguir implementar estes princípios, como base para as ações empresariais em busca da Qualidade Total, conseguirá atingir seus objetivos.

O SEBRAE (1997) define os princípios da qualidade total da seguinte forma:

1. Total Satisfação dos Clientes: atendimento aos clientes, conhecimento dos clientes, avaliação sistemática dos clientes, parceria com o cliente, superação de expectativas, e comparação de desempenho com os concorrentes;

2. Gerência Participativa: incentivo à manifestação de idéias e de opiniões, compartilhamento de informações, participação nas decisões, estímulo à formação de times da qualidade, e atitudes do gerente: liderança para orientar e facilitar;

3. Desenvolvimento de recursos humanos: valorização do ser humano, capacitação para o trabalho, educação, motivação no trabalho, e satisfação com o trabalho;

4. Constância de propósitos: persistência, continuidade, coerência nas atitudes e práticas, planejamento estratégico, alinhamento, e convergência de ações;

5. Aperfeiçoamento Contínuo: predisposição para melhorias, inovações, fixação de novas metas, uso de novas tecnologias, e utilização de indicadores de desempenho;

6. Gerência de Processos: cadeia cliente/fornecedor; mensuração por meio de indicadores, e integração de processos;

7. Delegação: descentralização, autonomia para tomada de decisão, decisão onde está a ação, e respaldo para ações delegadas;

8. Disseminação de informações: conhecimento do negócio, da missão, do propósito, da estratégia e dos planos, troca de informações com o meio externo, sistema interno de difusão das informações, credibilidade da informação, fluxo de informações rápido e constante, e transparência da organização;

9. Garantia da Qualidade: ações sistemáticas e planejadas, estabilidade dos processos e das rotinas, confiabilidade, formalização do processo, e garantia da qualidade em serviços;

10. Não-aceitação de Erros: não se conformar com o erro, definição do certo, atitude preventiva e custo da qualidade. 
Segundo o SEBRAE (1997), o Programa Sebrae da Qualidade Total ultrapassa os limites de um treinamento ou de uma consultoria, consistindo em um processo contínuo de Gestão da Qualidade Total, com a introdução de novas crenças e atitudes, de parâmetros gerenciais participativos e inovação nos procedimentos operacionais, sendo suas principais vantagens as seguintes:

- abertura de novas frentes: ao implantar a qualidade a empresa abre portas para outros mercados. Adquire certo status ao diferenciar-se de seus concorrentes. A qualidade total qualifica-a para novos mercados;

- competitividade: as micro e pequenas empresas podem ganhar competitividade, fornecendo produtos e serviços de alta qualidade e a preços mais baixos;

- custos mais reduzidos: as micro e pequenas empresas que implantam qualidade podem diminuir consideravelmente seus custos, seja pela redução de desperdícios e retrabalhos, seja pela racionalização dos processos, ou ainda, pela eliminação de controle desnecessários e de burocracia ;

- criação de novos negócios: a qualidade propicia o reposicionamento estratégico da pequena empresa, em virtude do enfoque permanente no cliente, nas suas necessidades e aspirações. Fica-se mais próximo do cliente, facilitando a troca de informações. A prática da qualidade amplia a percepção para novos negócios e novas oportunidades;

- clima de incentivo e participação: a qualidade implica em gerência participativa. Os funcionários acompanham e são envolvidos no processo de implantação da qualidade, propiciando sinergia e clima organizacional positivo;

- direcionamento do marketing: é preciso saber em profundidade como é aceita a atual linha de produtos da empresa, para assim manter-se na vanguarda de seu segmento de mercado;

- retorno mais compensador: o resultado final do programa de qualidade total é a ampliação da lucratividade da empresa, sem que isto signifique necessariamente preços mais elevados ou maiores encargos sociais.

\subsection{HISTÓRICO DO PROGRAMA}

O Programa Sebrae da Qualidade Total, desenvolvido em parceria com o Instituto Brasileiro da Qualidade Nuclear, a MCG Qualidade e a Telesoft Informática, vem sendo implantado por pequenas empresas de todo o país desde 1993.

Na época de criação do PSQT, os conceitos de qualidade estavam sendo amplamente difundidos e aplicados nas empresas, fundamentalmente em indústrias de maior porte, que possuíam condições financeiras de contratar empresas ou profissionais especializados na 
aplicação de seus métodos. Não existia porém nenhum método que difundisse os conceitos da qualidade de uma forma adequada às micro e pequenas empresas, ou seja, de uma maneira simples e a um custo suficientemente baixo. Foi pensando nisso que o SEBRAE desenvolveu seu programa, com as seguintes características e objetivos (PANIGAS, 1998):

- massificar os conceitos da gestão pela qualidade total: disseminar os conceitos da qualidade ao maior número possível de pequenas empresas;

- ser auto implantável: os empresários e alguns funcionários são treinados no método de implantação e, após o apoio de um consultor por um período de tempo, a empresa deve estar capacitada para continuar o processo por conta própria;

- ter um baixo custo de implantação e, por conseqüência, um preço final baixo para a empresa;

- fornecer um material didático de apoio adequado às características e necessidades da micro e pequena empresa, com uma linguagem simples e de fácil compreensão, um texto objetivo, a utilização de exemplos e estruturado na forma de módulos com aplicação progressiva;

- trabalhar com as lideranças das empresas: a participação dos empresários é condição fundamental para o engajamento da empresa ao programa;

- trabalhar com grupos de empresas: facilita a troca de informações, promove o incentivo ao trabalho coletivo e reduz os custos globais do programa;

- trabalhar em parceria com entidades e associações de empresas: essas se responsabilizam pela divulgação do PSQT e pelo fornecimento da infra-estrutura necessária ao treinamento.

A primeira versão do programa foi estruturada da forma exposta na tabela 4.1.

Em 1997, o SEBRAE após estudo dos resultados de Programas já realizados reformulou o PSQT, lançando uma nova versão desse. Tal versão é a enfocada nesta pesquisa.

Segundo CÂNDIDO (1998), cabe ressaltar que da metodologia anterior para a nova, procurou-se manter a linha geral do programa em treinamento coletivo (grupos de empresas), consultoria individual e auto-implantação.

Uma visão geral da segunda versão do programa é apresentada na tabela 4.2.

O Programa possui uma carga horária de 88 (oitenta e oito) horas de treinamento e 20 (vinte) horas de consultoria, com uma duração aproximada de dez meses.

Fazendo uma comparação entre as metodologias a tabela 4.3 resume as principais alterações ocorridas (CÂNDIDO, 1998). 
Tabela 4.1 - Estrutura do Programa Sebrae - $1^{\text {a }}$ versão

\begin{tabular}{|l|c|}
\hline \multicolumn{1}{|c|}{ ETAPA } & DURAÇÃo \\
\hline A) SENSIBILIZAÇÃO & $4 \mathrm{~h}$ \\
\hline B) IMPLANTAÇÃO ORIENTADA (14 módulos) & 25h \\
B.1) Fundamentos Básicos da Gestão da Qualidade (1º ao $7^{\circ}$ módulo) & \\
1. Conceitos Básicos da Qualidade Total & \\
2. Preparando-se para a Qualidade & \\
3. Satisfação do Cliente & \\
4. Gerência Estratégica & \\
5. Gerência Participativa & \\
6. Eliminando o Desperdício & \\
7. Estrutura Voltada para o Cliente & \\
B.2) Ferramentas da Qualidade(7º ao $14^{\circ}$ módulo) & \\
8. Avaliação do Processo de Implantação & \\
9. Gerência de Processos & \\
10. Análise e Melhoria de Processos 1 & \\
11. Análise e Melhoria de Processos 2 & \\
12. Indicadores da Qualidade & \\
13. Garantia da Qualidade & \\
14. Avaliação e Encerramento & \\
B.3) Consultoria de apoio à implantação & \\
\hline C) SUSTENTAÇÃO (12 reuniões) & \\
\hline D) APERFEIÇOAMENTO ESPECÍFICO & \\
\hline
\end{tabular}

Fonte: SEBRAE (1995a) 
Tabela 4.2 - Estrutura do Programa Sebrae - $2^{\mathrm{a}}$ versão

\begin{tabular}{|l|c|c|}
\hline \multicolumn{1}{|c|}{ ETAPA } & \multicolumn{2}{|c|}{ DURAÇÃO } \\
\hline A) COMPROMISSO COM O ÊXITO (sensibilização) & Treinamento & Consultoria \\
& $\mathbf{4 h}$ & - \\
\hline B) BLOCO I - A CONQUISTA DA QUALIDADE & Treinamento & Consultoria \\
1. O Conceito de Melhor & $4 \mathrm{~h}$ & $2 \mathrm{~h}$ \\
2. Política da Qualidade & $4 \mathrm{~h}$ & $2 \mathrm{~h}$ \\
3. Parceria com o Futuro & $4 \mathrm{~h}$ & $2 \mathrm{~h}$ \\
4. A Satisfação Total & $4 \mathrm{~h}$ & $2 \mathrm{~h}$ \\
5. O Poder da Participação & $4 \mathrm{~h}$ & - \\
6. O Novo Gerente & $4 \mathrm{~h}$ & - \\
7. Auditoria do Programa & $4 \mathrm{~h}$ & - \\
Total de horas & & \\
\hline C) BLOCO II - D-OLHO NA QUALIDADE & $\mathbf{2 8 h}$ & $\mathbf{8 h}$ \\
1. Eliminando o Desperdício & Treinamento & Consultoria \\
2. Descarte e Organização & $4 \mathrm{~h}$ & $2 \mathrm{~h}$ \\
3. Limpeza e higiene & $4 \mathrm{~h}$ & $2 \mathrm{~h}$ \\
4. Ordem Mantida & $4 \mathrm{~h}$ & - \\
5. Auditoria do Programa & $4 \mathrm{~h}$ & - \\
Total de horas & $4 \mathrm{~h}$ & - \\
\hline & & \\
D) BLOCO III - MELHORIA DE PROCESSOS & $\mathbf{2 0 h}$ & $\mathbf{4 h}$ \\
1. Indicadores da Qualidade & Treinamento & Consultoria \\
2. Análise e Mellhoria & $8 \mathrm{~h}$ & $2 \mathrm{~h}$ \\
3. Garantia da Qualidade & $16 \mathrm{~h}$ & $2 \mathrm{~h}$ \\
4. Auditoria do Programa & $8 \mathrm{~h}$ & $4 \mathrm{~h}$ \\
Total de horas & $4 \mathrm{~h}$ & - \\
\hline Total geral & $\mathbf{3 6 h}$ & $\mathbf{8 h}$ \\
\hline & $\mathbf{8 8 h}$ & $\mathbf{2 0 h}$ \\
\hline
\end{tabular}

Fonte: Elaboração Própria a partir de dados fornecidos pelo SEBRAE (1997)

Tabela 4.3- Comparação entre as metodologias

\begin{tabular}{|l|l|}
\hline \multicolumn{1}{|c|}{$\mathbf{1}^{\text {a }}$ Versão } & \multicolumn{1}{c|}{$\mathbf{2}^{\mathbf{a}}$ Versão } \\
\hline Empresário principal gestor e executor & $\begin{array}{l}\text { Empresário: principal gestor } \\
\text { Equipe tarefa: execução }\end{array}$ \\
\hline Enfoque na auto-implantação & Maior enfoque na auto-implantação \\
\hline Etapa de sustentação definida e separada & Etapa de sustentação incorporada \\
\hline Cronograma de 14 semanas & Cronograma de 40 semanas (aproximadamente) \\
\hline Princípios da qualidade fixos no módulo 2 & Princípios da qualidade disseminados \\
\hline Conteúdo nem sempre ligado às tarefas & Conteúdo sempre ligado às tarefas \\
\hline Consultoria solicitada & Consultoria amarrada aos blocos e aos módulos \\
\hline
\end{tabular}

Fonte: CÂNDIDO (1998) 
Segundo estas comparações, pode-se destacar os seguintes aspectos (CÂNDIDO, 1998):

- maior enfoque nas tarefas ou atividades de implantação como forma de internalizar conceitos e ferramentas;

- maior enfoque no empresário e dono do negócio como principal gestor do processo;

- maior enfoque na auto-implantação. Apesar de se definir ações lógicas e programadas de tempo e conteúdo, a auto-implantação permite a empresa adequar o programa a sua realidade e características;

- criação de uma equipe de multiplicadores, para atuar na implantação das ferramentas da qualidade;

- extinção da fase de sustentação, com a ampliação do cronograma de implantação de catorze para trinta semanas;

- resgate dos resultados das tarefas e de indicadores ao longo do programa;

- as consultorias estão fixadas ao longo dos módulos dentro dos temas principais;

- maior capacitação dos empresários para a condução de reuniões e gerenciamento de equipes;

- atualização e incorporação dos conteúdos de estratégia empresarial, condução de reuniões, ferramentas e indicadores da qualidade.

A segunda versão do programa sofreu algumas modificações a partir do início de 1999, passando então o programa a ter uma terceira versão. As mudanças foram:

- transferência do módulo Indicadores de Desempenho Empresarial do Bloco III para o Bloco I;

- os módulos Política da Qualidade e Parceria com o futuro, do Bloco I, foram reformulados e passaram a chamar Princípios da Qualidade e Gestão Estratégica;

- acrescentou-se 12 horas de treinamento e 4 horas de consultoria ao Bloco I;

- os módulos Ordem Mantida e Auditoria do Programa, do Bloco II, foram agregados ao módulo Limpeza e Higiene, diminuindo 3 horas de treinamento e acrescentando 2 horas de consultoria ao Bloco;

- introduziu-se o módulo Gerenciamento de Processos ao Bloco III e inverteu-se a ordem do módulo Garantia da Qualidade e Análise de Melhoria. Houve também neste Bloco uma diminuição de $1 \mathrm{~h}$ de auditoria e aumento de $2 \mathrm{~h}$ de consultoria;

- quanto às ferramentas da qualidade utilizadas no programa, substituiu-se a ferramenta 3Q1POC (quando, quem, o que, por que, onde e como) pela 4Q1POC (quando, quem, o 
que, quanto, por que, onde e como) e acrescentou-se as ferramentas matriz de decisão e técnica do grupo nominal.

O programa reformulado é exposto na tabela abaixo:

Tabela 4.4 - Estrutura do Programa Sebrae - $3^{\mathrm{a}}$ versão

\begin{tabular}{|l|c|c|}
\hline \multicolumn{1}{|c|}{ ETAPA } & \multicolumn{2}{|c|}{ DURAÇÃO } \\
\hline A) COMPROMISSO COM O ÊXITO (sensibilização) & Treinamento & Consultoria \\
\hline B) BLOCO I - A CONQUISTA DA QUALIDADE & Treinamento & Consultoria \\
1. Conceito de Melhor & $4 \mathrm{~h}$ & $2 \mathrm{~h}$ \\
2. Princípios da Qualidade & $4 \mathrm{~h}$ & - \\
3. Gestão Estratégica & $4 \mathrm{~h}$ & $2 \mathrm{~h}$ \\
4. Indicadores de Desempenho Empresarial & $12 \mathrm{~h}$ & $2 \mathrm{~h}$ \\
5. Satisfação Total & $4 \mathrm{~h}$ & $2 \mathrm{~h}$ \\
6. Poder da Participação & $4 \mathrm{~h}$ & $2 \mathrm{~h}$ \\
7. Novo Gerente & $4 \mathrm{~h}$ & - \\
8. Auditoria do Programa & $4 \mathrm{~h}$ & $2 \mathrm{~h}$ \\
Total de horas & & \\
\hline C) BLOCO II - D-OLHO NA QUALIDADE & $\mathbf{4 0 h}$ & $\mathbf{1 2 h}$ \\
1. Eliminando o Desperdício & Treinamento & Consultoria \\
2. Descarte e Organização & $4 \mathrm{~h}$ & $2 \mathrm{~h}$ \\
3. Limpeza, Higiene e Ordem Mantida & $3 \mathrm{~h}$ & - \\
4. Manutenção e Auditoria do Programa & $3 \mathrm{~h}$ & $2 \mathrm{~h}$ \\
Total de horas & $3 \mathrm{~h}$ & $2 \mathrm{~h}$ \\
\hline D) BLOCO III - MELHORIA DE PROCESSOS & & \\
1. Gerenciando Processos & $\mathbf{1 3 h}$ & $\mathbf{6 h}$ \\
2. Garantia da Qualidade & $8 \mathrm{~h}$ & $2 \mathrm{~h}$ \\
3. Análise e Melhoria & $8 \mathrm{~h}$ & \\
4. Auditoria do Programa & $16 \mathrm{~h}$ & $2 \mathrm{~h}$ \\
(30 dias após a auditoria - sustentação) & $3 \mathrm{~h}$ & $2 \mathrm{~h}$ \\
(60 dias após a auditoria - sustentação) & - & $2 \mathrm{~h}$ \\
Total de horas & $\mathbf{9 2 h}$ & $2 \mathrm{~h}$ \\
\hline Total geral & $\mathbf{3 5 h}$ & $\mathbf{1 0 h}$ \\
\hline$\quad$ Fon & Consultoria \\
\hline
\end{tabular}

Fonte: Elaboração Própria a partir de dados fornecidos pelo SEBRAE (1999c)

As fases da tabela anterior podem ser descritas da seguinte forma (SEBRAE, 1999c):

- Sensibilização: Compromisso com o Êxito: módulo com duração de quatro horas com o objetivo de despertar nos participantes a importância e necessidade de se implantar a Qualidade Total em suas empresas, e também mostrar como é fundamental a participação dos mesmos como líderes do processo de implantação do Programa;

- Bloco I: A Conquista da Qualidade - A Pequena Empresa Voltada Para o Cliente: bloco composto de oito módulos, sendo sete de quatro horas cada e um de doze horas, tendo 
como objetivo desenvolver uma nova postura gerencial orientada para a satisfação do cliente, para a melhoria da qualidade das relações internas, para maior produtividade e melhor posicionamento da empresa no mercado;

- Bloco II: D-Olho na Qualidade - 5S Para Pequenos Negócios: bloco composto de quatro módulos, sendo três de três horas cada e um de quatro horas, tendo como objetivo combater o desperdício, desenvolver e fixar hábitos de organização, limpeza e higiene nas empresas. O D-Olho na Qualidade baseia-se no método japonês 5S, ou seja, seiri (senso de arrumação), seiton (senso da ordenação), seisou (senso de limpeza), seiketsu (senso de asseio) e shitsuke (senso da auto-disciplina);

- Bloco III: Melhorias de Processos - Aperfeiçoamento Contínuo: neste bloco são formadas duas turmas por grupo, sendo a primeira de empresários e a segunda de multiplicadores, que devem ser pessoas que estejam diretamente ligadas ao processo de implantação, pois serão como uma equipe de apoio para os empresários. Os empresários participam de quatro módulos, sendo dois de quatro horas cada, um de oito horas e um de 3 horas, e os multiplicadores de três módulos, sendo dois de quatro horas cada e um de oito horas. Este bloco tem como objetivo a sistematização de métodos, técnicas e ferramentas de qualidade para adoção de uma postura de melhoria contínua e incrementar o desempenho da empresa.

\subsection{ESTRUTURA DO PROGRAMA}

Como terceira versão do PSQT é que será o enfoque desta pesquisa, vê-se necessário explicitar sua estrutura com mais detalhes, expondo suas metas, objetivos e carga horária , o que é feito nas tabelas 4.5, 4.6, 4.7 e 4.8:

Tabela 4.5 - Sensibilização: Compromisso com o Êxito

\begin{tabular}{|l|c|}
\hline \multicolumn{2}{|c|}{ SENSIBILIZAÇÃO - COMPROMISSO COM O ÊXITO } \\
\hline A) Treinamento & Deta \\
\hline \multicolumn{2}{|c|}{ Duração } \\
\hline $\begin{array}{l}\text { Visualizar e compreender a necessidade de implantar a qualidade } \\
\text { total e a importância da liderança no processo de implantação do } \\
\text { PSQT }\end{array}$ & $4 \mathrm{~h}$ \\
\hline B) Implantação Orientada Tarefa & Pessoas Envolvidas \\
\hline \multicolumn{2}{|c|}{$\bullet$ E + P } \\
\hline Sensibilização para a qualidade & \\
\hline $\begin{array}{l}\text { LEGENDA } \\
\text { E -Empresário P - Pessoas-chave }\end{array}$ & \\
\hline
\end{tabular}

Fonte: SEBRAE (1999c) 
Tabela 4.6 - Bloco I - A Conquista da Qualidade

BLOCO I - A CONQUISTA DA QUALIDADE

\begin{tabular}{|c|c|c|c|}
\hline \multicolumn{4}{|l|}{ A) Treinamento } \\
\hline Módulo & \multicolumn{2}{|l|}{ Meta } & Duração \\
\hline $\begin{array}{l}\text { 1. Conceito do } \\
\text { Melhor }\end{array}$ & \multicolumn{2}{|c|}{\begin{tabular}{|l} 
Assimilar os conceitos da qualidade e \\
preparar o início da implantação do PSQT
\end{tabular}} & $4 \mathrm{~h}$ \\
\hline $\begin{array}{l}\text { 2. Princípios da } \\
\text { Qualidade }\end{array}$ & \multicolumn{2}{|c|}{$\begin{array}{l}\text { Definir os princípios básicos da qualidade a } \\
\text { serem adotados e as mudanças que deverão } \\
\text { ser realizadas }\end{array}$} & $4 \mathrm{~h}$ \\
\hline 3. Gestão Estratégica & \multicolumn{2}{|c|}{$\begin{array}{l}\text { Ampliar a visão do negócio possibilitando } \\
\text { enxergar o ambiente futuro de atuação da } \\
\text { empresa, tendo em vista a satisfação dos } \\
\text { clientes }\end{array}$} & $4 \mathrm{~h}$ \\
\hline $\begin{array}{l}\text { Indicadores } \\
\text { Desempenho } \\
\text { Empresarial }\end{array}$ & \multicolumn{2}{|c|}{$\begin{array}{l}\text { Definir, implantar e administrar um sistema } \\
\text { de indicadores de desempenho empresarial, } \\
\text { tendo como base as informações coletadas } \\
\text { dos controles administrativos e gerenciais } \\
\text { existentes. }\end{array}$} & $12 \mathrm{~h}$ \\
\hline 4. Satisfação Total & \multicolumn{2}{|c|}{$\begin{array}{l}\text { Direcionar a empresa ao atendimento das } \\
\text { expectativas e necessidades dos clientes e } \\
\text { utilizar instrumentos da satisfação dos } \\
\text { clientes }\end{array}$} & $4 \mathrm{~h}$ \\
\hline $\begin{array}{l}5 . \quad \text { Poder } \\
\text { Participação }\end{array}$ & \multicolumn{2}{|c|}{$\begin{array}{l}\text { Tornar claro e internalizado que a } \\
\text { participação de todos é fundamental para } \\
\text { sucesso da qualidade total }\end{array}$} & $4 \mathrm{~h}$ \\
\hline 6. Novo Gerente & \multicolumn{2}{|c|}{$\begin{array}{l}\text { Identificar a estrutura organizacional e } 0 \\
\text { estilo gerencial mais adequados para } \\
\text { empresa }\end{array}$} & $4 \mathrm{~h}$ \\
\hline $\begin{array}{l}\text { Auditoria } \\
\text { Programa }\end{array}$ & \multicolumn{2}{|c|}{$\begin{array}{l}\text { Identificar as causas dos problemas } \\
\text { enfrentados com a implantação da qualidade } \\
\text { total e elaborar um plano de melhorias. }\end{array}$} & $4 \mathrm{~h}$ \\
\hline \multirow{2}{*}{\multicolumn{3}{|c|}{$\begin{array}{l}\text { Total de horas } \\
\text { B) Consultoria }\end{array}$}} & $40 \mathrm{~h}$ \\
\hline & & & \\
\hline Número & Objetivo & Momento & Duração \\
\hline $\mathrm{C} 1$ & $\begin{array}{l}\text { Ajudar no lançamento do } \\
\text { PSQT }\end{array}$ & $\begin{array}{l}\text { Na semana do } \\
\text { módulo } 1\end{array}$ & $2 \mathrm{~h}$ \\
\hline $\mathrm{C} 2$ & $\begin{array}{l}\text { Auxiliar na elaboração da } \\
\text { gestão estratégica }\end{array}$ & $\begin{array}{l}\text { Na semana após } \\
\text { o módulo } 3\end{array}$ & $2 \mathrm{~h}$ \\
\hline $\mathrm{C} 3$ & $\begin{array}{lr}\text { Ajudar o empresário na } \\
\text { identificação } & \text { dos } \\
\text { indicadores res } & \text { de } \\
\text { desempenho empresarial }\end{array}$ & $\begin{array}{|lr|}\text { Na semana } & \text { da } \\
\text { terceira etapa } & \text { de } \\
\text { Indicadores de } & \text { de } \\
\text { Desempenho } & \\
\text { Empresarial } & \\
\end{array}$ & $2 \mathrm{~h}$ \\
\hline $\mathrm{C} 4$ & $\begin{array}{l}\text { Colaborar na adequação } \\
\text { da pesquisa de satisfação } \\
\text { dos clientes }\end{array}$ & $\begin{array}{|lr|}\text { Na } & \text { semana } \\
\text { seguinte } & \text { ao } \\
\text { módulo } 4 & \\
\end{array}$ & $2 \mathrm{~h}$ \\
\hline C5 & $\begin{array}{lrr}\text { Checar } & 0 & \text { real } \\
\text { entendimento } & \text { dos } \\
\text { conceitos de } & \text { delegação } & \text { e }\end{array}$ & $\begin{array}{l}\text { Na semana do } \\
\text { módulo } 6\end{array}$ & $2 \mathrm{~h}$ \\
\hline
\end{tabular}




\begin{tabular}{|c|c|c|}
\hline & \begin{tabular}{l|l} 
revisão da estrutura da & \\
empresa, bem como apoiar & \\
nesses processos & \\
\end{tabular} & \\
\hline C6 & \begin{tabular}{ll|l|} 
Realizar a Auditoria do & $\begin{array}{l}\text { Na semana após } \\
\text { o treinamento } \\
\text { Bloco I }\end{array}$ \\
& \\
& Auditoria do \\
& Programa
\end{tabular} & $2 \mathrm{~h}$ \\
\hline \multicolumn{2}{|l|}{ Total de horas } & $12 \mathrm{~h}$ \\
\hline \multicolumn{3}{|c|}{ C) Implantação Orientada } \\
\hline Módulo & Tarefa de Implantação & Pessoas Envolvidas \\
\hline $\begin{array}{l}\text { 1. Conceito do } \\
\text { Melhor }\end{array}$ & $\begin{array}{l}\text { - Planejamento da reunião de lançamento } \\
\text { do PSQT } \\
\text { - Lançamento do PSQT }\end{array}$ & $\begin{array}{l}\text { - } \mathrm{E}+\mathrm{P} \\
\text { - } \mathrm{T}\end{array}$ \\
\hline $\begin{array}{ll}2 . & \text { Princípios } \\
\text { Qualidade }\end{array}$ & $\begin{array}{l}\text { - Definição dos princípios da qualidade, } \\
\text { valores da empresa e da pesquisa: Nossa } \\
\text { Empresa Trabalha com Qualidade Total ? } \\
\text { - Realização da pesquisa } \\
\text { - Tabulação e análise dos resultados da } \\
\text { pesquisa } \\
\text { - Apresentação dos princípios e valores e } \\
\text { divulgação dos resultados da pesquisa }\end{array}$ & $\begin{array}{l}\text { - } \mathrm{E}+\mathrm{P} \\
\text { - } \mathrm{E}+\mathrm{T} \\
\text { - } \mathrm{EA} \\
\text { - } \mathrm{E}+\mathrm{T}\end{array}$ \\
\hline 3. Gestão Estratégica & $\begin{array}{l}\text { - Definição da visão de futuro } \\
\text { - Definição da razão de ser da empresa } \\
\text { - Definição da política da qualidade } \\
\text { - Identificação e análise do ambiente } \\
\text { externo e interno da empresa } \\
\text { - Divulgação da visão de futuro, negócio, } \\
\text { missão, política da qualidade e ações } \\
\text { estratégicas }\end{array}$ & $\begin{array}{l}\text { - } E+P \\
\text { - } E+P \\
\text { - } E+P \\
\text { - } E+P \\
\text { - } E+P\end{array}$ \\
\hline $\begin{array}{ll}\text { Indicadores } & \text { de } \\
\text { Desempenho } & \\
\text { Empresarial }\end{array}$ & $\begin{array}{l}\text { - Sensibilização para a importância dos } \\
\text { Indicadores de Desempenho Empresarial } \\
\text { - Apresentação de uma metodologia para a } \\
\text { implantação de um Sistema de } \\
\text { Indicadores de Desempenho } \\
\text { - Orientação sobre a análise crítica dos } \\
\text { Indicadores como fonte de informações e } \\
\text { promoção de melhorias na empresa }\end{array}$ & $\begin{array}{l}\text { - } \mathrm{E}+\mathrm{EA} \\
\text { - } \mathrm{E}+\mathrm{EA} \\
\text { - } \mathrm{E}+\mathrm{EA}\end{array}$ \\
\hline 4. Satisfação Total & $\begin{array}{l}\text { - Preparação da equipe de apoio } \\
\text { - Planejamento da pesquisa (questionário) } \\
\text { de satisfação do cliente } \\
\text { - Aplicação do questionário aos clientes } \\
\text { selecionados } \\
\text { - Tabulação do questionário, interpretação } \\
\text { dos resultados e elaboração de ações de } \\
\text { melhoria } \\
\text { - Apresentação dos resultados } \\
\text { - Pesquisando diariamente a opinião do } \\
\text { cliente }\end{array}$ & $\begin{array}{l}\text { - } \mathrm{E}+\mathrm{EA} \\
\text { - } \mathrm{EA} \\
\text { - } \mathrm{EA} \\
\text { - } \mathrm{EA} \\
\text { - } \mathrm{E}+\mathrm{EA}+\mathrm{T} \\
\text { - } \mathrm{E}+\mathrm{EA}\end{array}$ \\
\hline
\end{tabular}




\begin{tabular}{|c|c|c|}
\hline 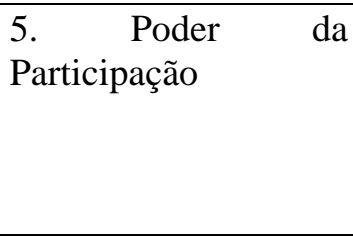 & $\begin{array}{ll}\text { - } & \text { Sensibilização para a participação } \\
\text { - } & \text { Instrumentos de participação } \\
\text { - } & \text { Promovendo a participação } \\
\end{array}$ & $\begin{array}{l}\text { - } \mathrm{E}+\mathrm{P} \\
\text { - } \mathrm{E}+\mathrm{EA} \\
\text { - } \mathrm{EA}+\mathrm{T}\end{array}$ \\
\hline 6. Novo Gerente & $\begin{array}{ll}\text { - } & \text { Reunião: Delegar é Preciso } \\
\text { - } & \text { Reunião para revisão da estrutura da } \\
& \text { empresa } \\
\text { - } & \text { Instituição do mural de comunicação } \\
& \text { interna } \\
\text { - } & \text { Reunião para criação de uma sistemática } \\
\text { de comunicação }\end{array}$ & $\begin{array}{l}\text { - } E+P \\
\text { - }+\mathrm{P}+\mathrm{P} \\
\text { - } \mathrm{E}+\mathrm{P}\end{array}$ \\
\hline $\begin{array}{l}\text { Auditoria } \\
\text { Programa }\end{array}$ & $\begin{array}{ll}\text { - } & \text { Auditoria do Programa } \\
\text { - } & \text { Avaliação do processo de implantação do } \\
& \text { PSQT } \\
\text { - } & \begin{array}{l}\text { Planejamento da continuidade da } \\
\text { implantação da qualidade total }\end{array} \\
\end{array}$ & $\begin{array}{l}\text { - } \mathrm{E}+\mathrm{EA} \\
\text { - } \mathrm{E}+\mathrm{P} \\
\text { - } \mathrm{E}+\mathrm{P}\end{array}$ \\
\hline $\begin{array}{l}\text { LEGENDA } \\
\text { E - Empresário }\end{array}$ & T - Todo o Pessoal & EA - Equipe de Apoio \\
\hline
\end{tabular}

Tabela 4.7 - Bloco II - D-OLHO na Qualidade BLOCO II - D-OLHO NA QUALIDADE

\begin{tabular}{|c|c|c|c|}
\hline \multicolumn{4}{|l|}{ A) Treinamento } \\
\hline Módulo & \multicolumn{2}{|l|}{ Meta } & Duração \\
\hline $\begin{array}{ll}\text { 1. } & \text { Eliminando } \mathrm{o} \\
\text { Desperdício } & \end{array}$ & \multicolumn{2}{|c|}{$\begin{array}{l}\text { Combater o desperdício promovendo um } \\
\text { ambiente limpo, organizado e funcional }\end{array}$} & $4 \mathrm{~h}$ \\
\hline $\begin{array}{l}\text { 2. Descarte e } \\
\text { Organização }\end{array}$ & \multicolumn{2}{|c|}{$\begin{array}{l}\text { Capacitar os empresários para implantar as } \\
\text { etapas de Descarte e Organização }\end{array}$} & $3 \mathrm{~h}$ \\
\hline $\begin{array}{l}\text { 3. Limpeza, Higiene e } \\
\text { Ordem Mantida }\end{array}$ & \multicolumn{2}{|c|}{$\begin{array}{l}\text { Capacitar os empresários para implantar as } \\
\text { etapas de Limpeza, Higiene e Ordem } \\
\text { Mantida }\end{array}$} & $3 \mathrm{~h}$ \\
\hline $\begin{array}{lr}4 . \quad \text { Manutenção } & \text { e } \\
\text { Auditoria } & \text { do } \\
\text { Programa } & \end{array}$ & \multicolumn{2}{|c|}{$\begin{array}{l}\text { Assegurar a continuidade do D-Olho nas } \\
\text { empresas e identificar as causas dos } \\
\text { problemas enfrentados com a implantação } \\
\text { deste bloco, elaborando um plano de } \\
\text { melhorias }\end{array}$} & $3 \mathrm{~h}$ \\
\hline \multicolumn{3}{|l|}{ Total de horas } & $13 \mathrm{~h}$ \\
\hline \multicolumn{4}{|l|}{ B) Consultoria } \\
\hline Número & Objetivo & Momento & Duração \\
\hline C1 & $\begin{array}{l}\text { Ajudar o empresário no } \\
\text { lançamento do D-Olho na } \\
\text { empresa }\end{array}$ & $\begin{array}{l}\text { Na semana do } \\
\text { módulo } 1\end{array}$ & $2 \mathrm{~h}$ \\
\hline C2 & $\begin{array}{l}\text { Checar a implantação do } \\
\text { D-Olho e ajudar na } \\
\text { elaboração dos padrões a } \\
\text { serem adotados pela } \\
\text { empresa }\end{array}$ & $\begin{array}{l}\text { Na semana do } \\
\text { módulo } 3\end{array}$ & $2 \mathrm{~h}$ \\
\hline
\end{tabular}




\begin{tabular}{|c|c|c|c|}
\hline C3 & $\begin{array}{l}\text { Ajudar o empresário na } \\
\text { implantação } \quad \text { da } \\
\text { manutenção e realizar a } \\
\text { auditoria do Bloco II }\end{array}$ & $\begin{array}{lr}\text { Na } & \text { semana } \\
\text { seguinte } & \text { ao } \\
\text { módulo } 4 & \end{array}$ & $2 \mathrm{~h}$ \\
\hline \multicolumn{3}{|l|}{ Total de horas } & $6 \mathrm{~h}$ \\
\hline \multicolumn{4}{|c|}{ C) Implantação Orientada } \\
\hline Módulo & \multicolumn{2}{|c|}{ Tarefa de Implantação } & Pessoas Envolvidas \\
\hline $\begin{array}{l}\text { 1. Eliminando o } \\
\text { Desperdício }\end{array}$ & \multicolumn{2}{|c|}{ • Lançamento do D-Olho } & - $E+P+E A$ \\
\hline $\begin{array}{lcc}2 . & \text { Descarte } & \mathrm{e} \\
\text { Organização } & \end{array}$ & \multicolumn{2}{|l|}{$\begin{array}{l}\text { - Executando o Descarte } \\
\text { - } \\
\text { Executando a Organização }\end{array}$} & $\begin{array}{l}\text { - } E+P+E A \\
\text { - } E+P+E A \\
\end{array}$ \\
\hline $\begin{array}{l}\text { 3. Limpeza, Higiene e } \\
\text { Ordem Mantida }\end{array}$ & \multicolumn{2}{|c|}{$\begin{array}{l}\text { - Executando a Limpeza } \\
\text { - Executando a Organização } \\
\text { - Executando a Ordem Mantida } \\
\end{array}$} & $\begin{array}{l}\text { - } \mathrm{E}+\mathrm{P}+\mathrm{EA} \\
\text { - } \mathrm{E}+\mathrm{P}+\mathrm{EA} \\
\text { - } \mathrm{E}+\mathrm{P}+\mathrm{EA} \\
\end{array}$ \\
\hline $\begin{array}{lr}\text { 4. Manutenção } & \text { e } \\
\text { Auditoria } & \text { do } \\
\text { Programa } & \end{array}$ & \multicolumn{2}{|c|}{$\begin{array}{l}\text { - Auditoria do Programa } \\
\text { - Avaliação do processo de implantação do } \\
\text { PSQT } \\
\text { - Planejamento da continuidade da } \\
\text { implantação da qualidade total }\end{array}$} & $\begin{array}{l}\text { - } E+E A \\
\text { - }+\mathrm{P} \\
\text { - } \mathrm{E}+\mathrm{P}\end{array}$ \\
\hline \multicolumn{4}{|c|}{$\begin{array}{ll}\text { LEGENDA } & \\
\text { E - Empresário } & \text { P - Pesssoas-chave } \\
\mathrm{T} \text { - Todo o Pessoal } & \text { EA - Equipe de Apoio } \\
\end{array}$} \\
\hline
\end{tabular}

Fonte: SEBRAE (1999c)

Tabela 4.8 - Bloco III - Melhoria de Processos

\begin{tabular}{|c|c|c|}
\hline \multicolumn{3}{|c|}{ BLOCO III - MELHORIA DE PROCESSOS } \\
\hline \multicolumn{3}{|l|}{ A) Treinamento } \\
\hline Módulo & Meta & Duração \\
\hline $\begin{array}{l}\text { 1. Gerenciando } \\
\text { Processos }\end{array}$ & $\begin{array}{l}\text { Sensibilizar e preparar os participantes para o início } \\
\text { do gerenciamento de processos de suas empresas }\end{array}$ & $\begin{array}{l}\text { 4h (E) } \\
\text { 4h (M) }\end{array}$ \\
\hline $\begin{array}{ll}2 . \quad \text { Garantia da } \\
\text { Qualidade }\end{array}$ & $\begin{array}{l}\text { Identificar e elaborar a documentação dos } \\
\text { procedimentos para o início da garantia da qualidade. }\end{array}$ & $\begin{array}{l}\text { 4h (E) } \\
\text { 4h (M) }\end{array}$ \\
\hline 3. Análise e Melhoria & $\begin{array}{l}\text { Preparar os participantes para implantação do } \\
\text { Método de Análise e Melhoria de Processos - MAMP } \\
-\quad \text { em suas empresas conscientizando-os da } \\
\text { importância da utilização do MAMP no dia-a-dia da } \\
\text { empresa }\end{array}$ & $\begin{array}{l}8 \mathrm{~h}(\mathrm{E}) \\
8 \mathrm{~h}(\mathrm{M})\end{array}$ \\
\hline $\begin{array}{l}\text { Auditoria } \\
\text { Programa }\end{array}$ & $\begin{array}{l}\text { Identificar as causas dos problemas que estão sendo } \\
\text { enfrentadas pelos participantes, com a implantação do } \\
\text { PSQT, elaborar um plano de melhorias e entender que } \\
\text { o processo da qualidade não tem fim, pois existem } \\
\text { inúmeras ações a serem feitas daqui para frente. }\end{array}$ & $3 \mathrm{~h}(\mathrm{E})$ \\
\hline \multicolumn{2}{|l|}{ Total de horas } & \\
\hline \multicolumn{2}{|l|}{ Empresário (E) } & $19 \mathrm{~h}$ \\
\hline \multicolumn{2}{|l|}{ Multiplicadores (M) } & $16 \mathrm{~h}$ \\
\hline \multicolumn{2}{|l|}{ Total Geral } & $35 \mathrm{~h}$ \\
\hline \multicolumn{3}{|l|}{ B) Consultoria } \\
\hline Número & Momento & Duração \\
\hline
\end{tabular}




\begin{tabular}{|c|c|c|c|}
\hline C1 & $\begin{array}{l}\text { Ajudar o empresário na } \\
\text { elaboração e identificação } \\
\text { de seus processos internos }\end{array}$ & 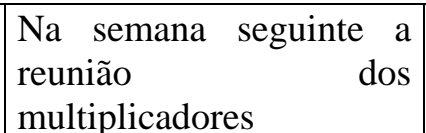 & $2 \mathrm{~h}$ \\
\hline C2 & $\begin{array}{l}\text { Colaborar na elaboração } \\
\text { de procedimentos e ajudar } \\
\text { na melhoria de processo }\end{array}$ & Na semana do módulo 3 & $2 \mathrm{~h}$ \\
\hline C3 & $\begin{array}{llr}\text { Checar } & \text { a } & \text { efetiva } \\
\text { implantação da descrição } \\
\text { de procedimento e } & \text { da } \\
\text { prática do } & \text { MAMP } & \text { na } \\
\text { empresa } & & \\
\end{array}$ & \begin{tabular}{|l|}
$\mathrm{Na}$ semana do \\
treinamento de auditoria \\
do programa
\end{tabular} & $2 \mathrm{~h}$ \\
\hline CM1 & $\begin{array}{l}\text { Dar suporte ao empresário } \\
\text { na implantação do PSQT }\end{array}$ & $\begin{array}{l}30 \text { dias após o módulo de } \\
\text { auditoria do programa }\end{array}$ & $2 \mathrm{~h}$ \\
\hline CM2 & $\begin{array}{l}\text { Realizar a auditoria do } \\
\text { programa (bloco I, II e III) } \\
\text { e confrontar as } \\
\text { expectativas ros dos } \\
\text { empresários levantadas no } \\
\text { Compromisso com o Êxito } \\
\text { com os resultados obtidos } \\
\text { até o momento }\end{array}$ & $\begin{array}{l}60 \text { dias após o módulo de } \\
\text { auditoria do programa } \\
\\
\end{array}$ & $2 \mathrm{~h}$ \\
\hline \multicolumn{3}{|l|}{ Total de horas } & 10h \\
\hline \multicolumn{4}{|c|}{ C) Implantação Orientada } \\
\hline Módulo & \multicolumn{2}{|c|}{ Tarefa de Implantação } & PE \\
\hline $\begin{array}{l}1 . \quad \text { Gerenciando } \\
\text { Processos }\end{array}$ & \multicolumn{2}{|c|}{$\begin{array}{l}\text { - Planejamento da reunião de introdução aos } \\
\text { - Donceitos de gerenciamento de processos } \\
\text { - } \text { proceminação dos conceitos de gerenciamento de } \\
\text { - Preparação da equipe de apoio para identificar e } \\
\text { estabelecer os processos e a cadeia cliente- } \\
\text { fornecedor interno da empresa } \\
\text { - Definição da cadeia cliente-fornecedor interno }\end{array}$} & $\begin{array}{ll}\text { - } & \mathrm{E}+\mathrm{P} \\
\text { - } & \mathrm{E}+\mathrm{P}+\mathrm{T} \\
\text { - } & \mathrm{E}+\mathrm{P}+\mathrm{EA} \\
& \mathrm{E}+\mathrm{P}+\mathrm{EA} \\
& +\mathrm{T}\end{array}$ \\
\hline $\begin{array}{l}\text { 2. Garantia da } \\
\text { Qualidade }\end{array}$ & \multicolumn{2}{|c|}{$\begin{array}{l}\text { - Sensibilização para documentação dos processos } \\
\text { - Reunião sobre Garantia da Qualidade } \\
\text { - Elaboração dos procedimentos }\end{array}$} & $\begin{array}{ll}- & \mathrm{E}+\mathrm{P} \\
- & \mathrm{E}+\mathrm{T} \\
- & \mathrm{M} \\
\end{array}$ \\
\hline 3. Análise e Melhoria & \multicolumn{2}{|c|}{$\begin{array}{l}\text { - Identificação de problemas } \\
\text { - Iniciação da aplicação do MAMP } \\
\text { - Analisando permanentemente os processos }\end{array}$} & $\begin{array}{ll}- & \mathrm{E}+\mathrm{P} \\
- & \mathrm{M} \\
- & \mathrm{M} \\
\end{array}$ \\
\hline Auditoria & \multicolumn{2}{|c|}{$\begin{array}{l}\text { - Auditoria do Programa } \\
\text { - Avaliação do processo de implantação do PSQT } \\
\text { - Planejamento da continuidade da implantação da } \\
\text { qualidade total }\end{array}$} & $\begin{array}{ll}\text { - } & E+E A \\
\text { - } & E+P \\
\text { - } & E+P\end{array}$ \\
\hline \multicolumn{4}{|c|}{$\begin{array}{l}\text { LEGENDA } \\
\text { PE - Pessoas Envolvidas E - Empresário } \\
\text { T - Todo o Pessoal } \quad \text { EA - Equipe de Apoio }\end{array}$} \\
\hline
\end{tabular}

Fonte: SEBRAE (1999c) 


\subsection{METODOLOGIA DO PROGRAMA}

O PSQT adota uma metodologia que pode ser dividida em treinamento, consultoria, implantação orientada e auditoria.

\subsubsection{TREINAMENTO}

Cada módulo é desenvolvido em uma reunião, com um grupo de empresas, cada uma com dois participantes (donos e membros da alta direção).

A cada reunião, os participantes são preparados para conduzir uma determinada etapa da implantação gradativa da Qualidade Total em suas empresas, o que é feito no intervalo entre uma e outra reunião, que varia de uma a duas semanas.

Os módulos que compõem o Bloco III são desenvolvidos, também, em reuniões com as equipes de apoio, que são os multiplicadores, de cada empresa, de forma a garantir a implantação efetiva do processo de melhoria contínua.

\subsubsection{CONSULTORIA}

O Programa prevê 28 (vinte e oito) horas de consultas e/ou visitas às empresas participantes, a título de consultoria, em função das necessidades relacionadas ao seu desenvolvimento.

\subsubsection{IMPLANTAÇÃO ORIENTADA}

As atividades e recursos do Programa estão voltados para a orientação e apoio ao empresário durante a implantação da Qualidade Total em sua empresa. O empresário dividirá tarefas com as pessoas-chave da organização e com as equipes internas de apoio.

\subsubsection{AUDITORIA}

Dentro de cada bloco é realizada uma auditoria por uma equipe interna da empresa, buscando avaliar o processo de implantação da qualidade total, comparar resultados atingidos frente aos objetivos propostos e também identificar falhas.

\subsection{O PAPEL DE CADA AGENTE NO PROGRAMA}

O Programa Sebrae de Qualidade Total é composto por seis agentes, sendo descrito a seguir o papel desempenhado por cada um deles:

- Facilitador: é o consultor, credenciado pelo SEBRAE. Ele dirige as reuniões do Programa, aplica os conteúdos dos módulos, tira dúvidas e apóia os participantes na implantação do programa em suas empresas; 
- Empresário: participa de todas as reuniões do Programa e lidera o processo de implantação da Qualidade Total em sua empresa, viabilizando a realização das tarefas de implantação;

- Segundo participante: de preferência o sócio ou alguém da direção da empresa que também participa das reuniões e, junto com o empresário, coordene a implantação da Qualidade Total na empresa;

- Pessoas-chave: são pessoas que interferem diretamente nas decisões estratégicas da empresa. Pelo seu grande poder de influência, devem, necessariamente, ser envolvidas no esforço de mudanças;

- Equipes de apoio: pequenos grupos de colaboradores organizados para realizar determinadas tarefas de implantação. As equipes de apoio previstas no Bloco III são chamadas de multiplicadores. Elas também participam das reuniões relativas a cada módulo da etapa;

- Pessoal da empresa: os colaboradores participam ativamente de Programa por meio de reuniões, de pesquisas e dos instrumentos que vão sendo implantados no decorrer do processo. 


\section{CAPÍTULO 5}

\section{INSUCESSO DOS PROGRAMAS DE QUALIDADE}

Muitas organizações fracassam totalmente em seus esforços pela qualidade, enquanto outras obtém resultados medíocres, dando a entender que o TQM é outro modismo em declínio. (OISHI et. al., 1998).

Portanto, devido ao fato de muitos programas de implementação da qualidade não serem bem sucedidos, vários estudiosos vêm realizando pesquisas com o objetivo de levantar as causas desse insucesso, que geram resultados insatisfatórios para as organizações.

\subsection{CAUSAS DE INSUCESSO NA IMPLANTAÇÃO DE PROGRAMAS DE QUALIDADE}

CROSBY (1993) diz que empresas cujos esforços pela qualidade acabam fracassando têm características em comum:

- a direção não entende que a qualidade deve fazer parte do modo como a empresa será administrada;

- as atividades relativas à instrução limitam-se ao treinamento em técnicas e são aplicadas apenas aos funcionários. Os próprios dirigentes recebem pouca ou nenhuma instrução em administração da qualidade;

- a qualidade não é medida em termos financeiros; e 
- os clientes e fornecedores não são considerados como parte integrante do processo de administração da qualidade.

Já TOLOVI JR. (1994) diz que as causas de insucesso do programa de qualidade são:

- educacionais - treinamento inadequado, escolha inadequada de multiplicadores;

- causas psicossociais: não-envolvimento da alta direção, desinteresse do nível gerencial;

- causas técnicas - sistema de remuneração inconsistente, falta de apoio técnico, planejamento inadequado e;

- causas psicológicas: ansiedade por resultados, descuido por motivação.

WOOD JR. \& URDAN (1994) dizem que os insucessos da aplicação de programas de qualidade se devem a problemas como:

- criação de uma burocracia interna paralela;

- foco na imagem, não em fatos e resultados;

- falta de apoio da alta gerência;

- baixo grau de comprometimento nos diversos níveis hierárquicos;

- foco nos processos internos, e não nos mais críticos;

- conflitos de interesse e poder;

- benefícios intangíveis e/ou desproporcionais ao esforço;

- dificuldade em manter o momentum da mudança.

VALLE (1995) diz que fatores comportamentais e gerenciais/administrativos certamente contribuirão para a falha do programa da qualidade, sendo eles:

- identificação dos culpados para os problemas existentes;

- inexistência de um sistema de informações para a qualidade;

- descontinuidade do programa;

- atividades preventivas pouco desenvolvidas;

- despreparo para mudanças;

- canais de comunicação obstruídos;

- falta de apoio da alta administração e;

- fraca coordenação interdepartamental.

TATIKONDA \& TATIKONDA (1996) colocam que apesar das boas intenções, trabalho árduo e alto gasto, muitos dos esforços de implantação da qualidade falham, o que ocorre não por causa de ineficiência dos princípios da qualidade e sim porque eles são aplicados de forma 
incorreta. Os autores atribuem as falhas nos esforços de implantação da qualidade a dez razões principais, sendo elas:

- ausência de visão e não integração da qualidade no planejamento estratégico;

- ausência de foco no consumidor;

- falta de comprometimento da gerência;

- treinamento sem propósito;

- falta de análise custo-benefício;

- estrutura organizacional falha;

- criação de burocracia da qualidade;

- ausência de indicadores da qualidade ou má utilização desses;

- não reconhecimento ao corpo funcional pelas iniciativas de qualidade;

- sistemas contábeis falhos e defasados.

BACKES (1998) aponta como causas de insucesso na implantação de programas de qualidade:

- falta de comprometimento da alta administração;

- ausência de planejamento;

- resistência às mudanças;

- falta de atenção para as pessoas, no que tange à motivação e capacitação dessas.

TAMIMI \& SEBASTIANELLI (1998), a partir de uma entrevista realizada com 188 profissionais da área de qualidade, sendo $80 \%$ deles de indústria e $20 \%$ de serviço, detectaram vinte e cinco barreiras para a adoção da qualidade, agrupadas nos seguintes obstáculos:

- liderança: planejamento estratégico não inclui objetivos de qualidade; excesso de pessoas no gerenciamento e; o alto escalão não está explicitamente comprometido com a qualidade;

- planejamento estratégico: qualidade é tratada como uma iniciativa isolada; ninguém é responsável pela qualidade; os planos de ação da qualidade são vagos; o planejamento estratégico não é direcionado ao consumidor; os recursos são inadequados para implantar efetivamente a qualidade total;

- foco no mercado e no cliente: qualidade não é definida pelo consumidor;

- informação e análise: não realização de benchmarking com as melhores práticas e/ou produtos de outras empresas; qualidade não é efetivamente medida;

- desenvolvimento e gerenciamento dos recursos humanos: corpo funcional não é treinado para utilizar técnicas de identificação e resolução de problemas, técnicas de discussão e 
comunicação de grupo nem nas ferramentas de melhoria da qualidade; funcionários não têm poder para implementar ações de qualidade total; corpo funcional não é reconhecido por realizações de melhoria de qualidade; recompensas gerenciais não têm ligação com o alcance dos objetivos de qualidade e; funcionários são resistentes às mudanças;

- processo gerencial: não há planejamento integrado com as atividades ligadas aos fornecedores;

- resultados do negócio: ações de melhoria de qualidade raramente atendem as expectativas dos resultados desejados; alta rotatividade do corpo funcional; os altos custos de implementação da qualidade total superam os benefícios e; alta rotatividade da gerência.

Na pesquisa realizada os principais obstáculos à implantação da qualidade total foram o desenvolvimento e gerenciamento dos recursos humanos e o planejamento estratégico, o que pode ser visto na figura a seguir:

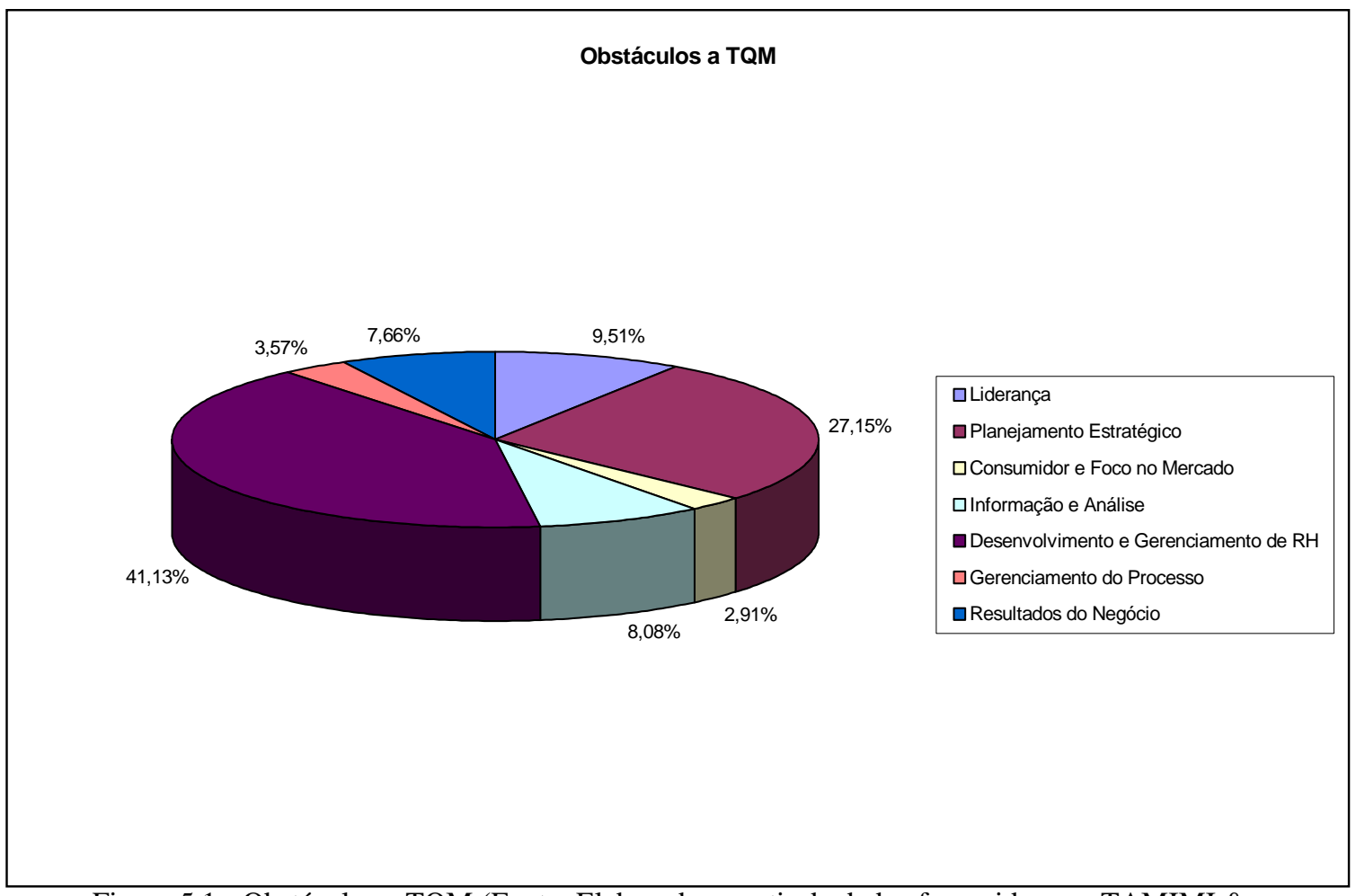

Figura 5.1 - Obstáculos a TQM (Fonte: Elaborado a partir de dados fornecidos por TAMIMI \& SEBASTIANELLI , 1998)

Para facilitar a visualização das causas apontadas pelos autores citados anteriormente elaborou-se a tabela 5.1 reunindo-as. 
Tabela 5.1 - Causas de insucesso dos Programas de Qualidade

\begin{tabular}{|c|c|c|c|c|c|c|c|}
\hline \multirow[t]{2}{*}{ Causas de Insucesso } & \multicolumn{7}{|c|}{ Autores } \\
\hline & 1 & 2 & 3 & 4 & 5 & 6 & 7 \\
\hline Qualidade não é medida em termos financeiros & $\mathrm{X}$ & & & & $\mathrm{X}$ & & $\mathrm{X}$ \\
\hline Ausência de foco no consumidor & $\mathrm{X}$ & & & & $\mathrm{X}$ & & $\mathrm{X}$ \\
\hline Treinamento inadequado & $\mathrm{X}$ & $\mathrm{X}$ & & & $\mathrm{X}$ & & $\mathrm{X}$ \\
\hline Falta de comprometimento da alta-direção & $\mathrm{X}$ & $\mathrm{X}$ & $\mathrm{X}$ & $\mathrm{X}$ & $\mathrm{X}$ & $\mathrm{X}$ & $\mathrm{X}$ \\
\hline Falta de comprometimento dos níveis hierárquicos & & & $\mathrm{X}$ & & & & \\
\hline Falta de apoio técnico & & $\mathrm{X}$ & & & & & \\
\hline Ansiedade por resultados & & $\mathrm{X}$ & & & & & \\
\hline Descuido por motivação & & $\mathrm{X}$ & & & & $\mathrm{X}$ & \\
\hline Criação de burocracia interna paralela & & & $\mathrm{X}$ & & $\mathrm{X}$ & & \\
\hline Foco na imagem e não em resultados & & & $\mathrm{X}$ & & & & \\
\hline Foco nos processos internos e não nos críticos & & & $\mathrm{X}$ & & & & \\
\hline Conflitos de interesse e poder & & & $\mathrm{X}$ & & & & \\
\hline Resistência às mudanças & & & $\mathrm{X}$ & $\mathrm{X}$ & & $\mathrm{X}$ & $\mathrm{X}$ \\
\hline Identificar culpados para os problemas & & & & $\mathrm{X}$ & & & \\
\hline Descontinuidade do programa & & & & $\mathrm{X}$ & & & \\
\hline Atividades preventivas pouco desenvolvidas & & & & $\mathrm{X}$ & & & \\
\hline Canais de comunicação obstruídos & & & & $\mathrm{X}$ & & & \\
\hline Fraca coordenação interdepartamental & & & & $\mathrm{X}$ & & $\mathrm{X}$ & \\
\hline Ausência de planejamento & $\mathrm{X}$ & & & & $\mathrm{X}$ & & $\mathrm{X}$ \\
\hline Estrutura organizacional falha & & & & & $\mathrm{X}$ & & \\
\hline Ausência/má utilização de indicadores & & & & & $\mathrm{X}$ & & \\
\hline $\begin{array}{l}\text { Não reconhecimento ao corpo funcional pelas } \\
\text { iniciativas de qualidade }\end{array}$ & & $\mathrm{X}$ & $\mathrm{X}$ & & $\mathrm{X}$ & & $\mathrm{X}$ \\
\hline Sistemas contábeis falhos e defasados & & & & & $\mathrm{X}$ & & \\
\hline Não realização de benchmarking & & & & & & & $\mathrm{X}$ \\
\hline $\begin{array}{l}\text { Falta de autonomia dos funcionários } \\
\text { implementação de ações da qualidade }\end{array}$ & & & & & & & $\mathrm{X}$ \\
\hline $\begin{array}{lllll}\text { Ações de } & \text { melhoria não atendem } & \text { resultados } \\
\text { esperados } & & & & \end{array}$ & & & & & & & $\mathrm{X}$ \\
\hline Alta rotatividade dos funcionários & & & & & & & $\mathrm{X}$ \\
\hline $\begin{array}{lrl}\text { Legenda } & & \\
\text { 1- CROSBY } & \text { 2- TOLOVI JR. } & \text { 3- WOOD \& } \\
\text { 5- TATIKONDA \& TATIKONDA } & \text { 6- BACKES }\end{array}$ & & & & & & & \\
\hline
\end{tabular}

Fonte: Elaboração Própria 


\subsection{CAUSAS DE INSUCESSO NA IMPLANTAÇÃO DO PROGRAMA SEBRAE DE QUALIDADE TOTAL}

Em se tratando de micro e pequenas empresas, alguns fatores de insucesso na implantação de Programas de Qualidade, foram levantados por quatro autores e uma pesquisa feita pelo Sebrae-MG, citados abaixo, que analisaram o Programa Sebrae de Qualidade Total.

De acordo com o SEBRAE (1995), em uma pesquisa realizada para avaliar o Programa Sebrae de Qualidade Total no estado de Minas Gerais, concluiu-se que as principais causas de insucesso do Programa são:

- dificuldade em conciliar a implantação com a rotina de trabalho;

- resistências à mudança;

- prazo muito curto de implantação;

- necessidade de maior suporte dos consultores.

ALENCAR FILHO (1995) coloca como principais causas do fracasso do PSQT, as seguintes:

- dificuldade na utilização de ferramentas da qualidade;

- incompatibilidade do programa com algumas atividades;

- falta de envolvimento do pequeno empresário;

- falta de motivação dos funcionários.

CÂNDIDO (1998) coloca como causas principais que afetam no resultado do PSQT as seguintes:

- falta de técnica de repasse da metodologia;

- falta de tempo do empresário na coordenação e execução das atividades do programa;

- falta de tempo dos trabalhadores;

- falta de acompanhamento dos consultores do programa;

- resistências internas;

- dificuldade na utilização de ferramentas da qualidade;

- estrutura paralela;

- falta de um processo de diagnóstico da estrutura e das condições das empresas.

O estudo feito por ORTEGA (1998), apontou como causas de insucesso do PSQT as seguintes:

- falta de motivação dos funcionários;

- difícil adaptação do Programa Sebrae de Qualidade Total aos diferentes tipos de negócios; 
- resistências internas;

- falta de tempo do proprietário;

- falta de suporte do consultor.

PANIGAS (1998) cita como causas de insucesso na implantação do PSQT as seguintes:

- não definir uma política de qualidade;

- não ter comprometimento e a participação efetiva da direção da empresa;

- iniciar o programa e não dar continuidade, demonstrando ausência de liderança;

- não conhecer profundamente os clientes;

- carência de propósitos consistentes perseverança para buscá-los;

- não conhecer o mercado de atuação;

- falta de engajamento das pessoas no programa;

- descontinuidade nas ações administrativas;

- ninguém assumir a responsabilidade pela qualidade;

- pouco tempo de consultoria para a implantação do programa nas empresas;

- deficiência na capacitação de uma equipe de apoio para a implantação do programa;

- falta de apoio para a continuidade do programa após o repasse;

- inadequação da metodologia ao tipo de empresa.

Montou-se a tabela 5.2 reunindo as causas de insucesso do Programa Sebrae de Qualidade Total apontadas pelos autores citados anteriormente. 
Tabela 5.2 - Causas de insucesso do PSQT

\begin{tabular}{|l|c|c|c|c|c|}
\hline \multicolumn{1}{|c|}{ Causas de Insucesso } & \multicolumn{5}{c|}{ Autores } \\
\hline & $\mathbf{1}$ & $\mathbf{2}$ & $\mathbf{3}$ & $\mathbf{4}$ & $\mathbf{5}$ \\
\hline Deficiência de técnica de repasse da metodologia & & & $\mathrm{X}$ & & $\mathrm{X}$ \\
\hline Falta de tempo do empresário & & & $\mathrm{X}$ & $\mathrm{X}$ & \\
\hline Falta de tempo dos funcionários & & & $\mathrm{X}$ & & \\
\hline $\begin{array}{l}\text { Dificuldade de conciliar a implantação com a rotina de } \\
\text { trabalho }\end{array}$ & $\mathrm{X}$ & & & & \\
\hline Falta de acompanhamento dos consultores & & & $\mathrm{X}$ & $\mathrm{X}$ & $\mathrm{X}$ \\
\hline Resistências internas & & & $\mathrm{X}$ & $\mathrm{X}$ & \\
\hline Dificuldade na utilização de ferramentas & & $\mathrm{X}$ & $\mathrm{X}$ & & \\
\hline Estrutura paralela & & & $\mathrm{X}$ & & \\
\hline Falta de um processo de diagnóstico & & & $\mathrm{X}$ & & \\
\hline Falta de envolvimento da direção & $\mathrm{X}$ & $\mathrm{X}$ & & $\mathrm{X}$ & $\mathrm{X}$ \\
\hline Falta de envolvimento dos funcionários & & $\mathrm{X}$ & & $\mathrm{X}$ & $\mathrm{X}$ \\
\hline $\begin{array}{l}\text { Incompatibilidade do Programa com diferentes tipos de } \\
\text { negócio }\end{array}$ & $\mathrm{X}$ & $\mathrm{X}$ & & $\mathrm{X}$ & $\mathrm{X}$ \\
\hline Ausência de planejamento & & & & & \\
\hline Não conhecer profundamente os clientes & & & & & $\mathrm{X}$ \\
\hline Não conhecer o mercado & & & & & $\mathrm{X}$ \\
\hline Carência de propósitos & & & & & $\mathrm{X}$ \\
\hline Descontinuidade de ações administrativas & & & & & $\mathrm{X}$ \\
\hline Descontinuidade do Programa & & & & & $\mathrm{X}$ \\
\hline Ninguém assumir a responsabilidade pela qualidade & & & & $\mathrm{X}$ \\
\hline Prazo curto de implantação & & & & $\mathrm{X}$ \\
\hline Legenda & & & & \\
\hline 1- SEBRAE 2-ALENCAR FILHO & & & & \\
\hline
\end{tabular}

Fonte: Elaboração Própria 


\section{CAPÍTULO 6}

\section{TRABALHO DE CAMPO E DESCRIÇÃO DAS EMPRESAS}

\subsection{METODOLOGIA}

A metodologia é essencial para o processo de investigação, sendo, segundo BOTOMÉ (1997) ferramenta fundamental para auxiliar nas decisões e orientar condutas de maior eficácia e economia no processo de produção do conhecimento.

\subsubsection{CARACTERIZAÇÃO DA PESQUISA}

Para alcançar o objetivo proposto realizou-se um estudo comparativo de casos, que segundo TRIVIÑOS (1987) é classificado dessa forma por se estabelecer comparações entre dois ou mais enfoques específicos. O autor ainda coloca que em geral, esta linha de investigação segue os passos do método comparativo, descrevendo, explicando e comparando por justaposição e comparação propriamente dita os fenômenos.

O estudo feito levou em consideração o conteúdo das três fases componentes do Programa Sebrae de Qualidade Total (A Conquista da Qualidade; D-Olho na Qualidade e Melhoria de Processos) e dos resultados finais alcançados pelas empresas. A pesquisa foi realizada em dez pequenas empresas industriais, localizadas em Franca - SP, que foram treinadas 
pela metodologia do Programa. Assim, foi possível, uma vez que os dados foram coletados e analisados, explorar o referido programa, avaliando os resultados obtidos com a implantação do mesmo e compreender melhor as causas de insucesso em sua implantação.

As dez empresas pesquisadas no trabalho de campo localizam-se em Franca - SP. A escolha do local para realizar o trabalho de campo foi feita a partir de uma pesquisa em várias cidades do estado de São Paulo, como Ribeirão Preto, Araçatuba, Piracicaba, Araraquara, assim como no estado de Minas Gerais, nas cidades de Uberlândia e Belo Horizonte. As cidades de Franca e Belo Horizonte foram as únicas que apresentaram empresas que possuíam as condições para a realização da pesquisa: pequenas indústrias que implantaram a última versão do Programa Sebrae de Qualidade Total. Optou-se por realizar o trabalho de campo em Franca pela proximidade da cidade de São Carlos, facilitando o deslocamento da pesquisadora, e por reunir um pólo de empresas de um mesmo setor. O número de empresas em Franca que possuíam as condições para a realização da pesquisa, anteriormente citadas, foi de dez, por isso a realização da pesquisa nesta quantidade de empresas.

A pesquisa vai além do caráter exploratório, que segundo BERVIAN \& CERVO (1996) tem por objetivo buscar maiores informações sobre determinado assunto, e do caráter descritivo, que de acordo com TRIVIÑOS (1987) visa aprofundar a descrição de uma determinada realidade, pois foi feita a sistematização das causas de insucesso do Programa Sebrae de Qualidade Total, e também a proposição de ajustes que possam contribuir de forma mais efetiva para a melhoria nos resultados da implantação do referido programa.

\subsubsection{QUESTÕES DA PESQUISA}

Segundo TRIVIÑOS (1987), as questões de pesquisa representam o que o investigador deseja esclarecer. Neste sentido, diz o autor, elas são profundamente orientadoras do trabalho do investigador.

De acordo com os dados mostrados na revisão bibliográfica pode-se dizer que apesar de já terem sido feitos vários estudos procurando levantar as causas de insucesso na implantação de programas de qualidade, tais estudos revelam pontos coincidentes e não coincidentes e em grande parte deles são levadas em consideração as grandes empresas, o que nem sempre é aplicável às micro e pequenas. Percebe-se também que tais causas são apontadas pontualmente e de forma dispersa, faltando uma visão mais global do insucesso dos programas de qualidade, o que pode não contribuir para melhorias efetivas desses. Nesse sentido, as questões da pesquisa são: 
- o agrupamento das causas de insucesso na implantação do PSQT em alguns fatores ajudará a melhor compreender as falhas do programa?

- o fator organizacional é relevante para a compreensão das causas de insucesso?

- o fator comportamental é relevante para a compreensão das causas de insucesso?

- o fator metodológico é relevante para a compreensão das causas de insucesso?

\subsubsection{VARIÁVEIS DA PESQUISA}

As variáveis são características observáveis de algo, sendo imprescindíveis para se ter uma idéia clara dos rumos e conteúdos de uma pesquisa (TRIVIÑOS, 1987).

De acordo com o objetivo declarado e as questões da pesquisa estabelecidas, as variáveis de pesquisa são as seguintes:

- Causas de insucesso na implantação de programas de qualidade, agrupadas nos seguintes fatores:

> organizacional: refere-se aos aspectos formais da organização tendo um caráter oficial por originar-se da direção, sua ação visa o coletivo como são os planos, as políticas e as estratégias;

> comportamental: refere-se aos aspectos informais da organização tendo um caráter espontâneo por originar-se dos comportamentos individuais e das relações interpessoais;

$>$ metodológico: refere-se à forma do Programa e ao desenvolvimento dos conteúdos de conhecimentos, de habilidades e de atitudes.

- Programa Sebrae de Qualidade Total: Programa de Implantação da Qualidade Total, com metodologia desenvolvida para as pequenas empresas. O Programa é dividido em três blocos temáticos e tem como objetivo capacitar os empresários e sua equipe na auto implantação dos conceitos, princípios e ferramentas da Gestão pela Qualidade Total.

\subsubsection{TÉCNICA DE COLETA DE DADOS}

O processo de coleta de dados foi realizado por meio de entrevistas semi-estruturadas com os pequenos empresários/pessoas-chave da implantação do PSQT nas empresas e com funcionários que participaram do treinamento; aplicação de questionários aos consultores do PSQT que foram facilitadores do Programa nas empresas pesquisadas; e análise documental. 
Deve-se ressaltar que dentre as perguntas contidas nas entrevistas e nos questionários utilizados na pesquisa, as que possuem relação com causas de insucesso do PSQT foram elaboradas de acordo com as causas de insucesso levantadas na literatura pesquisada.

Segundo TRIVIÑOS (1987), a entrevista semi-estruturada parte de certos questionamentos básicos, apoiados em teorias e hipóteses (ou questões), que interessam à pesquisa, e que, em seguida, oferecem amplo campo de interrogativas que vão surgindo à medida que se recebem as respostas do informante.

O questionário é uma das formas mais usadas para a coleta de dados, pois possibilita medir com melhor exatidão as respostas às questões relacionadas a um problema central (MOTTA, 2000).

E, por último, em relação a análise documental o autor coloca que é um tipo de estudo descritivo que fornece ao investigador a possibilidade de reunir uma grande quantidade de informações através de registros contidos em documentos.

\subsection{DESCRIÇÃO DAS EMPRESAS}

\subsubsection{EMPRESA A}

\subsubsection{Histórico}

A Empresa A foi fundada em 01/05/87 por dois irmãos e mais um sócio. Os três, antes de montarem a Empresa A, trabalharam em outras empresas do setor calçadista e a partir da experiência e conhecimento adquirido resolveram abrir um negócio próprio.

Inicialmente fabricava-se apenas dois modelos de calçado masculino: dockside e timberg e apenas os três sócios trabalhavam na Empresa A, um em período integral e os outros dois apenas a noite, pois ainda eram empregados de outras empresas. Após um ano e meio de funcionamento da Empresa A outro sócio passou também a se dedicar integralmente às atividades dessa, sendo que nessa época já haviam sido contratados outros funcionários. O terceiro sócio, passou a se dedicar integralmente às atividades da Empresa A em 1991. Atualmente a empresa A possui apenas dois sócios, irmãos, que são os diretores da organização. O terceiro sócio saiu da empresa há cerca de cinco anos (1996).

A Empresa A ao longo dos anos teve um crescimento expressivo devido ao aquecimento do setor calçadista. De 1987 a 1990 trabalhava-se com duas linhas de calçado, hoje, em 2001 opera-se doze linhas, permitindo a produção de uma grande variedade de cores e modelos. 
O investimento em tecnologia e maquinário realizado pela Empresa A é alto, procurando-se trabalhar com tecnologia de ponta.

Atualmente a Empresa A trabalha não só com calçados masculinos, marca que leva o nome da Empresa A, como também atua com a linha feminina, que recebe outra marca, pretendendo com isso fortalecer principalmente a linha verão.

\subsubsection{Estrutura}

A Empresa A classifica-se como de pequeno porte, sendo composta por 20 funcionários e mais dois sócios. Os sócios, que são irmãos, ocupam cargos de diretoria, sendo um deles o principal responsável pela parte comercial e o outro pela parte de produção. A Empresa A possui um funcionário em cargo de gerência, um em cargo de chefia, dois na parte administrativa e dezesseis no operacional (chão de fábrica). Os demais funcionários trabalham na parte operacional. A Empresa A também trabalha com representantes externos, autônomos, para auxiliar a parte de vendas da empresa.

O organograma da Empresa A é estruturado da seguinte forma:

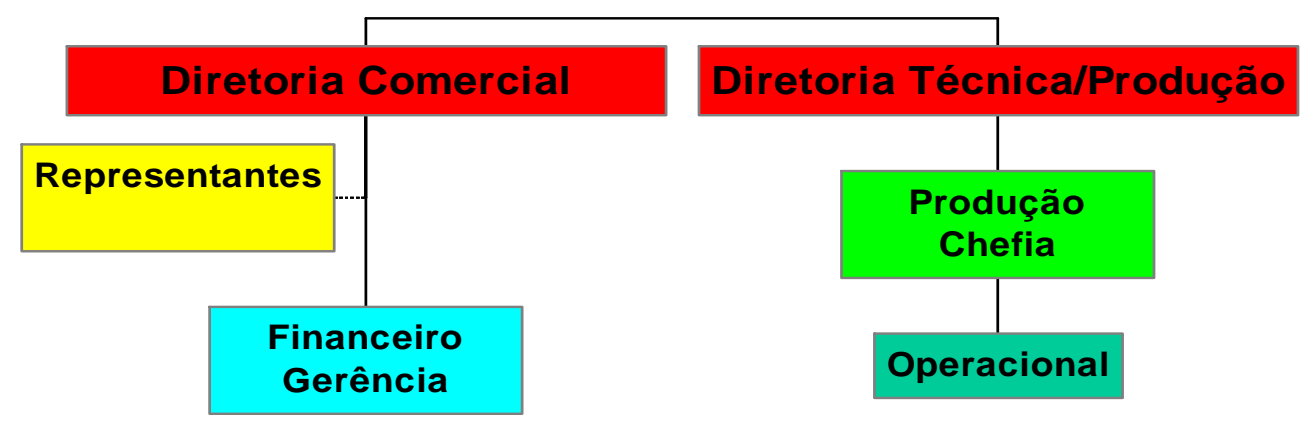

Figura 6.1 - Organograma da Empresa A

Ambos os sócios da Empresa A possuem curso superior incompleto, estando o nível de escolaridade formal dos funcionários distribuído da seguinte forma: $30 \%$ possuem o $1^{\circ}$ grau incompleto, $50 \%$ o $1^{\circ}$ grau completo e os $20 \%$ restantes possuem o $2^{\circ}$ grau completo.

A Empresa A produz calçados masculinos, femininos e infantis, sendo o volume de produção de 50.000 pares/ano. A produção é feita apenas por encomenda. Trabalha-se com terceirização de serviços para realização da chanfração, pesponto, pré-fezado e a costura manual do calçado. 
Os equipamentos utilizados são mais ou menos modernos (20\%) e modernos (80\%). Na produção o trabalho é feito de forma automática (com força motriz sob supervisão humana) em 30\% dos equipamentos e de forma semi-automática (com força motriz e operação humana) em $40 \%$ dos equipamentos. Os 30\% restantes da operação de fabricação do calçado são realizados utilizando-se ferramentas manuais, com completa operação humana. O processo produtivo é feito em linha.

A Empresa A é informatizada, exceto o almoxarifado e o setor de expedição e os equipamentos são ligados em rede. Adota-se um programa para controle de estoques e utiliza os serviços de uma firma de assessoria para auxílio na parte de informatização. A Internet é utilizada pela Empresa A apenas em caráter informativo, não realizando-se vendas/compras através deste canal.

\subsubsection{Mercado e Estratégia de Atuação}

O mercado de atuação da Empresa A abrange a cidade de Franca (10\%), a cidade de São Paulo (50\%) e os outros $40 \%$ estão distribuídos entre as regiões Norte, Nordeste e Centro-Oeste.

Os principais fornecedores da Empresa A são: Curtume A Cuca Couros, empresa de grande porte, localizada em Apucarana - PR, fornecedora de couros; W \& A Solados, empresa de pequeno porte, localizada em Franca - SP, fornecedora de solados; Amazonas S/A, empresa de grande porte, localizada em Franca - SP, fornecedora de solados; Qualiflex, empresa de pequeno porte, localizada em Franca - SP, fornecedora de palmilhas e Quimican, empresa de médio porte, localizada em Franca - SP, fornecedora de cola.

A Empresa A possui como clientes diversas pequenas lojas de varejo, concorrentes entre si, estando em quase sua totalidade concentradas na cidade de São Paulo. O mercado em que a Empresa A atua é bastante competitivo, tendo inúmeros concorrentes, em sua grande maioria indústrias de calçados localizadas na cidade de Franca.

A Empresa A adota a estratégia de diferenciação de produtos, sempre buscando inovar seus modelos e fazer novos lançamentos a cada coleção, sendo a divulgação dos produtos da Empresa A feita, principalmente, através de anúncios em revistas do ramo calçadista.

\subsubsection{Recursos Humanos}

A Empresa A remunera os seus funcionários com um valor igual ao do mercado e oferece como benefício distribuição de cestas básicas, vinculada com a produtividade e faltas. A 
Empresa A também possui convênios com supermercados, óticas e farmácias localizadas em Franca.

A Empresa A não tem como prática o investimento em treinamento. O último treinamento que realizou foi o Programa Sebrae de Qualidade Total, em 1999.

As taxas de rotatividade e absenteísmo são muito baixas e quando há a necessidade de contratar um funcionário isto não é feito de acordo com um padrão. Às vezes coloca-se um anúncio na porta da empresa ou em jornais locais, ou então realiza-se entrevistas com pessoas que procuram emprego diretamente na empresa. A seleção é feita a partir de uma entrevista, com o responsável pela produção, e depois um teste de três dias. Caso a pessoa passe no teste é feito então, um contrato temporário e depois desse prazo a pessoa é contratada ou mandada embora.

\subsubsection{Situação Financeira}

O faturamento da Empresa A não sofreu alteração significativa nos anos de 1997 a 2000, atingindo neste último o valor de $\mathrm{R} \$ 450.000,00$. A empresa sofre problemas com inadimplência e não tem falta de capital de giro.

\subsubsection{EMPRESA B}

\subsubsection{Histórico}

A Empresa B foi fundada em 1989, sendo inicialmente uma sociedade cuja atividade inicial consistia apenas na parte de modelagem de calçados, pois os dois sócios possuíam experiência profissional nesta atividade. Após dois anos de atividade a Empresa B entrou no ramo de fabricação de solados, que tinha uma concorrência baixa na época, e seis meses depois começou a fabricar calçados.

As atividades da Empresa B foram se acumulando e a parte de modelagem foi sendo diminuída até parar totalmente no fim de 1992. Em meados de 1993, devido a problemas de sociedade, a Empresa B deixou de fabricar calçados. No final de 1993 a sociedade foi desfeita, ficando apenas um dos sócios que é o atual proprietário da empresa.

De 1994 em diante buscou-se conhecer mais o mercado e investir na indústria, principalmente em novas tecnologias/maquinário. De 1991 a 1998 os solados produzidos na Empresa B tinham como matéria prima a borracha termoplástica (TR). No fim de 1998 começou-se a produzir solados poliuretano (PU), de melhor qualidade. Para isso adquiriu-se quatro máquinas injetoras. Atualmente a Empresa B produz solados para calçados masculinos e 
também, em baixa escala, para calçados infantis. Mas, a empresa pretende, até o início do ano 2001, entrar no mercado de solados para calçados femininos.

\subsubsection{Estrutura}

A Empresa B classifica-se como de pequeno porte, com um corpo funcional composto por 32 funcionários além do proprietário, que ocupa o cargo de diretor geral. A Empresa B possui uma recepcionista e três funcionários em cargos de chefia. Os outros vinte e nove funcionários estão alocados no chão-de-fábrica. A Empresa B trabalha com quatro representantes externos, autônomos, responsáveis pela área de vendas da empresa.

O organograma da Empresa B está estruturado da seguinte forma:

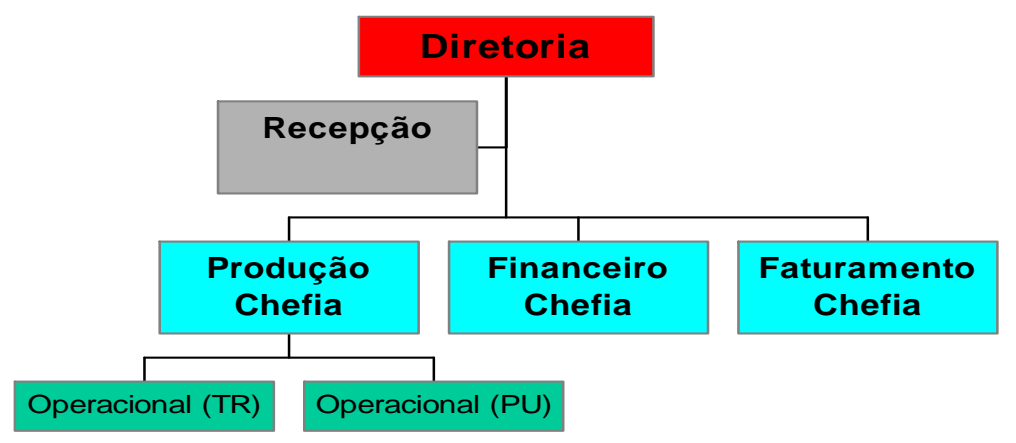

Figura 6.2 - Organograma da empresa B

O proprietário da Empresa B possui curso superior completo e o nível de escolaridade formal dos funcionários está distribuído da seguinte forma: $40 \%$ possuem o $1^{\circ}$ grau incompleto, $20 \%$ possuem o $1^{\circ}$ grau completo, $34 \%$ possuem o $2^{\circ}$ grau incompleto e $6 \%$ possuem curso superior incompleto.

A Empresa B produz diversos modelos de calçados, trabalhando com dois tipos de materiais: poliuretano e borracha termoplástica.

A produção é feita em quase sua totalidade por encomenda. Produz-se para estoques raramente, apenas quando há alguma ociosidade e seja certo que o produto a ser estocado possa ser absorvido pelo mercado. A Empresa B utiliza serviço de terceiros para as atividades relacionadas com o departamento pessoal e contabilidade.

Os equipamentos utilizados são mais ou menos modernos (25\%) e modernos (75\%). A Empresa B trabalha com duas linhas produtivas, em uma delas $70 \%$ do trabalho é feito de forma 
automática (com força motriz sob supervisão humana) e 30\% semi-automática (com força motriz e operação humana) e na outra o percentual é de 50\% de forma automática e 50\% semiautomática. O processo produtivo é feito em células de produção.

A Empresa B é informatizada e os equipamentos são ligados em rede. Não adota-se aplicativos específicos, apenas utilizas programas simples, feito no Excell, para controle de estoque. A Empresa B utiliza a Internet desde junho de 2001 apenas em caráter informativo, não realizando-se vendas/compras através deste canal.

\subsubsection{Mercado e Estratégia de Atuação}

O mercado de atuação da empresa B abrange a cidade de Franca (85\%) e algumas outras cidades da região (15\%).

Os principais fornecedores da Empresa B são: Basf, empresa de grande porte, localizada em Mauá - SP, fornecedora de poliuretano; Coim do Brasil, empresa grande, localizada em Vinhedo -SP, também fornecedora de poliuretano e, Amazonas, empresa grande, localizada em Paulínea-SP, fornecedora de borracha termoplástica. A competição entre os fornecedores de poliuretano é bastante acirrada, permitindo à Empresa B barganhar preço.

A Empresa B possui como clientes principais as seguintes empresas: HB, Sândalo e Free-Way, empresas de grande porte, localizadas em Franca - SP e Braddocky Young Shoes, Score e Artman's, empresas de pequeno porte, localizadas também em Franca - SP. Todas essas empresas são concorrentes entre si.

O mercado em que a Empresa $\mathrm{B}$ atua é bastante competitivo, tendo inúmeros concorrentes que trabalham com fabricação de solado de TR (borracha termoplástica), entre eles a empresa Franplastic, empresa de pequeno porte, localizada em Franca - SP. Já em relação ao solado de poliuretano a principal concorrente é a Amazonas Componam, empresa de grande porte, localizada em Franca - SP.

A Empresa B tem como estratégia de atuação a diferenciação de produtos, inovando constantemente os modelos de seus solados.

Não é feito investimento em propaganda para divulgação dos produtos há quatro anos. A divulgação é feita boca-a-boca pelos próprios representantes da empresa.

\subsubsection{Recursos Humanos}

A Empresa B remunera os seus funcionários com um valor igual ao do mercado e oferece como benefício bonificação por produtividade e qualidade. Esta bonificação é dada da 
seguinte forma: a produtividade e qualidade do operário é avaliada pelo chefe de produção que atribui uma nota ao trabalho de 0 (ruim), 1 (médio) e 2 (bom). Cada nota tem um valor monetário específico. No final do mês os valores são somados e repassados ao funcionário.

A Empresa não investe em treinamento para os funcionários. A taxas de rotatividade da empresa é de $30 \%$ e a de absenteísmo cerca de $8 \%$. A contratação de funcionários e feita de maneira informal, geralmente através de placas de anúncio na porta da empresa. A seleção é feita a partir de uma entrevista, com o chefe de produção e depois realiza-se um teste de três dias com o provável funcionário. Caso a pessoa passe no teste é feito então, um contrato temporário e depois desse prazo a pessoa é contratada ou mandada embora.

\subsubsection{Situação Financeira}

O faturamento da Empresa B apresentou um crescimento significativo nos últimos anos, dobrando de valor de 1998 para 1999 devido à entrada de máquinas novas na linha de produção. Os valores de faturamento da empresa nos anos de 1997, 1998, 1999 e 2000 foram, respectivamente de $\mathrm{R} \$ 70.000,00 ; \mathrm{R} \$ 90.000,00 ; \mathrm{R} \$ 180.000,00$ e $\mathrm{R} \$ 280.000,00$.

A empresa enfrenta problemas com inadimplência, representando cerca de $3 \%$ do valor das vendas da empresa, mas não tem problemas com falta de capital de giro.

\subsubsection{EMPRESA C}

\subsubsection{Histórico}

A Empresa C foi fundada em 1993 por dois sócios. Inicialmente só trabalhava-se com comércio de palmilhas, passando a produzi-las a partir de 1995. Desde então a Empresa C vem crescendo gradativamente e para isso investe continuamente em maquinários modernos. O mercado de atuação foi se expandindo ao longo dos anos, possibilitando à Empresa $\mathrm{C}$ atuar não só no estado de São Paulo como também em Minas Gerais, Rio de Janeiro, Paraná e Rio Grande do Sul.

Em 1998 a Empresa C passou a atuar no segmento de brinquedos pedagógicos e também a produzir protetores para os pés. Atualmente a Empresa C está aumentando as instalações para poder adquirir novas máquinas e tem como meta iniciar, ainda no ano de 2001, a produção de um quarto tipo de produto. 


\subsubsection{Estrutura}

A Empresa C classifica-se como de pequeno porte, com um corpo funcional composto por 66 funcionários mais dois sócios, sendo esses cônjuges. Os proprietários ocupam cargos de diretoria. Além dos diretores existem 4 funcionários em cargo de gerência, 3 em cargos de chefia, 1 recepcionista, 6 em cargos administrativos e os 52 restantes trabalham no chão de fábrica A Empresa C trabalha com representantes que atuam como vendedores externos da empresa.

O organograma da Empresa C é estruturado da seguinte forma:

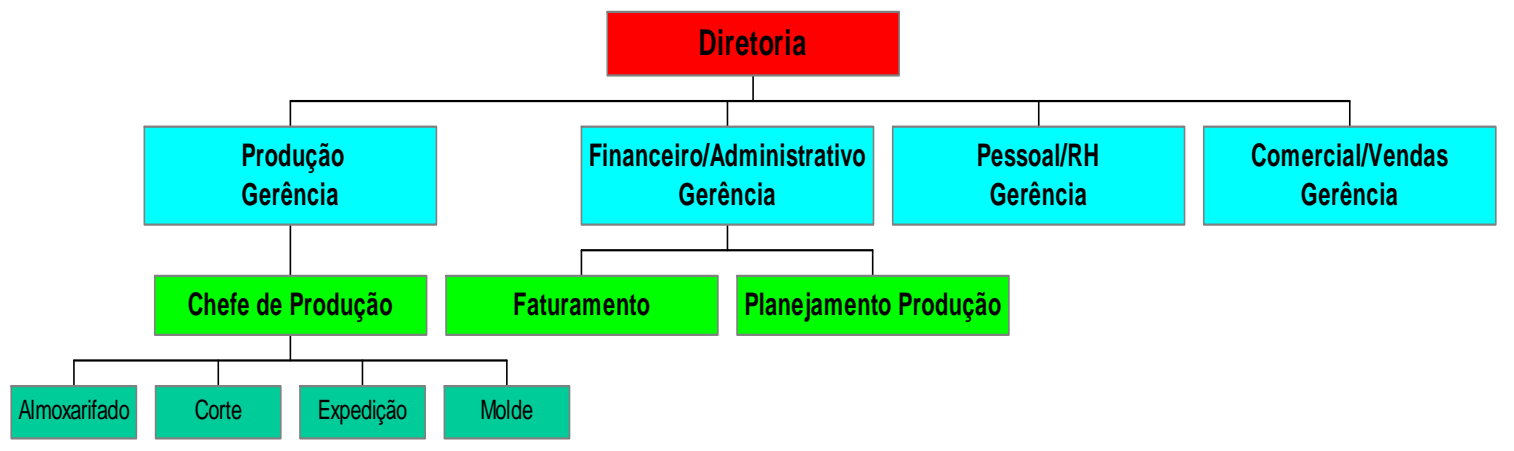

Figura 6.3 - Organograma da Empresa C

Em se tratando do grau de instrução dos sócios da Empresa C, um deles possui nível superior incompleto e o outro segundo grau completo. Já o nível de escolaridade formal dos funcionários está distribuído da seguinte forma: $20 \%$ possuem o $1^{\circ}$ grau incompleto, $30 \%$ possuem o $1^{\circ}$ grau completo, $28 \%$ possuem o $2^{\circ}$ grau incompleto, $20 \%$ o segundo grau completo e $2 \%$ curso superior completo.

A Empresa C fabrica os seguintes produtos: palmilhas, brinquedos pedagógicos e protetores de calos e joanetes, sendo que cada um deles possui diversos modelos.

A produção é feita em quase sua totalidade por encomenda (90\%), sendo apenas $10 \%$ da produção feita para estoque. A Empresa C utiliza serviço de terceiros para fazer o pesponto em alguns tipos de palmilhas, colagem de imãs em palmilhas magnéticas e na montagem dos brinquedos pedagógicos. Os equipamentos utilizados são mais ou menos modernos (30\%) e modernos (70\%). O trabalho é feito de forma automática (com força motriz sob supervisão humana) em $60 \%$ do processo de produção; de forma semi-automática (com força motriz e 
operação humana) em 30\% do processo de produção e os $10 \%$ restantes correspondem ao trabalho de embalagem que é totalmente manual. O processo produtivo é organizado em linha.

A Empresa C é informatizada, os equipamentos são ligados em rede e faz-se uso da Internet. A Empresa C utiliza um aplicativo que faz controles de recebimento de mercadoria, estoques, faturamento, contas a pagar e a receber, faturamento etc.

\subsubsection{Mercado e Estratégia de Atuação}

O mercado de atuação da Empresa C abrange Franca e região (60\%), algumas cidades do estado do Rio de Janeiro e do Paraná (35\%) e uma pequena parcela da produção é destinada ao mercado internacional (2\%), abrangendo os seguintes países: Uruguai, Bolívia, Argentina, Colômbia e México.

Os principais fornecedores da Empresa C são: Bertonsini, empresa grande, localizada Franca - SP, fornecedora de cola; Eloplás, empresa grande, localizada em Ribeirão Preto - SP, fornecedora de embalagem e Ortobon, empresa grande, também fornecedora de poliuretano, localizada em São José do Rio Preto - SP.

A Empresa C possui como clientes principais as seguintes empresas: Calçados Pé de Ferro, localizada em Franca - SP; Tess Calçados, localizada no Rio de Janeiro - RJ, Avon Brasil, localizada em São Paulo - SP e Fujivara, localizada em Apucarana - PR. Todas essas empresas são de grande porte.

O mercado em que a Empresa $\mathrm{C}$ atua é bastante competitivo, sendo o seu principal concorrente a empresa Confortec, indústria de grande porte, localizada em Franca - SP.

A Empresa C adota como estratégia a diferenciação de produtos, inovando constantemente suas palmilhas, procurando lançar sempre novos modelos no mercado..

A Empresa C investe em propaganda através de anúncios em revista, outdoors, mala direta e home page na Internet.

\subsubsection{Recursos Humanos}

A Empresa C remunera os seus funcionários com um valor igual ao do mercado, não oferecendo benefícios a eles.

A Empresa C investe em treinamento para os funcionários. O pessoal operacional em geral participa dos cursos ministrados pelo SENAI (Serviço Nacional de Aprendizado Industrial). Já em relação ao pessoal que ocupa cargos administrativos e de níveis hierárquicos 
mais altos, estes geralmente fazem cursos do SEBRAE. (Serviço Brasileiro de Apoio à Micro e Pequena Empresa).

A taxa de rotatividade da empresa é de $10 \%$ e a de absenteísmo cerca de $20 \%$, chegando a prejudicar a produção.

A contratação de funcionários é feita de maneira informal, geralmente através de placas de anúncio na porta da empresa. A seleção é feita a partir de uma entrevista, com o chefe de produção e depois o candidato realiza-se um teste de três dias. Se a pessoa passar no teste é feito então, um contrato de um mês e depois desse prazo a pessoa é contratada ou mandada embora.

\subsubsection{Situação Financeira}

A empresa não autorizou publicar dados de faturamento. Já em relação à inadimplência a empresa enfrenta problemas, o que não ocorre em relação à falta de capital de giro.

\subsubsection{EMPRESA D}

\subsubsection{Histórico}

A empresa D foi fundada em 1976, na cidade de Franca - SP. Nos primeiros doze anos a Empresa D tinha razão social diferente da utilizada hoje e funcionava em outro local, mas fabricava o mesmo produto: palmilha.

Nos doze primeiros anos o crescimento da empresa não foi muito significativo, mas após a mudança de local e razão social, quando a empresa passou a operar em maiores instalações e adquiriu máquinas mais modernas a expansão da produção foi significativa, o que foi favorecido pela expansão do mercado de calçados a partir de 1989 com a ida de várias empresas desse setor para a cidade de Franca.

Hoje em dia a Empresa D produz 25.000 palmilhas/dia, visando aumentar a produção e expandir o mercado de atuação.

\subsubsection{Estrutura}

A Empresa D classifica-se como de pequeno porte, sendo composta de 63 funcionários e mais dois sócios. Os sócios, que são irmãos, ocupam os cargo de diretoria da empresa sendo também os principais responsáveis pelos setores de vendas e compras da organização. A Empresa D possui um gerente geral, três funcionários na área de chefia e uma recepcionista. Os demais funcionários trabalham na parte operacional. A área contábil é de responsabilidade de uma empresa externa. 
O organograma da Empresa D é estruturado da seguinte forma:

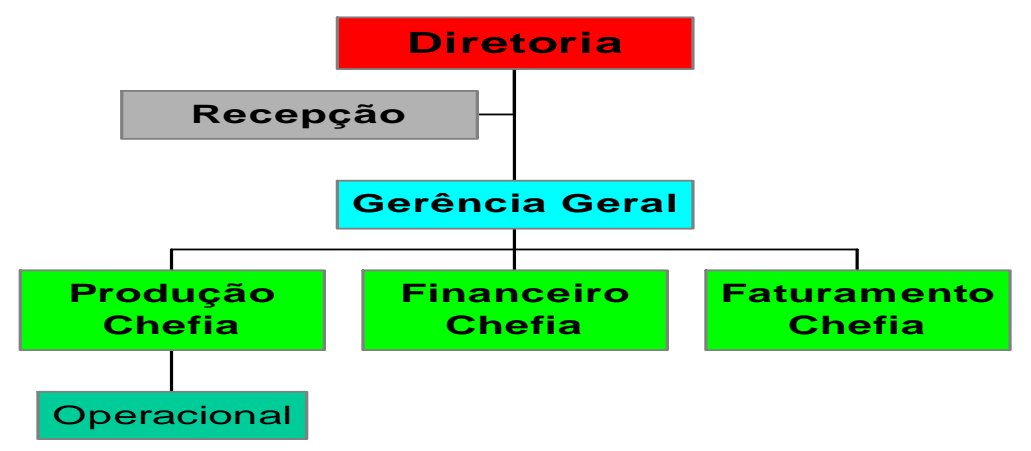

Figura 6.4: Organograma da empresa D

O grau de instrução de um dos sócios é de nível superior incompleto, já o outro sócio tem o $1^{\circ}$ grau completo. O nível de escolaridade formal dos funcionários está distribuído da seguinte forma: $60 \%$ possuem o $1^{\circ}$ grau incompleto, $30 \%$ o $1^{\circ}$ grau completo e os $10 \%$ restantes possuem o $2^{\circ}$ grau completo.

A Empresa D produz palmilhas para calçados masculinos, fabricando uma grande variedade de modelos. A produção é feita apenas por encomenda e não se trabalha com terceirização dos serviços.

Os equipamentos utilizados são mais ou menos modernos (70\%) e modernos (30\%), sendo operados de forma semi-automática, isto é, com força motriz e operação humana. O processo produtivo é feito em linha.

A Empresa D é informatizada e os equipamentos são ligados em rede. A empresa não utiliza nenhum aplicativo específico para controles gerenciais e não faz uso da Internet.

\subsubsection{Mercado e Estratégia de Atuação}

O mercado de atuação da Empresa D abrange apenas a cidade de Franca. A cidade possui um número muito grande de empresas de calçados, que absorvem toda a produção da Empresa D.

Os principais fornecedores da Empresa D são: Damas S/A, empresa de grande porte, localizada em Osasco, fornecedora de papelão; Metalúrgica Aço Real, empresa de grande porte, localizada na região sul do país e; Bertonsini, empresa de grande porte, localizada em Franca SP, fornecedora de cola. A competição entre os fornecedores de cola é bastante acirrada. 
A Empresa D tem como principais clientes empresas de grande porte, concorrentes entre si, fabricantes de calçados. Todas estão localizadas na cidade de Franca, sendo elas: Samello, Democrata e San Genaro.

O mercado de atuação da Empresa D é bastante competitivo, tendo vários concorrentes na cidade. Esses são principalmente indústrias de pequeno e médio porte, dentre elas: Francopaulo, Palmisola, Palmilhas Dois Irmãos e Qualiflex.

A Empresa D adota como estratégia a diferenciação de produtos e prima muito pela qualidade desses. O investimento em pesquisa para inovação de produtos é constante.

\subsubsection{Recursos Humanos}

A Empresa D remunera os seus funcionários com um valor igual ao do mercado e oferece benefícios como: convênio médico e odontológico, cesta básica e vale transporte.

A Empresa D investe em treinamento principalmente para os níveis hierárquicos mais altos. As pessoas que recebem o treinamento repassam para o pessoal da fábrica. A Empresa D também promove palestras para todo o corpo funcional.

A taxa de rotatividade e absenteísmo é muito baixa e quando há a necessidade de contratar um funcionário isto não é feito de acordo com um padrão. Às vezes coloca-se anúncio na porta da empresa ou em jornais locais, ou então o processo de contratação é feito com pessoas que procuram emprego diretamente na empresa, o que é muito comum. A seleção é feita a partir de uma entrevista, com o chefe de produção, e depois um teste de três dias. Caso a pessoa passe no teste é feito então, um contrato temporário e depois desse prazo a pessoa é contratada ou mandada embora.

\subsubsection{Situação Financeira}

O faturamento da Empresa D não sofreu alteração significativa nos anos de 1997 a 2000, atingindo neste último o valor de R\$ $1.200 .000,00$. A Empresa D não sofre problemas com inadimplência e não tem falta de capital de giro.

\subsubsection{EMPRESA E}

\subsubsection{Histórico}

A Empresa E foi fundada em abril de 1998 por dois sócios. Antes da fundação da empresa ambos proprietários também eram sócios em uma outra empresa que apenas comercializava EVA (Etileno Acetato Vinil). Essa empresa tinha uma clientela muito boa e o 
volume de vendas era alto. Percebendo que a tendência era de um aumento gradativo das vendas do EVA os sócios resolveram fabricar o produto.

No começo a qualificação dos funcionários era baixa, o que foi sendo sanado aos poucos através de treinamentos, auxílio de consultoria externa e apoio do SEBRAE. A Empresa E foi se estruturando aos poucos e hoje é a terceira maior fabricante de placas de EVA em Franca-SP.

A Empresa E está aumentando as instalações para ampliar o espaço do escritório e tem como um dos objetivos principais para o ano de 2001 implantar as normas ISO 9000.

\subsubsection{Estrutura}

A Empresa E classifica-se como de pequeno porte, sendo composta de 75 funcionários e mais dois sócios. Os sócios, que são casados, ocupam os cargos de diretoria. A Empresa E possui dez funcionários na área de chefia, dezessete na administração e quarenta e oito no chão de fábrica.

Um dos sócios da Empresa E possui como nível de instrução $2^{\circ}$ grau completo e o outro o $1^{\circ}$ grau completo. Já o nível de escolaridade dos funcionários divide-se da seguinte forma: $1^{\circ}$ grau incompleto $(16 \%), 1^{\circ}$ grau completo $(30 \%), 2^{\circ}$ grau incompleto $(10 \%), 2^{\circ}$ grau completo (25\%), Superior Incompleto (10\%), Superior Completo (8\%) e Pós-Graduação (1\%).

O organograma de Empresa E é estruturado da seguinte forma:

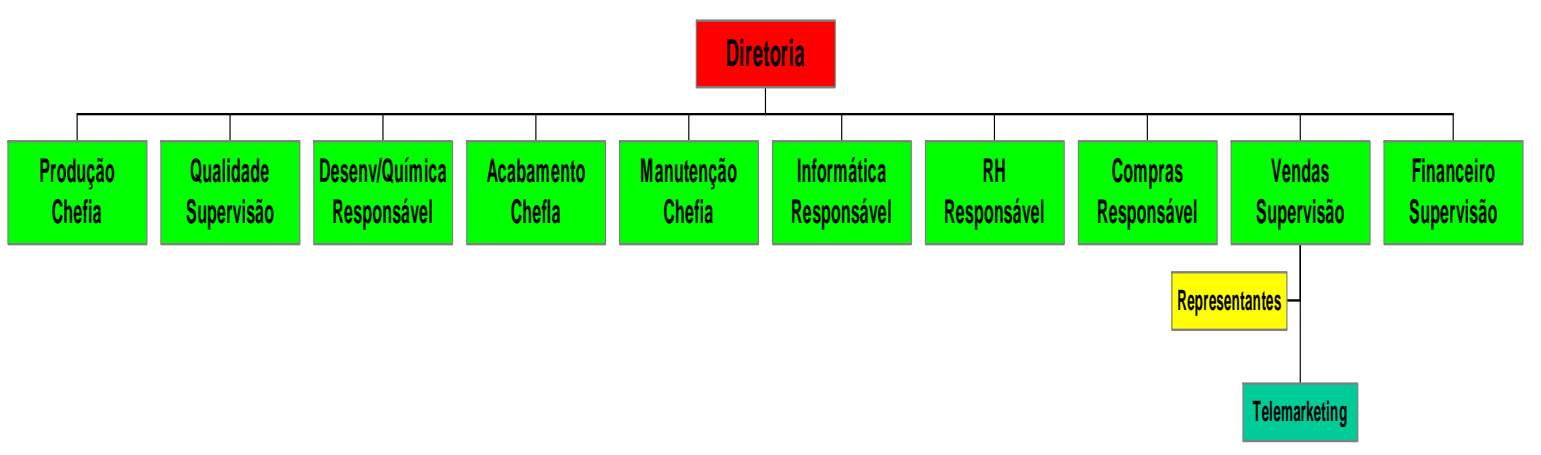

Figura 6.5: Organograma da Empresa E

A Empresa E produz placas de EVA (Etileno Acetato Vinil), com uma grande variedade de cores, densidade e desenhos, o que representa um total de 400 (quatrocentos) tipos diferentes de placas de EVA. A produção é feita por encomenda. Trabalha-se com estoque apenas em 
épocas sazonais, geralmente em junho e julho e de dezembro a fevereiro. A empresa terceiriza apenas o serviço de manutenção.

Os equipamentos utilizados são mais ou menos modernos (20\%) e modernos (80\%), sendo operados de forma semi-automática (60\%), isto é, com força motriz e operação humana. O restante da produção (40\%) é feito através de ferramentas manuais, com completa operação humana. O processo produtivo é organizado em linha.

A Empresa E é informatizada e os equipamentos são ligados em rede. A empresa utiliza um software denominado $\mathrm{CHB}$, nome da empresa fabricante, que realiza controle de estoques, financeiro, compras e folha de pagamento.

\subsubsection{Mercado e Estratégia de Atuação}

O mercado de atuação da Empresa E abrange a cidade de Franca, que absorve 60\% da produção. Os $40 \%$ restantes atendem a cidade de São Paulo e algumas cidades do estado de Minas Gerais.

Os principais clientes da Empresa E são empresas de grande porte, sendo elas e suas respectivas localizações as seguintes: Alpargatas - São Paulo-SP; Free Way - Franca - SP; Lui Lui - Franca - SP; Cacique - MG e San Marino - Franca - SP.

A Empresa E tem como principais fornecedores as seguintes empresas: Bayer, empresa de grande porte, localizada em Paulínea - SP, fornecedora de aceleradores; Du Pont, empresa de grande porte, localizada nos Estados Unidos, fornecedora de EVA granulado e OPP, empresa de grande porte, localizada no Rio Grande do Sul, fornecedora de EVA granulado. A competição entre os fornecedores de EVA granulado é forte, mas a empresa prefere trabalhar com o material importado por ser de melhor qualidade. Isso só não ocorre quando o preço do material importado é muito caro, chegando a inviabilizar a sua utilização. Fora o EVA granulado a empresa procura trabalhar sempre com os mesmos fornecedores para não ocorrer variação na qualidade do produto fabricado.

O mercado de atuação da Empresa E é bastante competitivo, tendo vários concorrentes na cidade. Esses são principalmente indústrias de médio e grande porte, sendo elas: Amazonas S/A - localizada em Franca - SP; MSM - Franca - SP; Borrachas Franca - Rio Grande do Sul.

A Empresa E adota como estratégia a diferenciação de produtos e prima muito pela qualidade desses. O investimento em pesquisa para inovação de produtos é constante. 


\subsubsection{Recursos Humanos}

A Empresa E remunera os seus funcionários com um valor igual ao do mercado e oferece como benefício apenas convênio médico.A Empresa E investe em treinamento para os funcionários, mas não de uma forma planejada, e sim de acordo com a necessidade do momento. Atualmente têm-se dado prioridade ao treinamento objetivando a obtenção da ISO 9000.

A taxa de rotatividade e absenteísmo são muito baixas e quando há a necessidade de contratar um funcionário isto ainda não é feito de acordo com um padrão. Às vezes coloca-se anúncio na porta da empresa ou em jornais locais ou então o processo seletivo é feito com pessoas que procuram emprego diretamente na empresa, o que é comum. A seleção é feita a partir de uma entrevista, com o chefe de produção e depois um teste de três dias. Se a pessoa passa no teste é feito então, um contrato temporário e depois, a efetivação ou não do funcionário. Mas, essa forma de contratação está sendo revista e será padronizada, passando a ser um processo mais rigoroso, onde será incluído uma análise preliminar de currículo e serão estabelecidas algumas exigências de qualificação para a ocupação de cada cargo.

\subsubsection{Situação Financeira}

O faturamento da empresa vem crescendo a cada ano. Em 1998 atingiu o valor de R\$ 168.000,00, já em 1999 e 2000 os valores foram, respectivamente, de: R\$ 720.000,00 e R\$ $900.000,00$. A empresa sofre problemas com inadimplência e não tem falta de capital de giro.

\subsubsection{EMPRESA F}

\subsubsection{Histórico}

A Empresa F, localizada em Franca - SP, foi fundada em 02/02/88 por dois sócios. Inicialmente produzia-se calçados femininos, sendo o volume de produção de 50 pares/dia.

Em 1989 a Empresa F entra em um novo processo de desenvolvimento e a sociedade chega ao fim, entrando outro sócio na empresa, não atuante nas atividades dessa. Em 1991 a Empresa muda para uma nova estrutura física e sua produção aumenta, entretanto, devido a uma necessidade de mercado, a produção passa a ser voltada para calçados masculinos.

Os calçados masculinos da Empresa F são lançados no mercado com uma marca que não foi bem aceita, surgindo assim a necessidade de uma nova marca. Lança-se então uma outra marca que dessa vez foi muito bem aceita pelos clientes. 
A Empresa F passa a conquistar novos mercados, a investir em tecnologia e em melhoria da qualidade de seus produtos. A produção aumenta, atingindo em 1995 o volume de 600 pares/dia.

Em meados de 1999 a Empresa F construiu um novo barracão no Distrito Industrial da cidade de Franca, sendo este barracão a unidade 2 da empresa.

Desde o início de 2001 a empresa vem passando por reestruturações na área produtiva, comercial e humana, sendo que atualmente a atuação de mercado da empresa concentra-se na produção de calçados de estilo jovem, para pessoas com espírito de aventura, voltadas para consciência ecológica e envolvidas com esporte.

\subsubsection{Estrutura}

A Empresa F classifica-se como de pequeno porte, sendo composta de 73 funcionários e mais dois sócios. Apenas um dos sócios atua na empresa ocupando o cargo de diretor geral. A empresa possui três funcionários em cargos de gerência, uma recepcionista, quatro funcionários em cargos administrativos e os sessenta e cinco restantes trabalham no chão-de-fábrica

O organograma da Empresa F é estruturado da seguinte forma:

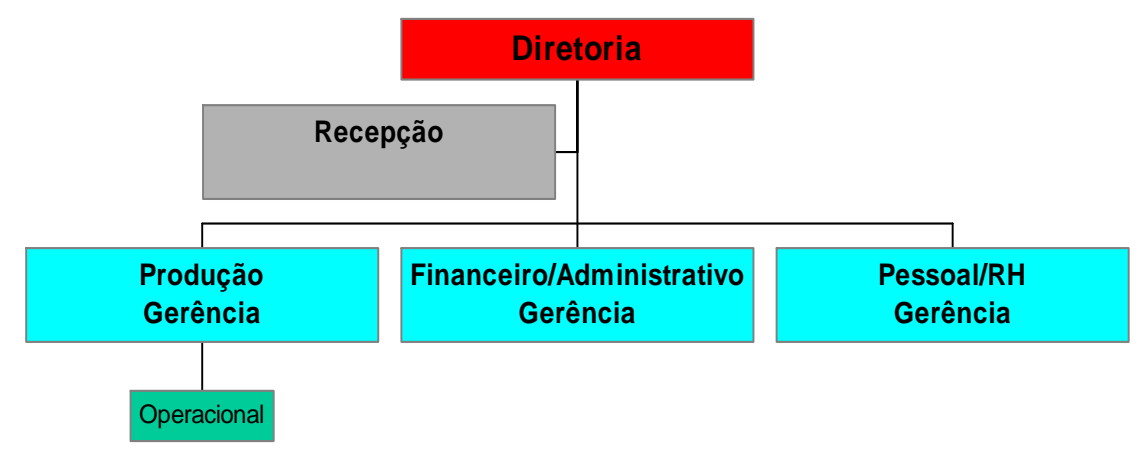

Figura 6.6: Organograma de Empresa F

O sócio que tem atuação na Empresa F possui como formação o $2^{\circ}$ grau completo, e o nível de escolaridade dos funcionários divide-se da seguinte forma: $1^{\circ}$ grau incompleto (54\%), $1^{\circ}$ grau completo (30\%), $2^{\circ}$ grau incompleto (6\%), $2^{\circ}$ grau completo (5\%), Superior Incompleto (3\%), Superior Completo (2\%). 
A Empresa F produz calçados masculinos, de vários modelos, chegando a lançar de 75 a 80 modelos por coleção. São produzidos cerca de 1200 pares/dia.

Praticamente $100 \%$ da produção é feita sob encomenda. A produção para estoque só é feita quando o número de pedidos sob encomenda não são suficientes para ocupar a capacidade produtiva da Empresa F, o que é raro de acontecer.

Os equipamentos utilizados são modernos e o processo produtivo é organizado em células de produção. As máquinas são operadas de forma semi automática em cerca de $96 \%$ do processo produtivo, sendo os demais $6 \%$ das operações de produção, que correspondem ao acabamento final e colocação do cadarço no calçado, feitas de forma manual.

\subsubsection{Mercado e Estratégia de Atuação}

O mercado de atuação da Empresa F abrange vários estados do país, sendo o Rio Grande do Sul, Santa Catarina, Rio de Janeiro e a região nordeste as áreas de maior representatividade. O mercado regional representa apenas $15 \%$ do mercado da empresa, já o mercado nacional absorve $65 \%$ da produção e o mercado internacional $20 \%$ da produção, sendo esta última destinada aos seguintes países: Chile, Uruguai e Bolívia.

A Empresa F tem como clientes pequenas empresas varejistas de calçados, não havendo nenhum grande cliente ou um ou dois clientes de maior representatividade

Os principais fornecedores da Empresa F são: Amazonas S/A, grande empresa, localizada em Franca - SP, fornecedora de solados; OM solas, empresa de médio porte, localizada em Franca - SP, fornecedora de solados; Manaus, empresa de grande porte, localizada em Franca - SP, fornecedora de solados e Impec, empresa de pequeno porte, localizada em Franca - SP, fornecedora de palmilhas.

$\mathrm{O}$ mercado em que a Empresa $\mathrm{F}$ atua é bastante competitivo, sendo o principal concorrente da empresa a indústria de calçados Free Way, empresa de grande porte, localizada em Franca - SP.

A Empresa F adota como estratégia de atuação a diferenciação de produtos procurando sempre lançar novos modelos de calçados, trabalhando com solados personalizados, estando sempre atenta às tendências de mercado.

O investimento em propaganda da Empresa F é feito através de anúncio em outdoors, revistas especializadas do setor calçadista, divulgação dos produtos em feiras como a Fenac (Feira Nacional do Calçado) entre outras e; home page da empresa na Internet . 


\subsubsection{Recursos Humanos}

A Empresa F remunera os seus funcionários com um valor maior que o do mercado, mas não oferece nenhum tipo de benefício aos funcionários.

A empresa não tem a prática de investir em treinamento. Os treinamentos são muito esporádicos e realizados principalmente pelas pessoas de cargos hierárquicos mais elevados (diretoria/ gerência).

A taxa de rotatividade e absenteísmo são muito baixas, não prejudicando a produção.

A contratação, quando necessária é feita através de anúncio (placa de aviso) na porta da empresa. . A seleção é feita a partir de uma entrevista, com o gerente de produção, e depois um teste de três dias. Caso a pessoa passe no teste é feito então, um contrato temporário e depois desse prazo a pessoa é contratada ou mandada embora.

\subsubsection{Situação Financeira}

A empresa não revelou dados de faturamento. Em se tratando de problemas com inadimplência eles ocorrem na empresa, mas não há falta de capital de giro.

\subsubsection{EMPRESA G}

\subsubsection{Histórico}

A Empresa G foi fundada em março de 1989 por um dos sócios atuais da empresa. No ano de sua fundação, a empresa iniciou-se com apenas oito funcionários, sendo que estes faziam todo o serviço, pois não havia nenhuma mão-de-obra externa. Eram produzidos 18 pares/dia e, entre estes, fabricava-se botinas e botas sociais. Toda a parte burocrática e administrativa era conduzida pelo fundador.

A Empresa $G$ foi crescendo ao longo dos anos e por isso houve a necessidade de mudança de instalações, passando a funcionar então em um prédio de 875 metros quadrados de área construída, entre elas: produção, recepção, escritório e varejo. Os dois filhos do fundador passaram a fazer parte da composição societária da empresa, atuando na diretoria. Esses, assim como o fundador da empresa, antes de trabalharem na empresa possuíam experiência profissional no ramo calçadista.

A Empresa G fabrica atualmente calçados sociais masculinos, de diversos modelos, atuando em todo o mercado nacional. 


\subsubsection{Estrutura}

A Empresa G classifica-se como de pequeno porte, sendo composta por 28 funcionários e mais 3 sócios. Todos os sócios atuam na empresa sendo um deles o presidente e os outros dois diretores da empresa. A empresa possui três funcionários que ocupam cargos de gerência, uma recepcionista, dois em cargos administrativos e os vinte e três restantes trabalham no operacional (chão-de-fábrica). A Empresa G possui representantes externos, autônomos que auxiliam a parte de vendas da empresa

O organograma da Empresa G é estruturado da seguinte forma:

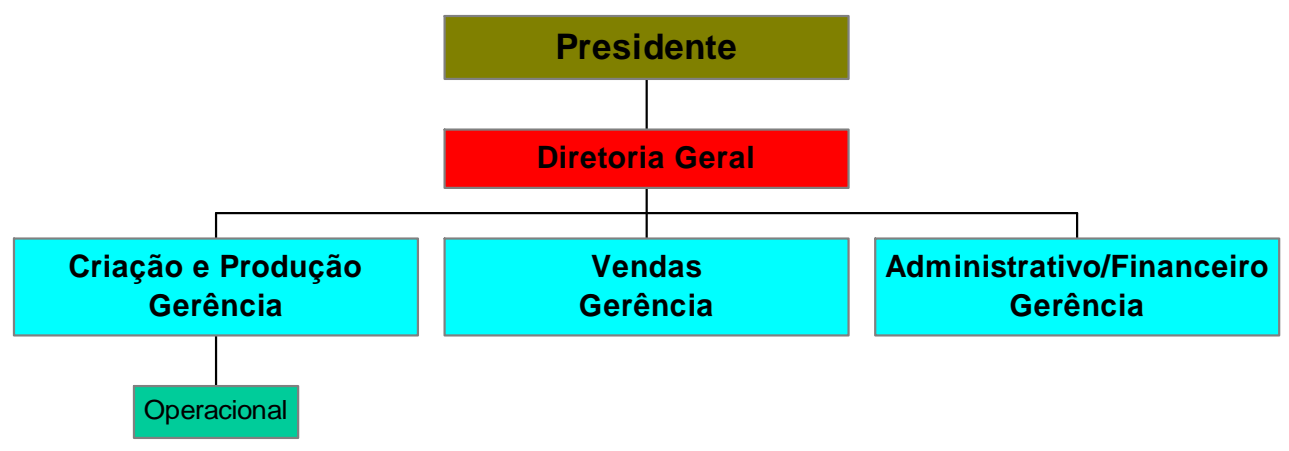

Figura 6.7: Organograma da Empresa G

Os sócios da Empresa $G$ possuem os seguintes níveis de instrução: $1^{\circ}$ grau completo, fundador, $2^{\circ}$ grau completo, sócio-diretor, Superior Completo, sócio-diretor. Já o nível de escolaridade dos funcionários divide-se da seguinte forma: $1^{\circ}$ grau incompleto $(40 \%), 1^{\circ}$ grau completo (40\%), $2^{\circ}$ grau incompleto (10\%), $2^{\circ}$ grau completo (8\%), Superior Completo (2\%).

A Empresa G produz calçados sociais masculinos, de vários modelos, sendo a média de 47 modelos por coleção. São produzidos 250 pares/dia. A Empresa G possui três marcas próprias de calçados.

A produção é feita apenas sob encomenda, os equipamentos são novos, embora não sejam de tecnologia de ponta. O trabalho é feito de forma semi-automática (60\%) e uma boa parte da operação (40\%) é feita manualmente correspondendo às operações de dobração, moldação e colocação de enfeites. O processo produtivo é organizado em linhas de produção

A Empresa G terceiriza as operações de corte e pesponto. As empresas terceirizadas trabalham exclusivamente para a Empresa G.

A Empresa $G$ é informatizada e os equipamentos são ligados em rede e têm acesso à Internet. Há a utilização de um aplicativo específico para o setor calçadista que auxilia os 
controles gerencias, registrando dados de programação da produção, pedidos, estoque, vendas, recebimento de matéria-prima etc.

\subsubsection{Mercado e Estratégia de Atuação}

O mercado de atuação da Empresa $G$ tem abrangência nacional, sendo os estados de Paraná, Minas Gerais e São Paulo os mais representativos. A empresa não vende em Franca, com exceção da pequena loja de varejo que fica na fábrica. Toda a produção destina-se ao mercado nacional.

Os principais clientes da Empresa G são: Calzolaio \& Calzolaio - pequenas lojas de varejo, localizadas em Curitiba - PR; Elmo Calçados - rede de lojas varejistas, localizadas em Belo Horizonte - MG e; Paquetá Comércio, também uma rede de lojas varejistas, localizada em Porto Alegre - RS.

A Empresa $G$ tem como principais fornecedores as seguintes empresas: Curtume Moderno, grande empresa, localizada na Fazenda Pedra de Bode - Bahia, fornecedora de couros; Curtidora Áquila, empresa de grande porte, localizada em Campo Bom - RS, fornecedora de solados e; Amazonas, empresa de grande porte, localizada em Franca - SP, fornecedora de solados. Existe competição entre fornecedores, o que permite à Empresa G conseguir preços menores na compra de matéria-prima.

O mercado em que a Empresa $G$ atua é bastante competitivo, sendo as empresas Calçados Sândalo, Calçados Jacometti e Calçados Passport as concorrentes principais. Todas elas estão localizadas em Franca - SP, sendo as duas primeiras de grande porte e a última de pequeno porte.

A estratégia de atuação da Empresa $G$ é de diferenciação de produtos procurando sempre lançar novos modelos de calçados, trabalhando com solados personalizados, estando sempre atenta às tendências de mercado. Os modelos dos sapatos da empresa são feitos inspirados na moda italiana, para isso todo ano alguns funcionários participam de eventos do setor na calçadista na Itália.

O investimento da Empresa G em propaganda é destinado a anúncio em outdoors e revistas especializadas. 


\subsubsection{Recursos Humanos}

A Empresa $G$ remunera os seus funcionários com um valor maior que o do mercado e oferece como benefício assistência médica e odontológica. A empresa também possui convênio com redes de farmácia e supermercados da cidade.

O investimento em treinamento é feito pela Empresa G tanto a nível operacional quanto para os níveis hierárquicos mais altos. O pessoal operacional realiza cursos profissionalizantes e os demais participam de palestras, cursos do SEBRAE, entre outros. Porém a empresa não possui uma política padrão de treinamento, este ocorre de acordo com a necessidade do momento.

A contratação de funcionários é feita mediante a apresentação de um currículo, preenchimento de ficha, realização de entrevista e contratação temporária, antes da efetivação do funcionário. Atualmente a Empresa G está exigindo que o funcionário tenha no mínimo $1^{\circ}$ grau completo para se candidatar à vaga de trabalho.

As taxa de rotatividade e absenteísmo são muito baixas, não representando um número significativo, que chegue a prejudicar a produção.

\subsubsection{Situação Financeira}

A Empresa $G$ vem apresentando um valor crescente de faturamento ao longo dos anos. Em 1997 o faturamento foi de R\$ 1.890.528,57; em 1998 de R\$ 1.150.246,80; em 1999 de $\mathrm{R} \$ 2.347 .762,34$ e no ano de 2000 o valor de $\mathrm{R} \$ 3.124 .082,66$. A empresa raramente possui problemas com inadimplência e não existe carência de capital de giro.

\subsubsection{EMPRESA H}

\subsubsection{Histórico}

A Empresa $\mathrm{H}$ foi fundada no início de 1998, por dois sócios. Inicialmente a Empresa $\mathrm{H}$ comprava viras e solados de borracha prontos e realizava apenas a parte de acabamento desses produtos. A partir de 1991 teve início a produção de viras e em 1994 a produção de solados, quando a Empresa H mudou de instalação física devido ao aumento do volume de produção.

Em 1996, os três sócios atuais, arrendaram a Empresa H. Desde maio de 2001, passou também a ser fabricado placas compactas de borrachas, sendo que para isso investiu-se em maquinários novos, de última geração. A Empresa $\mathrm{H}$ pretende aumentar o volume produtivo das placas compactas, pois por enquanto o processo produtivo ainda está em fase de teste e adaptação, e com isso espera aumentar o volume de vendas da empresa. 


\subsubsection{Estrutura}

A Empresa H classifica-se como de pequeno porte, sendo composta por 65 funcionários e mais três sócios. Todos os sócios atuam na empresa ocupando respectivamente os cargos de diretoria comercial, diretoria financeira/administrativa e diretoria de produção/compras. A empresa possui uma recepcionista, quatro pessoas em cargos administrativos e os 60 funcionários restantes estão alocados no chão-de-fábrica. Trabalha-se com representantes autônomos que auxiliam na parte de vendas.

O organograma da Empresa H é estruturado da seguinte forma:

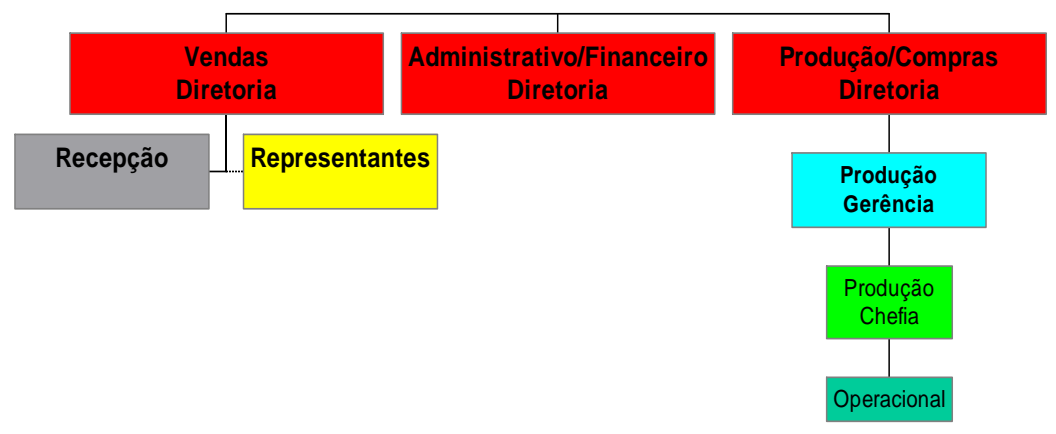

Figura 6.8: Organograma da Empresa $\mathrm{H}$

Todos os sócios da Empresa H possuem, como nível de instrução, o curso Superior Completo. Já o nível de escolaridade dos funcionários divide-se da seguinte forma: $1^{\circ}$ grau incompleto (30\%), $1^{\circ}$ grau completo (44\%), $2^{\circ}$ grau incompleto (8\%), $2^{\circ}$ grau completo (8\%), Superior Incompleto (5\%) e Superior Completo (5\%).

A Empresa H produz solados e placas de borracha de EVA (Etileno Vinil Acetato) e de borracha compacta. A média de produção de solados é de 5000 pares/dia e de placas 1000/dia.

A produção é feita quase totalmente sob encomenda. Produz-se para estoque apenas quando não há pedidos para serem processados, mas apenas com produtos que têm venda certa.

Os equipamentos que a Empresa $\mathrm{H}$ utiliza no processo produtivo podem ser classificados da seguinte forma: modernos, isto é de tecnologia de ponta (25\%); mais ou menos modernos (40\%) e obsoletos, isto é bem antigos, de tecnologia ultrapassada (35\%). O trabalho é realizado de forma semi-automática (com força motriz e operação humana) em cerca de 95\% do 
maquinário, os $5 \%$ restantes são feitos de forma manual que correspondem à atividade de embalar o produto. O processo produtivo é organizado em linhas de produção

A Empresa $\mathrm{H}$ utiliza computadores apenas no setor administrativo, não existe ligação em rede entre computadores. Os controles de produção: estoque, recebimento de matéria-prima, expedição etc. são feitos de forma manual e depois os números são repassados para a gerência de produção. Os computadores têm acesso à Internet.

\subsubsection{Mercado e Estratégia de Atuação}

A Empresa $\mathrm{H}$ atua em vários estados brasileiros. Cerca de $15 \%$ dos produtos são destinados para a cidade de Franca e região e os demais 65\% estão distribuídos entre os estados de Minas Gerais, Goiás, Paraná e Rio Grande do Sul.

Os principais clientes da Empresa H são: Calçados Sândalo, Calçados Alberto e J. J. Vitine, empresas de grande porte, localizadas em Franca - SP.

A Empresa $\mathrm{H}$ tem como principais fornecedores as seguintes empresas: Rhodia - S/A, empresa de grande porte, localizada no Rio de Janeiro -RJ, fornecedora de produtos químicos; Monte Cristo Plásticos Ltda, empresa de grande porte, localizada em Claraval - MG, fornecedora de EVA e; Quimar, empresa de grande porte, localizada em Diadema - SP, fornecedora de óxido de ferro. A empresa trabalha com fornecedores que concorrem entre si, principalmente os que produzem EVA e sílica, conseguindo muitas vezes obter preços menores na compra de matériaprima.

O mercado em que a Empresa $\mathrm{H}$ atua é bastante competitivo, sendo os principais concorrentes as empresas Amazonas S.A; MSM e Amapá do Sul, todas de grande porte, sendo as duas primeiras localizadas em Franca - SP e a última localizada em Novo Hamburgo - RS.

A Empresa $\mathrm{H}$ utiliza como estratégia de atuação a de custos, primando muito pela qualidade do produto, sempre no mesmo padrão, e também pela entrega de seus produtos sempre dentro do prazo combinado com o cliente.

O investimento em propaganda da Empresa $\mathrm{H}$ é baixo, destinado apenas a anúncios em revistas e jornais especializados, distribuídos nas indústrias e lojas do setor calçadista.

\subsubsection{Recursos Humanos}

A Empresa $\mathrm{H}$ remunera os seus funcionários com um valor igual ao das outras empresas do ramo. O único benefício que oferece aos funcionários são cestas básicas, mas de forma esporádica. 
A Empresa $\mathrm{H}$ investe em treinamentos para as pessoas que trabalham em cargos administrativos, gerência e diretoria, que participam de cursos e palestras frequentemente. O nível operacional não participa de treinamentos técnicos, a não ser quando chega algum equipamento novo na empresa. O treinamento de CIPA (Comissão Interna de Prevenção de Acidentes) é praticamente o único oferecido aos funcionários.

A contratação, quando necessária é feita através de anúncio (placa de aviso) na porta da empresa . A seleção é feita a partir de entrevista, com o gerente de produção. Caso a pessoa seja selecionada é feito um teste de três dias e se a pessoa for aprovada ela é contratada temporariamente por um mês. Após esse prazo a pessoa é contratada ou mandada embora.

A rotatividade de funcionários na Empresa $\mathrm{H}$ é alta por problemas de sazonalidade enfrentados pelo setor, que sofre queda de produção no mês de dezembro, voltando a ter incremento por volta do mês de março. Em se tratando de absenteísmo, o número de faltas é irrisório, não chegando a prejudicar a produção.

\subsubsection{Situação Financeira}

O faturamento da Empresa H não sofreu muita variação de 1997 a 2000, apresentando os seguintes valores nesses anos, respectivamente: R\$ 3.000.000,00; R\$ 3.100.000,00; R\$ 3.100.000,000 e R\$3.200.000,00.

A Empresa $\mathrm{H}$ possui problemas com inadimplência, chegando a representar $5 \%$ do valor das vendas e chega a possuir falta de capital de giro em épocas de vendas baixas (períodos sazonais).

\subsubsection{EMPRESA I}

\subsubsection{Histórico}

A Empresa I foi fundada no início de 1985, por dois sócios, iniciando com a produção de calçados masculinos de linha jovem.

O crescimento da Empresa I foi acontecendo aos poucos e esta foi diversificando os seus produtos. Atualmente os calçados masculinos de linha jovem continuam a ser produzidos, mas produz-se também sapatos masculinos sociais.

No ano de 1985 a Empresa I atingiu uma produção de 120 pares/dia, sendo que no ano de 1999 a produção chegou ao número de 1200 pares/dia. Porém, devido à crise energética que atinge o país, afetando diretamente a indústria, houve em junho de 2001 uma grande demissão 
de funcionários e uma queda brusca na produção. Dos 64 funcionários que a Empresa I possuía restaram 38 e a produção caiu pela metade, passando a ser de 600 pares/dia.

A Empresa I, que trabalhava apenas com produção para outras marcas através de licenciamento, lançou sua própria marca em novembro de 2001, sendo seu objetivo principal em 2002 realizar altos investimentos em propaganda para fortalecê-la.

\subsubsection{Estrutura}

A Empresa I classifica-se como de pequeno porte, sendo composta por 38 funcionários e mais 2 sócios. Apenas um dos sócios é atuante, ocupando o cargo de diretor geral. A Empresa I possui cinco funcionários que ocupam as seguintes gerências: administrativa; planejamento; compras; financeira e de produção; uma recepcionista e um contador. Os 31 funcionários restantes ocupam cargos operacionais (chão de fábrica).

O organograma da Empresa I é estruturado da seguinte forma:

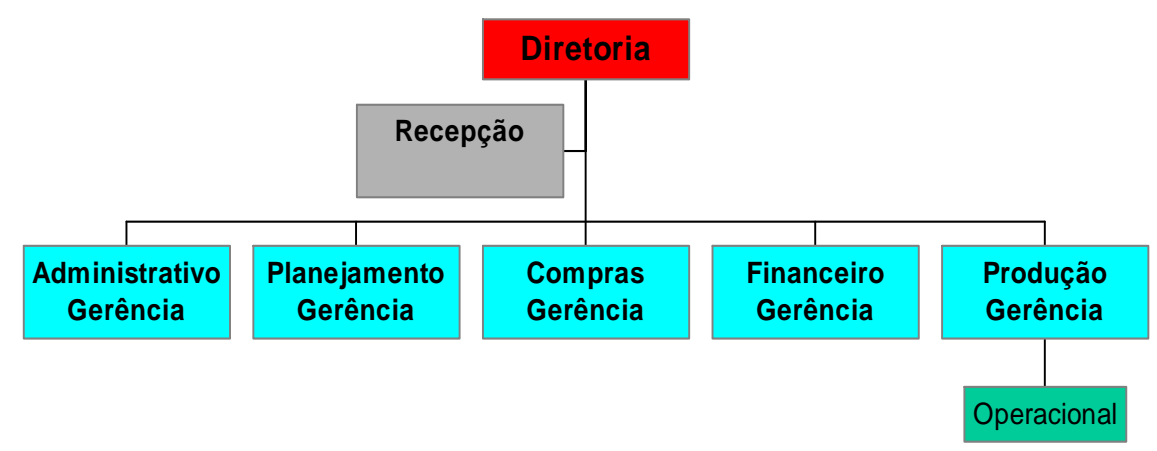

Figura 6.9: Organograma da Empresa I

O sócio que atua na Empresa I possui como grau de instrução o Superior Completo. Já nível de escolaridade dos funcionários divide-se da seguinte forma: $1^{\circ}$ grau incompleto (60\%), $1^{\circ}$ grau completo (20\%), $2^{\circ}$ grau completo (10\%) e Superior Completo (10\%).

A Empresa I produz apenas calçados masculinos, sendo cerca de 25 modelos diferentes entre uma coleção e outra. A média de produção é de 500 pares/dia. A produção é feita apenas sob encomenda.

Os equipamentos que a Empresa I utiliza no processo produtivo podem ser classificados da seguinte forma: modernos, isto é de tecnologia de ponta (40\%); mais ou menos modernos (60\%). O trabalho é realizado de forma semi-automática em sua totalidade, isto é com força- 
motriz e operação humana em $100 \%$ do processo produtivo, que é organizado em linhas de produção.

A Empresa I trabalha com representantes autônomos que auxiliam na parte de vendas, e terceiriza as atividades de pesponto, bordado e pré-fezado do calçado.

A Empresa I é informatizada, os equipamentos são ligados em rede e têm acesso à Internet. Adota-se um aplicativo da empresa EXTRO que realiza controles desde recebimento e estoque de matéria-prima até de devoluções, financeiro, departamento pessoal, entre outros.

\subsubsection{Mercado e Estratégia de Atuação}

A Empresa I atua em vários estados brasileiros, não atingindo o mercado regional. Cerca de $80 \%$ da produção é destinada ao mercado nacional, sobretudo aos estados do Rio de Janeiro, Minas Gerais, São Paulo e Rio Grande do sul; e 20\% da produção é destinada ao mercado internacional - Estados Unidos.

Os principais clientes da Empresa I são: Redley, empresa de grande porte, localizada no Rio de Janeiro - RJ; Mr. Cat, empresa de grande porte, localizada no Rio de Janeiro - RJ e; Ocean Pacific, empresa de grande porte que atua com lojas franqueadas em todo o país.

A Empresa I tem como principais fornecedores as seguintes empresas: Amazonas S/A, empresa de grande porte, localizada em Franca - SP, fornecedora de solado e cola; Quimifran, empresa de médio porte, localizada em Franca - SP; fornecedora de couro e; Cartonagem São Luiz, empresa de médio porte, localizada em Franca - SP, fornecedora de caixas. A Empresa I adquire produtos de fornecedores concorrentes, conseguindo muitas vezes obter preços menores na compra de matéria-prima.

O mercado em que a Empresa I atua é bastante competitivo, sendo os principais concorrentes as empresas Free Way, empresa de grande porte, localizada em Franca - SP e; Lui Lui, empresa de grande porte, localizada em São Paulo - SP.

A Empresa I adota como estratégia de atuação a diferenciação de produtos, mas também procura trabalhar com produtos com preços mais baixos que os da concorrência.

O investimento em propaganda feito pela Empresa I é destinado a anúncios em revistas do ramo, outdoor e página na Internet. 


\subsubsection{Recursos Humanos}

A Empresa I remunera os seus funcionários com um valor igual ao das outras empresas do ramo. O único benefício que oferece aos funcionários são cestas básicas, com distribuição vinculada ao índice de faltas.

A Empresa I investe em treinamentos para as pessoas que trabalham em cargos administrativos, gerência e diretoria, que participam de cursos e palestras. O nível operacional não participa de treinamentos técnicos, a não ser quando chega algum equipamento novo na empresa.

A contratação, quando necessária é feita via sindicato ou agência de emprego. Após a seleção é feito um contrato temporário e se a pessoa desempenhar bem as atividades do cargo, faz-se a contratação efetiva.

A rotatividade da Empresa I é baixa e o absenteísmo ocorre com um certa freqüência, principalmente com o pessoal com menos tempo de casa, chegando a ocorrer duas ou três faltas de funcionário por semana.

\subsubsection{Situação Financeira}

O faturamento da Empresa I nos anos de 1998 a 2000 apresentou os seguintes números, respectivamente: $\mathrm{R} \$$ 1.900.000,00; $\mathrm{R} \$ 2.500 .000,00$ e $\mathrm{R} \$ 3.000 .000,00$.

A empresa não enfrenta problemas com inadimplência, mas as vezes há falta de capital de giro, chegando a empresa a utilizar recursos de terceiros (empréstimo bancário).

\subsubsection{EMPRESA J}

\subsubsection{Histórico}

A Empresa J, de estrutura familiar, foi fundada no início em 01/04/74 por dois sócios, visando a produção de solados de couro e borracha.

A empresa J foi crescendo gradativamente e chegou a produzir calçados mas há cerca de um ano voltou a produzir apenas solados, que são em sua grande maioria destinados a uma outra empresa, produtora de calçados, pertencente à mesma família

A empresa busca fortalecer a sua produção, continuando com o objetivo de se fazer uma grande produtora de componentes para calçados. 


\subsubsection{Estrutura}

A Empresa J classifica-se como de pequeno porte, sendo composta por 85 funcionários e mais 2 sócios. Os dois sócios atuam na empresa compondo o conselho diretor dessa. Um dos sócios concentra-se mais na área de finanças e o outro nas áreas de vendas e qualidade. A Empresa $\mathrm{J}$ possui quatro funcionários em cargos de chefia, cinco funcionários em cargos administrativos e 76 no operacional.

O organograma da Empresa J é estruturado da seguinte forma:

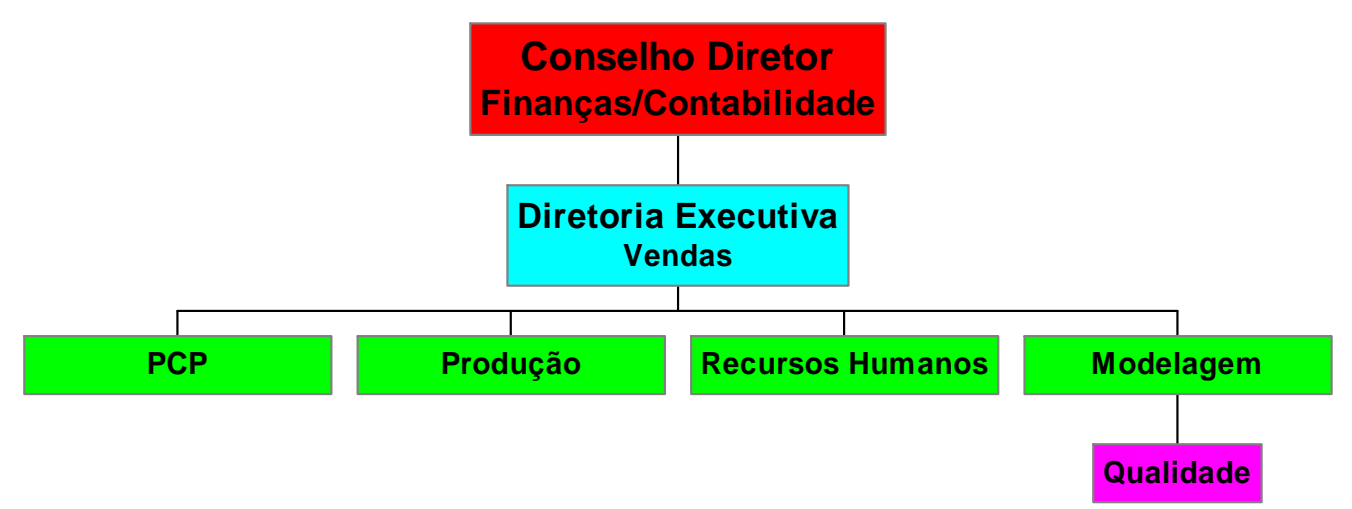

Figura 6.10: Organograma da Empresa J

Os sócios da Empresa J possuem como grau de instrução o Superior Completo. Já o nível de escolaridade dos funcionários divide-se da seguinte forma: $1^{\circ}$ grau completo (95\%), $2^{\circ}$ grau completo (3,5\%) e Superior Incompleto (1,5\%).

A Empresa J produz solados de couro e borracha e, em menor quantidade, saltos de madeira. Outra atividade que a empresa realiza é a pintura de sola. A produção é feita apenas sob encomenda.

Os equipamentos que a Empresa I utiliza no processo produtivo podem ser classificados em sua totalidade como mais ou menos modernos, sendo operados de forma semi-automática. O layout é organizado em linhas de produção.

A Empresa J terceiriza apenas a atividade de injeção de solados.

A Empresa $\mathrm{J}$ é informatizada, os equipamentos são ligados em rede e têm acesso à Internet. A empresa utiliza aplicativos para realização de controles gerenciais. 


\subsubsection{Mercado e Estratégia de Atuação}

A Empresa $\mathrm{J}$ atua no mercado regional, na cidade de Franca e exporta uma pequena parte da produção para os Estados Unidos (5\%).

Os principais clientes da Empresa J são: Sândalo, empresa de grande porte, localizada em Franca - SP e Bass, empresa de grande porte, localizada nos Estados Unidos.

A Empresa J tem como principais fornecedores as seguintes empresas: Curtuma Bamak S/A, empresa de grande porte, localizada em Santa Catarina, fornecedora de couros e Amazonas S/A, empresa de grande porte, localizada em Franca - SP,

O mercado em que a Empresa $\mathrm{J}$ atua é bastante competitivo, existindo vários concorrentes, a maioria empresas de grande porte, localizados tanto no mercado interno, principalmente no estado do Rio Grande do Sul e nas cidades de Birigui e Jaú; e no mercado externo, principalmente na Itália e Espanha.

A Empresa $\mathrm{J}$ trabalha com produtos padronizados para cada cliente, cada um exige um solado diferente, e adota como estratégia de atuação o enfoque em custos.

\subsubsection{Recursos Humanos}

A Empresa $\mathrm{J}$ remunera os seus funcionários com um valor igual ao das outras empresas do ramo. Os benefícios que oferece aos funcionários são: cesta básica, assistência médica e remuneração complementar vinculada à produtividade

Está sendo montado, por três psicólogos e um assistente, uma programação de treinamentos, a ser aplicado em toda a empresa.

A rotatividade da Empresa J é baixa (2\%), ficando abaixo do índice normal da Organização Internacional do Trabalho, que é de 3\%.

\subsubsection{Situação Financeira}

O faturamento da Empresa J apresentou uma queda de 1997 para 1998, apresentando um leve crescimento em 1999 e um maior crescimento em 2000. Os valores atingidos1997 a 2000 foram os seguintes, respectivamente: $\mathrm{R} \$$ 8.383.193,00; $\mathrm{R} \$$ 6.827.396,00; $\mathrm{R} \$$ 6.942.234,00 e R\$ 8.069.267,00.

A empresa não enfrenta problemas com inadimplência, mas as vezes há falta de capital de giro, o que não chega a prejudicar o funcionamento e produtividade da empresa. 
A tabela a seguir mostra as principais características das empresas descritas anteriormente:

Tabela 6.1: Características das empresas pesquisadas

\begin{tabular}{|c|c|c|c|c|c|}
\hline$\underbrace{\text { Características }}_{\text {Empresas }}$ & $\begin{array}{l}\text { Data de } \\
\text { Fundação }\end{array}$ & $\begin{array}{l}\text { Número de } \\
\text { Funcionários }\end{array}$ & $\begin{array}{l}\text { Número de } \\
\text { Sócios }\end{array}$ & Produto & $\begin{array}{l}\text { Mercado de } \\
\text { Atuação }\end{array}$ \\
\hline A & 1987 & 20 & 2 & $\begin{array}{l}\text { Calçados } \\
\text { masculinos, } \\
\text { femininos e } \\
\text { infantis }\end{array}$ & Nacional \\
\hline B & 1989 & 32 & $\begin{array}{l}\text { Firma } \\
\text { Individual }\end{array}$ & $\begin{array}{l}\text { Calçados } \\
\text { masculinos } \\
\text { adulto } \\
\text { infantil } \\
\end{array}$ & $\begin{array}{l}\text { Franca } \\
\text { Região }\end{array}$ \\
\hline $\mathbf{C}$ & 1993 & 66 & 2 & $\begin{array}{l}\text { Palmilhas, } \\
\text { protetores } \\
\text { para os pés e } \\
\text { brinquedos } \\
\text { pedagógicos }\end{array}$ & Nacional \\
\hline $\mathbf{D}$ & 1976 & 63 & 2 & Palmilhas & Franca \\
\hline $\mathbf{E}$ & 1998 & 75 & 2 & $\begin{array}{l}\text { Borracha para } \\
\text { a indústria de } \\
\text { calçados }\end{array}$ & $\begin{array}{l}\text { São Paulo e } \\
\text { Minas Gerais }\end{array}$ \\
\hline $\mathbf{F}$ & 1988 & 73 & 2 & $\begin{array}{l}\text { Calçados } \\
\text { masculinos }\end{array}$ & Nacional \\
\hline G & 1989 & 28 & 2 & $\begin{array}{l}\text { Caçados } \\
\text { masculinos }\end{array}$ & Nacional \\
\hline $\mathbf{H}$ & 1998 & 65 & 3 & $\begin{array}{lr}\text { Solados } & \text { e } \\
\text { placas } & \text { de } \\
\text { borracha } & \\
\end{array}$ & Nacional \\
\hline $\mathbf{I}$ & 1985 & 38 & 2 & $\begin{array}{l}\text { Calçados } \\
\text { masculinos } \\
\end{array}$ & Nacional \\
\hline $\mathbf{J}$ & 1974 & 85 & 2 & $\begin{array}{lr}\text { Solados } & \text { de } \\
\text { couro } & \mathrm{e} \\
\text { borracha } & \\
\end{array}$ & Franca e EUA \\
\hline
\end{tabular}

Fonte: Elaboração Própria 


\section{CAPÍTULO 7}

\section{APRESENTAÇÃO DOS DADOS}

Os dados e informações apresentados a seguir foram coletados através de: entrevistas, com o proprietário/pessoa-chave e um funcionário de cada empresa pesquisada, participante do PSQT; e através de questionários enviados via e-mail a três consultores do Programa.

\subsection{ENTREVISTAS COM OS PROPRIETÁRIOS/PESSOAS-CHAVE}

\subsubsection{EMPRESA A}

Para coleta de dados a respeito da forma de administração da Empresa A e sobre a implantação do Programa Sebrae de Qualidade Total nessa foi realizada entrevista com o sócioproprietário da empresa, que participou do PSQT como pessoa-chave .

A Empresa A tem um estilo de gerência centralizador, em que a maioria das decisões são de responsabilidade dos sócios da empresa. O proprietário reconhece que a participação dos funcionários na tomada de decisões relevantes é considerada importante, mas na realidade é exercida muito pouco.

A empresa possui como atividade de caráter participativo o canal aberto de comunicação, sendo o fluxo de informação na empresa de cima para baixo de média difusão e de baixo para cima de baixa difusão. A diretoria e gerência da empresa consideram que a 
disseminação de informações é de média importância e coloca que não há restrições na divulgação de informações aos funcionários. Os funcionários de produção recebem informações sobre evolução de vendas, dos índices de produtividade e dos índices de qualidade.

A Empresa A iniciou a implantação do PSQT em março de 1999, terminando o em dezembro do mesmo ano.

Segundo o proprietário Qualidade Total relaciona-se principalmente a dois aspectos principais: melhoria contínua de processos e atendimento das necessidades dos clientes.

Já o Programa de Qualidade Total é tido como: uma orientação para um melhor atendimento das necessidades do cliente e o aprimoramento de processos e técnicas, sendo os objetivos principais do Programa a mudança de estrutura, atendimento e cultura da empresa, melhoria de processos e melhoria de relacionamento/ trabalho dos recursos humanos.

O empresário considera que entrou no PSQT no momento certo sendo que a dinâmica da economia, o mercado e as alterações de tecnologia os principais fatores que influenciaram a empresa a implantar o Programa, buscando através deste crescimento organizado, sobrevivência e adaptação ao mercado, satisfação do cliente e melhoria do trabalho/relacionamento dos Recursos Humanos.

Antes da implantação do PSQT a empresa fez um diagnóstico visando levantar as necessidades da empresa em relação à qualidade, verificando então a necessidade de implantação do Programa.

O proprietário entrevistado foi o principal responsável pela implantação do PSQT na empresa, sendo este e mais duas pessoas da área de produção (chefes) as pessoas-chave do Programa. Um dos participantes que foi pessoa-chave durante a implantação não trabalha mais na empresa.

Na época da implantação do Programa, fora as pessoas-chave, quinze funcionários participaram do repasse do treinamento na empresa. Desses quinze apenas sete ainda trabalham na Empresa A.

O proprietário participou de todas as reuniões do Programa, tendo um nível alto de envolvimento. As demais pessoas-chave tiveram um nível de envolvimento médio e os demais funcionários da empresa também.

A empresa procurou incentivar, utilizando recursos monetários, a participação dos funcionários no Programa. Os funcionários que se dispunham a participar das reuniões, feitas depois do expediente normal de trabalho, recebiam hora extra. Os funcionários não foram resistentes à implantação do Programa. 
No Bloco I, a responsabilidade pela qualidade foi disseminada a todos, os conceitos e princípios da qualidade foram repassados mas assimilados parcialmente pelos funcionários e a missão e a política da qualidade também foram elaborados mas disseminados parcialmente na empresa.

Durante a implantação do Programa foi elaborado como instrumento de pesquisa de satisfação do cliente a carta-resposta. A empresa obteve $40 \%$ de retorno. As sugestões enviadas pelos clientes foram analisadas e as melhores acatadas, resultando, por exemplo, na mudança de embalagem dos calçados.

A empresa estabeleceu os seguintes indicadores de desempenho: satisfação de clientes; qualidade das vendas; reclamação de clientes; produtividade da mão-de-obra e índice de treinamento de pessoal.

Em se tratando do Bloco II da empresa, D’Olho na Qualidade, todos os módulos foram implantados integralmente, havendo uma grande colaboração dos funcionários no cumprimento das atividades a eles designadas.

Já no Bloco III houve a identificação e padronização dos processos da empresa, e foram implantadas as seguintes ferramentas da qualidade: Brainstorming, 4Q1POC, Lista de Verificação; PDCA; Diagrama de Causa e Efeito e Fluxogramas. Houve dificuldade na implantação das ferramentas por falta de preparo dos funcionários o que acabava desmotivandoos a utilizá-las, pois sentiam difilcudades em compreendê-las.

Buscando verificar se houve mudanças em algumas práticas gerenciais da empresa com a implantação do PSQT levantou-se as informações mostradas na tabela 7.1.

A pesquisa de satisfação de clientes é feita através dos representantes da empresa, que têm contato direto com esses. Mas como não existe um formulário padrão o representante faz uma sondagem com os clientes de maneira informal.

O planejamento estratégico da empresa é elaborado pelos diretores (proprietários) e pelo chefe de produção.

De acordo com o proprietário os resultados alcançados com o Programa atenderam parcialmente as expectativas iniciais, sendo necessário contratar um Engenheiro de Produção para complementar o que a empresa não conseguiu desenvolver bem, que foram principalmente os tópicos relativos ao BLOCO III - melhoria de processos. 
Tabela 7.1: Mudanças nas práticas gerenciais: Empresa A

\begin{tabular}{|l|l|l|l|}
\hline \multicolumn{1}{|c|}{ Prática Gerencial Antes } & \multicolumn{1}{|c|}{ Durante } & \multicolumn{1}{|c|}{ Depois } \\
\hline $\begin{array}{l}\text { Especificação de materiais e } \\
\text { serviços comprados }\end{array}$ & Baixa utilização & Em implantação & Utiliza \\
\hline $\begin{array}{l}\text { Registro de materiais e serviços } \\
\text { comprados }\end{array}$ & Baixa utilização & Em implantação & Utiliza \\
\hline $\begin{array}{l}\text { Estabelecimento aos fornecedores } \\
\text { de critérios de aceitação de } \\
\text { produtos }\end{array}$ & Baixa utilização & Em implantação & Utiliza \\
\hline Pesquisa de Satisfação de Clientes & Muito pouco & Em implantação & Pesquisa \\
\hline $\begin{array}{l}\text { Cálculo dos Custos da Qualidade } \\
\text { Participação dos funcionários da } \\
\text { produção na solução de } \\
\text { problemas/atividades melhoria } \\
\text { produto/processo }\end{array}$ & $\begin{array}{l}\text { Participavam } \\
\text { pouco }\end{array}$ & Em implantaçaro & Calcula \\
\hline Planejamento Estratégico & $\begin{array}{l}\text { Não } \\
\text { instituído estava }\end{array}$ & Foi instituído & Está instituído \\
\hline
\end{tabular}

Fonte: Elaboração Própria

O proprietário considera que após a implantação do PSQT:

$\Rightarrow \quad$ retorno financeiro: será alcançado a longo prazo;

$\Rightarrow \quad$ qualidade do processo: índice de perdas: diminuiu; índice de retrabalho: diminuiu; custos da qualidade: diminuiu;

$\Rightarrow \quad$ qualidade do produto: reclamação dos clientes: diminuiu; devolução de produtos: diminuiu; confiança do cliente no produto: aumentou; imagem do produto no mercado: melhorou;

$\Rightarrow \quad$ funcionários: produtividade: melhorou; participação/envolvimento com a qualidade: aumentou; motivação no trabalho: aumentou; número de funcionários: aumentou;

$\Rightarrow \quad$ participação da empresa no mercado: aumentou - houve abertura de novos mercados;

$\Rightarrow \quad$ volume de vendas: aumentou;

$\Rightarrow \quad$ clientes: satisfação: aumentou; exigência com o produto/serviços: aumentou; número de clientes: aumentou.

A utilização das ferramentas da qualidade ajudaram bastante na parte de solução de problemas, mas atualmente só utiliza-se a lista de verificação.

Um outro ponto a se destacar é que com a implantação do D’Olho na Qualidade o ambiente de trabalho melhorou muito, apresentando excelente condições de: limpeza, iluminação, ausência ruídos, arejamento etc. 
Em se tratando de questões metodológicas do Programa o treinamento passado em sala de aula foi satisfatório e a adequação do o conteúdo do material utilizado às necessidades das pequenas empresas, principalmente na etapa do D’Olho, deixou a desejar porque o exemplo ilustrado nas fitas de vídeo (aplicação do D’Olho com a tripulação de um barco) é difícil de ser visualizado em uma empresa, sendo também muito cansativo.

A qualidade técnica do material utilizado, o apoio do consultor e do Sebrae foram avaliados como satisfatórios e o tempo de duração do Programa foi considerado suficiente mas distribuído de forma inadequada, sendo destinado muito tempo para a execução de alguns atividades (Bloco I), e pouco tempo para outras (Bloco III).

A empresa não repassou a metodologia/conhecimentos/informações adquiridos com o PSQT aos funcionários que foram contratados após a implantação do Programa. A cultura da empresa em relação à qualidade encontra-se em desenvolvimento, sendo que pretende-se contratar no ano de 2002 um gerente de qualidade para auxiliar a empresa a trabalhar com a Gestão da Qualidade Total.

\subsubsection{EMPRESA B}

Para coleta de dados a respeito da forma de administração e sobre a implantação do Programa Sebrae de Qualidade Total na Empresa B foi realizada entrevista com o proprietário, que participou do PSQT como pessoa-chave.

A Empresa B tem um estilo de gerência centralizadora com controle direto das atividades dos funcionários, sendo que a maioria das decisões é de responsabilidade do proprietário da empresa. O proprietário reconhece que a participação dos funcionários na tomada de decisões relevantes é importante, mas admite ter dificuldade em delegar autoridade aos funcionários, assim estes acabam participando pouco do processo de tomada de decisões da empresa.

A empresa possui como atividade de caráter participativo equipes de melhoria de processos, sendo o fluxo de informação na empresa tanto de cima para baixo como de baixo para cima de alta difusão. A gerência da empresa considera que a disseminação de informações é de elevada importância, sendo que as informações de caráter estratégico não são divulgadas aos funcionários da empresa. Os funcionários de produção recebem informações sobre evolução de vendas, dos índices de produtividade e dos índices de qualidade. 
A Empresa B iniciou a implantação do PSQT em março de 1999, terminando-a em novembro do mesmo ano. A empresa teve conhecimento do PSQT através de outra empresa, que recomendou ao proprietário da Empresa B que implantasse o Programa.

Segundo o proprietário, Qualidade Total relaciona-se principalmente a três aspectos principais: melhoria contínua de processos, atendimento às necessidades dos clientes e ausência de defeitos nos produtos.

O Programa de Qualidade Total é uma orientação para um melhor atendimento das necessidades do cliente e o aprimoramento de processos e técnicas, sendo os objetivos principais dele a mudança de estrutura, atendimento e cultura da empresa e melhoria de processos.

O empresário considera que entrou no PSQT no momento certo sendo a dinâmica da economia e o mercado os principais fatores que influenciaram a empresa a implantar o Programa, buscando através deste crescimento organizado, satisfação do cliente e melhoria do trabalho/relacionamento dos Recursos Humanos.

Antes da implantação do PSQT a empresa não realizou um diagnóstico visando levantar as necessidades da empresa em relação à qualidade.

Na Empresa B o principal responsável pela implantação do PSQT foi o gerente de produção, sendo este, o proprietário e o chefe de produção as pessoas-chave do Programa. Dos três apenas o proprietário ainda trabalha na empresa, sendo que o cargo de gerente de produção nem existe mais na empresa.

Na época da implantação do Programa, fora as pessoas-chave, vinte e três funcionários participaram do repasse do treinamento na empresa. Desses vinte e três, dezesseis ainda trabalham na Empresa B.

O proprietário participou de todas as reuniões do Programa, tendo um nível de envolvimento médio. As demais pessoas-chave, assim como os funcionários tiveram também um nível de envolvimento médio.

A empresa não fez restrições em relação ao treinamento para os funcionários de baixa escolaridade, eles participaram de todas as reuniões de repasse do PSQT na empresa, embora tenham apresentado muita dificuldade para entender partes do programa, principalmente as atividade do Bloco III.

A empresa procurou incentivar, utilizando distribuição de prêmios/brindes para funcionários que se destacaram em melhores sugestões e que demonstraram maior envolvimento. Alguns funcionários demonstraram resistência à implantação do Programa. 
No Bloco I, a responsabilidade pela qualidade foi disseminada a todos, os conceitos e princípios da qualidade foram repassados mas assimilados parcialmente pelos funcionários e a missão e a política da qualidade também foram elaborados mas disseminados parcialmente na empresa.

Durante a implantação do Programa foi elaborado como instrumento de pesquisa de satisfação do cliente a carta-resposta. A empresa obteve um retorno muito baixo o que não contribuiu para empresa em termos de sugestões de melhorias ao produto/serviço.

A empresa estabeleceu apenas alguns indicadores de desempenho, sendo eles: defeitos da produção, cumprimento dos prazos de produção e indicador de mão-de-obra.

Em se tratando do Bloco II da empresa, D’Olho, todas os módulos foram implantados integralmente, havendo uma excelente participação e colaboração dos funcionários no cumprimento das atividades a eles designadas.

Já no Bloco III houve a identificação e padronização dos processos da empresa, e foram implantadas as seguintes ferramentas da qualidade: Brainstorming; 4Q1POC; Diagrama de Causa e Efeito e Fluxogramas. Houve dificuldade na implantação das ferramentas pela complexidade de algumas delas, desmotivação dos funcionários e tempo curto para a implantação das ferramentas

Buscando verificar se houve mudanças em algumas práticas gerenciais da empresa com a implantação do PSQT levantou-se as seguintes informações:

Tabela 7.2: Mudanças nas práticas gerenciais: Empresa B

\begin{tabular}{|l|l|l|l|}
\hline \multicolumn{1}{|c|}{ Prática Gerencial } & \multicolumn{1}{|c|}{ Antes } & \multicolumn{1}{c|}{ Durante } & \multicolumn{1}{|c|}{ Depois } \\
\hline $\begin{array}{l}\text { Especificação de materiais e } \\
\text { serviços comprados }\end{array}$ & Utilizava & Utilizou & Utiliza \\
\hline $\begin{array}{l}\text { Registro de materiais e serviços } \\
\text { comprados }\end{array}$ & Utilizava & Utilizou & Utiliza \\
\hline $\begin{array}{l}\text { Estabelecimento aos fornecedores } \\
\text { de critérios de aceitação de } \\
\text { produtos }\end{array}$ & Utilizava & Utilizou & Utiliza \\
\hline Pesquisa de Satisfação de Clientes & Em implantação & Em implantação & Em implantação \\
\hline Cálculo dos Custos da Qualidade & Em implantação & Em implantação & Em implantação \\
\hline $\begin{array}{l}\text { Participação dos funcionários da } \\
\text { produção na solução de } \\
\text { problemas/atividades melhoria } \\
\text { produto/processo }\end{array}$ & Participavam & Participaram & Participam \\
\hline Planejamento Estratégico & Estava instituído & Foi instituído & Ë instituído \\
\hline
\end{tabular}

Fonte: Elaboração Própria 
A pesquisa de satisfação de clientes ainda não foi efetivamente instituída porque a empresa está fazendo um levantamento e cadastro dos clientes, buscando classificar os clientes em ordem de importância e verificando características peculiares desses.

O planejamento estratégico da empresa é elaborado apenas pelo proprietário e pelos funcionários que ocupam os cargos de nível de chefia.

De acordo com o proprietário os resultados alcançados com o Programa atenderam as expectativas iniciais, os resultados alcançados foram satisfatórios.

O proprietário considera que após a implantação do PSQT:

$\Rightarrow \quad$ retorno financeiro: será alcançado a longo prazo;

$\Rightarrow \quad$ qualidade do processo: índice de perdas: diminuiu; índice de retrabalho: não sofreu alteração; custos da qualidade: não respondeu (o custo da qualidade não foi calculado, impossibilitando uma avaliação de sua alteração);

$\Rightarrow \quad$ qualidade do produto: reclamação dos clientes: diminuiu; devolução de produtos: não sofreu alteração; confiança do cliente no produto: não sofreu alteração; imagem do produto no mercado: melhorou;

$\Rightarrow \quad$ funcionários: produtividade: não alterou; participação/envolvimento com a qualidade: aumentou; motivação no trabalho: aumentou; número de funcionários: não alterou;

$\Rightarrow \quad$ participação da empresa no mercado: aumentou - houve abertura de novos mercados;

$\Rightarrow \quad$ volume de vendas: aumentou;

$\Rightarrow \quad$ clientes: satisfação: aumentou; exigência com o produto/serviços: não alterou, número de clientes: não alterou.

A utilização das ferramentas da qualidade ajudaram na parte de solução de problemas, mas atualmente só utiliza-se o fluxograma.

A empresa procura repassar o D’Olho na empresa regularmente (uma vez ao ano pelo menos), mas acredita que o ambiente de trabalho ainda é regular devido à falta de espaço, o que dificulta a organização do material (estoque) e o arejamento do local de trabalho.

Em se tratando de questões metodológicas do Programa o treinamento passado em sala de aula foi satisfatório. Tanto a adequação do conteúdo do material utilizado às necessidades das pequenas empresas quanto a qualidade técnica do material utilizado também foram satisfatórios.

O apoio dado pelo Sebrae foi considerado ótimo e o tempo de duração do PSQT foi considerado suficiente, só fazendo uma ressalva para a parte de implantação de ferramentas que 
tinha um tempo muito curto para que os funcionários pudessem assimilar e implantá-las. O apoio do consultor foi considerado satisfatório.

A empresa não repassou a metodologia/conhecimentos/informações adquiridos com o PSQT aos funcionários que foram contratados após a implantação desse, embora reconheça que deveria repassar. A cultura da empresa em relação à qualidade encontra-se em desenvolvimento.

O proprietário sugeriu como ponto a ser melhorado no PSQT seria a questão do repasse do Programa dentro da empresa. Segundo o proprietário o consultor que deveria repassar o Programa devido a questões didáticas. O proprietário diz ter muita dificuldade em se expressar e falar em público, acreditando que isso prejudicou o aprendizado dos funcionários.

A empresa também enfrentou problemas de horário para a realização das reuniões, nem sempre todos compareciam, mostrando-se resistentes em permanecer na empresa após o horário de trabalho normal por não acharem que o treinamento era importante para o trabalho deles. Isto acabou prejudicando a assimilação do conteúdo e a participação e contribuição dos funcionários.

\subsubsection{EMPRESA C}

Para coleta de dados a respeito da forma de administração e sobre a implantação do Programa Sebrae de Qualidade Total na Empresa C foi realizada entrevista com um funcionário que participou do PSQT como pessoa-chave. O proprietário não se dispôs a dar entrevista à pesquisadora.

A Empresa C tem um estilo de gerência centralizadora, sendo que a maioria das decisões é de responsabilidade do proprietário da empresa. A participação dos funcionários na tomada decisões relevantes às vezes é exercida mas apenas em níveis gerenciais.

A empresa possui como atividade de caráter participativo equipes para soluções de problemas sendo o fluxo de informação na empresa de cima para baixo de média difusão e de baixo para cima de baixa difusão. A gerência da empresa considera que a disseminação de informações é de elevada importância, sendo que as informações de caráter estratégico não são divulgadas aos funcionários da empresa por falta de confiança nesses. Os funcionários de produção recebem informações sobre evolução dos índices de produtividade.

A Empresa C iniciou a implantação do PSQT em fevereiro de 2000, terminando em novembro do mesmo ano. A empresa teve conhecimento do PSQT através do Sebrae e também recebeu recomendações de outra empresa, que havia implantado o PSQT e obtido bons resultados. 
Segundo o entrevistado, Qualidade Total relaciona-se principalmente a dois aspectos principais: melhoria contínua de processos e ausência de defeitos nos produtos, tendo o Programa de Qualidade Total o objetivo principal de melhoria do trabalho e relacionamento dos recursos humanos da empresa.

O entrevistado considera que a empresa entrou no PSQT no momento certo sendo o mercado, muito concorrido, o principal fator que influenciou a empresa a implantar o Programa, buscando através deste crescimento organizado, sobrevivência e adaptação da empresa.

Antes da implantação do PSQT a empresa não realizou um diagnóstico visando levantar as necessidades da empresa em relação à qualidade.

Na Empresa C o principal responsável pela implantação do PSQT foi, no início, o proprietário, mas este acabou deixando a responsabilidade de coordenação e implantação do PSQT nas mãos do chefe de produção. As pessoas-chave do PSQT foram: o proprietário, o chefe de produção e o encarregado de desenvolvimento (entrevistado), no terceiro bloco o proprietário foi substituído pelo chefe de seção. Os quatro ainda trabalham na empresa.

Na época da implantação do Programa, fora as pessoas-chave, sessenta funcionários participaram do repasse do treinamento na empresa. Desses sessenta apenas trinta ainda trabalham na Empresa C.

O proprietário não participou de todas as reuniões do programa. Segundo o entrevistado o proprietário alegou estar muito ocupado com os negócios da empresa e viagens, além de estar desmotivado com o programa.

As demais pessoas-chave mostraram bastante envolvimento com o programa e os demais funcionários tiveram um nível de envolvimento médio.

A empresa não fez restrições em relação ao treinamento para os funcionários de baixa escolaridade, eles participaram de todas as reuniões de repasse do PSQT na empresa.

A empresa não reconheceu os funcionários pelas iniciativas da qualidade, apesar de ter elaborado instrumentos de recompensa como prêmios individuais e coletivos (por equipe). O entrevistado acredita que os instrumentos acabaram não sendo utilizados porque o proprietário, pelo fato de ter ficado desmotivado com o PSQT, vetou a distribuição dos prêmios e recompensas aos funcionários.

Os funcionários não foram resistentes à implantação do PSQT.

No Bloco I, a responsabilidade pela qualidade não foi disseminada a todos e sim delegada a uma equipe de trabalho. Os conceitos e princípios da qualidade foram repassados mas 
assimilados parcialmente. Já a missão e a política da qualidade foram elaboradas e disseminados por toda a empresa

Durante a implantação do Programa foi elaborado como instrumento de pesquisa de satisfação do cliente a carta-resposta. A empresa obteve um retorno muito baixo, cerca de $10 \%$, o que não contribuiu para empresa em termos de sugestões de melhorias ao produto/serviço.

A empresa estabeleceu apenas alguns indicadores de desempenho, sendo eles: satisfação de clientes, reclamação de clientes, produção média, taxa de rotatividade e índice de treinamento de pessoal.

Em se tratando do Bloco II, D’Olho na Qualidade, todas os módulos foram implantados integralmente, havendo uma excelente participação e colaboração dos funcionários no cumprimento das atividades a eles designadas. Houve um pouco de dificuldade na parte de organização pelo grande volume de trabalho, acarretando um atraso para o cumprimento da atividade.

Já no Bloco III houve a identificação e padronização dos processos da empresa, e foram implantadas as seguintes ferramentas da qualidade: Brainstorming; 4Q1POC; Diagrama de Causa e Efeito, PDCA e Gráficos. Houve dificuldade na implantação das ferramentas devido à falta de persistência e apoio dos responsáveis pelo repasse das ferramentas.

Buscando verificar se houve mudanças em algumas práticas gerenciais da empresa com a implantação do PSQT levantou-se as seguintes informações:

Tabela 7.3: Mudanças nas práticas gerenciais - Empresa C

\begin{tabular}{|l|l|l|l|}
\hline \multicolumn{1}{|c|}{ Prática Gerencial Antes } & \multicolumn{1}{|c|}{ Durante } & \multicolumn{1}{|c|}{ Depois } \\
\hline $\begin{array}{l}\text { Especificação de materiais e } \\
\text { serviços comprados }\end{array}$ & Baixa utilização & Em implantação & Em implantação \\
\hline $\begin{array}{l}\text { Registro de materiais e serviços } \\
\text { comprados }\end{array}$ & Utilizava & Utilizou & Utiliza \\
\hline $\begin{array}{l}\text { Estabelecimento aos fornecedores } \\
\text { de critérios de aceitação de } \\
\text { produtos }\end{array}$ & Não utilizava & Baixa utilização & Baixa utilização \\
\hline Pesquisa de Satisfação de Clientes & Muito pouco & Muito pouco & Muito pouco \\
\hline $\begin{array}{l}\text { Cálculo dos Custos da Qualidade } \\
\text { Participação dos funcionários da } \\
\text { produção na solução de } \\
\text { problemas/atividades melhoria } \\
\text { produto/processo participava }\end{array}$ & Em implantação & Não parcula \\
\hline $\begin{array}{l}\text { Planejamento Estratégiciparam } \\
\text { Não participam }\end{array}$ & $\begin{array}{l}\text { Não soube } \\
\text { responder }\end{array}$ & $\begin{array}{l}\text { Não } \\
\text { responder soube }\end{array}$ & $\begin{array}{l}\text { Não } \\
\text { responder }\end{array}$ \\
\hline
\end{tabular}

Fonte: Elaboração Própria 
A empresa pesquisa a satisfação do cliente de uma maneira bastante informal através dos representantes da empresa, que possuem contato direto com os clientes.

O entrevistado não soube dizer se a empresa possui um planejamento estratégico estabelecido formalmente. Segundo ele o que acontece na empresa é que o proprietário traça algumas ações estratégicas, mas as divulga muito pouco, até mesmo para os funcionários de níveis hierárquicos mais altos.

De acordo com o entrevistado, os resultados alcançados com a implantação do PSQT atenderam parcialmente as expectativas iniciais porque não foi implantado corretamente e acabou gerando uma desmotivação geral. O proprietário acreditava que o PSQT ia ser a solução dos problemas da empresa e que os resultados seriam imediatos, a expectativa que ele colocou no Programa estava além da realidade.

O entrevistado considera que após a implantação do PSQT:

$\Rightarrow \quad$ retorno financeiro: não sofreu alteração;

$\Rightarrow \quad$ qualidade do processo: índice de perdas: não sofreu alteração; índice de retrabalho: diminuiu; custos da qualidade: não respondeu (o custo da qualidade não foi calculado, impossibilitando uma avaliação de sua alteração);

$\Rightarrow \quad$ qualidade do produto: reclamação dos clientes: diminuiu; devolução de produtos: não sofreu alteração; confiança do cliente no produto: aumentou; imagem do produto no mercado: não sofreu alteração;

$\Rightarrow \quad$ funcionários: produtividade: não alterou; participação/envolvimento com a qualidade: não alterou; motivação no trabalho: aumentou; número de funcionários: diminuiu (por fatores externos/ mercado, não devido ao PSQT);

$\Rightarrow \quad$ participação da empresa no mercado: aumentou - houve abertura de novos mercados;

$\Rightarrow \quad$ volume de vendas: não alterou;

$\Rightarrow \quad$ clientes: satisfação: aumentou; exigência com o produto/serviços: aumentou de clientes: número: não soube responder

A utilização das ferramentas da qualidade ajudou na parte de solução de problemas, principalmente o Brainstorming e o Diagrama Espinha de Peixe. Atualmente a empresa ainda utiliza o Diagrama.

O ambiente de trabalho em relação à limpeza, iluminação, arejamento etc. que era regular antes da implantação do D’Olho melhorou bem, mas a empresa ainda precisa fazer alguns ajustes para que as condições de trabalho sejam excelentes, o que já está sendo 
providenciado pois a empresa está em fase de reforma de suas instalações. Segundo o entrevistado, o maior benefício que o Programa gerou para a empresa foi a parte do D’Olho, que auxiliou muito as questões de limpeza e organização.

Em se tratando de questões metodológicas do Programa, o treinamento passado em sala de aula foi ótimo e tanto a adequação do conteúdo do material utilizado às necessidades das pequenas empresas quanto a qualidade técnica do material utilizado também foram ótimos.

O apoio dado pelo Sebrae foi ótimo e o tempo de duração do PSQT suficiente para a implantação das atividades do Programa. $\mathrm{O}$ apoio do consultor foi considerado ótimo.

A empresa não repassou os conhecimento adquiridos e a metodologia do PSQT aos funcionários que foram contratados após a implantação desse. O entrevistado reconhece que isso deveria ser feito mas acredita que a empresa não vá tomar essa iniciativa pela falta de apoio do proprietário. A cultura da empresa em relação à qualidade encontra-se pouco desenvolvida e a empresa não está planejando adotar nenhuma iniciativa em prol da qualidade.

O entrevistado acredita que se tivesse havido maior empenho do proprietário, o que auxiliaria em um maior engajamento de todos no PSQT, os resultados alcançados teriam sido bem melhores.

Segundo o entrevistado, outros pontos que prejudicaram a implantação do Programa, foram: conflitos de idéias entre pessoas-chave e uma grande ansiedade do proprietário em relação aos resultados do PSQT.

Em se tratando da continuidade das ações de qualidade na empresa, o entrevistado coloca que dois fatores principais a prejudicam: alta rotatividade dos funcionários e o não repasse aos novos o que foi aprendido com o Programa. Muitas vezes o funcionário entra na empresa e só aprende a executar a tarefa, nem sabe porque está produzindo, quais os objetivos da empresa, qual a razão de executar o trabalho com qualidade, muito menos a respeito de como é importante a satisfação do cliente interno e externo. 


\subsubsection{EMPRESA D}

Para coleta de dados a respeito da forma de administração e sobre a implantação do Programa Sebrae de Qualidade Total na Empresa D foi realizada entrevista com um funcionário da empresa que participou do PSQT como pessoa-chave. O proprietário não se dispôs a dar entrevista à pesquisadora.

A Empresa D tem um estilo de gerência descentralizadora, sendo que as decisões são delegadas a todos os níveis, nas devidas proporções. A participação dos funcionários na tomada de decisões relevantes é considerada importante e é exercida na maioria das vezes.

A empresa possui como atividade de caráter participativo o canal aberto de comunicação e programas de sugestões individuais, sendo o fluxo de informação na empresa de cima para baixo de alta difusão e de baixo para cima de média difusão. A gerência da empresa considera que a disseminação de informações é de elevada importância, sendo que as informações de caráter estratégico não são divulgadas aos funcionários da empresa, pois eles não compreendem a informação. Os funcionários de produção recebem informações sobre evolução dos índices de produtividade, evolução dos índices de qualidade e desempenho de equipe.

A Empresa D iniciou a implantação do PSQT em março de 1999, terminando em dezembro do mesmo ano. A empresa teve conhecimento do Programa através do Sebrae e por recomendações de outras empresas, que haviam implantado o PSQT e obtido bons resultados.

Segundo o entrevistado, Qualidade Total relaciona-se principalmente à melhoria contínua de processos, ausência de defeitos nos produtos e atendimento às necessidades dos clientes. Já o Programa de Qualidade Total é entendido como uma orientação para atender as necessidades dos clientes e o aprimoramento de processos e técnicas, tendo como principais objetivos: a melhoria de processos, a orientação para compreensão da Gestão da Qualidade Total, a melhoria do trabalho/relacionamento dos recursos humanos e o enfoque no cliente.

O entrevistado considera que a empresa entrou no PSQT no momento certo sendo o mercado e as alterações de tecnologia os principais fatores que influenciaram a empresa a implantar o Programa, buscando através deste crescimento organizado, sobrevivência e adaptação da empresa, satisfação do cliente, compreensão e entendimento da Gestão da Qualidade Total e melhoria do trabalho/relacionamento dos recursos humanos.

Antes da implantação do PSQT a empresa realizou um diagnóstico visando levantar as necessidades da empresa em relação à qualidade. 
Na Empresa D o principal responsável pela implantação do PSQT foi o proprietário. As pessoas-chave do PSQT, além do proprietário foram o gerente de RH/finanças e o gerente de produção. Os três ainda trabalham na empresa.

O proprietário deixou de participar de duas reuniões do Programa por motivo de agenda, mas apesar disso o envolvimento dele no PSQT foi alto, assim como o envolvimento das pessoas-chave. Já os demais funcionários apresentaram um nível médio de envolvimento durante a implantação do PSQT.

A empresa não fez restrições em relação ao treinamento para os funcionários de baixa escolaridade, eles participaram de todas as reuniões de repasse do PSQT na empresa.

A empresa não reconheceu os funcionários pelas iniciativas da qualidade, nem mesmo chegou a elaborar instrumentos de recompensa/premiações etc.

Alguns funcionários, por problema de cultura, foram resistentes à implantação do PSQT.

No Bloco I, a responsabilidade pela qualidade foi disseminada a todos e os conceitos e princípios da qualidade foram repassados mas assimilados parcialmente. Já a missão e a política da qualidade foram elaborados e disseminados parcialmente.

Durante a implantação do Programa foi elaborado como instrumento de pesquisa de satisfação do cliente a carta-resposta. A empresa obteve um retorno muito baixo, o que não contribuiu para empresa em termos de sugestões de melhorias ao produto/serviço.

A empresa estabeleceu os seguintes indicadores de desempenhos: satisfação de clientes, defeitos da produção, qualidade de vendas, reclamação de clientes, cumprimento de prazos na produção, mão-de-obra, produção média, faturamento médio e índice de treinamento de pessoal. Segundo o entrevistado a empresa não viu necessidade em estabelecer indicadores financeiros.

Em se tratando do Bloco II, D’Olho na Qaulidade, todas os módulos foram implantados integralmente, gerando excelentes resultados para a empresa.

Já no Bloco III, a identificação e padronização dos processos da empresa foram parciais por dois motivos principais: falta de persistência e apoio dos responsáveis pelo repasse das ferramentas e desmotivação dos funcionários.

Em relação às ferramentas da qualidade foram implantadas as seguintes: Brainstorming; 4Q1POC e Lista de Verificação. Houve dificuldade na implantação das ferramentas devido à falta de persistência e apoio dos responsáveis pelo repasse e ao tempo curto para implantação.

Buscando verificar se houve mudanças em algumas práticas gerenciais da empresa com a implantação do PSQT levantou-se as seguintes informações: 
Tabela 7.4: Mudanças nas práticas gerenciais - Empresa D

\begin{tabular}{|l|l|l|l|}
\hline \multicolumn{1}{|c|}{ Prática Gerencial Antes } & \multicolumn{1}{|c|}{ Durante } & \multicolumn{1}{|c|}{ Depois } \\
\hline $\begin{array}{l}\text { Especificação de materiais e } \\
\text { serviços comprados }\end{array}$ & Utilizava & Utilizou & Utiliza \\
\hline $\begin{array}{l}\text { Registro de materiais e serviços } \\
\text { comprados }\end{array}$ & Baixa utilização & Baixa utilização & Em implantação \\
\hline $\begin{array}{l}\text { Estabelecimento aos fornecedores } \\
\text { de critérios de aceitação de } \\
\text { produtos }\end{array}$ & Utilizava & Utilizou & Utiliza \\
\hline Pesquisa de Satisfação de Clientes & Pesquisa & Pesquisou & Pesquisa \\
\hline $\begin{array}{l}\text { Cálculo dos Custos da Qualidade } \\
\text { Participação dos funcionários da } \\
\text { produção na solução de } \\
\text { problemas/atividades melhoria } \\
\text { produto/processo }\end{array}$ & $\begin{array}{l}\text { Participavam } \\
\text { pouco }\end{array}$ & Calcula & Carticula \\
\hline Planejamento Estratégico & $\begin{array}{l}\text { Não } \\
\text { instituído estava }\end{array}$ & Foi instituído & Éstá instituído \\
\hline
\end{tabular}

Fonte: Elaboração própria

A empresa pesquisa a satisfação do cliente de uma maneira bastante informal através dos representantes da empresa, que possuem contato direto com os clientes.

O Planejamento Estratégico da empresa é elaborado pelo diretor e a gerência da empresa.

Segundo os entrevistado, os resultados alcançados com a implantação do PSQT atenderam parcialmente as expectativas iniciais porque, é difícil repassar o conteúdo do Programa aos funcionários de forma com que eles possam compreender bem. O responsável pela implantação não tinha facilidade didática, o que acabou prejudicando o alcance de um bom resultado das tarefas/atividades do Programa.

O entrevistado considera que após a implantação do PSQT:

$\Rightarrow \quad$ retorno financeiro: será alcançado a longo prazo;

$\Rightarrow \quad$ qualidade do processo: índice de perdas: diminuiu; índice de retrabalho: diminuiu; custos da qualidade: não respondeu (o custo da qualidade não foi calculado antes da implantação do PSQT, impossibilitando uma avaliação de sua alteraçao);

$\Rightarrow \quad$ qualidade do produto: reclamação dos clientes: diminuiu; devolução de produtos: não sofreu alteração; confiança do cliente no produto: aumentou; imagem do produto no mercado: melhorou;

$\Rightarrow \quad$ funcionários: produtividade: aumentou; participação/envolvimento com a qualidade: aumentou; motivação no trabalho: aumentou; número de funcionários: aumentou; 
$\Rightarrow \quad$ participação da empresa no mercado: aumentou - houve abertura de novos mercados;

$\Rightarrow \quad$ volume de vendas: aumentou;

$\Rightarrow \quad$ clientes: satisfação: aumentou; exigência com o produto/serviços: aumentou; número de clientes: aumentou.

A utilização das ferramentas da qualidade ajudou muito a empresa na solução de problemas. Atualmente ainda utiliza-se as seguintes ferramentas: 4Q1POC, a Lista de Verificação e o Brainstorming.

O ambiente de trabalho em relação à limpeza, iluminação, arejamento etc. que era bom antes da implantação do D’Olho passou a ser excelente. Este também auxiliou muito a organização da empresa, que melhorou consideravelmente.

Em se tratando de questões metodológicas do Programa o treinamento passado em sala de aula foi ótimo e tanto a adequação do o conteúdo do material utilizado às necessidades das Pequenas Empresas quanto a qualidade técnica do material utilizado também foram ótimos.

O apoio dado pelo Sebrae foi ótimo e o tempo de duração do PSQT foi considerado suficiente para a implantação das atividades do Programa, exceto a parte de implantação das ferramentas, que teve o tempo considerado curto $\mathrm{O}$ apoio do consultor foi considerado ótimo.

A empresa não repassou a metodologia/conhecimentos/informações adquiridos com o PSQT aos funcionários que foram contratados após a implantação do Programa. A cultura da empresa em relação à qualidade encontra-se em desenvolvimento e a empresa pretende adotar algumas iniciativas em prol da qualidade através da promoção de cursos, palestras e vídeos aos funcionários, mas não há data definida para que essas iniciativas tenham início.

O entrevistado coloca como crítica ao Programa a quantidade de horas semanais destinadas ao treinamento em sala de aula, que são muito longas, chegando a ser cansativo.

Um outro ponto levantado pelo entrevistado refere-se à dificuldade em dar continuidade à Gestão da Qualidade Total após a implantação do PSQT. Segundo o entrevistado é muito difícil repassar os conhecimento adquiridos através do Programa aos novos funcionários. A empresa até chegou a propor ao Sebrae uma forma de acompanhamento do processo de implantação e manutenção da qualidade, o que acabou não acontecendo pela burocracia e o valor monetário elevado que a empresa teria que arcar. 


\subsubsection{EMPRESA E}

Para coleta de dados a respeito da forma de administração e sobre a implantação do Programa Sebrae de Qualidade Total na Empresa E foi realizada entrevista com um consultor externo da empresa, que participou do PSQT como pessoa-chave.

A Empresa E tem um estilo de gerência centralizador, em que a maioria das decisões é de responsabilidade de um dos proprietários da empresa. A participação dos funcionários na tomada de decisões relevantes não é considerada importante, sendo pouco exercida. A cultura centralizadora do proprietário impede a participação dos funcionários.

A empresa possui como atividade de caráter participativo programa de sugestões individuais. E, apesar de o proprietário ser centralizador e não permitir a participação dos funcionários nas decisões, a gerência da empresa considera que a disseminação de informações é de elevada importância. Os funcionários de produção não recebem informações sobre evolução de vendas; rentabilidade da empresa; evolução de índices de produtividade e de qualidade; desempenho de equipe, etc. Eles praticamente executam e se preocupam apenas com o próprio trabalho.

A Empresa E iniciou a implantação do PSQT em abril de 2000, terminando em janeiro de 2002.

Segundo o entrevistado, Qualidade Total relaciona-se à melhoria contínua, pela empresa, de seus processos e estrutura para atingir a qualidade quanto ao seu produto, no ambiente de trabalho e também para a comunidade, procurando satisfazer as necessidades de seus clientes.

O Programa de Qualidade Total relaciona-se principalmente à introdução/aprendizado de técnicas e ferramentas da qualidade, tendo como principal objetivo realizar mudanças na estrutura, atendimento e cultura da empresa.

O consultor considera que a empresa entrou no PSQT no momento certo sendo que a adaptação da empresa ao mercado/concorrência foi o principal fator que influenciou a empresa a implantar o Programa, buscando através deste a sua sobrevivência no mercado.

Antes da implantação do PSQT a empresa fez um diagnóstico visando levantar as necessidades da empresa em relação à qualidade, verificando então a necessidade de implantação do Programa.

O entrevistado e a sócia-proprietária da empresa, que tem menos poder decisório que o outro sócio, foram os principais responsáveis pela implantação do PSQT na empresa, juntamente com o químico responsável e o engenheiro de produção as pessoas-chave do 
Programa. Das pessoas-chave o engenheiro de produção não trabalha mais na empresa $\mathrm{Na}$ Empresa E quatro funcionários, a pedido da própria empresa ao Sebrae, participaram como pessoas-chave.

Na época da implantação do Programa, fora as pessoas-chave, setenta e quatro funcionários participaram do repasse do treinamento na empresa. Desses apenas trinta e cinco ainda trabalham na Empresa E.

O sócio-proprietário não participou das reuniões do Programa porque não achava interessante participar, não se envolvendo na implantação do PSQT. As pessoas-chave tiveram um nível alto de envolvimento e os funcionários um nível médio de envolvimento na implantação do Programa.

A empresa reconheceu os funcionários pelas iniciativas da qualidade, chegando a promover os que fizeram melhores contribuições à empresa. Apesar disso muitos funcionários foram resistentes à implantação do PSQT, pois eles já tinham opinião própria formada, não acreditando que mudá-las iria beneficiar o seu trabalho e a empresa como um todo. Todos os funcionários receberam o repasse, inclusive os de baixa escolaridade.

No Bloco I, a responsabilidade pela qualidade foi disseminada a todos, os conceitos e princípios da qualidade foram repassados mas assimilados parcialmente pelos funcionários e a missão e a política da qualidade foram elaborados e disseminados por toda a empresa.

Durante a implantação do Programa foi elaborado como instrumento de pesquisa de satisfação do cliente a carta-resposta, mas o retorno não foi significativo.

A empresa estabeleceu apenas alguns indicadores de desempenho, sendo eles: satisfação de clientes e defeitos na produção.

Em se tratando do Bloco II da empresa, D’Olho na Qualidade, todas os módulos foram implantados integralmente, havendo uma grande colaboração dos funcionários no cumprimento das atividades a eles designadas.

Já no Bloco III, a identificação e padronização dos processos da empresa foram feitos parcialmente devido à falta de persistência e apoio dos responsáveis pelo repasses, e foram implantadas as seguintes ferramentas da qualidade: Brainstorming, 4Q1POC, Diagrama de Causa e Efeito, Fluxogramas e Gráficos. Houve dificuldade na implantação das ferramentas por falta de preparo dos funcionários o que acabava desmotivando-os a utilizá-las, pois sentiam difilcudades em compreendê-las.

Buscando verificar se houve mudanças em algumas práticas gerenciais da empresa com a implantação do PSQT levantou-se as seguintes informações: 
Tabela 7.5: Mudanças nas práticas gerenciais - Empresa E

\begin{tabular}{|l|l|l|l|}
\hline \multicolumn{1}{|c|}{ Prática Gerencial Antes } & \multicolumn{1}{|c|}{ Durante } & \multicolumn{1}{|c|}{ Depois } \\
\hline $\begin{array}{l}\text { Especificação de materiais e } \\
\text { serviços comprados }\end{array}$ & Não utilizava & Baixa utilização & Baixa utilização \\
\hline $\begin{array}{l}\text { Registro de materiais e serviços } \\
\text { comprados }\end{array}$ & Utilizava & Utilizou & Utiliza \\
\hline $\begin{array}{l}\text { Estabelecimento aos fornecedores } \\
\text { de critérios de aceitação de } \\
\text { produtos }\end{array}$ & Utilizava & Utilizou & Utiliza \\
\hline Pesquisa de Satisfação de Clientes & Não pesquisava & Pesquisou & Pesquisa \\
\hline $\begin{array}{l}\text { Cálculo dos Custos da Qualidade } \\
\text { Participação dos funcionários da } \\
\text { produção na calculava } \\
\text { problemas/atividades mação de melhoria } \\
\text { produto/processo Narticipavam }\end{array}$ & Participaram & Naro calcula \\
\hline Planejamento Estratégico & $\begin{array}{l}\text { Não participam pouco } \\
\text { instituído estava }\end{array}$ & Não foi instituído & $\begin{array}{l}\text { Não } \\
\text { instituído está }\end{array}$ \\
\hline
\end{tabular}

Fonte: Elaboração Própria

A pesquisa de satisfação de clientes é feita através da aplicação de questionários com os clientes da empresa.

De acordo com o entrevistado os resultados alcançados com o Programa atenderam as expectativas iniciais, proporcionando ganhos e grande melhoria à empresa em relação à Qualidade Total.

O entrevistado considera que após a implantação do PSQT:

$\Rightarrow \quad$ retorno financeiro: aumentou o retorno financeiro da empresa;

$\Rightarrow \quad$ qualidade do processo: índice de perdas: diminuiu; índice de retrabalho: diminuiu; custos da qualidade: não sabe dizer pois não é medido;

$\Rightarrow \quad$ qualidade do produto: reclamação dos clientes: diminuiu; devolução de produtos: diminuiu; confiança do cliente no produto: não sofreu alteração; imagem do produto no mercado: não sofreu alteração;

$\Rightarrow \quad$ funcionários: produtividade: aumentou; participação/envolvimento com a qualidade: aumentou; motivação no trabalho: aumentou; número de funcionários: diminuiu (em função da economia/mercado, não devido ao Programa);

$\Rightarrow \quad$ participação da empresa no mercado: aumentou - houve abertura de novos mercados;

$\Rightarrow \quad$ volume de vendas: não alterou; 
$\Rightarrow \quad$ clientes: satisfação: aumentou; exigência com o produto/serviços: aumentou; número de clientes: não alterou

A utilização das ferramentas da qualidade enriqueceu o potencial dos gerentes para a solução de problemas. Atualmente várias ferramentas ainda são utilizadas pela empresa, sendo elas: Brainstorming, Diagrama de Causa e Efeito, Gráficos, 4Q1POC, Fluxograma, Lista de Verificação e Técnica do Grupo Nominal.

A implantação do D’Olho na Qualidade, proporcionou à empresa uma boa melhora em relação à organização, limpeza, iluminação, ausência de ruídos, arejamento etc.

Em se tratando de questões metodológicas do Programa, o treinamento passado em sala de aula foi considerado ótimo, a adequação do conteúdo do material utilizado às necessidades das pequenas empresas foi satisfatória assim como a qualidade técnica do material utilizado e o apoio do Sebrae. O tempo de duração do Programa foi suficiente para implantar todas as tarefas propostas e o apoio do consultor foi considerado ótimo.

A empresa repassa os conhecimentos adquiridos com o PSQT aos funcionários novos, o que é feito através de consultores externos. A empresa está buscando a certificação ISO 9000, sendo imprescindível que a Gestão da Qualidade Total esteja arraigada por toda a empresa, porém, segundo o entrevistado, a cultura da empresa pela qualidade ainda se encontra em desenvolvimento, podendo ser melhorada.

O entrevistado colocou como sugestão de melhoria o desenvolvimento, por parte do Sebrae, de uma melhor forma de ajudar melhor as empresas que não possuem pessoas com didática e até mesmo formação (escolaridade) para repassar e aplicar o conteúdo do PSQT.

\subsubsection{EMPRESA F}

Para coleta de dados a respeito da forma de administração e sobre a implantação do Programa Sebrae de Qualidade Total na Empresa F foi realizada entrevista com o supervisor de produção, que participou do PSQT como pessoa-chave. O proprietário da empresa não se dispôs a dar entrevista à pesquisadora.

A Empresa $\mathrm{F}$ tem um estilo de gerência descentralizadora. A participação dos funcionários na tomada de decisões é considerada importante e exercida na maioria das vezes, sendo a decisão delegada a todos os níveis, nas devidas proporções.

A empresa ainda não possui atividade de caráter participativo. O canal aberto de comunicação está em processo de implantação, assim como a divulgação de informações aos 
funcionários de produção sobre evolução das vendas, rentabilidade da empresa, evolução dos índices de qualidade e produtividade e desempenho individual/equipe.

O fluxo de informação na empresa tanto de cima para baixo como inversamente é de baixa difusão. A disseminação de informações é considerada importante pela gerência/diretoria da empresa, mas o canal de comunicação ainda é falho, o que acaba impedindo a divulgação de informações por toda a empresa.

A Empresa F iniciou a implantação do PSQT em março de 1999, terminando-a em dezembro do mesmo ano.

Segundo o entrevistado, Qualidade Total relaciona-se à melhoria contínua de processos e ao atendimento das necessidades dos clientes. Já o Programa de Qualidade Total relaciona-se principalmente à orientação para atender as necessidades dos clientes, sendo seu principal objetivo proporcionar mudanças na estrutura, atendimento e cultura da empresa.

O entrevistado considera que a empresa entrou no PSQT no momento certo sendo o mercado (exigências) o principal fator que influenciou a empresa a implantar o Programa, buscando através deste a melhoria do trabalho e relacionamento dos Recursos Humanos da Empresa e uma maior satisfação do cliente.

A empresa teve conhecimento do Programa através de recomendação de outras empresas.

Antes da implantação do PSQT a empresa fez um diagnóstico visando levantar as necessidades da empresa em relação à qualidade.

O principal responsável pela implantação do PSQT foi um dos sócios, o que tem maior participação e maior poder de decisão na empresa. Este sócio, o funcionário entrevistado ( supervisor de produção), e o gerente de produção foram as pessoas-chave do Programa. O gerente de produção não trabalha mais na empresa.

$\mathrm{Na}$ época da implantação do Programa, fora as pessoas-chave, quarenta e cinco funcionários participaram do repasse do treinamento na empresa. O entrevistado não soube dizer quantos funcionários ainda trabalham na empresa, mas disse que ao menos $20 \%$ deles já não estão mais trabalhando na empresa.

O sócio-proprietário participou de todas as reuniões do Programa tendo um alto envolvimento durante a implantação dos dois primeiros blocos. No último bloco, apesar de o proprietário e as pessoas-chave terem participado do treinamento no Sebrae quase nada foi feito na empresa devido a problemas internos (conflitos). 
O nível de envolvimento das pessoas-chave e dos funcionários, também considerando os dois primeiros blocos, foi médio. O PSQT foi repassado a todos os funcionários, incluindo os de baixa escolaridade. Os funcionários não foram resistentes à implantação do Programa.

A empresa não reconheceu os funcionários pelas iniciativas da qualidade.

No Bloco I, a responsabilidade pela qualidade foi disseminada a todos, os conceitos e princípios da qualidade foram repassados mas assimilados parcialmente pelos funcionários e a missão e a política da qualidade foram elaborados e disseminados por toda a empresa.

Durante a implantação do Programa foi elaborado como instrumento de pesquisa de satisfação do cliente a carta-resposta, mas o retorno não foi significativo.

A empresa não estabeleceu indicadores de desempenho. O treinamento no Sebrae foi feito e havia-se planejado elaborar os indicadores. Como a elaboração não foi feita no prazo estipulado no Bloco I, a empresa objetivava implantar os indicadores até a finalização do Programa, mas a descontinuidade do repasse na empresa a partir do Bloco III acabou inviabilizando tal ação.

Em se tratando do Bloco II da empresa, D’Olho na Qualidade, todas os módulos foram implantados integralmente. Antes da implantação do D’Olho na Qualidade, o ambiente de trabalho em relação à iluminação, ausência ruídos, arejamento etc. já era bom, não modificando muito. Os aspectos que apresentaram melhoras mais significativas foram em relação à organização e limpeza.

Já no Bloco III a identificação e padronização dos processos da empresa foram feitos parcialmente devido à falta de persistência e apoio dos responsáveis pelo repasse e a desmotivação dos funcionários. As ferramentas da qualidade nem chegaram a ser implantadas, portanto não são utilizadas atualmente na empresa.

Buscando verificar se houve mudanças em algumas práticas gerenciais da empresa com a implantação do PSQT levantou-se as informações mostradas na tabela 7.6.

A pesquisa de satisfação de clientes é feita através do contato direto com o cliente, que às vezes faz alguma crítica/sugestão. Não há uma pesquisa padrão, feita periodicamente através de algum instrumento específico. 
Tabela 7.6: Mudanças nas práticas gerenciais - Empresa F

\begin{tabular}{|c|c|c|c|}
\hline $\begin{array}{l}\text { Prática Gerencial } \\
\end{array}$ & Antes & Durante & Depois \\
\hline $\begin{array}{lccc}\begin{array}{l}\text { Especificação } \\
\text { serviços comprados }\end{array} & \text { materiais } & \text { e } \\
\end{array}$ & Utilizava & Utilizou & Utiliza \\
\hline $\begin{array}{l}\text { Registro de materiais e serviços } \\
\text { comprados }\end{array}$ & Utilizava & Utilizou & Utiliza \\
\hline $\begin{array}{l}\text { Estabelecimento aos fornecedores } \\
\text { de critérios de aceitação de } \\
\text { produtos }\end{array}$ & Não Utilizava & Em implantação & Em implantação \\
\hline Pesquisa de Satisfação de Clientes & Não pesquisava & Pesquisou & $\begin{array}{l}\text { Pesquisa muito } \\
\text { pouco }\end{array}$ \\
\hline Cálculo dos Custos da Qualidade & Não calculava & Em implantação & Não sabe \\
\hline $\begin{array}{l}\text { Participação dos funcionários da } \\
\text { produção na solução } \\
\text { problemas/atividades de melhoria } \\
\text { produto/processo }\end{array}$ & $\begin{array}{l}\text { Participavam } \\
\text { pouco }\end{array}$ & Participaram & Participam \\
\hline Planejamento Estratégico & \begin{tabular}{ll|} 
Não & estava \\
instituído
\end{tabular} & Foi instituído & Não sabe \\
\hline
\end{tabular}

Fonte: Elaboração Própria

De acordo com o entrevistado os resultados alcançados com o Programa atenderam parcialmente as expectativas iniciais por deficiência da empresa no gerenciamento das atividades e tarefas do PSQT. A falha não foi do Sebrae e nem do consultor, e sim da empresa.

O entrevistado considera que após a implantação do PSQT:

$\Rightarrow \quad$ retorno financeiro: aumentou o retorno financeiro da empresa;

$\Rightarrow \quad$ qualidade do processo: índice de perdas: diminuiu; índice de retrabalho: diminuiu; custos da qualidade: não sabe dizer;

$\Rightarrow \quad$ qualidade do produto: reclamação dos clientes: diminuiu; devolução de produtos: diminuiu; confiança do cliente no produto: aumentou; imagem do produto no mercado: melhorou;

$\Rightarrow \quad$ funcionários: produtividade: não alterou; participação/envolvimento com a qualidade: aumentou; motivação no trabalho: aumentou; número de funcionários: não soube responder;

$\Rightarrow \quad$ participação da empresa no mercado: aumentou - houve abertura de novos mercados;

$\Rightarrow \quad$ volume de vendas: aumentou;

$\Rightarrow \quad$ clientes: satisfação: aumentou; exigência com o produto/serviços: aumentou; número de clientes: aumentou. 
Em se tratando de questões metodológicas do Programa, o treinamento passado em sala de aula, a adequação do conteúdo do material utilizado às necessidades das pequenas empresas, a qualidade técnica do material utilizado, o apoio do Sebrae e o apoio do consultor foram considerados ótimos. O tempo de duração do Programa foi considerado muito curto para implantar todas as tarefas propostas.

A empresa não repassa os conhecimentos adquiridos com o PSQT aos funcionários novos, mas a partir do início de 2002 tem como objetivo retomar o programa, recomeçando - o desde o início. Segundo o entrevistado, a cultura da empresa em relação à qualidade se encontra em desenvolvimento, tendo muito a melhorar.

O entrevistado não colocou nenhuma crítica ou sugestão ao Programa reforçando que o conflito interno (problemas devido à negligência de funcionário) que ocorreu na empresa desestruturou completamente a implantação do PSQT, pois a empresa precisou parar com o PSQT para resolver o ocorrido: houve um problema muito grande de qualidade da produção por descuido e até mesmo desleixo do gerente de produção, que enviou produto fora dos padrões de qualidade a um importante cliente da empresa, gerando muito retrabalho, prejuízo financeiro e quase a perda do cliente.

\subsubsection{EMPRESA G}

Para coleta de dados a respeito da forma de administração e sobre a implantação do Programa Sebrae de Qualidade Total na Empresa G foi realizada entrevista pessoal com um funcionário da empresa, que participou do PSQT como pessoa-chave . O proprietário não se dispôs a dar entrevista à pesquisadora.

A Empresa G tem um estilo de gerência centralizador, em que a maioria das decisões são de responsabilidade do proprietário da empresa e dos diretores. Segundo o entrevistado, o proprietário até acredita que a participação dos funcionários na tomada de decisões seria importante, mas acaba tomando a maioria das decisões sozinho, levando em consideração as opiniões dos funcionários raramente.

A empresa possui como atividade de caráter participativo equipes de melhoria de processo. E, apesar de o proprietário ser centralizador e não permitir muito a participação dos funcionários nas decisões, a gerência da empresa considera que a disseminação de informações é de elevada importância. Os funcionários de produção recebem informações apenas sobre a evolução dos índices de qualidade da empresa. A empresa faz restrições em divulgar certas informações de caráter estratégico aos funcionários da empresa. 
O fluxo de informações na empresa de cima para baixo é considerado de alta difusão e de baixo para cima também.

A Empresa G iniciou a implantação do PSQT em janeiro de 1999, terminando-a em outubro do mesmo ano.

Segundo o entrevistado, Qualidade Total relaciona-se à melhoria contínua de processos e ao atendimento das necessidades dos clientes. Já o Programa de Qualidade Total relaciona-se principalmente à orientação para atender as necessidades do cliente, sendo os principais objetivos do Programa a melhoria de processos e o foco no cliente.

O consultor considera que a empresa entrou no PSQT até tarde demais, deveria ter implantado o PSQT antes. O mercado, muito exigente, foi o principal fator que influenciou a empresa a implantar o Programa, buscando através deste a compreensão da Gestão da Qualidade Total e a satisfação do cliente.

Antes da implantação do PSQT a empresa fez um diagnóstico visando levantar as necessidades da empresa em relação à qualidade.

O proprietário da empresa foi o principal responsável pela implantação do PSQT na empresa, sendo este, o funcionário entrevistado (diretor administrativo) e a programadora da produção as pessoas-chave do Programa. Todos eles ainda trabalham na empresa.

Na época da implantação do Programa, fora as pessoas-chave, trinta e quatro funcionários participaram do repasse do treinamento na empresa. Desses, vinte e seis ainda trabalham na Empresa G.

O proprietário participou das reuniões do PSQT tendo um alto nível de envolvimento durante a implantação do Programa. As pessoas-chave assim como os demais funcionários também tiveram um nível alto de envolvimento durante a implantação do Programa.

A empresa reconheceu os funcionários pelas iniciativas da qualidade, distribuindo prêmios e brindes aos funcionários. O entrevistado citou como exemplo a premiação da sala mais limpa no $3^{\circ}$ módulo do D’Olho na Qualidade.

A empresa enfrentou resistência de alguns funcionários em relação à implantação do PSQT, que não queriam mudar a forma de trabalho.

No Bloco I, a responsabilidade pela qualidade foi disseminada a todos, os conceitos e princípios da qualidade foram repassados e assimilados pelos funcionários e a missão e a política da qualidade foram elaboradas e disseminadas por toda a empresa. 
Durante a implantação do Programa foi elaborado como instrumento de pesquisa de satisfação do cliente a pesquisa via telefone, gerando algumas sugestões e contribuições para a empresa em relação à melhoria de seu produto/serviço.

A empresa estabeleceu os seguintes indicadores de desempenho: defeitos da produção, cumprimento de prazos na produção, mão de obra (produção) e índice de treinamento de pessoal.

Em se tratando do Bloco II da empresa, D’Olho, todas os módulos foram implantados integralmente, havendo uma grande colaboração dos funcionários no cumprimento das atividades a eles designadas.

Já no Bloco III todos os processos da empresa foram identificados e padronizados, e foram implantadas as seguintes ferramentas da qualidade: Brainstorming, 4Q1POC, Lista de Verificação, Diagrama de Causa e Efeito e Fluxogramas e Gráficos. Não houve dificuldade na implantação das ferramentas, exceto em alguns casos isolados que eram funcionários de grau de escolaridade muito baixo, não tendo assim preparo suficiente para aprender o porquê e como utilizar as ferramentas

Buscando verificar se houve mudanças em algumas práticas gerenciais da empresa com a implantação do PSQT levantou-se as seguintes informações:

Tabela 7.7: Mudanças nas práticas gerenciais - Empresa G

\begin{tabular}{|l|l|l|l|}
\hline \multicolumn{1}{|c|}{ Prática Gerencial Antes } & \multicolumn{1}{|c|}{ Durante } & \multicolumn{1}{|c|}{ Depois } \\
\hline $\begin{array}{l}\text { Especificação de materiais e } \\
\text { serviços comprados }\end{array}$ & Baixa utilização & Utilizou & Utiliza \\
\hline $\begin{array}{l}\text { Registro de materiais e serviços } \\
\text { comprados }\end{array}$ & Não utilizava & Utilizou & Utiliza \\
\hline $\begin{array}{l}\text { Estabelecimento aos fornecedores } \\
\text { de critérios de aceitação de } \\
\text { produtos }\end{array}$ & Não utilizava & Utilizou & Utiliza \\
\hline Pesquisa de Satisfação de Clientes & Não pesquisava & Pesquisou & Não pesquisa \\
\hline $\begin{array}{l}\text { Cálculo dos Custos da Qualidade } \\
\text { Participação dos funcionários da } \\
\text { produção na solução de } \\
\text { problemas/atividades melhoria } \\
\text { produto/processo participavam }\end{array}$ & Não calculou & Calcula \\
\hline Planejamento Estratégico & Participam & Paramam \\
\hline
\end{tabular}

Segundo o entrevistado, a empresa não faz uma pesquisa direta com o cliente, por acreditar não ser necessário, mas procura sempre estar a frente da concorrência, buscando 
conhecer as tendências do mercado internacional, por meio de viagens à Itália, que dita a moda do calçado masculino, e participação em feiras.

O Planejamento Estratégico da empresa é elaborado pelo proprietário, diretores e o gerente de produção.

De acordo com o entrevistado, os resultados alcançados com o Programa atenderam as expectativas iniciais, proporcionando grande melhoria à empresa em relação à Qualidade Total.

O entrevistado considera que após a implantação do PSQT:

$\Rightarrow \quad$ retorno financeiro: houve retorno financeiro para a empresa;

$\Rightarrow \quad$ qualidade do processo: índice de perdas: diminuiu; índice de retrabalho: diminuiu; custos da qualidade: não pode afirmar pois não era medido antes do programa, mas acredita que tenha diminuído;

$\Rightarrow \quad$ qualidade do produto: reclamação dos clientes: diminuiu; devolução de produtos: diminuiu; confiança do cliente no produto: aumentou; imagem do produto no mercado: melhorou;

$\Rightarrow \quad$ funcionários: produtividade: aumentou; participação/envolvimento com a qualidade: aumentou; motivação no trabalho: aumentou; número de funcionários: não alterou;

$\Rightarrow \quad$ participação da empresa no mercado: aumentou - houve abertura de novos mercados;

$\Rightarrow \quad$ volume de vendas: diminuiu (em função do mercado/economia, não devido ao PSQT);

$\Rightarrow \quad$ clientes: satisfação: aumentou; exigência com o produto/serviços: aumentou; número de clientes: não alterou.

A utilização das ferramentas da qualidade auxiliou na solução de problemas, melhorando a qualidade dos produtos. Atualmente, as únicas ferramentas utilizadas pela empresa são os Gráficos.

A implantação do D’Olho na Qualidade proporcionou à empresa uma boa melhora em relação à organização, limpeza, iluminação, ausência ruídos, arejamento etc., passando de regular a bom.

Em se tratando de questões metodológicas do Programa, o treinamento passado em sala de aula, a adequação do conteúdo do material utilizado às necessidades das Pequenas Empresas, a qualidade técnica do material utilizado e o apoio do SEBRAE foram considerados ótimos. O tempo de duração do Programa foi suficiente para implantar todas as tarefas propostas e o apoio do consultor foi considerado ótimo. 
A empresa repassa os conhecimentos adquiridos com o PSQT aos funcionários novos, inclusive está revendo o Programa na empresa. O entrevistado considera que a cultura da empresa em relação à qualidade está muito desenvolvida

O entrevistado colocou como sugestão de melhoria o fato de o SEBRAE poder oferecer às empresas uma forma, ou um novo produto que pudesse dar continuidade às ações de Gestão da Qualidade nas empresas que implantaram o Programa, melhorando o que foi aprendido com o Programa e instituindo novas atividades, técnicas e ações.

\subsubsection{EMPRESA H}

Para coleta de dados a respeito da forma de administração e sobre a implantação do Programa Sebrae de Qualidade Total na Empresa H entrevista com um dos sócios-proprietários da empresa, que participou do PSQT como pessoa-chave.

A Empresa $\mathrm{H}$ tem um estilo de gerência centralizador, em que a maioria das decisões são de responsabilidade dos proprietários da empresa. Mas, apesar de as decisões serem centradas nos proprietários às vezes leva-se em consideração as sugestões e opiniões dos funcionários antes de tomar as decisões. Segundo o entrevistado a participação de todos é importante para que todos tenham o mesmo ideal e a mesma visão das necessidades.

O fluxo de informação na empresa de cima para baixo é de média difusão e de baixo para cima de baixa difusão.

A empresa possui como atividade de caráter participativo programas de sugestões individuais e equipes de melhoria de processo. A gerência/diretoria da empresa considera a disseminação de informações de média importância. Os funcionários de produção recebem informações apenas sobre a evolução dos índices de qualidade da empresa. A empresa faz restrições em divulgar certas informações de caráter estratégico aos funcionários da empresa.

A Empresa H iniciou a implantação do PSQT em abril de 2000, teminando-a em janeiro de 2001.

Segundo o entrevistado, Qualidade Total relaciona-se à melhoria contínua de processos e ao atendimento das necessidades dos clientes. Já o Programa de Qualidade Total relaciona-se principalmente ao aprimoramento de processos e técnicas, sendo os principais objetivos de um Programa de Qualidade Total mudanças na estrutura, atendimento e cultura e a melhoria de processos da empresa. 
O entrevistado considera que a empresa entrou no PSQT no momento certo. O mercado foi o principal fator que influenciou a empresa a implantar o PSQT, buscando com o Programa a sobrevivência e adaptação da empresa.

Antes da implantação do PSQT a empresa não fez um diagnóstico visando levantar as necessidades da empresa em relação à qualidade.

O principal responsável pela implantação do PSQT foi o entrevistado, que é sócioproprietário. Além dele, mais dois gerentes da empresa foram as pessoas-chave do Programa. Dos gerentes apenas um ainda trabalha na Empresa $\mathrm{H}$.

Na época da implantação do Programa, fora as pessoas-chave, sessenta funcionários participaram do treinamento na empresa. Desses, apenas trinta ainda trabalham na Empresa H.

O proprietário participou das reuniões do PSQT tendo um alto nível de envolvimento durante a implantação do Programa. As pessoas-chave também tiveram um nível alto de envolvimento durante a implantação do Programa, já os funcionários tiveram um nível de envolvimento médio. Os funcionários de baixa escolaridade também participaram do repasse do PSQT na empresa.

A empresa reconheceu os funcionários pelas iniciativas da qualidade através do sorteio de brindes.

A empresa não enfrentou resistência de funcionários em relação à implantação do PSQT.

No Bloco I, a responsabilidade pela qualidade foi disseminada a todos, os conceitos e princípios da qualidade foram repassados e assimilados pelos funcionários e a missão e a política da qualidade foram elaborados e disseminados por toda a empresa.

Durante a implantação do Programa foi elaborado como instrumento de pesquisa de satisfação do cliente a carta resposta, gerando algumas sugestões e contribuições para a empresa em relação à melhoria de seu produto/serviço. Foram enviadas 500 cartas e o retorno foi de $25 \%$ delas.

A empresa não elaborou indicadores de desempenho por considerar não ser importante para a empresa estabelecê-los.

Em se tratando do Bloco II da empresa, D’Olho na Qualidade, todos os módulos foram implantados integralmente.

Já no Bloco III os processos da empresa foram identificados e padronizados parcialmente devido à falta de persistência e apoio dos responsáveis pelo repasse do PSQT na empresa e por falta de tempo dos funcionários. 
Foram implantadas as seguintes ferramentas da qualidade: Diagrama de Causa e Efeito, Fluxograma e Gráficos. Não houve dificuldade na implantação das ferramentas.

Buscando verificar se houve mudanças em algumas práticas gerenciais da empresa com a implantação do PSQT levantou-se as seguintes informações:

Tabela 7.8: Mudanças nas práticas gerenciais - Empresa $\mathrm{H}$

\begin{tabular}{|l|l|l|l|}
\hline \multicolumn{1}{|c|}{ Prática Gerencial Antes } & \multicolumn{1}{|c|}{ Durante } & \multicolumn{1}{|c|}{ Depois } \\
\hline $\begin{array}{l}\text { Especificação de materiais e } \\
\text { serviços comprados }\end{array}$ & Utilizava & Utilizou & Utiliza \\
\hline $\begin{array}{l}\text { Registro de materiais e serviços } \\
\text { comprados }\end{array}$ & Utilizava & Utilizou & Utiliza \\
\hline $\begin{array}{l}\text { Estabelecimento aos fornecedores } \\
\text { de critérios de aceitação de } \\
\text { produtos }\end{array}$ & Utilizava & Utilizou & Utiliza \\
\hline Pesquisa de Satisfação de Clientes & Muito Pouco & Muito pouco & Pesquisa \\
\hline Cálculo dos Custos da Qualidade & Calculava & Calculou & Calcula \\
\hline $\begin{array}{l}\text { Participação dos funcionários da } \\
\text { produção na solução de } \\
\text { problemas/atividades melhoria } \\
\text { produto/processo }\end{array}$ & $\begin{array}{l}\text { Participavam } \\
\text { pouco }\end{array}$ & $\begin{array}{l}\text { Participaram } \\
\text { pouco }\end{array}$ & Participam pouco \\
\hline $\begin{array}{l}\text { Planejamento Estratégico } \\
\text { Nanostá } \\
\text { instituído estava }\end{array}$ & Não foi instituído & $\begin{array}{l}\text { Não } \\
\text { instituído }\end{array}$ \\
\hline
\end{tabular}

Fonte: Elaboração Própria

Segundo o entrevistado a empresa faz pesquisa com o cliente através do contato direto com os representantes que procuram levantar informações sobre a satisfação e as necessidades dos clientes de maneira informal.

Já em relação ao Planejamento Estratégico, o entrevistado diz que a empresa não possui um planejamento formal, fazendo o seguinte comentário “as ações da empresa são estabelecidas de acordo com a vivência da empresa, com o que aconteceu no passado".

De acordo com o entrevistado, os resultados alcançados com o Programa atenderam parcialmente as expectativas iniciais, mas isso ocorreu, segundo o entrevistado, devido à dificuldades próprias da empresa, não atingindo assim o desejado. $\mathrm{O}$ entrevistado ainda coloca que durante a implantação do PSQT houve uma mudança na diretoria da empresa e o ingresso de dois novos diretores que acabaram não participando do Programa pois não viam importância em estar implantando a Qualidade Total, o que acabou prejudicando os resultados porque os funcionários subordinados a estes diretores não recebiam apoio para se dedicar às tarefas e atividades do PSQT. 
O entrevistado considera que após a implantação do PSQT:

$\Rightarrow \quad$ retorno financeiro: não sofreu alteração;

$\Rightarrow \quad$ qualidade do processo: índice de perdas: diminuiu; índice de retrabalho: diminuiu; custos da qualidade: não sofreu alteração;

$\Rightarrow \quad$ qualidade do produto: reclamação dos clientes: diminuiu; devolução de produtos: diminuiu; confiança do cliente no produto: não sofreu alteração; imagem do produto no mercado: melhorou;

$\Rightarrow \quad$ funcionários: produtividade: aumentou; participação/envolvimento com a qualidade: aumentou; motivação no trabalho: não alterou; número de funcionários: diminuiu;

$\Rightarrow \quad$ participação da empresa no mercado: não alterou - não houve abertura de novos mercados;

$\Rightarrow \quad$ volume de vendas: não alterou ;

$\Rightarrow \quad$ clientes: satisfação: aumentou; exigência com o produto/serviços: não alterou; número de clientes: não alterou.

Segundo o entrevistado a empresa não conseguiu visualizar benefícios com a utilização das ferramentas da qualidade que foram implantadas durante o PSQT, não utilizando-as atualmente. O entrevistado ainda coloca que o motivo de não estar utilizando as ferramentas, assim como a maioria do conteúdo do PSQT é que a empresa está em fase de reestruturação organizacional.

A implantação do D’Olho na qualidade contribuiu muito para a organização da empresa, principalmente em se tratando da identificação de arquivos pessoais, materiais de uso comum, identificação e organização de material estocado etc. Em se tratando das questões de limpeza, arejamento e ruído, consideradas como regulares pelo entrevistado, antes da implantação do PSQT, não sofreram alteração, precisando ainda ser melhoradas.

Em se tratando de questões metodológicas do Programa, o treinamento passado em sala de aula, a adequação do o conteúdo do material utilizado às necessidades das pequenas empresas, a qualidade técnica do material utilizado e o apoio do SEBRAE foram considerados ótimos. O tempo de duração do Programa foi suficiente para implantar todas as tarefas propostas e o apoio do consultor foi considerado ótimo.

A empresa não repassa os conhecimentos adquiridos com o PSQT aos funcionários novos, mas pretende adotar, sem data programada, uma política de repasse do conhecimento 
adquirido com o PSQT aos novos funcionários. O entrevistado considera que a cultura da empresa em relação à qualidade está pouco desenvolvida

O entrevistado não fez nenhuma crítica ou sugestão de melhoria ao PSQT.

\subsubsection{EMPRESA I}

Para coleta de dados a respeito da forma de administração e sobre a implantação do Programa Sebrae de Qualidade Total na Empresa I foi realizada entrevista pessoal com um dos gerentes da empresa, que participou do PSQT como pessoa-chave. O proprietário não concedeu entrevista à pesquisadora porque não participou da implantação do PSQT na empresa.

A Empresa I tem um estilo de gerência descentralizador, em que a participação dos funcionários na tomada de decisões relevantes é considerada importante sendo exercida na maioria das decisões. Na Empresa I a decisão é delegada a todos os níveis, nas devidas proporções.

O fluxo de informação na empresa de cima para baixo é de alta difusão e de baixo para cima de média difusão.

Atualmente a empresa não possui atividades de caráter participativo. Na época da implantação do PSQT foram estabelecidos programas de sugestões individuais, mas depois acabaram sendo deixados de lado.

A gerência/diretoria da empresa considera a disseminação de informações de elevada importância. Os funcionários de produção recebem informações apenas sobre a evolução dos índices de produtividade da empresa. A empresa faz restrições em divulgar certas informações de caráter estratégico aos funcionários.

A Empresa I iniciou a implantação do PSQT em fevereiro de 2000, terminando-a em dezembro do mesmo ano.

Segundo o entrevistado, Qualidade Total relaciona-se à melhoria contínua de processos e o Programa de Qualidade Total relaciona-se principalmente à introdução/aprendizado de técnicas e ferramentas da qualidade. O entrevistado considera que o principal objetivo de um Programa de Qualidade Total é a realização de mudanças na estrutura, atendimento e cultura da empresa.

O entrevistado considera que a empresa entrou no PSQT no momento errado pois a empresa estava realizando algumas mudanças em seus produtos e logo que terminou o Programa entrou na crise que está enfrentando atualmente, acabando por não dar continuidade às ações da qualidade. O que foi aprendido no PSQT não foi aproveitado. 
O mercado foi o principal fator que influenciou a empresa a implantar o PSQT, buscando através deste principalmente a melhoria do trabalho (ganhos de produtividade) e um melhor relacionamento dos recursos humanos da empresa. A empresa I teve conhecimento do PSQT através do Sebrae.

Antes da implantação do PSQT a empresa não fez um diagnóstico visando levantar as necessidades da empresa em relação à qualidade.

O principal responsável pela implantação do PSQT foi o encarregado de PCP (Planejamento e Controle da Produção). Além dele e do entrevistado, mais um gerente da empresa foi também pessoa-chave do programa. Todos ainda trabalham na empresa.

Na época da implantação do Programa, além das pessoas-chave, quarenta funcionários participaram do treinamento. Desses, apenas dezenove ainda trabalham na Empresa I.

O proprietário não participou das reuniões do PSQT, não se envolveu durante a implantação do Programa. A iniciativa de implantação do Programa partiu do empresário mas ele não considerava importante a sua participação na sala de aula e nos repasses à empresa.

As pessoas-chave também tiveram um nível alto de envolvimento durante a implantação do Programa, já os funcionários tiveram um nível de envolvimento médio. Os funcionários de baixa escolaridade também participaram do repasse do PSQT na empresa.

A empresa reconheceu os funcionários pelas iniciativas da qualidade através da participação nos lucros da empresa.

A empresa não enfrentou resistência de funcionários em relação à implantação do PSQT.

No Bloco I, a responsabilidade pela qualidade foi delegada a uma equipe de trabalho, que coordenava as atividades do Programa dentro da empresa. Os conceitos e princípios da qualidade foram repassados e assimilados parcialmente pelos funcionários e a missão e a política da qualidade foram elaborados e disseminados por toda a empresa.

Durante a implantação do Programa foi elaborado como instrumento de pesquisa de satisfação do cliente a carta resposta, gerando um retorno muito pequeno sem contribuir para a melhoria do produto/serviço da empresa. .

A empresa elaborou alguns indicadores de desempenho, sendo eles: satisfação de clientes, defeitos da produção e cumprimento de prazos na produção.

Em se tratando do Bloco II da empresa, D’Olho na Qualidade, todos os módulos foram implantados integralmente.

Já no Bloco III todos os processos da empresa foram identificados mas não chegaram a ser padronizados. 
Foram implantadas as seguintes ferramentas da qualidade: 4Q1POC, Diagrama de Causa e Efeito, Fluxograma e Gráficos. Houve dificuldade na implantação das ferramentas devido a dois fatores principais: tempo curto para a implantação e falta de preparo de alguns funcionários (baixa escolaridade).

Buscando verificar se houve mudanças em algumas práticas gerenciais da empresa com a implantação do PSQT levantou-se as seguintes informações:

Tabela $7 . .9$ : Mudanças nas práticas gerenciais - Empresa I

\begin{tabular}{|l|l|l|l|}
\hline \multicolumn{1}{|c|}{ Prática Gerencial Antes } & \multicolumn{1}{|c|}{ Durante } & \multicolumn{1}{|c|}{ Depois } \\
\hline $\begin{array}{l}\text { Especificação de materiais e } \\
\text { serviços comprados }\end{array}$ & Baixa utilização & Em implantação & Utiliza \\
\hline $\begin{array}{l}\text { Registro de materiais e serviços } \\
\text { comprados }\end{array}$ & Utilizava & Utilizou & Utiliza \\
\hline $\begin{array}{l}\text { Estabelecimento aos fornecedores } \\
\text { de critérios de aceitação de } \\
\text { produtos } \\
\text { Pesquisa de Satisfação de Clientes }\end{array}$ & Baixa Utilização & Em implantação & Utiliza \\
\hline $\begin{array}{l}\text { Cálculo dos Custos da Qualidade } \\
\text { Participação dos funcionários da } \\
\text { produção na solução de } \\
\text { problemas/atividades melhoria } \\
\text { produto/processo }\end{array}$ & Participavam & Muito pouco & Muito pouco \\
\hline $\begin{array}{l}\text { Planejamento Estratégico } \\
\text { Participaram }\end{array}$ & \begin{tabular}{l} 
Carcula \\
\hline instituído estava
\end{tabular} & Não foi instituído & $\begin{array}{l}\text { Não } \\
\text { instituído está }\end{array}$ \\
\hline
\end{tabular}

Fonte: Elaboração Própria

Segundo o entrevistado, a empresa faz pesquisa com o cliente através do contato direto com os representantes que procuram levantar informações sobre a satisfação e as necessidades dos clientes de maneira informal.

De acordo com o entrevistado, os resultados alcançados com o Programa atenderam parcialmente as expectativas iniciais, mas isso ocorreu, segundo o entrevistado, devido à dificuldades próprias da empresa, que entrou no PSQT no momento errado, pois no meio do Programa a empresa deixou de trabalhar com marcas de terceiros e passou a trabalhar com a marca própria e encontrou, e ainda está encontrando, dificuldades para a aceitação do produto no mercado, e o Programa no meio do Bloco III praticamente foi deixado de lado. O entrevistado considera que após a implantação do PSQT:

$\Rightarrow \quad$ retorno financeiro: não sofreu alteração; 
$\Rightarrow \quad$ qualidade do processo: índice de perdas: não sofreu alteração; índice de retrabalho: não sofreu alteração; custos da qualidade: não sofreu alteração;

$\Rightarrow \quad$ qualidade do produto: reclamação dos clientes: devolução de produtos e confiança do cliente no produto e imagem do produto no mercado: não tem como medir porque na metade da implantação a empresa a empresa passou a ter outros clientes;

$\Rightarrow \quad$ funcionários: produtividade: não sofreu alteração; participação/envolvimento com a qualidade: aumentou; motivação no trabalho: aumentou; número de funcionários: diminuiu (devido à crise enfrentada pela empresa e não ao PSQT);

$\Rightarrow \quad$ participação da empresa no mercado: não alterou; não houve abertura de novos mercados;

$\Rightarrow \quad$ volume de vendas: diminuiu (devido à crise) ;

$\Rightarrow \quad$ clientes: satisfação dos clientes e exigência dos clientes com o produto/serviços: não tem como medir devido à mudança da clientela; número de clientes: não alterou.

Segundo o entrevistado, a empresa não conseguiu visualizar benefícios com a utilização das ferramentas da qualidade porque a empresa praticamente abandonou o programa na metade do Bloco III. As pessoas-chave participaram de todas as reuniões no SEBRAE mas o repasse na empresa não foi feito integralmente. Atualmente a empresa não utiliza nenhuma ferramenta da qualidade.

A implantação do D’Olho na Qualidade contribuiu muito para a organização da empresa. Em se tratando das questões de limpeza, arejamento e ruído, mesmo antes da implantação do Programa elas já eram excelentes, permanecendo assim depois da implantação.

Em se tratando de questões metodológicas do Programa o treinamento passado em sala de aula foi considerado satisfatório, a adequação do conteúdo do material utilizado às necessidades das pequenas empresas deixou a desejar porque o conteúdo do Programa em alguns momentos, principalmente no Bloco III, é de difícil compreensão. A qualidade técnica do material utilizado foi considerada ótima e o apoio do SEBRAE satisfatório. O entrevistado avalia que o tempo de duração do PSQT foi muito curto e diz que o apoio do consultor foi ótimo.

A empresa não repassa os conhecimentos adquiridos com o PSQT aos funcionários novos, mas pretende retomar, sem data programada, o PSQT. O entrevistado considera que a cultura da empresa em relação à qualidade está em desenvolvimento.

O entrevistado não fez nenhuma crítica ou sugestão de melhoria ao PSQT. 


\subsubsection{EMPRESA $J$}

Para coleta de dados a respeito da forma de administração e sobre a implantação do Programa Sebrae de Qualidade Total na Empresa J foi realizada entrevista com um dos sóciosproprietários da empresa, que participou do PSQT como pessoa-chave.

A Empresa J tem um estilo de gerência descentralizador, em que a maioria das decisões são de responsabilidade dos proprietários da empresa mas os supervisores procuram ouvir os seus colaboradores e repassar as informações à gerência. A participação dos funcionários na tomada de decisões relevantes é considerada importante sendo às vezes exercida.

O fluxo de informação na empresa de cima para baixo é de média difusão e de baixo para cima de baixa difusão.

A empresa possui como atividade de caráter participativo programas de sugestões individuais e equipes de melhoria de processo, mas a empresa está reestruturando o sistema de comunicação da empresa buscando torná-lo mais eficiente. A gerência/diretoria da empresa considera a disseminação de informações de média importância..Os funcionários de produção recebem informações apenas sobre a evolução das vendas e a evolução dos índices de qualidade da empresa. A empresa não divulga algumas informações aos funcionários pelo fato de não compreenderem o conteúdo da informação e também pelo desinteresse de alguns funcionários em participar e ter conhecimento do que se passa na empresa.

A Empresa J iniciou a implantação do PSQT em janeiro de 1999, teminando-a em dezembro do mesmo ano.

Segundo o entrevistado, Qualidade Total relaciona-se à melhoria contínua de processos e à padronização e sistematização de processos. Já o Programa de Qualidade Total relaciona-se principalmente à introdução e aprendizado de técnicas e ferramentas da qualidade e à orientação para atender as necessidades do cliente. Os objetivos de um Programa de Qualidade Total são a mudança na estrutura, atendimento e cultura da empresa e principalmente o foco no cliente, isto é a satisfação do cliente interno e externo.

O entrevistado considera que a empresa entrou no PSQT no momento certo. O mercado foi o principal fator que influenciou a empresa a implantar o PSQT, buscando com o Programa crescimento organizado e a padronização da qualidade do produto. A empresa $\mathrm{J}$ teve conhecimento do PSQT através do Sebrae.

Antes da implantação do PSQT a empresa fez um diagnóstico visando levantar as necessidades da empresa em relação à qualidade. 
O principal responsável pela implantação do PSQT foi o entrevistado, que é sócioproprietário. Além dele, o gerente de produção e o supervisor de PCP foram as pessoas-chave do Programa. Dentre os dois últimos apenas um ainda trabalha na empresa J.

O entrevistado não soube precisar quantos funcionários foram treinados no PSQT, mas relatou que apenas cerca de um terço dos funcionários treinados ainda trabalha na empresa.

O sócio-proprietário participou de todas as reuniões do PSQT tendo um alto nível de envolvimento durante a implantação do Programa. As pessoas-chave e os demais funcionários também tiveram um nível alto de envolvimento durante a implantação do Programa.

A empresa reconheceu os funcionários pelas iniciativas da qualidade através da criação de incentivos (prêmios) à qualidade e produtividade. A empresa realizava reuniões onde eram dadas notas quanto aos níveis de qualidade e a partir daí atribuía as premiações.

A empresa enfrentou resistência de funcionários apenas no início da implantação do Programa, mas depois eles passaram a colaborar e até exigir treinamentos.

No Bloco I, a responsabilidade pela qualidade foi disseminada a todos, os conceitos e princípios da qualidade foram repassados e assimilados pelos funcionários e a missão e a política da qualidade foram elaborados e disseminados por toda a empresa.

Durante a implantação do Programa foi elaborado como instrumento de pesquisa de satisfação do cliente a carta resposta, gerando algumas sugestões e contribuições para a empresa em relação à melhoria de seu produto/serviço.

A empresa elaborou os seguintes indicadores de desempenho: satisfação de clientes; defeitos da produção; cumprimento de prazos na produção; mão-de-obra; produção média; margem de contribuição e taxa de rotatividade de pessoal.

Em se tratando do Bloco II da empresa, D’Olho na Qualidade, todos os módulos foram implantados integralmente.

Já no Bloco III todos os processos da empresa foram identificados e padronizados.

Foram implantadas as seguintes ferramentas da qualidade: Brainstorming, 4Q1POC, Lista de Verificação, Diagrama de Causa e Efeito e Gráficos. Houve dificuldade na implantação das ferramentas devido à falta de persistência e apoio dos responsáveis pelo repasse, falta de preparo dos funcionários e tempo curto para implantação.

Buscando verificar se houve mudanças em algumas práticas gerenciais da empresa com a implantação do PSQT, levantou-se as seguintes informações: 
Tabela 7.10: Mudanças nas práticas gerenciais - Empresa J

\begin{tabular}{|l|l|l|l|}
\hline \multicolumn{1}{|c|}{ Prática Gerencial Antes } & \multicolumn{1}{|c|}{ Durante } & \multicolumn{1}{|c|}{ Depois } \\
\hline $\begin{array}{l}\text { Especificação de materiais e } \\
\text { serviços comprados }\end{array}$ & Utilizava & Utilizou & Utiliza \\
\hline $\begin{array}{l}\text { Registro de materiais e serviços } \\
\text { comprados }\end{array}$ & Utilizava & Utilizou & Utiliza \\
\hline $\begin{array}{l}\text { Estabelecimento aos fornecedores } \\
\text { de critérios de aceitação de } \\
\text { produtos }\end{array}$ & Utilizava & Utilizou & Utiliza \\
\hline Pesquisa de Satisfação de Clientes & Pesquisava & Pesquisou & Pesquisa \\
\hline $\begin{array}{l}\text { Cálculo dos Custos da Qualidade } \\
\text { Participação dos funcionários da } \\
\text { produção na solução de } \\
\text { problemas/atividades melhoria } \\
\text { produto/processo }\end{array}$ & $\begin{array}{l}\text { Participavam } \\
\text { pouco }\end{array}$ & Calculou & Calcula \\
\hline Planejamento Estratégico & $\begin{array}{l}\text { Não } \\
\text { instituído estava }\end{array}$ & Participam \\
\hline
\end{tabular}

Fonte: Elaboração Própria

Segundo o entrevistado, a empresa faz pesquisa direto com o cliente em sua produção, uma vez que destina o seu produto praticamente a uma única empresa.

Já em relação ao Planejamento Estratégico, o entrevistado diz que ele é elaborado pelos proprietários, diretoria e pelos líderes de todos os setores da empresa.

De acordo com o entrevistado, os resultados alcançados com o Programa atenderam totalmente as expectativas iniciais.

O entrevistado considera que após a implantação do PSQT:

$\Rightarrow \quad$ retorno financeiro: será a longo prazo;

$\Rightarrow \quad$ qualidade do processo: índice de perdas: diminuiu; índice de retrabalho: diminuiu; custos da qualidade: diminuiu;

$\Rightarrow \quad$ qualidade do produto: reclamação dos clientes: diminuiu; devolução de produtos: diminuiu; confiança do cliente no produto: aumentou; imagem do produto no mercado: melhorou;

$\Rightarrow \quad$ funcionários: produtividade: aumentou; participação/envolvimento com a qualidade: aumentou; motivação no trabalho: aumentou; número de funcionários: diminuiu (não devido ao PSQT mas pela reestruturação que foi feita na empresa);

$\Rightarrow \quad$ participação da empresa no mercado: não alterou - não houve abertura de novos mercados;

$\Rightarrow \quad$ volume de vendas: não soube responder ; 
$\Rightarrow \quad$ clientes: satisfação: aumentou; exigência com o produto/serviços: aumentou; número de clientes: não alterou.

Segundo o entrevistado a utilização de ferramentas da qualidade gerou como principal benefício para a empresa o auxílio para encontrar-se as causas dos problemas na produção, diminuindo a ocorrência desses. A empresa ainda utiliza todas as ferramentas da qualidade que implantou no PSQT.

A implantação do D’Olho na Qualidade contribuiu muito para a organização da empresa e também para a melhoria das condições de limpeza, arejamento e ruído, que passaram de boas, antes da implantação do PSQT, para excelentes após a implantação do Programa.

Em se tratando de questões metodológicas do Programa, o treinamento passado em sala de aula, a adequação do conteúdo do material utilizado às necessidades das pequenas empresas, a qualidade técnica do material utilizado e o apoio do SEBRAE foram considerados ótimos. O tempo de duração do Programa foi suficiente para implantar todas as tarefas propostas e o apoio do consultor foi considerado ótimo.

A empresa repassa os conhecimentos adquiridos com o PSQT aos funcionários novos, inclusive no momento está reimplantando o Programa. O entrevistado considera que a cultura da empresa em relação à qualidade encontra-se em desenvolvimento.

O entrevistado não fez nenhuma crítica ao Programa, colocando que o SEBRAE não deve em hipótese alguma parar este tipo de treinamento, porém, diz ser necessário que após um tempo as turmas sejam chamadas para reuniões de avaliações e reciclagem.

\subsection{ENTREVISTAS COM FUNCIONÁRIOS TREINADOS PELO PSQT}

Para coleta de dados a respeito da implantação do PSQT nas empresas pesquisadas realizou-se entrevistas com funcionários dessas empresas que participaram do Programa como integrantes de equipe de apoio. As únicas exceções foram que na Empresa $\mathrm{H}$ o funcionário entrevistado não participou de tal equipe porque a empresa não formou equipes de apoio durante o Programa e na Empresa I não foi possível realizar a entrevista com o funcionário devido a crise que a empresa estava enfrentando na época da realização da pesquisa de campo. A Empresa I estava trabalhando com pouquíssimos funcionários e os que se encontravam na empresa não haviam participado do Programa, não havendo previsão de quando os funcionários voltariam a trabalhar normalmente. 


\subsubsection{EMPRESA A}

Para coleta de dados a respeito da implantação do PSQT na empresa A realizou-se também entrevista com um funcionário da empresa, que participou do Programa como integrante de equipe de apoio.

O funcionário entrevistado entende que a Qualidade Total enfoca principalmente a melhoria contínua de processos/serviços e o atendimento das necessidades dos clientes, e um Programa de Qualidade Total visa sobretudo o aprimoramento de processos e técnicas possibilitando uma maior agilidade na execução das atividades para fornecer respostas mais ágeis aos clientes.

O funcionário reconhece que tanto o seu próprio nível de envolvimento na implantação do PSQT como o dos proprietários foi considerado alto, sendo que a empresa reconheceu o seu trabalho, monetariamente, pelas iniciativas da qualidade.

Os conceitos e princípios da qualidade apesar de repassados foram assimilados parcialmente pelos funcionários, já a missão e a política da qualidade, cujo funcionário ajudou na elaboração foi disseminada por toda a empresa.

O funcionário coloca que a empresa não elaborou indicadores de desempenho, ou se elaborou ele não teve conhecimento disso.

O funcionário participou de todas as etapas do D’Olho na Qualidade e foi treinado também na parte de ferramentas, não tendo dificuldade em assimilá-las, embora não as utilize em suas atividades atualmente.

De uma forma geral o funcionário avalia que realizou grande parte das atividades a ele delegadas nos três Blocos, durante a implantação do Programa, considerando que o repasse dessas atividades pelas pessoas-chave foi ótimo.

O funcionário não soube responder quais foram os motivos principais pelos quais todas as atividades do PSQT não foram implantadas pela empresa.

O PSQT gerou como benefício principal para o seu trabalho uma maior preocupação em executar suas atividades com qualidade assim como uma maior preocupação com o cliente interno e externo da empresa, sendo que atualmente ele procura aplicar os conceitos e princípios da qualidade na realização de seu trabalho.

Para a empresa o funcionário considera que o maior benefício alcançado com o Programa foi que os funcionários passaram a se preocupar mais em executar as suas atividades com qualidade.

O funcionário disse não ter nenhuma crítica e/ou sugestões de melhoria ao PSQT. 


\subsubsection{EMPRESA B}

O funcionário entrevistado entende que a Qualidade Total enfoca principalmente a ausência de defeitos nos produtos e um Programa de Qualidade Total visa sobretudo a orientação para as necessidades dos clientes

O funcionário coloca que o seu nível de envolvimento na implantação do PSQT foi alto, já o do proprietário foi considerado baixo, sendo que a empresa não reconheceu o seu trabalho pelas iniciativas da qualidade.

Os conceitos e princípios da qualidade apesar de repassados foram assimilados parcialmente pelos funcionários, já a missão e a política da qualidade, cujo funcionário ajudou na elaboração foi disseminada parcialmente pela empresa.

O funcionário coloca que participou do estabelecimento de indicadores de desempenho e também de todas as etapas do D’Olho da Qualidade. O funcionário também foi treinado na parte de ferramentas, não tendo dificuldade em assimilá-las, o que não pode ser generalizado para todos os funcionários, pois segundo o entrevistado muitos deles tiveram dificuldade em aprender não só as ferramentas como também quase todo o conteúdo do Bloco III.

De uma forma geral o funcionário avalia que realizou grande parte das atividades a ele delegadas durante a implantação do Programa, considerando que o repasse dessas atividades pelas pessoas-chave deixou a desejar por ter faltado um pouco mais de empenho e garra das pessoas chave, com o passar dos dias as coisas ficavam só nas palavras, muitas atividades do PSQT não foram colocadas em prática.

O funcionário não soube responder quais foram os motivos principais pelos quais não foram implantadas todas as atividades do PSQT.

O PSQT gerou como benefício principal para o seu trabalho uma maior preocupação em executar suas atividades com qualidade assim como uma maior preocupação com o cliente interno e externo da empresa, maior conscientização do que é qualidade e uma visão mais ampla do mercado de trabalho. Atualmente o funcionário diz aplicar os conceitos e princípios da qualidade em seu trabalho. Já em se tratando das ferramentas, atualmente elas não são utilizadas pelo funcionário porque a empresa não habituou-se a utilizá-las, e se ainda utiliza alguma esta não tem relação com as atividades desempenhadas pelo funcionário.

O funcionário considera que o maior benefício alcançado para a empresa com o Programa foi que os funcionários passaram a se preocupar mais em executar as suas atividades com qualidade e a terem uma maior conscientização do que é qualidade. 
O funcionário disse não ter nenhuma crítica e/ou sugestões de melhoria ao PSQT, só fazendo o seguinte comentário: "Sobre o PSQT é uma forma de demonstrarmos o que de melhor podemos fazer para melhorar o nosso modo de vida, tanto em casa, ou na escola e principalmente no trabalho. Eu teria ficado muito satisfeita se todos na empresa tivessem aderido ao PSQT e isto tivesse partido com mais disciplina de seus principais idealizadores.”

\subsubsection{EMPRESA C}

O funcionário entrevistado entende que a Qualidade Total tem como foco principal a melhoria contínua de processos e o atendimento das necessidades dos clientes e um Programa de Qualidade Total visa sobretudo a introdução/aprendizado de técnicas e ferramentas da qualidade e a orientação para as necessidades dos clientes.

O funcionário considera que tanto o seu nível de envolvimento na implantação do PSQT como o do proprietário pode ser considerado médio.

Os conceitos e princípios da qualidade foram repassados e assimilados pelos funcionários, bem como a missão e a política da qualidade, cujo funcionário ajudou na elaboração, foram elaboradas e disseminadas por toda a empresa.

O funcionário coloca que não participou do estabelecimento de indicadores de desempenho, sendo esta tarefa realizada pelo principal responsável pela implantação do PSQT.

O entrevistado participou de todas as etapas do D’Olho da Qualidade, considerando-o muito útil para a empresa.

Já na parte de implantação de ferramentas, o entrevistado sentiu dificuldades em entender a ferramenta e sua utilização, principalmente o Diagrama Espinha de Peixe.

De uma forma geral o funcionário avalia que realizou grande parte das atividades a ele delegadas durante o Bloco I, todas as atividades do Bloco II e grande parte das atividades do Bloco III, considerando que o repasse dessas atividades pelas pessoas-chave foi satisfatório.

Segundo o entrevistado, os principais motivos pelos quais a empresa não conseguiu implantar todas as atividades do PSQT foram a metodologia do programa ser de difícil entendimento e a falta de interesse de algumas pessoas.

O PSQT gerou como benefício principal para o seu trabalho uma maior conscientização do que é qualidade e uma maior preocupação em executar suas atividades com qualidade. Atualmente o funcionário diz aplicar os conceitos e princípios da qualidade em seu trabalho, visando desempenhar bem as suas funções e assim auxiliar o trabalho coletivo, a eficiência da empresa e a sobrevivência desta no mercado. 
Já em se tratando das ferramentas, atualmente a única utilizada pelo funcionário é a Lista de Verificação.

O entrevistado considera como benefícios gerados para a empresa os seguintes: funcionários passaram a preocupar-se em executar suas atividades com qualidade; maior conscientização do que é qualidade e redução de custos.

O funcionário disse não ter nenhuma crítica e/ou sugestões de melhoria ao PSQT, só coloca o seguinte comentário: "Ë difícil às vezes envolver as pessoas no Programa porque algumas acham que não serve para nada, quando na verdade Qualidade Total é Qualidade de Vida.”

\subsubsection{EMPRESA D}

O funcionário entrevistado entende que a Qualidade Total tem como foco principal a melhoria contínua de processos, o atendimento das necessidades dos clientes e ausência de defeitos nos produtos e um Programa de Qualidade Total visa sobretudo a orientação para atender as necessidades do cliente.

O funcionário considera que tanto o seu nível de envolvimento na implantação do PSQT como o do proprietário pode ser considerado médio.

A empresa não reconheceu o trabalho do funcionário pelas iniciativas da qualidade, não estabelecendo durante o programa uma forma premiação, incentivo etc.

Os conceitos e princípios da qualidade foram repassados e assimilados pelo funcionário; a missão e a política da qualidade, cujo funcionário ajudou na elaboração foram elaboradas e disseminadas por toda a empresa.

O funcionário coloca que participou do estabelecimento de indicadores de desempenho e de todas as etapas do D’Olho na Qualidade (Bloco II).

Já na parte de implantação de ferramentas o entrevistado não sentiu dificuldades em entender e utilizar as ferramentas considerando que elas foram de fácil assimilação.

De uma forma geral o funcionário avalia que realizou grande parte das atividades a ele delegadas durante o Bloco I, poucas atividades do Bloco II e poucas atividades do Bloco III, considerando que o repasse dessas atividades pelas pessoas-chave foi satisfatório.

Segundo o entrevistado a empresa implantou todas as atividades do PSQT.

O PSQT gerou como benefícios principais para o trabalho do entrevistado os seguintes: passou a preocupar-se em executar suas atividades com qualidade; conscientização do que é qualidade e preocupação com o cliente interno/externo. Atualmente o funcionário diz aplicar os 
conceitos e princípios da qualidade em seu trabalho. Já em se tratando das ferramentas, atualmente o funcionário não as utiliza.

Em relação aos benefícios gerados para a empresa, o entrevistado considera que foram os seguintes: funcionários passaram a preocupar-se em executar suas atividades com qualidade; procupação com o cliente interno/externo e redução de custos.

O funcionário disse não ter nenhuma crítica e/ou sugestões de melhoria ao PSQT.

\subsubsection{EMPRESA E}

O funcionário entrevistado entende que a Qualidade Total engloba os seguintes itens: processos padronizados e sistematizados, melhoria contínua de processos, ausência de defeitos nos produtos e atendimento às necessidades dos clientes, sendo este o alvo principal da empresa.

Já em se tratando do que vem a ser um Programa de Qualidade Total o funcionário coloca que é a introdução, o aprendizado e o aprimoramento de processos, técnicas e ferramentas da qualidade e a orientação para atender as necessidades dos clientes.

O funcionário reconhece que tanto o seu próprio nível de envolvimento da sóciaproprietária como o seu próprio nível de envolvimento durante a implantação do PSQT foram médios. A empresa reconheceu o trabalho do funcionário pelas iniciativas da qualidade atribuindo-lhe o cargo de encarregado do setor de Informática e PCP.

Os conceitos e princípios da qualidade foram repassados e assimilados pelos funcionários e a missão e a política da qualidade, cujo funcionário não ajudou na elaboração, foram elaboradas e disseminadas por toda a empresa.

O funcionário participou da elaboração dos indicadores de desempenho, embora poucos tenham sido estabelecidos.

O funcionário participou de todas as etapas do D’Olho na Qualidade e foi treinada também na parte de ferramentas, tendo dificuldade em assimilar algumas delas. Atualmente ele não utiliza nenhuma ferramenta da qualidade em seu trabalho.

O funcionário cita um ponto que pode ter prejudicado o aprendizado e o bom resultado das utilização das ferramentas e também de outras atividades/técnicas do Programa é o fato de que muitas vezes haver omissão por parte dos funcionários, inclusive dele mesmo, de falar certas coisas sobre a empresa como medo de se prejudicarem.

De uma forma geral o funcionário avalia que realizou todas as atividades a ele delegadas no Bloco I, e grande parte das do Bloco II e Bloco III, considerando que o repasse dessas 
atividades pelas pessoas-chave foi ótimo, sendo muito bem empregadas pelas pessoas-chave, facilitando o entendimento de todos os envolvidos.

O funcionário coloca que todas as atividades do Programa foram implantadas.

O PSQT gerou como benefício principal para o seu trabalho uma maior preocupação em executar suas atividades com qualidade, uma maior preocupação com o cliente interno e externo da empresa, e uma melhor conscientização do que é qualidade. Atualmente o funcionário aplica conceitos e princípios da qualidade em seu trabalho dizendo ser uma forma de melhor entender e ajudar a empresa a crescer no mercado.

Para a empresa o funcionário considera que os benefícios alcançados com o Programa foram: os funcionários passaram a se preocupar mais em executar as suas atividades com qualidade passando a se conscientizar sobre o que é qualidade, maior preocupação com o cliente interno e externo, aumento de produtividade e redução de custos.

O funcionário não fez nenhuma crítica e/ou sugestões de melhoria ao PSQT, somente coloca que o tempo destinado à implantação do Programa deveria ser melhor aproveitado tanto pelos funcionários como pela diretoria.

\subsubsection{EMPRESA F}

O funcionário entrevistado entende que a Qualidade Total engloba principalmente os seguintes itens: melhoria contínua de processos e atendimento às necessidades dos clientes.

Já em se tratando do que vem a ser um Programa de Qualidade Total, o funcionário coloca que é uma orientação para atender as necessidades dos clientes e o aprimoramento de processos e técnicas.

O funcionário reconhece que o seu nível de envolvimento durante a implantação do PSQT foi médio, já o do proprietário foi alto. A empresa não reconheceu o trabalho do funcionário pelas iniciativas da qualidade. O Programa acabou se perdendo e a empresa não atribuiu prêmios/brindes etc. aos funcionários.

Os conceitos e princípios da qualidade foram repassados mas não foram totalmente assimilados pelo entrevistado e segundo ele, pelos funcionários de uma maneira geral. A missão e a política da qualidade foram elaboradas e disseminadas por toda a empresa e os indicadores de desempenho não foram estabelecidos.

O funcionário participou de todas as etapas do D’Olho da Qualidade. 
De uma forma geral o funcionário avalia que realizou grande parte das atividades a ele delegadas no Bloco I, todas as do Bloco II e poucas do Bloco III, mesmo porque neste último quase nada foi repassado na empresa.

$\mathrm{O}$ entrevistado considera que o repasse das atividades pelas pessoas-chave deixou a desejar porque o treinamento era repassado e esquecido, não havia um acompanhamento e incentivo desses para que as tarefas fossem cumpridas.

O principal motivo para a não implantação de todas as atividades do programa foi a falta de apoio das pessoas-chave.

O PSQT gerou como benefício principal para o trabalho do entrevistado uma maior preocupação com o cliente interno e externo e uma maior conscientização do que é qualidade. Atualmente o funcionário aplica conceitos e princípios da qualidade em seu trabalho assim como tudo o que conseguiu aprender com o PSQT, buscando um melhor desempenho de suas atividades.

Para a empresa o funcionário considera que os benefícios alcançados com o Programa foram: os funcionários passaram a se preocupar mais em executar as suas atividades com qualidade.

O funcionário coloca como sugestão ao PSQT que após a sua aplicação na empresa deveria haver um acompanhamento pelo menos durante uns seis meses de algum consultor ou pelo Sebrae para ver se o PSQT foi implantado. Caso não tenha sido, o consultor deveria nos mostrar o que não foi implantado, auxiliando-nos a corrigir as falhas. Desta forma se evitaria a perda do Programa.

\subsubsection{EMPRESA G}

O funcionário entrevistado entende que a Qualidade Total é o atendimento das necessidades do cliente, sendo o Programa de Qualidade Total uma orientação para o atendimento das necessidades do cliente.

A empresa reconheceu o trabalho do funcionário pelas iniciativas da qualidade atribuindo-lhe novas funções e responsabilidades, além de ter dado premiações/brindes pelas suas iniciativas.

Os conceitos e princípios da qualidade foram repassados e assimilados pelos funcionários e a missão e a política da qualidade, cujo funcionário não ajudou na elaboração foram elaboradas e disseminadas por toda a empresa. 
O funcionário participou da elaboração dos indicadores de desempenho, de todas as etapas do D’Olho da Qualidade e foi treinado também na parte de ferramentas, não tendo dificuldade em assimilá-las.

De uma forma geral o funcionário avalia que realizou todas as atividades a ele delegadas no Bloco I, Bloco II e Bloco III, considerando que o repasse dessas atividades pelas pessoaschave foi satisfatório.

O funcionário coloca que todas as atividades do Programa foram implantadas .

O PSQT gerou como benefício principal para o trabalho do entrevistado uma maior preocupação em executar suas atividades com qualidade, uma maior preocupação com o cliente interno e externo da empresa, e uma melhor conscientização do que é qualidade. Atualmente o funcionário aplica conceitos e princípios da qualidade em seu trabalho.

Para a empresa o funcionário considera que os benefícios alcançados com o Programa foram: os funcionários passaram a se preocupar mais em executar as suas atividades com qualidade, uma maior preocupação com o cliente interno e externo, aumento de produtividade e redução de custos.

O funcionário disse não ter nenhuma crítica e/ou sugestões de melhoria ao PSQT, colocando que o SEBRAE é muito bem preparado para repassar o Programa.

\subsubsection{EMPRESA H}

O funcionário entrevistado entende que a Qualidade Total é a melhoria contínua de processos e o Programa de Qualidade Total a introdução/aprendizado de técnicas e ferramentas da qualidade.

A empresa reconheceu o trabalho do funcionário pelas iniciativas da qualidade através da distribuição de prêmios (brindes).

Os conceitos e princípios da qualidade foram repassados e assimilados pelos funcionários e a missão e a política da qualidade, cujo funcionário não ajudou na elaboração foram elaboradas mas disseminadas parcialmente pela empresa.

O funcionário não participou da elaboração dos indicadores de desempenho, porque a empresa não estabeleceu-os.

O funcionário participou de todas as etapas do D’Olho da Qualidade e foi treinado também na parte de ferramentas, não tendo dificuldade em assimilá-las. 
De uma forma geral o funcionário avalia que realizou todas as atividades a ele delegadas no Bloco I, Bloco II e Bloco III, considerando que o repasse dessas atividades pelas pessoaschave foi satisfatório.

O funcionário não soube responder quais foram os motivos para a não implantação de todas as atividades do PSQT na empresa.

O PSQT gerou como benefício principal para o trabalho do entrevistado uma maior preocupação em executar suas atividades com qualidade. Atualmente o funcionário procura aplicar os conceitos e princípios da qualidade em seu trabalho.

Em se tratando das ferramentas da qualidade o funcionário não as utiliza em suas atividades.

Para a empresa o funcionário considera que o principal benefício alcançados com o Programa foi que os funcionários passaram a se preocupar mais em executar as suas atividades com qualidade.

O funcionário coloca como crítica ao PSQT o fato de o tempo para a implantação do Programa ter sido muito curto.

\subsubsection{EMPRESA $J$}

O funcionário entrevistado entende que a Qualidade Total engloba os seguintes pontos: atender as necessidades dos clientes, processos padronizados e sistematizados, melhoria contínua de processos, ausência de defeitos nos produtos, disseminação de informações, delegação, gerência participativa e desenvolvimento dos recursos humanos.

O Programa de Qualidade Total, segundo o entrevistado, é principalmente a introdução/aprendizado de técnicas e ferramentas da qualidade e o aprimoramento dos processos e técnicas.

O funcionário avalia como alto o envolvimento do proprietário da empresa durante a implantação do Programa e como médio o seu próprio envolvimento. A empresa reconheceu o trabalho do funcionário pelas iniciativas da qualidade através da distribuição de prêmios.

Os conceitos e princípios da qualidade foram repassados e assimilados pelos funcionários e a missão e a política da qualidade, cujo funcionário ajudou na elaboração, foram elaboradas por toda a empresa.

O funcionário participou da elaboração dos indicadores de desempenho estabelecidos pela empresa. 
O funcionário participou de todas as etapas do D’Olho da Qualidade e foi treinado também na parte de ferramentas, não tendo dificuldade em assimilá-las.

De uma forma geral o funcionário avalia que realizou todas as atividades a ele delegadas no Bloco I, Bloco II e poucas do Bloco III, considerando que o repasse dessas atividades pelas pessoas-chave deixou a desejar porque os critérios usados pela empresa para a escolha dos multiplicadores não foi adequado para as atividades que seriam desenvolvidas..

O funcionário coloca que os motivos para a não implantação das atividades do PSQT pela empresa foram as dificuldades para conciliar as atividades do Programa com a rotina do trabalho, falta de apoio dos facilitadores, desmotivação e falha no repasse das atividades.

O PSQT gerou como benefício principal para o trabalho do entrevistado uma maior preocupação em executar suas atividades com qualidade. Atualmente o funcionário procura aplicar os conceitos e princípios da qualidade em seu trabalho, colocando que quando se aprende a trabalhar preocupado com a qualidade do trabalho, não tem como voltar atrás.

Em se tratando das ferramentas da qualidade o funcionário não as utiliza em suas atividades.

Para a empresa o funcionário considera que o principal benefício alcançado com o Programa foram: os funcionários passaram a se preocupar mais em executar as suas atividades com qualidade.

O funcionário não fez críticas e/ou sugestões de melhoria ao PSQT

\subsection{ENTREVISTAS COM OS CONSULTORES DO PSQT}

As informações descritas a seguir foram coletadas através de questionários aplicados a três consultores que atuaram como facilitadores do PSQT nas empresas que foram pesquisadas.

\subsubsection{CONSULTOR 1}

O consultor entrevistado trabalha como facilitador do programa há oito anos e dentre as empresas pesquisadas foi facilitador das empresas: C, G, I e J.

Segundo o consultor, o que mais influencia as pequenas empresas a implantar o Programa Sebrae de Qualidade Total é o mercado, isto é, a possibilidade de ter acesso a mercados mais exigentes.

As pequenas empresas buscam com a implantação do PSQT: crescimento organizado; sobrevivência e adaptação da empresa; maior rentabilidade; satisfação do cliente e melhoria de 
relacionamento dos recursos humanos, sendo os principais benefícios obtidos pelas pequenas empresas com a implantação do Programa os seguintes: abertura de mercado; ganhos de competitividade e produtividade; redução de custos; melhoria da satisfação do cliente e maior envolvimento dos recursos humanos.

A pesquisa “Nossa Empresas Trabalha com Qualidade Total” feita no início da implantação do Programa não consegue avaliar as reais necessidades de empresa em relação à Gestão da Qualidade Total pois revela os pontos fortes e fracos da empresa. Um diagnóstico mais apurado deveria levar em conta os funcionários da mesma, o clima e a cultura organizacional, uma vez que a GQT está fundamentada na mudança comportamental

O prazo de implantação do Programa é considerado suficiente para a implantação das atividades e tarefas do programa, uma vez que o programa tem interesse de ser um " carro abri alas”, ou seja, é importante que não haja dependência com o consultor para que a empresa possa seguir o caminho sozinha.

O número de horas de consultoria foi considerado baixo. Mais horas de consultoria possibilitariam um melhor auxílio na reestruturação da empresa, na mudança de cultura e quebra de resistências.

A metodologia do PSQT foi avaliada como adequada ao público-alvo, sendo o mínimo necessário para uma empresa ter Gestão da Qualidade Total.

A qualidade do material didático foi avaliada da seguinte forma: (1) apostilas - baixa; (2) fitas de vídeo - satisfatória; (3) cartazes - satisfatória. O material poderia ser mais didático, focando cada segmento empresarial e não tão genérico. A qualidade das fitas está no seu fácil entendimento junto ao nível operacional.

A duração dos módulos repassados em sala de aula foi considerada adequada e os casos práticos apresentado durante os módulos adequados à realidade das pequenas empresas.

O PSQT quando trabalhado setorialmente apresenta melhores resultados do que quando trabalhado com empresas de diferentes setores por ser um grupo homogêneo. Assim, o consultor, desde que tenha familiaridade com o setor, poderá focar mais nos pontos críticos. 
Tabela 7.11: Avaliação do nível de implantação do PSQT - consultor 1

\begin{tabular}{|c|c|c|}
\hline \multicolumn{3}{|c|}{ BLOCO I - A CONQUISTA DA QUALIDADE } \\
\hline Módulo & Tarefa de Implantação & $\begin{array}{c}\text { Nível de } \\
\text { Implantação }\end{array}$ \\
\hline $\begin{array}{l}\text { 1. Conceito do } \\
\text { Melhor }\end{array}$ & $\begin{array}{l}\text { - Planejamento da reunião de lançamento do } \\
\text { PSQT } \\
\text { - Lançamento do PSQT }\end{array}$ & $\begin{array}{l}80 \text { a } 100 \% \\
80 \text { a } 100 \% \\
\end{array}$ \\
\hline $\begin{array}{l}\text { 2. Princípios da } \\
\text { Qualidade }\end{array}$ & $\begin{array}{l}\text { - Definição dos princípios da qualidade } \\
\text { - Definição dos valores da empresa } \\
\text { - Definição da pesquisa: Nossa Empresa } \\
\text { Trabalha com Qualidade Total ? } \\
\text { - Realização da pesquisa } \\
\text { - Tabulação e análise dos resultados da pesquisa } \\
\text { - Apresentação dos princípios e valores e } \\
\text { divulgação dos resultados da pesquisa }\end{array}$ & $\begin{array}{l}80 \text { a } 100 \% \\
60 \text { a } 79 \% \\
80 \text { a } 100 \% \\
80 \text { a } 100 \% \\
80 \text { a } 100 \% \\
80 \text { a } 100 \%\end{array}$ \\
\hline 3.Gestão Estratégica & $\begin{array}{l}\text { - Definição da visão de futuro } \\
\text { - Definição da razão de ser da empresa } \\
\text { - Definição da política da qualidade } \\
\text { - Identificação e análise do ambiente externo e } \\
\text { interno da empresa } \\
\text { - Divulgação da visão de futuro, negócio, missão, } \\
\text { política da qualidade e ações estratégicas } \\
\end{array}$ & $\begin{array}{l}40 \text { a } 59 \% \\
40 \text { a } 59 \% \\
40 \text { a } 59 \% \\
40 \text { a } 59 \% \\
40 \text { a } 59 \%\end{array}$ \\
\hline $\begin{array}{ll}\text { Indicadores } & \text { de } \\
\text { Desempenho } & \\
\text { Empresarial } & \end{array}$ & $\begin{array}{l}\text { - Sensibilização para a importância dos } \\
\text { Indicadores de Desempenho Empresarial } \\
\text { - Apresentação de uma metodologia para a } \\
\text { implantação de um Sistema de Indicadores de } \\
\text { Desempenho } \\
\text { - Orientação sobre a análise crítica dos } \\
\text { Indicadores como fonte de informações e } \\
\text { promoção de melhorias na empresa }\end{array}$ & $\begin{array}{l}40 \text { a } 59 \% \\
40 \text { a } 59 \% \\
20 \text { a } 39 \%\end{array}$ \\
\hline 4. Satisfação Total & $\begin{array}{l}\text { - Preparação da equipe de apoio } \\
\text { - Planejamento da pesquisa (questionário) de } \\
\text { satisfação do cliente } \\
\text { - Aplicação do questionário aos clientes } \\
\text { selecionados } \\
\text { - Tabulação do questionário, interpretação dos } \\
\text { resultados e elaboração de ações de melhoria } \\
\text { - Apresentação dos resultados }\end{array}$ & $\begin{array}{l}40 \text { a } 59 \% \\
20 \text { a } 39 \% \\
20 \text { a } 39 \% \\
40 \text { a } 59 \% \\
40 \text { a } 59 \%\end{array}$ \\
\hline $\begin{array}{l}\text { 5. Poder } \\
\text { Participação }\end{array}$ & $\begin{array}{l}\text { - Sensibilização para a participação } \\
\text { - Instrumentos de participação } \\
\text { - Promovendo a participação }\end{array}$ & $\begin{array}{l}20 \text { a } 39 \% \\
20 \text { a } 39 \% \\
20 \text { a } 39 \%\end{array}$ \\
\hline 6. Novo Gerente & $\begin{array}{l}\text { - Reunião: Delegar é Preciso } \\
\text { - Reunião para revisão da estrutura da empresa } \\
\text { - Instituição do mural de comunicação interna } \\
\text { - Reunião para criação de uma sistemática de } \\
\text { comunicação }\end{array}$ & $\begin{array}{l}20 \text { a } 39 \% \\
20 \text { a } 39 \% \\
20 \text { a } 39 \% \\
20 \text { a } 39 \%\end{array}$ \\
\hline
\end{tabular}




\begin{tabular}{|c|c|c|}
\hline $\begin{array}{l}\text { Auditoria } \\
\text { Programa }\end{array}$ & $\begin{array}{l}\text { - Auditoria do Programa } \\
\text { - Avaliação do processo de implantação do PSQT } \\
\text { - Planejamento da continuidade da implantação } \\
\text { da qualidade total }\end{array}$ & $\begin{array}{l}20 \text { а } 39 \% \\
20 \text { а } 39 \% \\
20 \text { а } 39 \%\end{array}$ \\
\hline \multicolumn{3}{|c|}{ BLOCO II - D-OLHO NA QUALIDADE } \\
\hline Módulo & Tarefa de Implantação & $\begin{array}{c}\text { Nível de } \\
\text { Implantação }\end{array}$ \\
\hline $\begin{array}{l}\text { 1. } \quad \text { Eliminando } \\
\text { Desperdício }\end{array}$ & - Lançamento do D-Olho & 60 a $79 \%$ \\
\hline \begin{tabular}{ll|}
2. & Descarte \\
Organização &
\end{tabular} & $\begin{array}{l}\text { - Executando o Descarte } \\
\text { - Executando a Organização }\end{array}$ & $\begin{array}{l}60 \text { a } 79 \% \\
60 \text { a } 79 \% \\
\end{array}$ \\
\hline $\begin{array}{l}\text { 3. Limpeza, Higiene } \\
\text { e Ordem Mantida }\end{array}$ & $\begin{array}{l}\text { - Executando a Limpeza } \\
\text { - Executando a Organização } \\
\text { - Executando a Ordem Mantida }\end{array}$ & $\begin{array}{l}60 \text { a } 79 \% \\
20 \text { a } 39 \% \\
20 \text { a } 39 \%\end{array}$ \\
\hline \begin{tabular}{|lr} 
4. Manutenção & e \\
Auditoria & do \\
Programa &
\end{tabular} & $\begin{array}{l}\text { - Auditoria do Programa } \\
\text { - Avaliação do processo de implantação do } \\
\text { PSQT } \\
\text { - Planejamento da continuidade da implantação } \\
\text { da qualidade total }\end{array}$ & $\begin{array}{l}40 \text { a } 59 \% \\
40 \text { a } 59 \% \\
40 \text { a } 59 \%\end{array}$ \\
\hline \multicolumn{3}{|c|}{ BLOCO III - MELHORIA DE PROCESSOS } \\
\hline Módulo & Tarefa de Implantação & \begin{tabular}{|c|} 
Nível de \\
Implantação
\end{tabular} \\
\hline $\begin{array}{l}\text { 1. Gerenciando } \\
\text { Processos }\end{array}$ & $\begin{array}{l}\text { - Planejamento da reunião de introdução aos } \\
\text { conceitos de gerenciamento de processos } \\
\text { - Disseminação dos conceitos de gerenciamento } \\
\text { de processos e cadeia cliente-fornecedor interno } \\
\text { - Preparação da equipe de apoio para identificar e } \\
\text { estabelecer os processos e a cadeia cliente- } \\
\text { fornecedor interno da empresa } \\
\text { - Definição da cadeia cliente-fornecedor interno }\end{array}$ & $\begin{array}{l}20 \text { a } 39 \% \\
20 \text { a } 39 \% \\
20 \text { a } 39 \% \\
20 \text { a } 39 \% \\
\end{array}$ \\
\hline $\begin{array}{ll}\text { 2. } & \text { Garantia } \\
\text { Qualidade } & \text { da }\end{array}$ & $\begin{array}{l}\text { - Sensibilização para documentação dos } \\
\text { processos } \\
\text { - Reunião sobre Garantia da Qualidade } \\
\text { - Elaboração dos procedimentos } \\
\end{array}$ & $\begin{array}{l}20 \text { a } 39 \% \\
20 \text { a } 39 \% \\
20 \text { a } 39 \% \\
\end{array}$ \\
\hline $\begin{array}{l}\text { 3. Análise e } \\
\text { Melhoria }\end{array}$ & $\begin{array}{l}\text { - Identificação de problemas } \\
\text { - Aplicação do MAMP } \\
\text { - Analisando permanentemente os processos }\end{array}$ & $\begin{array}{l}20 \text { a } 39 \% \\
20 \text { a } 39 \% \\
20 \text { a } 39 \%\end{array}$ \\
\hline Auditoria & $\begin{array}{l}\text { - Auditoria do Programa } \\
\text { - Avaliação do processo de implantação do PSQT } \\
\text { - Planejamento da continuidade da implantação } \\
\text { da qualidade total }\end{array}$ & $\begin{array}{l}20 \text { a } 39 \% \\
20 \text { a } 39 \% \\
20 \text { a } 39 \%\end{array}$ \\
\hline
\end{tabular}


A etapa de sustentação do Programa (auditorias 30 e 60 dias após o término da implantação do PSQT), é avaliada como de fundamental para a continuidade do Programa, porém em grande parte das empresas o programa morre aí.

O acompanhamento a longo prazo pelo Sebrae do Gerenciamento da Qualidade Total nas empresas que implantaram o PSQT é considerado viável e poderia ser feito com reuniões mensais de implantação de melhorias de processos e consultorias na empresa.

Os seguintes fatores foram considerados como principais à não implantação do PSQT pelas empresas:

- ausência de foco no consumidor;

- ausência de planejamento;

- criação de uma estrutura Interna (paralela) da qualidade;

- dificuldade na utilização de ferramentas e técnicas da qualidade;

- treinamento inadequado à realidade da empresa;

- falta de envolvimento do pequeno empresário; e

- falta de tempo do pequeno empresário.

Fez-se os seguintes comentários em relação à implantação do PSQT nas empresas:

- Empresa J: a visão do proprietário, persistência, o treinamento dos funcionários e a criação de uma estrutura para a qualidade permitiram a sustentação e implantação do PSQT. Implantação 100\%. Consultor não mantém mais contato.

- Empresa I: não implantou totalmente. Fatores principais foram a falta de envolvimento do proprietário e a estrutura de implantação. A qualidade não foi priorizada. Nível de implantação de 30\%. Consultor não mantém mais contato.

- Empresa C: implantou 80\% mas continua a implantação, principalmente a área de processos, mantendo reuniões com os funcionários. Fatores como a cultura do empresário, criação de uma estrutura para a qualidade, recursos físicos e a importância dada ao processo foram fundamentais. Consultor não mantém mais contato.

- Empresa G: implantou 30\%. Após o término do programa ele não teve continuidade, virando mais uma carta de "intenções” do que um fato real. Falta de compromisso do empresário, de uma estrutura de implantação e de persistência. O consultor não tem mais contato. 


\subsubsection{CONSULTOR 2}

O consultor entrevistado trabalha como facilitador do programa há seis anos e dentre as empresas pesquisadas foi facilitador da empresa $\mathrm{E}$.

O que mais influencia as pequenas empresas a implantar o Programa Sebrae de Qualidade Total é a dinâmica da economia e o mercado.

As pequenas empresas buscam com a implantação do PSQT: sobrevivência e adaptação da empresa; maior rentabilidade e satisfação do cliente, sendo os principais benefícios obtidos pelas pequenas empresas com a implantação do Programa os seguintes: abertura de mercado; ganhos de competitividade e produtividade; redução de custos; melhoria da satisfação do cliente e maior envolvimento dos recursos humanos. O consultor diz também que com o PSQT o empresário aprende a gerir melhor a empresa, principalmente dar importância a realização de reuniões, onde se torna possível o gerenciamento participativo, reduzindo o desperdício de idéias.

A pesquisa “Nossa Empresa Trabalha com Qualidade Total” feita no início da implantação do Programa consegue avaliar as reais necessidades de empresa em relação à Gestão da Qualidade Total.

O prazo de implantação do PSQT é considerado suficiente para a implantação das atividades e tarefas do Programa. O consultor ainda coloca que as empresas que por necessidade priorizaram a implantação do Programa realizaram todas as tarefas, dizendo que se a empresa der mais tempo para a realização das atividades, o processo infelizmente esfria.

O número de horas de consultoria foi considerado adequado e o apoio do consultor durante a implantação do PSQT também.

A metodologia do PSQT foi avaliada como adequada ao público-alvo.

A qualidade do material didático foi avaliada da seguinte forma: (1) apostilas satisfatória; (2) fitas de vídeo - satisfatória; (3) cartazes - baixa. O consultor diz que as fitas de vídeo são excelentes, mas ficaram desatualizadas.

A duração dos módulos repassados em sala de aula foi considerada adequada e a quantidade de casos práticos apresentados durante os módulos foi considerada suficiente, sendo estes casos adequados à realidade das pequenas empresas.

O PSQT quando trabalhado setorialmente apresenta melhores resultados do que quando trabalhado com empresas de diferentes setores em um mesmo grupo. O consultor comenta que os resultados são melhores pois acarreta diálogos pertinentes durante os treinamentos e um maior envolvimento das pessoas com a implantação. 
Tabela 7.12 - Avaliação do nível de implantação do PSQT - consultor 2

\begin{tabular}{|c|c|c|}
\hline \multicolumn{3}{|c|}{ BLOCO I - A CONQUISTA DA QUALIDADE } \\
\hline Módulo & Tarefa de Implantação & $\begin{array}{c}\text { Nível de } \\
\text { Implantação }\end{array}$ \\
\hline $\begin{array}{l}\text { 1. Conceito do } \\
\text { Melhor }\end{array}$ & $\begin{array}{l}\text { - Planejamento da reunião de lançamento do } \\
\text { PSQT } \\
\text { - Lançamento do PSQT }\end{array}$ & $\begin{array}{l}80 \text { a } 100 \% \\
80 \text { a } 100 \% \\
\end{array}$ \\
\hline $\begin{array}{l}\text { 2. Princípios da } \\
\text { Qualidade }\end{array}$ & $\begin{array}{l}\text { - Definição dos princípios da qualidade } \\
\text { - Definição dos valores da empresa } \\
\text { - Definição da pesquisa: Nossa Empresa } \\
\text { Trabalha com Qualidade Total ? } \\
\text { - Realização da pesquisa } \\
\text { - Tabulação e análise dos resultados da pesquisa } \\
\text { - Apresentação dos princípios e valores e } \\
\text { divulgação dos resultados da pesquisa }\end{array}$ & $\begin{array}{l}80 \text { a } 100 \% \\
80 \text { a } 100 \% \\
80 \text { a } 100 \% \\
80 \text { a } 100 \% \\
80 \text { a } 100 \% \\
80 \text { a } 100 \%\end{array}$ \\
\hline 3.Gestão Estratégica & $\begin{array}{l}\text { - Definição da visão de futuro } \\
\text { - Definição da razão de ser da empresa } \\
\text { - Definição da política da qualidade } \\
\text { - Identificação e análise do ambiente externo e } \\
\text { interno da empresa } \\
\text { - Divulgação da visão de futuro, negócio, missão, } \\
\text { política da qualidade e ações estratégicas } \\
\end{array}$ & $\begin{array}{l}60 \text { a } 79 \% \\
60 \text { a } 79 \% \\
60 \text { a } 79 \% \\
60 \text { a } 79 \% \\
60 \text { a } 79 \%\end{array}$ \\
\hline $\begin{array}{ll}\text { Indicadores } & \text { de } \\
\text { Desempenho } & \\
\text { Empresarial } & \end{array}$ & $\begin{array}{l}\text { - Sensibilização para a importância dos } \\
\text { Indicadores de Desempenho Empresarial } \\
\text { - Apresentação de uma metodologia para a } \\
\text { implantação de um Sistema de Indicadores de } \\
\text { Desempenho } \\
\text { - Orientação sobre a análise crítica dos } \\
\text { Indicadores como fonte de informações e } \\
\text { promoção de melhorias na empresa }\end{array}$ & $\begin{array}{l}60 \text { a } 79 \% \\
60 \text { a } 79 \% \\
60 \text { a } 79 \%\end{array}$ \\
\hline 4. Satisfação Total & $\begin{array}{l}\text { - Preparação da equipe de apoio } \\
\text { - Planejamento da pesquisa (questionário) de } \\
\text { satisfação do cliente } \\
\text { - Aplicação do questionário aos clientes } \\
\text { selecionados } \\
\text { - Tabulação do questionário, interpretação dos } \\
\text { resultados e elaboração de ações de melhoria } \\
\text { - Apresentação dos resultados }\end{array}$ & $\begin{array}{l}60 \text { a } 79 \% \\
60 \text { a } 79 \% \\
60 \text { a } 79 \% \\
60 \text { a } 79 \% \\
60 \text { a } 79 \%\end{array}$ \\
\hline $\begin{array}{l}\text { 5. Poder } \\
\text { Participação }\end{array}$ & $\begin{array}{l}\text { - Sensibilização para a participação } \\
\text { - Instrumentos de participação } \\
\text { - Promovendo a participação } \\
\end{array}$ & \begin{tabular}{|l|}
80 a $100 \%$ \\
60 a $79 \%$ \\
60 a $79 \%$ \\
\end{tabular} \\
\hline 6. Novo Gerente & $\begin{array}{l}\text { - Reunião: Delegar é Preciso } \\
\text { - Reunião para revisão da estrutura da empresa } \\
\text { - Instituição do mural de comunicação interna } \\
\text { - Reunião para criação de uma sistemática de } \\
\text { comunicação }\end{array}$ & $\begin{array}{l}60 \text { a } 79 \% \\
60 \text { a } 79 \% \\
60 \text { a } 79 \% \\
60 \text { a } 79 \%\end{array}$ \\
\hline
\end{tabular}




\begin{tabular}{|c|c|c|}
\hline $\begin{array}{l}\text { Auditoria } \\
\text { Programa }\end{array}$ & $\begin{array}{l}\text { - Auditoria do Programa } \\
\text { - Avaliação do processo de implantação do PSQT } \\
\text { - Planejamento da continuidade da implantação } \\
\text { da qualidade total }\end{array}$ & $\begin{array}{l}60 \text { a } 79 \% \\
60 \text { а } 79 \% \\
60 \text { а } 79 \%\end{array}$ \\
\hline \multicolumn{3}{|c|}{ BLOCO II - D-OLHO NA QUALIDADE } \\
\hline Módulo & Tarefa de Implantação & $\begin{array}{c}\text { Nível de } \\
\text { Implantação }\end{array}$ \\
\hline $\begin{array}{l}\text { 1. Eliminando } \\
\text { Desperdício }\end{array}$ & - Lançamento do D-Olho & 80 a $100 \%$ \\
\hline \begin{tabular}{ll|} 
2. & Descarte \\
Organização &
\end{tabular} & $\begin{array}{l}\text { - Executando o Descarte } \\
\text { - Executando a Organização }\end{array}$ & $\begin{array}{l}80 \text { a } 100 \% \\
80 \text { a } 100 \%\end{array}$ \\
\hline $\begin{array}{l}\text { 3. Limpeza, Higiene } \\
\text { e Ordem Mantida }\end{array}$ & $\begin{array}{l}\text { - Executando a Limpeza } \\
\text { - Executando a Organização } \\
\text { - Executando a Ordem Mantida } \\
\end{array}$ & $\begin{array}{l}80 \text { a } 100 \% \\
80 \text { a } 100 \% \\
80 \text { a } 100 \% \\
\end{array}$ \\
\hline $\begin{array}{lr}\text { 4. Manutenção } & \text { e } \\
\text { Auditoria } & \text { do } \\
\text { Programa } & \end{array}$ & $\begin{array}{l}\text { - Auditoria do Programa } \\
\text { - Avaliação do processo de implantação do } \\
\text { PSQT } \\
\text { - Planejamento da continuidade da implantação } \\
\text { da qualidade total }\end{array}$ & $\begin{array}{l}60 \text { a } 79 \% \\
60 \text { a } 79 \% \\
60 \text { a } 79 \%\end{array}$ \\
\hline \multicolumn{3}{|c|}{ BLOCO III - MELHORIA DE PROCESSOS } \\
\hline Módulo & Tarefa de Implantação & \begin{tabular}{|c|} 
Nível de \\
Implantação \\
\end{tabular} \\
\hline $\begin{array}{l}\text { 1. Gerenciando } \\
\text { Processos }\end{array}$ & $\begin{array}{l}\text { - Planejamento da reunião de introdução aos } \\
\text { conceitos de gerenciamento de processos } \\
\text { - Disseminação dos conceitos de gerenciamento } \\
\text { de processos e cadeia cliente-fornecedor interno } \\
\text { - Preparação da equipe de apoio para identificar e } \\
\text { estabelecer os processos e a cadeia cliente- } \\
\text { fornecedor interno da empresa } \\
\text { - Definição da cadeia cliente-fornecedor interno }\end{array}$ & $\begin{array}{l}80 \text { a } 100 \% \\
80 \text { a } 100 \% \\
80 \text { a } 100 \% \\
60 \text { a } 79 \%\end{array}$ \\
\hline $\begin{array}{ll}\text { 2. } & \text { Garantia } \\
\text { Qualidade } & \text { da }\end{array}$ & $\begin{array}{l}\text { - Sensibilização para documentação dos } \\
\text { processos } \\
\text { - Reunião sobre Garantia da Qualidade } \\
\text { - Elaboração dos procedimentos }\end{array}$ & $\begin{array}{l}80 \text { a } 100 \% \\
60 \text { a } 79 \% \\
40 \text { a } 59 \%\end{array}$ \\
\hline $\begin{array}{l}\text { 3. Análise e } \\
\text { Melhoria }\end{array}$ & $\begin{array}{l}\text { - Identificação de problemas } \\
\text { - Aplicação do MAMP } \\
\text { - Analisando permanentemente os processos }\end{array}$ & $\begin{array}{l}60 \text { a } 79 \% \\
60 \text { a } 79 \% \\
40 \text { a } 59 \% \\
\end{array}$ \\
\hline Auditoria & $\begin{array}{l}\text { - Auditoria do Programa } \\
\text { - Avaliação do processo de implantação do PSQT } \\
\text { - Planejamento da continuidade da implantação } \\
\text { da qualidade total }\end{array}$ & $\begin{array}{l}60 \text { a } 79 \% \\
60 \text { a } 79 \% \\
60 \text { а } 79 \%\end{array}$ \\
\hline
\end{tabular}

Fonte: Elaboração Própria

O consultor coloca que em se tratando da etapa de sustentação do Programa, o ideal seria que o consultor retornasse à empresa, depois de alguns meses do término dos treinamentos, 
para auditar a continuidade do estabelecido. Percebe-se que existe muito entusiasmo nos treinamentos, mas no dia a dia, a tendência é do empresário colocar o PSQT em segundo plano, considerando os cenários atuais de muitas mudanças.

O acompanhamento a longo prazo pelo Sebrae do Gerenciamento da Qualidade Total nas empresas que implantaram o PSQT é considerado viável e poderia ser feito com auditorias feitas pelo consultor, que faria pelo menos duas visitas no ano seguinte ao término do treinamento.

Os seguintes fatores foram considerados como principais para a não implantação do PSQT pelas empresas:

- $\quad$ ausência de foco no consumidor;

- $\quad$ ausência de planejamento;

- $\quad$ qualidade não é medida em termos financeiros;

- $\quad$ falta de envolvimento do pequeno empresário;

- $\quad$ falta de tempo do pequeno empresário/responsável pela implantação;

- $\quad$ falta de tempo dos funcionários;

- $\quad$ resistências internas; e

- deficiência de técnica de repasse da metodologia (pelo responsável na implantação do Programa dentro da empresa).

Fez-se os seguintes comentários em relação á implantação do PSQT na empresa:

- Empresa E: a empresa implantou parcialmente o PSQT, cerca de 60\%, devido a uma série de problemas que a empresa enfrentou na época, principalmente no tocante a liderança que teve que priorizar a produção e o comercial, devidamente compreensível no período. O consultor ainda mantém contato com a empresa pois está auxiliando-a na certificação da ISO 9000.

\subsubsection{CONSULTOR 3}

O consultor entrevistado trabalha como facilitador do programa há doze anos e dentre as empresas pesquisadas foi facilitador das seguintes empresas: A, B, D e F.

O que mais influencia as pequenas empresas a implantar o Programa Sebrae de Qualidade Total é a dinâmica da economia e a busca da competitividade, sendo que esta última se desdobra em: interação e proximidade do cliente externo, redução de custos e valorização e busca de melhores resultados junto aos clientes internos. 
As pequenas empresas buscam com a implantação do PSQT: sobrevivência e adaptação da empresa; satisfação do cliente e melhoria de relacionamento dos recursos humanos, sendo os principais benefícios obtidos pelas pequenas empresas com a implantação do Programa os seguintes: ganhos de produtividade; redução de custos; melhoria da satisfação do cliente e maior envolvimento dos recursos humanos.

A pesquisa “Nossa Empresa Trabalha com Qualidade Total” feita no início da implantação do Programa consegue avaliar as reais necessidades de empresa em relação à Gestão da Qualidade Total. Mas, acrescenta o consultor, acredita-se que se apresentada um pouco mais adiante, isto é quando os clientes internos tivessem um conhecimento melhor sobre Qualidade e um ambiente mais propício a se manifestarem, o resultado poderia ser mais fundamentado.

O prazo de implantação do Programa é considerado suficiente para a implantação das atividades e tarefas do programa; o número de horas de consultoria é tido como adequado.

Em relação ao apoio do consultor ao pequeno empresário na implantação do PSQT, o consultor coloca que poderia melhorar em alguns casos pois se o consultor tornar-se o responsável pelo repasse dos módulos na empresa ele se torna uma "muleta" do empresário tirando dele a oportunidade de desenvolver-se mais como líder da empresa e do processo de implantação. Como caso raro o consultor exemplifica que em uma empresa, quando o empresário falava nos repasses dos módulos, o mesmo ficava extremamente gago. Por isso foi necessário a atuação do consultor de uma maneira mais próxima nos repasses.

A metodologia do PSQT foi avaliada como adequada ao público-alvo, sendo considerada muito boa. O consultor só ressalta que em algumas dinâmicas de grupo não se consegue atuar em empresas com um número de funcionários muito reduzido.

A qualidade do material didático foi avaliada da seguinte forma: (1) apostilas satisfatória; (2) fitas de vídeo - alta; (3) cartazes - satisfatória. O consultor diz que o filme utilizado no Bloco II poderia possuir um cenário mais apropriado ao público alvo.

A duração dos módulos repassados em sala de aula foi considerada adequada e a quantidade de casos práticos apresentados durante os módulos foi considerada suficiente, sendo estes casos adequados à realidade das pequenas empresas.

O PSQT quando trabalhado setorialmente apresenta melhores resultados do que quando trabalhado com empresas de diferentes setores em um mesmo grupo. 
Tabela 7.13: Avaliação do nível de implantação do PSQT - consultor 3

\begin{tabular}{|c|c|c|}
\hline \multicolumn{3}{|c|}{ BLOCO I - A CONQUISTA DA QUALIDADE } \\
\hline Módulo & Tarefa de Implantação & $\begin{array}{c}\text { Nível de } \\
\text { Implantação }\end{array}$ \\
\hline $\begin{array}{l}\text { 1. Conceito do } \\
\text { Melhor }\end{array}$ & $\begin{array}{l}\text { - Planejamento da reunião de lançamento do } \\
\text { PSQT } \\
\text { - Lançamento do PSQT }\end{array}$ & $\begin{array}{l}60 \text { a } 79 \% \\
80 \text { a } 100 \% \\
\end{array}$ \\
\hline $\begin{array}{l}\text { 2. Princípios da } \\
\text { Qualidade }\end{array}$ & $\begin{array}{l}\text { - Definição dos princípios da qualidade } \\
\text { - Definição dos valores da empresa } \\
\text { - Definição da pesquisa: Nossa Empresa } \\
\text { Trabalha com Qualidade Total ? } \\
\text { - Realização da pesquisa } \\
\text { - Tabulação e análise dos resultados da pesquisa } \\
\text { - Apresentação dos princípios e valores e } \\
\text { divulgação dos resultados da pesquisa }\end{array}$ & $\begin{array}{l}80 \text { a } 100 \% \\
60 \text { a } 79 \% \\
80 \text { a } 100 \% \\
80 \text { a } 100 \% \\
80 \text { a } 100 \% \\
60 \text { a } 79 \%\end{array}$ \\
\hline 3.Gestão Estratégica & $\begin{array}{l}\text { - Definição da visão de futuro } \\
\text { - Definição da razão de ser da empresa } \\
\text { - Definição da política da qualidade } \\
\text { - Identificação e análise do ambiente externo e } \\
\text { interno da empresa } \\
\text { - Divulgação da visão de futuro, negócio, missão, } \\
\text { política da qualidade e ações estratégicas } \\
\end{array}$ & $\begin{array}{l}60 \text { a } 79 \% \\
80 \text { a } 100 \% \\
60 \text { a } 79 \% \\
80 \text { a } 100 \% \\
60 \text { a } 79 \%\end{array}$ \\
\hline $\begin{array}{ll}\text { Indicadores } & \text { de } \\
\text { Desempenho } & \\
\text { Empresarial } & \end{array}$ & $\begin{array}{l}\text { - Sensibilização para a importância dos } \\
\text { Indicadores de Desempenho Empresarial } \\
\text { - Apresentação de uma metodologia para a } \\
\text { implantação de um Sistema de Indicadores de } \\
\text { Desempenho } \\
\text { - Orientação sobre a análise crítica dos } \\
\text { Indicadores como fonte de informações e } \\
\text { promoção de melhorias na empresa }\end{array}$ & $\begin{array}{l}80 \text { a } 100 \% \\
60 \text { a } 79 \% \\
60 \text { a } 79 \%\end{array}$ \\
\hline 4. Satisfação Total & $\begin{array}{l}\text { - Preparação da equipe de apoio } \\
\text { - Planejamento da pesquisa (questionário) de } \\
\text { satisfação do cliente } \\
\text { - Aplicação do questionário aos clientes } \\
\text { selecionados } \\
\text { - Tabulação do questionário, interpretação dos } \\
\text { resultados e elaboração de ações de melhoria } \\
\text { - Apresentação dos resultados }\end{array}$ & $\begin{array}{l}60 \text { a } 79 \% \\
80 \text { a } 100 \% \\
60 \text { a } 79 \% \\
80 \text { a } 100 \% \\
60 \text { a } 79 \%\end{array}$ \\
\hline $\begin{array}{l}\text { 5. Poder } \\
\text { Participação }\end{array}$ & $\begin{array}{l}\text { - Sensibilização para a participação } \\
\text { - Instrumentos de participação } \\
\text { - Promovendo a participação }\end{array}$ & $\begin{array}{l}80 \text { a } 100 \% \\
80 \text { a } 100 \% \\
80 \text { a } 100 \% \\
\end{array}$ \\
\hline 6. Novo Gerente & $\begin{array}{l}\text { - Reunião: Delegar é Preciso } \\
\text { - Reunião para revisão da estrutura da empresa } \\
\text { - Instituição do mural de comunicação interna } \\
\text { - Reunião para criação de uma sistemática de } \\
\text { comunicação }\end{array}$ & $\begin{array}{l}80 \text { а } 100 \% \\
60 \text { a } 79 \% \\
60 \text { a } 79 \% \\
60 \text { а } 79 \% \\
\end{array}$ \\
\hline
\end{tabular}




\begin{tabular}{|c|c|c|}
\hline $\begin{array}{l}\text { Auditoria } \\
\text { Programa }\end{array}$ & $\begin{array}{l}\text { - Auditoria do Programa } \\
\text { - Avaliação do processo de implantação do PSQT } \\
\text { - Planejamento da continuidade da implantação } \\
\text { da qualidade total }\end{array}$ & $\begin{array}{l}80 \text { a } 100 \% \\
80 \text { a } 100 \% \\
80 \text { a } 100 \%\end{array}$ \\
\hline \multicolumn{3}{|c|}{ BLOCO II - D-OLHO NA QUALIDADE } \\
\hline Módulo & Tarefa de Implantação & $\begin{array}{c}\text { Nível de } \\
\text { Implantação }\end{array}$ \\
\hline $\begin{array}{l}\text { 1. Eliminando } \quad 0 \\
\text { Desperdício }\end{array}$ & - Lançamento do D-Olho & 80 a $100 \%$ \\
\hline $\begin{array}{ll}\text { 2. } & \text { Descarte } \\
\text { Organização } & \text { e }\end{array}$ & $\begin{array}{l}\text { - Executando o Descarte } \\
\text { - Executando a Organização }\end{array}$ & $\begin{array}{l}80 \text { a } 100 \% \\
80 \text { a } 100 \%\end{array}$ \\
\hline $\begin{array}{l}\text { 3. Limpeza, Higiene } \\
\text { e Ordem Mantida }\end{array}$ & $\begin{array}{l}\text { - Executando a Limpeza } \\
\text { - Executando a Organização } \\
\text { - Executando a Ordem Mantida }\end{array}$ & $\begin{array}{l}80 \text { a } 100 \% \\
80 \text { a } 100 \% \\
60 \text { a } 79 \%\end{array}$ \\
\hline $\begin{array}{lr}\text { 4. Manutenção } & \text { e } \\
\text { Auditoria } & \text { do } \\
\text { Programa } & \end{array}$ & $\begin{array}{l}\text { - Auditoria do Programa } \\
\text { - Avaliação do processo de implantação do } \\
\text { PSQT } \\
\text { - Planejamento da continuidade da implantação } \\
\text { da qualidade total }\end{array}$ & $\begin{array}{l}60 \text { a } 79 \% \\
80 \text { a } 100 \% \\
60 \text { a } 79 \%\end{array}$ \\
\hline \multicolumn{3}{|c|}{ BLOCO III - MELHORIA DE PROCESSOS } \\
\hline Módulo & Tarefa de Implantação & \begin{tabular}{|c|} 
Nível de \\
Implantação \\
\end{tabular} \\
\hline $\begin{array}{l}\text { 1. Gerenciando } \\
\text { Processos }\end{array}$ & $\begin{array}{l}\text { - Planejamento da reunião de introdução aos } \\
\text { conceitos de gerenciamento de processos } \\
\text { - Disseminação dos conceitos de gerenciamento } \\
\text { de processos e cadeia cliente-fornecedor interno } \\
\text { - Preparação da equipe de apoio para identificar e } \\
\text { estabelecer os processos e a cadeia cliente- } \\
\text { fornecedor interno da empresa } \\
\text { - Definição da cadeia cliente-fornecedor interno }\end{array}$ & $\begin{array}{l}80 \text { a } 100 \% \\
80 \text { a } 100 \% \\
80 \text { a } 100 \% \\
80 \text { a } 100 \%\end{array}$ \\
\hline $\begin{array}{l}\text { 2. Garantia } \\
\text { Qualidade }\end{array}$ & $\begin{array}{l}\text { - Sensibilização para documentação dos } \\
\text { processos } \\
\text { - Reunião sobre Garantia da Qualidade } \\
\text { - Elaboração dos procedimentos }\end{array}$ & $\begin{array}{l}80 \text { a } 100 \% \\
60 \text { a } 79 \% \\
60 \text { а } 79 \%\end{array}$ \\
\hline $\begin{array}{l}\text { 3. Análise } \\
\text { Melhoria }\end{array}$ & $\begin{array}{l}\text { - Identificação de problemas } \\
\text { - Aplicação do MAMP } \\
\text { - Analisando permanentemente os processos }\end{array}$ & $\begin{array}{l}60 \text { a } 79 \% \\
60 \text { а } 79 \% \\
60 \text { а } 79 \% \\
\end{array}$ \\
\hline Auditoria & $\begin{array}{l}\text { - Auditoria do Programa } \\
\text { - Avaliação do processo de implantação do PSQT } \\
\text { - Planejamento da continuidade da implantação } \\
\text { da qualidade total }\end{array}$ & $\begin{array}{l}80 \text { a } 100 \% \\
80 \text { a } 100 \% \\
60 \text { a } 79 \%\end{array}$ \\
\hline
\end{tabular}

Fonte: Elaboração Própria

O consultor coloca que em se tratando da etapa de sustentação do Programa, ela só dá resultados mediante a existência de três aspectos que devem estar relacionados: um grupo 
sensibilizado e conscientizado efetivamente das vantagens do PSQT; visão madura, profissional e competitiva do(s) líder(es) empresarial(ais) e; exigência dos funcionários da organização quanto da continuidade do Programa.

O acompanhamento a longo prazo pelo Sebrae do Gerenciamento da Qualidade Total nas empresas que implantaram o PSQT é considerado viável, não sugerindo-se de que forma poderia ser feito. O consultor apenas coloca que sem sombra de dúvida tal acompanhamento só vem a somar, sendo inclusive uma solicitação frequente das empresas que participam do PSQT.

Os seguintes fatores foram considerados como principais para a não implantação do PSQT pelas empresas:

- $\quad$ falta de envolvimento do pequeno empresário;

- $\quad$ falta de tempo do pequeno empresário/responsável pela implantação;

- $\quad$ falta de tempo dos funcionários;

- $\quad$ resistências internas:

- $\quad$ não reconhecimento do corpo funcional pelas iniciativas da qualidade; e

- $\quad$ qualidade não é medida em termos financeiros;

O consultor 3 fez os seguintes comentários em relação às empresas em que foi facilitador:

- Empresa A: implantou cerca de 90\% do programa, conseguindo implantar todas as atividades dos Blocos I e II. Já o Bloco III foi implantado parcialmente porque o programa na época contava somente com um dos sócios da empresa. O outro sócio não ia ao repasse e não se mostrava solidário ao programa em alguns momentos, se contrapondo à implantação. Tal sócio acreditava que o mais importante era a produção sendo que o treinamento não era necessário. Segundo informações, tal visão mudou após o empresário ter feito o Empretec (curso de Empreendedorismo ministrado pelo Sebrae). O empresário não mantém contato profissional e nem realiza nenhuma atividade junto à empresa.

- Empresa B: implantou cerca de $85 \%$ do Programa., conseguindo implantar todas as atividades dos Blocos I e II. Em relação ao Bloco III, na época de sua implantação, a empresa passava por uma fase de alta produção para atender ao mercado, inclusive com a aquisição de mais uma máquina e a instituição de mais um turno (noturno) para atender a demanda. Diante disto os multiplicadores receberam o repasse dos módulos porém a implantação do Bloco ficou incompleta, pois não havia naquele momento condição de 
realizá-la por completo. O consultor não mantém nenhum contato profissional e não realiza nenhuma atividade junto à empresa;

- $\quad$ Empresa D: implantou cerca de 60\% do Programa. O PSQT desenvolveu-se plenamente durante o Bloco I, com a presença de três profissionais recebendo o repasse (um dos proprietários, um líder de produção e um líder da administração), porém ao término do Bloco I , o empresário não foi mais às reuniões de repasse, sendo o Programa monitorado à sua ausência. Ao término do Bloco II o líder da produção também deixou de ir aos repasses, alegando que o pique de produção estava em níveis muito elevados e que havia a necessidade de atender à demanda e por isso ele estava virando turnos, sobrecarregado de trabalho e que não havia naquele momento condições de se repassar o final do Bloco II (módulos Higiene e Ordem Mantida) e o Bloco 3.

- Empresa F: implantou cerca de 80\% do Programa, conseguindo implantar todas as atividades dos Blocos I e II. Quanto ao Bloco III, na época de sua implantação a empresa passava por uma fase de alta produção para atender ao mercado, e o que agravava ainda mais era que a produção estava literalmente amontoada em um prédio pequeno, aguardando a mudança para as novas instalações. O trabalho no prédio onde a empresa funcionava era desgastante, havendo dificuldade de disponibilização de local para realizar os repasses internos. O Bloco III teve o módulo 1 e 2 repassado e implementado, porém o módulo 3 foi apenas repassado, ficando sua implementação para o futuro, quando a empresa mudasse de local. O consultor não mantém contato com a empresa e nem realiza nenhuma atividade junto a essa.

- $\quad$ Empresa H: implantou cerca de 70\% do Programa, conseguindo implantar praticamente todas as atividades do Bloco I e II e parcialmente as do Bloco III. 


\title{
CAPÍTULO 8
}

\begin{abstract}
ANÁLISE DOS DADOS
Neste capítulo será feita a análise dos dados a partir da revisão bibliográfica e do trabalho de campo.
\end{abstract}

\subsection{ANÁLISE DAS EMPRESAS}

A análise a seguir contempla as entrevistas com os empresários e funcionários das empresas. Os dados refletem as entrevistas realizadas.

\subsubsection{EMPRESA A}

O PSQT atendeu parcialmente as expectativas iniciais da empresa, sendo necessário contratar um Engenheiro de Produção para complementar o que a empresa não conseguiu desenvolver, principalmente as atividades do Bloco III. A empresa realizou um diagnóstico para verificar suas necessidades em relação à Qualidade Total.

O Bloco I foi totalmente repassado, mas os conceitos e princípios da qualidade não foram assimilados por todos os funcionários e a missão e política da qualidade não foram disseminadas por toda a empresa. No Bloco I a empresa elaborou e realizou a pesquisa de satisfação de clientes e estabeleceu indicadores de desempenho.

Já no Bloco II todos os módulos foram implantados, havendo uma grande colaboração dos funcionários para a realização das atividades. 
No Bloco III, a padronização e identificação dos processos foram feitas. Sete ferramentas da qualidade foram implantadas, havendo uma certa dificuldade dos funcionários em compreendêlas, o que desmotivava a sua utilização. Houve a oposição de um dos sócios à implantação das atividades, dificultando a consolidação do processo.

Avaliação metodológica do PSQT: a metodologia do PSQT foi satisfatória, considerandose de difícil visualização no Bloco II da aplicação de seu conteúdo na empresa, uma vez que as fitas com o conteúdo do Bloco tinham como exemplo ilustrativo uma viagem em um barco. A qualidade técnica do material foi satisfatória e o tempo de duração do programa suficiente mas mal distribuído.

Continuidade do Programa: a empresa não repassa aos funcionários novos os conhecimentos adquiridos com o PSQT, havendo uma descontinuidade das ações do Programa na empresa.

Causas de insucesso à implantação do PSQT: as seguintes causas de insucesso, demonstradas na tabela 8.1 foram encontradas na Empresa A:

Tabela 8.1 - Causas de Insucesso: Empresa A

\begin{tabular}{|l|l|c|}
\hline & \multicolumn{1}{|c|}{ Causas de Insucesso } & \\
\hline 1 & Ausência de foco no consumidor & \\
\hline 2 & Ausência de planejamento & \\
\hline 3 & Criação de uma estrutura interna paralela & \\
\hline 4 & Não reconhecimento do corpo funcional pelas iniciativas da qualidade & $\mathrm{X}$ \\
\hline 5 & Dificuldade de utilização de ferramentas e técnicas & \\
\hline 6 & Treinamento inadequado & $\mathrm{X}$ \\
\hline 7 & Qualidade não é medida em termos financeiros & \\
\hline 8 & Falta de envolvimento do pequeno empresário & \\
\hline 9 & Falta de envolvimento dos funcionários & $\mathrm{X}$ \\
\hline 10 & Falta de tempo do pequeno empresário & \\
\hline 11 & Falta de tempo dos funcionários & \\
\hline 12 & Resistências Internas (por parte dos sócios) & \\
\hline 13 & Difícil adaptação a diferentes tipos de negócios & \\
\hline 14 & Falta de apoio do consultor & \\
\hline 15 & Deficiência de técnica de repasse da metodologia & \\
\hline
\end{tabular}

Fonte: Elaboração Própria

Benefícios alcançados pela empresa com a implantação do Programa: a especificação e registro de materiais e serviços que eram baixos passaram a ser feitas integralmente; critérios de aceitação de produtos aos fornecedores passou a ser instituído, antes apenas alguns produtos possuíam tais critérios; custos da qualidade passaram a ser calculados; funcionários passaram a ter uma participação maior na solução de problemas/melhorias de produtos e processos; planejamento estratégico passou a ser instituído. 
Outros benefícios que também ocorreram foram: aumento de produtividade; maior envolvimento dos funcionários com a qualidade; maior motivação dos funcionários no trabalho; abertura de mercado; aumento do volume de vendas; aumento do número de clientes; aumento da satisfação dos clientes; clientes passaram a ser mais exigentes; melhorias em questões de organização, limpeza, arejamento e ruídos, alcançadas através da implantação do D’OLHO na Qualidade (Bloco II); utilização de ferramentas auxiliou a solução de problemas.

Sugestões de melhoria ao PSQT: o tempo de duração deveria ser melhor distribuído, o Bloco III deveria ter uma duração maior e outras partes poderiam ter um tempo mais curto para implantação e que o conteúdo da fita de vídeo do D’Olho na Qualidade deveria abordar uma empresa e não uma viagem de barco.

\subsubsection{EMPRESA B}

O PSQT atendeu as expectativas iniciais, sendo os resultados alcançados satisfatórios. Deve-se ressaltar que a empresa não realizou diagnóstico buscando avaliar as necessidades da empresa em relação à qualidade antes da implantação do PSQT.

O Bloco I foi totalmente repassado na empresa, mas os conceitos e princípios da qualidade não foram assimilados por todos os funcionários e a missão e política da qualidade não foram disseminadas por toda a empresa. A empresa elaborou e realizou a pesquisa de satisfação de clientes e estabeleceu indicadores de desempenho.

Já o Bloco II foi totalmente implantado, havendo uma grande colaboração dos funcionários para executar as atividades.

No Bloco III, os processos foram padronizados e identificados. Algumas ferramentas da qualidade (quatro) foram implantadas, mas houve dificuldade na implantação por serem consideradas complexas pelos funcionários o que acabou prejudicando o envolvimento desses pois se sentiam desmotivados e porque o tempo para implantação das ferramentas foi curto.

A implantação completa do Bloco III na empresa B foi, na época, prejudicada por um aumento de demanda muito grande e comprou-se novo maquinário, o que tomou o tempo não só dos funcionários, como também das pessoas-chave, responsáveis pelo repasse do PSQT na empresa. Assim não foi possível conciliar o atendimento à demanda com a implantação do PSQT pois era necessário um envolvimento maior com a produção.

Avaliação metodológica do Programa: o treinamento repassado em sala de aula foi satisfatório e tanto a adequação do conteúdo do material utilizado às necessidades das pequenas empresas quanto a qualidade técnica do material utilizado foram satisfatórios. O apoio dado pelo 
Sebrae foi ótimo e o tempo de duração do Programa considerado suficiente para a implantação das atividades, exceto na parte de implantação das ferramentas, que foi considerado curto.

Continuidade do Programa: a empresa procura repassar na empresa regularmente (uma vez por ano) o D’Olho na Qualidade. Os conhecimentos adquiridos nos outros Blocos não são repassados aos funcionários novos.

Causas de insucesso à implantação do PSQT: as seguintes causas de insucesso, demonstradas na tabela 8.2 foram encontradas na Empresa B:

Tabela 8.2 - Causas de Insucesso: Empresa B

\begin{tabular}{|c|c|c|}
\hline & Causas de Insucesso & \\
\hline 1 & Ausência de foco no consumidor & \\
\hline 2 & Ausência de planejamento & \\
\hline 3 & Criação de uma estrutura interna paralela & \\
\hline 4 & Não reconhecimento do corpo funcional pelas iniciativas da qualidade & \\
\hline 5 & Dificuldade de utilização de ferramentas e técnicas & $\mathrm{X}$ \\
\hline 6 & Treinamento inadequado & \\
\hline 7 & Qualidade não é medida em termos financeiros & $\mathrm{X}$ \\
\hline 8 & Falta de envolvimento do pequeno empresário & \\
\hline 9 & Falta de envolvimento dos funcionários & $\mathrm{X}$ \\
\hline 10 & Falta de tempo do pequeno empresário & \\
\hline 11 & Falta de tempo dos funcionários & $\mathrm{X}$ \\
\hline 12 & Resistências Internas (funcionários em relação às reuniões após expediente) & $\mathrm{X}$ \\
\hline 13 & Difícil adaptação a diferentes tipos de negócios & \\
\hline 14 & Falta de apoio do consultor & \\
\hline 15 & $\begin{array}{l}\text { Deficiência de técnica de repasse da metodologia (do proprietário em falar em } \\
\text { público) }\end{array}$ & $\mathrm{X}$ \\
\hline
\end{tabular}

Fonte: Elaboração Própria

Benefícios alcançados pela empresa com a implantação do Programa: diminuição do índice de perdas de produção; diminuição do número de reclamações de clientes; melhoria da imagem do produto no mercado; abertura de mercado; aumento da satisfação dos clientes; clientes passaram a ser mais exigentes; melhorias em questões de organização, limpeza, arejamento e ruídos, alcançadas através da implantação do D’OLHO na Qualidade (Bloco II).

Sugestões de melhoria: o consultor deveria repassar o Programa na empresa devido a questões didáticas, pois nem sempre, como é o caso da empresa, o responsável pelo repasse tem facilidade de falar em público, o que acaba dificultando o aprendizado dos funcionários.

\subsubsection{EMPRESA C}

O PSQT atendeu parcialmente as expectativas iniciais, pois não foi implantado corretamente (falhas gerenciais da empresa), o que acabou levando a uma desmotivação geral. 
Deve-se ressaltar que a empresa não realizou diagnóstico buscando avaliar as necessidades da empresa em relação à qualidade antes da implantação do PSQT.

No Bloco I a empresa não disseminou a responsabilidade pela qualidade a todos e sim delegou a uma equipe de trabalho, criando assim uma estrutura paralela para acompanhamento dos resultados do PSQT. Os conceitos e princípios da qualidade foram repassados mas assimilados de forma parcial e a missão e política da qualidade foram elaborados e disseminados por toda a empresa. A empresa elaborou e aplicou a pesquisa de satisfação de clientes e estabeleceu indicadores de desempenho.

Já no Bloco II todos os módulos foram implantados integralmente, havendo uma excelente participação e colaboração dos funcionários na execução das atividades a eles designadas.

No Bloco III houve a identificação e padronização dos processos da empresa e cinco ferramentas da qualidade foram implantadas, mas houve dificuldade na implantação devido a falta de persistência e apoio dos responsáveis pelo repasse das ferramentas (pessoas-chave).

Avaliação metodológica do PSQT : o treinamento repassado em sala de aula, a adequação do conteúdo do material utilizado às necessidades das pequenas empresas e a qualidade técnica do material utilizado foram considerados ótimos. $\mathrm{O}$ apoio dado pelo Sebrae e pelo consultor também foram ótimos e o tempo de duração do Programa foi considerado suficiente para a implantação das atividades.

Continuidade do Programa: a empresa não repassa aos funcionários novos os conhecimentos adquiridos com o PSQT, havendo uma descontinuidade das ações do Programa na empresa. A falta de apoio do proprietário e alta rotatividade dos funcionários são fatores que prejudicam a continuidade do Programa na empresa. Esta não planeja adotar nenhuma iniciativa em prol da qualidade.

Causas de insucesso à implantação do PSQT: as causas de insucesso, demonstradas na tabela 8.3 foram encontradas na Empresa C.

Em relação a Causa 1, destaca-se que a ausência de foco no consumidor pode ser percebida pelo fato de o proprietário não ligar Qualidade Total, nem o PSQT ao atendimento das necessidades dos clientes e sobretudo a fatores do ambiente interno da empresa. A pesquisa de satisfação/necessidades dos clientes que era feita muito pouco antes da implantação do PSQT não sofreu mudanças, reforçando a falta de foco no consumidor pela empresa.

É também importante colocar que na Causa 4: os instrumentos (brindes, premiações) para reconhecimento das iniciativas do corpo funcional chegaram a ser programados, mas acabaram não sendo instituídos pelo fato de o proprietário ter se desligado da implantação do Programa. 
A falta de tempo do pequeno empresário (Causa 10) foi alegada devido ao fato de o proprietário ocupar-se demais com viagens, não tendo tempo para participar de reuniões.

Tabela 8.3 - Causas de Insucesso: Empresa C

\begin{tabular}{|l|l|c|}
\hline \multicolumn{1}{|c|}{ Causas de Insucesso } & \\
\hline 1 & Ausência de foco no consumidor & $\mathrm{X}$ \\
\hline 2 & Ausência de planejamento & $\mathrm{X}$ \\
\hline 3 & Criação de uma estrutura interna paralela & $\mathrm{X}$ \\
\hline 4 & Não reconhecimento do corpo funcional pelas iniciativas da qualidade & $\mathrm{X}$ \\
\hline 5 & Dificuldade de utilização de ferramentas e técnicas & $\mathrm{X}$ \\
\hline 6 & Treinamento inadequado & $\mathrm{X}$ \\
\hline 7 & Qualidade não é medida em termos financeiros & $\mathrm{X}$ \\
\hline 8 & Falta de envolvimento do pequeno empresário & \\
\hline 9 & Falta de envolvimento dos funcionários & \\
\hline 10 & Falta de tempo do pequeno empresário & \\
\hline 11 & Falta de tempo dos funcionários & \\
\hline 12 & Resistências Internas & \\
\hline 13 & Difícil adaptação a diferentes tipos de negócios & \\
\hline 14 & Falta de apoio do consultor & \\
\hline 15 & Deficiência de técnica de repasse da metodologia & \\
\hline
\end{tabular}

Fonte: Elaboração Própria

Benefícios alcançados pela empresa com a Implantação do Programa: diminuição do índice de retrabalho; diminuição de reclamações dos clientes; aumento da confiança do cliente no produto; aumento da motivação dos funcionários no trabalho; abertura de mercado; aumento da satisfação dos clientes; melhorias em questões de organização, limpeza, arejamento e de ruídos, alcançadas através da implantação do D’OLHO na Qualidade (Bloco II); funcionários passaram a preocupar-se em executar suas atividades com qualidade; maior conscientização dos funcionários em relação à qualidade; utilização das ferramentas auxiliou na resolução de problemas; redução de custos.

Sugestões de melhoria ao PSQT: não foram feitas.

\subsubsection{EMPRESA D}

O PSQT atendeu parcialmente as expectativas iniciais, não alcançando os resultados esperados, sendo um dos motivos fortes para isto, segundo a pessoa-chave entrevistada, o fato de 0 responsável pela implantação do Programa ter muita dificuldade didática, de falar em público o que prejudicou a compreensão de seu conteúdo pelos funcionários. Deve-se ressaltar que a empresa realizou diagnóstico buscando avaliar as suas necessidades em relação à qualidade antes da implantação do PSQT. 
No Bloco I a empresa disseminou a responsabilidade pela qualidade a todos, os conceitos e princípios da qualidade foram repassados mas assimilados de forma parcial e a missão e política da qualidade foram elaborados e disseminados parcialmente pela empresa. A empresa elaborou e aplicou a pesquisa de satisfação de clientes e estabeleceu indicadores de desempenho.

Em relação ao Bloco II todos os módulos foram implantados integralmente, havendo uma excelente participação e colaboração dos funcionários na execução das atividades a eles designadas.

No Bloco III a identificação e padronização dos processos da empresa foram parciais e três ferramentas da qualidade foram implantadas, mas houve dificuldade na implantação devido a falta de persistência e apoio dos responsáveis pelo repasse das ferramentas (pessoas-chave) e ao tempo curto para implantação.

Avaliação metodológica do PSQT: o treinamento repassado em sala de aula, a adequação do conteúdo do material utilizado às necessidades das pequenas empresas e a qualidade técnica do material utilizado foram ótimos. O apoio dado pelo Sebrae e pelo consultor também foi ótimo e o tempo de duração do Programa foi suficiente para a implantação das atividades do Programa.

Continuidade do Programa: a empresa não repassa aos funcionários novos a metodologia/conhecimento/informações adquiridos com o PSQT, havendo uma descontinuidade das ações do Programa na empresa. A empresa até chegou a propor ao Sebrae uma forma de acompanhamento do Programa, mas acabou não dando certo pela burocracia e valor alto que a empresa teria que arcar. A empresa pretende adotar algumas iniciativas (cursos, palestras, vídeos) em prol da qualidade mas não enfocando o PSQT especificamente.

Causas de Insucesso à Implantação do PSQT: as causas de insucesso, encontradas na Empresa D estão demonstradas na tabela 8.4.

Em relação à causa 1, é importante destacar que apesar de o entrevistado ter relatado que o envolvimento do proprietário foi alto, percebe-se que isto ocorreu sobretudo no Bloco I, decaindo nos outros dois blocos, o que pode ser reforçado pelo comentário feito pelo consultor ${ }^{*}$ e pelo fato de ter sido relatado a falta de apoio das pessoas-chave (sendo o proprietário uma delas) no repasse das ferramentas.

Em se tratando da causa 10, o empresário deixou de participar de algumas reuniões do Programa alegando motivo de agenda, falta de tempo para participar das mesmas

Já em relação à causa 11, foi colocado que no período de implantação do Bloco III houve um grande aumento de demanda e os funcionários ficaram sem tempo para realizar as tarefas do PSQT, pois tinham que se dedicar à produção.

\footnotetext{
* Página 171 desta dissertação
} 
Tabela 8.4 - Causas de Insucesso: Empresa D

\begin{tabular}{|l|l|c|}
\hline \multicolumn{1}{|c|}{ Causas de Insucesso } & \\
\hline 1 & Ausência de Foco no Consumidor & \\
\hline 2 & Ausência de Planejamento & \\
\hline 3 & Criação de uma estrutura interna paralela & $\mathrm{X}$ \\
\hline 4 & Não reconhecimento do corpo funcional pelas iniciativas da qualidade & $\mathrm{X}$ \\
\hline 5 & Dificuldade de utilização de ferramentas e técnicas & $\mathrm{X}$ \\
\hline 6 & Treinamento inadequado & $\mathrm{X}$ \\
\hline 7 & Qualidade não é medida em termos financeiros & $\mathrm{X}$ \\
\hline 8 & Falta de envolvimento do pequeno empresário & $\mathrm{X}$ \\
\hline 9 & Falta de envolvimento dos funcionários & $\mathrm{X}$ \\
\hline 10 & Falta de tempo do pequeno empresário & \\
\hline 11 & Falta de tempo dos funcionários & $\mathrm{X}$ \\
\hline 12 & Resistências Internas (por parte de alguns funcionários devido à cultura) & \\
\hline 13 & Difícil adaptação a diferentes tipos de negócios & \\
\hline 14 & Falta de apoio do consultor & $\begin{array}{l}\text { Deficiência de técnica de repasse da metodologia (do responsável pelo repasse em } \\
\text { falar em público) }\end{array}$ \\
\hline
\end{tabular}

Fonte: Elaboração Própria

Benefícios alcançados pela empresa com a implantação do Programa: a empresa passou a calcular os custos da qualidade; maior participação dos funcionários da produção na solução de problemas/ melhoria de produtos/processos; planejamento estratégico passou a ser instituído.

Outros benefícios que também ocorreram foram os seguintes: diminuição do índice de perdas; diminuição do índice de retrabalho; diminuição da reclamação de clientes; aumento da confiança no produto; melhoria da imagem do produto no mercado; aumento de produtividade; maior envolvimento dos funcionários com a qualidade; maior motivação dos funcionários no trabalho; abertura de mercado; aumento do volume de vendas; aumento do número de clientes; aumento da satisfação dos clientes; clientes passaram a ser mais exigentes; ferramentas auxiliaram a solução de problemas da empresa; melhorias em questões de organização, limpeza, arejamento e ruídos, devido à implantação do D’OLHO na Qualidade (Bloco II); maior preocupação com o cliente interno e externo e redução de custos.

Sugestões de Melhoria ao PSQT: o tempo de treinamento em sala de aula deveria ser mais curto, pois a duração de 4 horas é muito cansativa.

\subsubsection{EMPRESA E}

O PSQT atendeu as expectativas iniciais da empresa, proporcionando ganhos e grande melhoria à empresa em relação à Qualidade Total. Deve-se ressaltar que a empresa realizou diagnóstico buscando avaliar as necessidades da empresa em relação à qualidade antes da implantação do PSQT. 
No Bloco I a empresa disseminou a responsabilidade pela qualidade a todos, os conceitos e princípios da qualidade foram repassados mas assimilados de forma parcial e a missão e política da qualidade foram elaborados e disseminados por toda a empresa. A empresa elaborou e aplicou a pesquisa de satisfação de clientes e estabeleceu indicadores de desempenho.

Já em relação ao Bloco II, todos os módulos foram implantados integralmente, havendo uma grande colaboração e empenho dos funcionários na execução das atividades a eles designadas.

No Bloco III a identificação e padronização dos processos da empresa foram feitas parcialmente devido à falta de persistência e apoio dos responsáveis pelo repasse. Foram implantadas seis ferramentas da qualidade, mas houve dificuldade na implantação devido à falta de preparo dos funcionários, tendo assim dificuldade em compreendê-las.

Avaliação metodológica do PSQT: o treinamento repassado em sala de aula, a adequação do conteúdo do material utilizado às necessidades das pequenas empresas e a qualidade técnica do material utilizado foram satisfatórias. O apoio dado pelo Sebrae foi satisfatório, o apoio do consultor foi ótimo e o tempo de duração do Programa foi suficiente implantar as atividades.

Continuidade do Programa: a empresa busca dar continuidade no que foi aprendido com o PSQT, repassa os conhecimentos adquiridos com o Programa aos funcionários novos, o que é feito através de consultores externos. A empresa está buscando a certificação ISO 9000.

Causas de Insucesso à Implantação do PSQT: as seguintes causas de insucesso, demonstradas na tabela 8.5, foram encontradas na Empresa E.

Tabela 8.5 - Causas de Insucesso: Empresa E

\begin{tabular}{|l|l|c|}
\hline & \multicolumn{1}{|c|}{ Causas de Insucesso } & \\
\hline 1 & Ausência de Foco no Consumidor & X \\
\hline 2 & Ausência de Planejamento & \\
\hline 3 & Criação de uma estrutura interna paralela & X \\
\hline 4 & Não reconhecimento do corpo funcional pelas iniciativas da qualidade & \\
\hline 5 & Dificuldade de utilização de ferramentas e técnicas & X \\
\hline 6 & Treinamento inadequado & X \\
\hline 7 & Qualidade não é medida em termos financeiros & \\
\hline 8 & Falta de envolvimento do pequeno empresário & X \\
\hline 9 & Falta de envolvimento dos funcionários (foram resistentes ao PSQT) & \\
\hline 10 & Falta de tempo do pequeno empresário & X \\
\hline 11 & Falta de tempo dos funcionários & \\
\hline 12 & Resistências Internas (funcionários: dificuldade de mudar a cultura) & \\
\hline 13 & Difícil adaptação a diferentes tipos de negócios & $\begin{array}{l}\text { Deficiência de técnica de repasse da metodologia (dificuldade do responsável em } \\
\text { falar em público) }\end{array}$ \\
\hline 14 & Falta de apoio do consltor & \\
\hline 15 & \\
\hline
\end{tabular}

Fonte: Elaboração Própria 
Benefícios alcançados pela empresa com a implantação do Programa: especificação de materiais e serviços comprados que antes não era utilizado passou a ter baixa utilização;a empresa passou a realizar pesquisa de satisfação de clientes; e funcionários de produção passaram a ter um pouco de participação na solução de problemas e atividades de melhoria de produto e processo.

Outros benefícios que ocorreram foram: aumento do retorno financeiro; diminuição do índice de perdas; diminuição do índice de retrabalho; diminuição da reclamação de clientes; diminuição da devolução de produtos; aumento de produtividade; maior envolvimento dos funcionários com a qualidade; maior motivação dos funcionários no trabalho; abertura de mercado; aumento da satisfação dos clientes; clientes passaram a ser mais exigentes; melhorias em questões de organização, limpeza, arejamento e ruídos, alcançadas através da implantação do D’OLHO na Qualidade (Bloco II); a utilização das ferramentas da qualidade enriqueceu o potencial dos gerentes na solução de problemas; maior preocupação com o cliente interno e externo; e redução de custos.

Sugestões de melhoria do PSQT: o Sebrae deveria estabelecer uma melhor forma de auxiliar as pessoas que não possuem didática para repassar o conteúdo do Programa na empresa.

\subsubsection{EMPRESA F}

O PSQT atendeu parcialmente as expectativas iniciais da empresa. Conforme colocado pela pessoa-chave entrevistada, isso ocorreu por deficiência da própria empresa no gerenciamento das atividades e tarefas do Programa. Deve-se ressaltar que a empresa realizou um diagnóstico buscando avaliar as necessidades da empresa em relação à qualidade antes da implantação do PSQT.

No Bloco I a empresa disseminou a responsabilidade pela qualidade a todos, os conceitos e princípios da qualidade foram repassados mas assimilados de forma parcial e a missão e política da qualidade foram elaboradas e disseminados por toda a empresa. A empresa elaborou e aplicou a pesquisa de satisfação de clientes e não estabeleceu indicadores de desempenho. Pretendia estabelecer com o decorrer do Programa, mas isso acabou não ocorrendo.

Já em relação ao Bloco II, todos os módulos foram implantados integralmente, havendo uma grande colaboração e empenho dos funcionários na execução das atividades a eles designadas.

No Bloco III a identificação e padronização dos processos da empresa foram feitos parcialmente devido à falta de persistência e apoio dos responsáveis pelo repasse e a desmotivação dos funcionários. As ferramentas da qualidade não foram implantadas.

Na época da implantação do Bloco III houve a necessidade de priorização da produção pelo aumento da demanda e pelo conflito interno ocasionado por um descuido do gerente de produção que levou a empresa a lidar com um grande problema de qualidade do produto e retrabalho, pois 
houve a necessidade de refazer um pedido grande duas vezes. Um outro ponto que atrapalhou a empresa a implantar o Bloco II foi que estava operando em um local amontoado e preferiu deixar para repassar os dois últimos módulos do Bloco quando mudasse de instalações.

Avaliação metodológica do PSQT : o treinamento repassado em sala de aula, a adequação do conteúdo às necessidades das pequenas empresas, a qualidade técnica do material utilizado, o apoio dado pelo Sebrae e o apoio do consultor foram ótimos. O tempo de duração do Programa foi considerado muito curto para implantar todas as tarefas propostas.

Continuidade do Programa: a empresa não repassa os conhecimentos adquiridos com o PSQT aos funcionários novos, notando-se que o repasse do Programa não foi concluído. Porém, segundo a pessoa-chave entrevistada o Programa seria retomado em 2002.

Causas de Insucesso à implantação do PSQT: as seguintes causas de insucesso, demonstradas na tabela 8.6, foram encontradas na empresa F:

Tabela 8.6 - Causas de Insucesso: Empresa F

\begin{tabular}{|l|l|c|}
\hline \multicolumn{1}{|c|}{ Causas de Insucesso } & \\
\hline 1 & Ausência de Foco no Consumidor & \\
\hline 2 & Ausência de Planejamento & \\
\hline 3 & Criação de uma estrutura interna paralela & $\mathrm{X}$ \\
\hline 4 & Não reconhecimento do corpo funcional pelas iniciativas da qualidade & \\
\hline 5 & Dificuldade de utilização de ferramentas e técnicas & $\mathrm{X}$ \\
\hline 6 & Treinamento inadequado & $\mathrm{X}$ \\
\hline 7 & Qualidade não é medida em termos financeiros & $\mathrm{X}$ \\
\hline 8 & Falta de envolvimento do pequeno empresário & $\mathrm{X}$ \\
\hline 9 & Falta de envolvimento dos funcionários & \\
\hline 10 & Falta de tempo do pequeno empresário & \\
\hline 11 & Falta de tempo dos funcionários & \\
\hline 12 & Resistências Internas & \\
\hline 13 & Difícil adaptação a diferentes tipos de negócios & \\
\hline 14 & Falta de apoio do consultor & \\
\hline 15 & Deficiência de técnica de repasse da metodologia & \\
\hline
\end{tabular}

Fonte: Elaboração Própria

Em relação às causas 8 e 9, constatou-se que a falta de tempo, acabou levando a um não envolvimento dos funcionários e proprietários nas tarefas do Bloco III, sendo que a falta de tempo (causas 10 e 11) foi alegada pelo fato do proprietário e dos funcionários terem que dar prioridade à produção, tendo que deixar as atividades do PSQT em segundo plano.

Benefícios alcançados pela empresa com a implantação do Programa: a implantação do PSQT proporcionou vários benefícios para a Empresa F, como: funcionários da produção passaram a ter uma participação maior na solução de problemas/melhorias de produtos e processos; diminuição do índice de perdas; diminuição do índice de retrabalho; diminuição da reclamação de 
clientes; diminuição da devolução de produtos; melhoria da imagem do produto no mercado; maior participação e envolvimento do funcionário com a qualidade; abertura de novos mercados; aumento do volume de vendas; aumento da satisfação dos clientes; aumento do número de clientes; e melhorias em questões de organização e limpeza através da implantação do D’OLHO na Qualidade (Bloco II).

Sugestões de melhoria ao PSQT : deveria haver um acompanhamento pelo menos durante seis meses de algum consultor ou de alguém do Sebrae para ver se o Programa realmente foi implantado. Caso contrário o consultor deveria auxiliar na correção das falhas, evitando a perda do Programa.

\subsubsection{EMPRESA G}

O PSQT atendeu as expectativas iniciais da empresa, proporcionando grandes melhorias em relação à Qualidade Total. Deve-se ressaltar que a empresa realizou um diagnóstico buscando avaliar as necessidades da empresa em relação à qualidade antes da implantação do PSQT.

No Bloco I a empresa disseminou a responsabilidade pela qualidade a todos, os conceitos e princípios da qualidade foram repassados e assimilados pelos funcionários e missão e a política da qualidade foram elaboradas e disseminados por toda a empresa. A empresa elaborou e aplicou a pesquisa de satisfação de clientes e estabeleceu indicadores de desempenho.

Em relação ao Bloco II, todos os módulos foram implantados integralmente, havendo uma grande colaboração e empenho dos funcionários na execução das atividades a eles designadas.

No Bloco III todos os processos foram identificados e padronizados e as ferramentas da qualidade foram implantadas. Não houve dificuldade na compreensão das ferramentas, exceto alguns casos isolados, de funcionários com grau de escolaridade muito baixo.

Avaliação metodológica do PSQT : o treinamento repassado em sala de aula, a adequação do conteúdo às necessidades das pequenas empresas, a qualidade técnica do material utilizado, o apoio dado pelo Sebrae e o apoio do consultor foram ótimos. O tempo de duração do Programa foi considerado suficiente para implantar todas as tarefas do Programa.

Continuidade do Programa: a empresa repassa os conhecimentos adquiridos com o PSQT aos funcionários novos, inclusive na época da entrevista, outubro de 1999, estava revendo o Programa na empresa.

Causas de Insucesso à implantação do PSQT: as seguintes causas de insucesso, demonstradas na tabela 8.7, foram encontradas na Empresa G: 
Tabela 8.7 - Causas de Insucesso: Empresa G

\begin{tabular}{|l|l|c|}
\hline \multicolumn{1}{|c|}{ Causas de Insucesso } & \\
\hline 1 & Ausência de Foco no Consumidor & \\
\hline 2 & Ausência de Planejamento & \\
\hline 3 & Criação de uma estrutura interna paralela & \\
\hline 4 & Não reconhecimento do corpo funcional pelas iniciativas da qualidade & \\
\hline 5 & Dificuldade de utilização de ferramentas e técnicas & \\
\hline 6 & Treinamento inadequado & $\mathrm{X}$ \\
\hline 7 & Qualidade não é medida em termos financeiros & \\
\hline 8 & Falta de envolvimento do pequeno empresário & \\
\hline 9 & Falta de envolvimento dos funcionários & $\mathrm{X}$ \\
\hline 10 & Falta de tempo do pequeno empresário & \\
\hline 11 & Falta de tempo dos funcionários & \\
\hline 12 & Resistências Internas (dos funcionários, devido à dificuldade em mudar a cultura) & \\
\hline 13 & Difícil adaptação a diferentes tipos de negócios & \\
\hline 14 & Falta de apoio do consultor & \\
\hline 15 & Deficiência de técnica de repasse da metodologia & \\
\hline
\end{tabular}
Fonte: Elaboração Própria

Benefícios alcançados pela empresa com a Implantação do Programa: especificação e registro de materiais e serviços que era baixa passou a ser feita integralmente; registro de materiais e serviços comprados passou a ser utilizado; critérios de aceitação de produtos aos fornecedores foram instituídos, pesquisa de satisfação de clientes passou a ser feita; custos da qualidade passaram a ser calculados; funcionários passaram a ter participação maior na solução de problemas/melhorias de produtos e processos.

Outros benefícios que ocorreram foram: aumento do retorno financeiro; diminuição do índice de perdas; diminuição do índice de retrabalho; diminuição da reclamação de clientes; aumento da confiança do cliente no produto; melhoria da imagem do produto no mercado; aumento de produtividade; maior envolvimento dos funcionários com a qualidade; maior motivação dos funcionários no trabalho; abertura de mercado; aumento da satisfação dos clientes; clientes passaram a ser mais exigentes; melhorias em questões de organização, limpeza, arejamento e ruídos, alcançadas através da implantação do D’OLHO na Qualidade (Bloco II); e ferramentas auxiliaram na resolução de problemas, melhorando a qualidade dos produtos,

Sugestões de melhoria: o Sebrae poderia oferecer às empresas uma forma, ou um novo produto que desse continuidade às ações de Gestão da Qualidade nas empresas que implantaram o Programa, melhorando o que foi aprendido e instituindo novas atividades, técnicas e ações.

\subsubsection{EMPRESA H}

Os resultados alcançados com o PSQT atenderam parcialmente as expectativas iniciais da empresa, o que ocorreu, segundo um dos sócios-proprietários entrevistado, devido a problemas 
internos da empresa, e não a falhas do Programa. A empresa não realizou diagnóstico buscando avaliar as necessidades da empresa em relação à qualidade antes da implantação do PSQT.

No Bloco I a responsabilidade pela qualidade foi disseminada a todos, os conceitos e princípios da qualidade foram repassados e assimilados pelos funcionários e missão e a política da qualidade elaboradas e disseminadas por toda a empresa. A empresa elaborou e aplicou a pesquisa de satisfação de clientes, mas não estabeleceu indicadores de desempenho por considerar não ser importante para a empresa.

Já em relação ao Bloco II, todos os módulos foram implantados integralmente, havendo uma grande colaboração e empenho dos funcionários na execução das atividades a eles designadas

No Bloco III os processos da empresa foram identificados e padronizados parcialmente devido à falta de persistência e apoio dos responsáveis pelo PSQT na empresa. As ferramentas da qualidade foram implantadas, não havendo dificuldades de compreensão.

Avaliação metodológica do PSQT : o treinamento repassado em sala de aula, a adequação do conteúdo às necessidades das pequenas empresas, a qualidade técnica do material utilizado, o apoio dado pelo Sebrae e pelo consultor foram ótimos. O tempo de duração do Programa foi considerado suficiente para implantar todas as tarefas do Programa.

Continuidade do Programa: a empresa não repassa os conhecimentos adquiridos com o PSQT aos funcionários novos, mas pretende adotar uma forma de repasse. O que foi aprendido com o PSQT está parado, e a cultura da empresa em relação à qualidade está pouco desenvolvida.

Causas de Insucesso à Implantação do PSQT: as seguintes causas de insucesso, mostradas na tabela 8.8, foram encontradas na Empresa $\mathrm{H}$.

Tabela 8.8 - Causas de Insucesso: Empresa H

\begin{tabular}{|l|l|c|}
\hline \multicolumn{1}{|c|}{ Causas de Insucesso } & \\
\hline 1 & Ausência de Foco no Consumidor & \\
\hline 2 & Ausência de Planejamento & $\mathrm{X}$ \\
\hline 3 & Criação de uma estrutura interna paralela & \\
\hline 4 & Não reconhecimento do corpo funcional pelas iniciativas da qualidade & \\
\hline 5 & Dificuldade de utilização de ferramentas e técnicas & \\
\hline 6 & Treinamento inadequado & $\mathrm{X}$ \\
\hline 7 & Qualidade não é medida em termos financeiros & \\
\hline 8 & Falta de envolvimento do pequeno empresário & $\mathrm{X}$ \\
\hline 9 & Falta de envolvimento dos funcionários & $\mathrm{X}$ \\
\hline 10 & Falta de tempo do pequeno empresário & \\
\hline 11 & Falta de tempo dos funcionários & \\
\hline 12 & Resistências Internas & \\
\hline 13 & Difícil adaptação a diferentes tipos de negócios & \\
\hline 14 & Falta de apoio do consultor & \\
\hline 15 & Deficiência de técnica de repasse da metodologia & \\
\hline
\end{tabular}

Fonte: Elaboração Própria 
É importante destacar que as resistências internas (causa 12) ocorreram por parte de dois novos diretores que entraram na empresa na época em que o PSQT estava sendo implantado. Os diretores mostraram-se resistentes às atividades do PSQT, não dando apoio aos subordinados para se dedicarem às tarefas do Programa.

Benefícios alcançados pela empresa com a implantação do Programa: na Empresa $H$, vários benefícios ocorreram, como: a empresa passou a realizar pesquisa de satisfação de clientes (ainda que de maneira informal); funcionários continuaram a participar pouco na solução de problemas e atividades de melhoria de produtos e processos; diminuição do índice de perdas; diminuição do índice de retrabalho; diminuição de reclamação dos clientes; diminuição da devolução de produtos; melhoria da imagem do produto no mercado; aumento de produtividade maior envolvimento dos funcionários com a qualidade; aumento do número de clientes aumento da satisfação dos clientes; e melhorias em questões de organização, principalmente na identificação de arquivos, materiais de uso comum, identificação e organização de material estocado etc.

Sugestões de melhoria ao PSQT: não foram feitas sugestões.

\subsection{EMPRESA I}

Os resultados alcançados com o PSQT atenderam parcialmente as expectativas iniciais, devido às dificuldades próprias da empresa, que sofreu dificuldades na aceitação de seu produto no mercado (deixou de trabalhar com marcas de terceiros e passou a produzir sua própria marca) e teve que voltar seus esforços para o mercado. Deve-se ressaltar que a empresa não realizou um diagnóstico buscando avaliar as necessidades da empresa em relação à qualidade antes da implantação do PSQT.

No Bloco I, a responsabilidade pela qualidade foi delegada a uma equipe de trabalho que coordenava as atividades do Programa dentro da empresa. Já os conceitos e princípios da qualidade foram repassados e assimilados pelos funcionários e a missão e política da qualidade foram elaboradas e disseminadas por toda a empresa. A empresa elaborou e aplicou a pesquisa de satisfação de clientes e estabeleceu indicadores de desempenho.

Já em relação ao Bloco II, todos os módulos foram implantados integralmente, havendo uma grande colaboração e empenho dos funcionários na execução das atividades a eles designadas.

No Bloco III todos os processos foram identificados mas não chegaram a ser padronizados. As ferramentas da qualidade foram implantadas mas houve dificuldade na implantação dessas devido a dois fatores principais: tempo curto para implantação e falta de preparo dos funcionários

Avaliação metodológica do PSQT: o treinamento repassado em sala de aula foi satisfatório e a adequação do conteúdo às necessidades das pequenas empresas deixou a desejar 
porque o conteúdo do Programa em alguns momentos, principalmente no Bloco III, é de difícil compreensão. A qualidade técnica do material utilizado foi ótima, o apoio dado pelo Sebrae satisfatório e o apoio do consultor foi ótimo. O tempo de duração do Programa foi considerado curto para implantar todas as tarefas do Programa.

Continuidade do Programa: a empresa não repassa os conhecimentos adquiridos com o Programa aos funcionários novos, percebendo-se que não há uma continuidade das ações da Qualidade na empresa. O entrevistado considera que a cultura da empresa em relação à qualidade está em desenvolvimento.

Causas de Insucesso à Implantação do PSQT: as causas de insucesso encontradas na Empresa I, estão demonstradas na tabela 8.9.

Tabela 8.9 - Causas de Insucesso: Empresa I

\begin{tabular}{|l|l|c|}
\hline \multicolumn{1}{|c|}{ Causas de Insucesso } & \\
\hline 1 & Ausência de Foco no Consumidor & $\mathrm{X}$ \\
\hline 2 & Ausência de Planejamento & $\mathrm{X}$ \\
\hline 3 & $\begin{array}{l}\text { Criação de uma estrutura interna paralela (responsabilidade pela qualidade } \\
\text { delegada a uma equipe) }\end{array}$ & $\mathrm{X}$ \\
\hline 4 & Não reconhecimento do corpo funcional pelas iniciativas da qualidade & \\
\hline 5 & Dificuldade de utilização de ferramentas e técnicas & $\mathrm{X}$ \\
\hline 6 & Treinamento inadequado & $\mathrm{X}$ \\
\hline 7 & Qualidade não é medida em termos financeiros & $\mathrm{X}$ \\
\hline 8 & Falta de envolvimento do pequeno empresário ( não participou do PSQT) & $\mathrm{X}$ \\
\hline 9 & Falta de envolvimento dos funcionários (devido a uma crise na empresa) & \\
\hline 10 & Falta de tempo do pequeno empresário & \\
\hline 11 & Falta de tempo dos funcionários & \\
\hline 12 & Resistências Internas & \\
\hline 13 & Difícil adaptação a diferentes tipos de negócios & \\
\hline 14 & Falta de apoio do consultor & \\
\hline 15 & Deficiência de técnica de repasse da metodologia & \\
\hline
\end{tabular}

Fonte: Elaboração Própria

Vê-se necessário destacar que em relação à causa 1 em nenhum momento a empresa relaciona o PSQT ou Qualidade Total às necessidades dos clientes e a pesquisa de satisfação do cliente é muito pouco realizada. Um outro fato que pode reforçar a ausência de foco no consumidor trata-se da empresa ter lançado sua marca no mercado e antes não ter feito uma avaliação para verificar a aceitação do produto.

Benefícios alcançados pela empresa com a implantação do Programa: especificação e registro de materiais e serviços que era baixa passou a ser feita integralmente; critérios de aceitação de produtos aos fornecedores passou a ser instituído, antes apenas alguns produtos possuíam 
critérios de aceitação; maior participação/envolvimento dos funcionários com a qualidade; maior motivação dos funcionários no trabalho.

Sugestões de melhoria ao PSQT : não foram feitas sugestões de melhoria ao PSQT.

\subsection{EMPRESA J}

Os resultados alcançados com o PSQT atenderam totalmente as expectativas iniciais da empresa. Deve-se ressaltar que a empresa realizou um diagnóstico buscando avaliar as necessidades da empresa em relação à qualidade antes da implantação do PSQT.

No Bloco I, a responsabilidade pela qualidade foi disseminada a todos, os conceitos e princípios da qualidade foram repassados e assimilados pelos funcionários e a missão e política da qualidade foram elaboradas e disseminadas por toda a empresa. A empresa elaborou e aplicou a pesquisa de satisfação de clientes e estabeleceu indicadores de desempenho.

Em relação ao Bloco II, todos os módulos foram implantados integralmente, houve uma grande colaboração e empenho dos funcionários no cumprimento das atividades a eles designadas.

No Bloco III todos os processos foram identificados e padronizados. As ferramentas da qualidade foram implantadas, mas houve dificuldade na implantação devido à falta de persistência e apoio dos responsáveis pelo repasse, falta de preparo dos funcionários e tempo curto para implantação.

Avaliação Metodológica do Programa: o treinamento repassado em sala de aula, a adequação do conteúdo às necessidades das pequenas empresas, a qualidade técnica do material utilizado e o apoio dado pelo Sebrae foram considerados ótimos. O tempo de duração do Programa foi considerado suficiente para implantar todas as tarefas do Programa e o apoio do consultor considerado ótimo.

Continuidade do Programa: a empresa repassa os conhecimentos adquiridos com o PSQT aos funcionários novos, inclusive já está reimplantando o PSQT. A cultura da empresa em relação à qualidade está em desenvolvimento.

Causa de Insucesso à implantação do PSQT: as seguintes causas de insucesso, demonstradas na tabela 8.10, foram encontradas na Empresa J: 
Tabela 8.10 - Causas de Insucesso: Empresa J

\begin{tabular}{|l|l|c|}
\hline \multicolumn{1}{|c|}{ Causas de Insucesso } & \\
\hline 1 & Ausência de Foco no Consumidor & \\
\hline 2 & Ausência de Planejamento & \\
\hline 3 & Criação de uma estrutura interna paralela & \\
\hline 4 & Não reconhecimento do corpo funcional pelas iniciativas da qualidade & $\mathrm{X}$ \\
\hline 5 & Dificuldade de utilização de ferramentas e técnicas & $\mathrm{X}$ \\
\hline 6 & Treinamento inadequado & $\mathrm{X}$ \\
\hline 7 & Qualidade não é medida em termos financeiros & $\mathrm{X}$ \\
\hline 8 & Falta de envolvimento do pequeno empresário & $\mathrm{X}$ \\
\hline 9 & Falta de envolvimento dos funcionários & \\
\hline 10 & Falta de tempo do pequeno empresário & \\
\hline 11 & Falta de tempo dos funcionários & $\mathrm{X}$ \\
\hline 12 & Resistências Internas & \\
\hline 13 & Difícil adaptação a diferentes tipos de negócios & \\
\hline 14 & Falta de apoio do consultor & \\
\hline 15 & Deficiência de técnica de repasse da metodologia & \\
\hline
\end{tabular}
Fonte: Elaboração Própria

Benefícios alcançados pela empresa com a Implantação do Programa: funcionários de produção passaram a participar mais da solução de problemas/melhoria de produtos e processos; planejamento estratégico passou a ser instituído; diminuição do índice de perdas; diminuição do índice de retrabalho; diminuição dos custos de qualidade; diminuição das reclamações dos clientes; aumento da confiança do cliente no produto; melhoria da imagem do produto no mercado; aumento de produtividade; maior envolvimento dos funcionários com a qualidade; maior motivação dos funcionários no trabalho; aumento do número de clientes; aumento da satisfação dos clientes; clientes passaram a ser mais exigentes; melhorias em questões de organização, limpeza, arejamento e ruídos, alcançadas através da implantação do D’OLHO na Qualidade (Bloco II); ferramentas auxiliaram a parte de solução de problemas na produção, diminuindo a ocorrência desses.

Sugestões de melhoria: a sugestão dada pelo proprietário entrevistado é que o Sebrae deveria, periodicamente, reunir os integrantes do grupo treinado através de reuniões de avaliação e reciclagem.

\subsection{ANÁLISE DOS CONSULTORES}

Buscando comparar a análise feita pelos consultores a respeito do Programa montou-se duas, com os respectivos comentários de cada uma delas. 
Tabela 8.11 - Avaliação dos Consultores: Pontos específicos do PSQT

\begin{tabular}{|c|c|c|c|}
\hline & Consultor 1 & Consultor 2 & Consultor 3 \\
\hline $\begin{array}{l}\text { Pesquisa "Nossa } \\
\text { Empresa trabalha } \\
\text { com Qualidade Total" }\end{array}$ & $\begin{array}{l}\text { Não consegue avaliar } \\
\text { as reais necessidades } \\
\text { da empresa em relação } \\
\text { a GQT }\end{array}$ & $\begin{array}{l}\text { Consegue avaliar as } \\
\text { reais necessidades da } \\
\text { empresa em relação à } \\
\text { GQT }\end{array}$ & $\begin{array}{l}\text { Consegue avaliar as } \\
\text { reais necessidades da } \\
\text { empresa em relação à } \\
\text { GQT, mas poderia ser } \\
\text { apresentada mais } \\
\text { adiante no programa }\end{array}$ \\
\hline Prazo de implantação & $\begin{array}{l}\text { Suficiente para } \\
\text { implantar as atividades } \\
\text { do programa }\end{array}$ & $\begin{array}{l}\text { Suficiente para } \\
\text { implantar as atividades } \\
\text { do programa }\end{array}$ & $\begin{array}{l}\text { Suficiente para } \\
\text { implantar as atividades } \\
\text { do programa }\end{array}$ \\
\hline $\begin{array}{l}\text { Número de horas de } \\
\text { consultoria }\end{array}$ & Baixo & Adequado & Adequado \\
\hline Apoio do consultor & Adequado & Adequado & $\begin{array}{l}\text { Poderia melhorar em } \\
\text { certos casos (de acordo } \\
\text { com a necessidade da } \\
\text { empresa) }\end{array}$ \\
\hline Metodologia & $\begin{array}{l}\text { Adequada ao público } \\
\text { alvo }\end{array}$ & $\begin{array}{l}\text { Adequada ao público } \\
\text { alvo }\end{array}$ & $\begin{array}{l}\text { Adequada ao público } \\
\text { alvo }\end{array}$ \\
\hline $\begin{array}{l}\text { Qualidade do } \\
\text { Material didático }\end{array}$ & $\begin{array}{l}\text { apostilas - baixa } \\
\text { fitas de vídeo - } \\
\text { satisfatória } \\
\text { cartazes - satisfatória } \\
\end{array}$ & $\begin{array}{l}\text { apostilas - satisfatória } \\
\text { fitas de vídeo - } \\
\text { satisfatória } \\
\text { cartazes - baixa } \\
\end{array}$ & $\begin{array}{l}\text { apostilas - satisfatória } \\
\text { fitas de vídeo - alta } \\
\text { cartazes - satisfatória }\end{array}$ \\
\hline Duração dos módulos & Adequada & Adequada & Adequada \\
\hline Casos práticos & $\begin{array}{l}\text { Número suficiente } \\
\text { Adequados às } \\
\text { necessidades das PEs }\end{array}$ & $\begin{array}{l}\text { Número suficiente } \\
\text { Adequados às } \\
\text { necessidades das PEs }\end{array}$ & $\begin{array}{l}\text { Número suficiente } \\
\text { Adequados às } \\
\text { necessidades das PEs }\end{array}$ \\
\hline $\begin{array}{l}\text { PSQT trabalhado } \\
\text { com grupos de um } \\
\text { mesmo setor }\end{array}$ & $\begin{array}{l}\text { Apresenta melhores } \\
\text { resultados }\end{array}$ & $\begin{array}{l}\text { Apresenta melhores } \\
\text { resultados }\end{array}$ & $\begin{array}{l}\text { Apresenta melhores } \\
\text { resultados }\end{array}$ \\
\hline $\begin{array}{l}\text { Etapa de Sustentação } \\
\text { (etapa do programa } \\
\text { que ocorre após } 30 \text { e } \\
60 \text { dias para verificar } \\
\text { a continuidade das } \\
\text { ações do PSQT) }\end{array}$ & $\begin{array}{l}\text { Fundamental, mas o } \\
\text { programa morre aí (em } \\
\text { geral) }\end{array}$ & $\begin{array}{l}\text { Falha. O ideal seria que } \\
\text { o consultor retornasse à } \\
\text { empresa após alguns } \\
\text { meses, não um/dois } \\
\text { meses após a } \\
\text { implantação. }\end{array}$ & $\begin{array}{l}\text { Só da resultados frente } \\
\text { a existência de três } \\
\text { aspectos relacionados: } \\
\text { grupo sensibilizado das } \\
\text { vantagens do PSQT; } \\
\text { visão madura dos } \\
\text { líderes e exigência dos } \\
\text { funcionários quanto a } \\
\text { continuidade do PSQT }\end{array}$ \\
\hline $\begin{array}{l}\text { Acompanhamento a } \\
\text { longo prazo }\end{array}$ & $\begin{array}{l}\text { Viável. Poderia ser } \\
\text { feito com reuniões } \\
\text { mensais de implantação } \\
\text { de melhorias e } \\
\text { consultorias } \\
\end{array}$ & $\begin{array}{l}\text { Viável. O consultor } \\
\text { poderia realizar } \\
\text { auditorias através de } \\
\text { visitas, no ano seguinte } \\
\text { à implantação. } \\
\end{array}$ & $\begin{array}{l}\text { Viável. Só vem a } \\
\text { somar, sendo uma } \\
\text { solicitação frequente } \\
\text { das empresas que } \\
\text { participam do PSQT } \\
\end{array}$ \\
\hline
\end{tabular}

Fonte: Elaboração Própria

A partir da tabela 8.11, demonstrada anteriormente pode-se perceber poucos pontos divergentes na opinião dos consultores, notando-se apenas a discordância de um deles a respeito da 
pesquisa feita no início do Programa para levantar a situação da empresa em relação à Qualidade Total.

Pontos importantes podem ser levantados através dos dados demonstrados na tabela:

- $\quad$ o apoio do consultor é adequado, mas casos isolados deveriam ser analisados para um melhor atendimento da empresa treinada;

- $\quad$ a qualidade técnica do material didático é satisfatória, merecendo melhorias;

- $\quad$ o PSQT quando trabalhado setorialmente apresenta melhores resultados;

- a etapa de sustentação é fundamental mas poderia ser modificada, sendo que seu resultado depende muito do empenho da empresa em dar continuidade nas ações do Programa. Isto nem sempre acontece (como foi revelado através do trabalho de campo feito nas empresas) ;

- o acompanhamento a longo prazo seria viável para consolidar a implantação do Programa.

Os consultores entrevistados relataram quais as principais causas de insucesso à implantação do PSQT, conforme apresentado na tabela 8.12.

As causas apontadas por pelo menos dois consultores foram as seguintes:

- $\quad$ ausência de foco no consumidor;

- $\quad$ ausência de planejamento;

- $\quad$ falta de envolvimento do pequeno empresário;

- $\quad$ falta de tempo do pequeno empresário;

- $\quad$ falta de tempo dos funcionários;

- $\quad$ qualidade não é medida em termos financeiros; e

- $\quad$ resistências internas.

Dentre essas sete causas duas tiveram unanimidade entre os consultores: a falta de envolvimento do pequeno empresário e a falta de tempo do pequeno empresário.

A "falta de envolvimento do pequeno empresário" foi a causa que mais ocorreu nas empresas pesquisadas e também é a causa mais citada dentre as pesquisas já realizadas, registrado na revisão bibliográfica.

Já a "falta de tempo do pequeno empresário", não teve uma ocorrência muito grande nas empresas pesquisadas (citada apenas em três delas) e também é citada em apenas duas dentre as cinco pesquisas realizadas específicas do PSQT. Nas outras pesquisas gerais, sobre Programas de Qualidade este fator não foi apontado.

Todas as causas citados na tabela 8.12, até mesmo as que não foram consideradas relevantes para o insucesso do PSQT pelos consultores, foram apontadas nas empresas pesquisadas, com maior ou menor freqüência. O mesmo ocorreu nas pesquisas registradas na revisão bibliográfica. 
Tabela 8.12: Fatores de Insucesso: Avaliação Consultores

\begin{tabular}{|c|c|c|c|}
\hline & Consultor 1 & Consultor 2 & Consultor 3 \\
\hline $\begin{array}{l}\text { ausência de foco no } \\
\text { consumidor }\end{array}$ & $\operatorname{sim}$ & $\operatorname{sim}$ & não \\
\hline $\begin{array}{l}\text { ausência de } \\
\text { planejamento }\end{array}$ & $\operatorname{sim}$ & $\operatorname{sim}$ & não \\
\hline $\begin{array}{l}\text { criação de uma } \\
\text { estrutura paralela da } \\
\text { qualidade }\end{array}$ & $\operatorname{sim}$ & não & não \\
\hline $\begin{array}{l}\text { não reconhecimento do } \\
\text { corpo funcional pelas } \\
\text { iniciativas da qualidade }\end{array}$ & $\operatorname{sim}$ & não & não \\
\hline $\begin{array}{l}\text { dificuldade na } \\
\text { utilização de } \\
\text { ferramentas e técnicas }\end{array}$ & $\operatorname{sim}$ & não & não \\
\hline $\begin{array}{l}\text { treinamento } \\
\text { inadequado à realidade } \\
\text { da empresa }\end{array}$ & $\operatorname{sim}$ & não & não \\
\hline $\begin{array}{l}\text { falta de envolvimento } \\
\text { do pequeno empresário }\end{array}$ & $\operatorname{sim}$ & $\operatorname{sim}$ & $\operatorname{sim}$ \\
\hline $\begin{array}{l}\text { falta de tempo do } \\
\text { pequeno empresário }\end{array}$ & $\operatorname{sim}$ & $\operatorname{sim}$ & $\operatorname{sim}$ \\
\hline $\begin{array}{l}\text { falta de tempo dos } \\
\text { funcionários }\end{array}$ & não & $\operatorname{sim}$ & $\operatorname{sim}$ \\
\hline $\begin{array}{l}\text { qualidade não é medida } \\
\text { em termos financeiros }\end{array}$ & não & $\operatorname{sim}$ & $\operatorname{sim}$ \\
\hline resistências internas & não & $\operatorname{sim}$ & $\operatorname{sim}$ \\
\hline $\begin{array}{llr}\text { difícil adaptação } & \text { a } \\
\text { diferentes tipos } & \text { de } \\
\text { negócio } & & \\
\end{array}$ & não & não & não \\
\hline $\begin{array}{l}\text { falta de apoio do } \\
\text { consultor }\end{array}$ & não & não & não \\
\hline $\begin{array}{l}\text { deficiência de técnica } \\
\text { de repasse da } \\
\text { metodologia }\end{array}$ & não & $\operatorname{sim}$ & não \\
\hline
\end{tabular}

Fonte: Elaboração Própria

\subsection{OBSERVAÇÕES DA PESQUISADORA}

A partir da pesquisa de campo realizada, a pesquisadora verificou ser necessário incluir algumas causas de insucesso como influentes na implantação do Programa Sebrae de Qualidade Total, sendo elas:

1. Falta de envolvimento das pessoas-chave: apontada nas empresas B, C, D, E, F, H e I;

2. Falta de tempo das pessoas-chave: apontada nas empresas B, D, E e F;

3. Ansiedade por resultados: apontada na empresa C;

4. Tempo curto para implantação do Programa: apontada nas empresas F, H e I; e 
5. Conteúdo do Programa de difícil entendimento: empresas C e I.

Das cinco causas citadas, as duas primeiras não foram apontadas em estudos anteriores, não sendo encontradas na literatura pesquisada. Viu-se necessário o estabelecimento dessas novas duas causas pelo fato de que as pessoas-chave são fundamentais na implantação do Programa; exercem diferentes papéis nessa implantação em relação aos funcionários e muitas vezes em relação ao proprietário da empresa, que nem sempre participa como pessoa-chave.

Já as três últimas causas já apareceram em outros estudos existentes na literatura, porém não foram apontados na seção 8.1 porque nesta seção as causas incluídas foram as de maior ocorrência na literatura, o que não foi o caso dessas três causas. Porém viu-se necessário citá-las, uma vez que ocorreram em alguns casos, nas empresas pesquisadas. Tal ocorrência será analisada seguir.

\subsection{CLASSIFICAÇÃO DAS CAUSAS DE INSUCESSO EM FATORES}

Buscando compreender melhor a ocorrências das causas de insucesso e a influência dessas na implantação do PSQT estabeleceu-se a classificação dessas causas em fatores organizacional, comportamental e metodológico.

As causas de insucesso, apontadas na literatura como as de maior ocorrência na implantação de Programas da Qualidade e também as causas observadas pela pesquisadora, foram classificadas dentro dos fatores organizacional, comportamental e metodológico, conforme a tabela 8.13.

É importante destacar que a causa 5, “dificuldade de utilização das ferramentas e técnicas”, pode ser classificada como organizacional, comportamental ou metodológica, dependendo do motivo de sua ocorrência. Ela recebe a classificação organizacional quando ocorre por falta de apoio dos responsáveis pelo repasse; a classificação comportamental quando ocorre por falta de preparo dos funcionários, dificultando a compreensão das ferramentas e a classificação dentro de fator metodológico ocorre devido ao tempo curto para implantação.

Percebe-se então que a classificação das causas de insucesso em fator organizacional, comportamental e metodológico é flexível, permitindo que uma mesma causa possa ser classificada nos três fatores estabelecidos. 
Tabela 8.13 - Classificação das Causas de Insucesso em Fatores

\begin{tabular}{|l|l|c|c|c|}
\hline \multicolumn{1}{|c|}{ Causas de Insucesso } & \multicolumn{1}{|c|}{ Fatores de insucesso } \\
\hline & \multicolumn{1}{|c|}{ O } & C & M \\
\hline 1 & Ausência de Foco no Consumidor & X & & \\
\hline 2 & Ausência de Planejamento & $\mathrm{X}$ & & \\
\hline 3 & Criação de uma estrutura interna paralela & $\mathrm{X}$ & & \\
\hline 4 & Não reconhecimento do corpo funcional pelas iniciativas da qualidade & $\mathrm{X}$ & & \\
\hline 5 & Dificuldade de utilização de ferramentas e técnicas & $\mathrm{X}$ & $\mathrm{X}$ & $\mathrm{X}$ \\
\hline 6 & Treinamento inadequado & & & $\mathrm{X}$ \\
\hline 7 & Qualidade não é medida em termos financeiros & $\mathrm{X}$ & & \\
\hline 8 & Falta de envolvimento do pequeno proprietário & & $\mathrm{X}$ & \\
\hline 9 & Falta de envolvimento dos funcionários & & $\mathrm{X}$ & \\
\hline 10 & Falta de tempo do pequeno empresário & $\mathrm{X}$ & & \\
\hline 11 & Falta de tempo dos funcionários & $\mathrm{X}$ & & \\
\hline 12 & Resistências Internas & & $\mathrm{X}$ & \\
\hline 13 & Difícil adaptação a diferentes tipos de negócios & & & $\mathrm{X}$ \\
\hline 14 & Falta de apoio do consultor & & & $\mathrm{X}$ \\
\hline 15 & Deficiência de técnica de repasse da metodologia & & $\mathrm{X}$ & \\
\hline 16 & Ansiedade por Resultados & & $\mathrm{X}$ & \\
\hline 17 & Falta de envolvimento das pessoas-chave & $\mathrm{X}$ & & \\
\hline 18 & Falta de tempo das pessoas-chave & & & $\mathrm{X}$ \\
\hline 19 & Conteúdo do PSQT de difícil entendimento & & & $\mathrm{X}$ \\
\hline 20 & Tempo curto para a implantação do PSQT & & & \\
\hline Legenda \\
O - Organizacional C - Comportamental M - Metodológico
\end{tabular}

Fonte: Elaboração Própria

Dentre as dez empresas pesquisadas, a ocorrência das causas de insucesso pode ser vista na tabela 8.14.

A partir dos números demonstrados na tabela 8.14 pode-se dizer que a ocorrência de insucesso do PSQT deve-se principalmente ao fator organizacional e comportamental, com diferença numérica de uma ocorrência a menos do primeiro para o segundo, e depois pelo metodológico.

Em relação ao fator organizacional, a causa que apresentou maior ocorrência foi a “qualidade não ser medida em termos financeiros”, dificultando a visualização pela organização de quanto ela está arcando com os custos da má qualidade, e conseqüentemente o quanto poderia ganhar se o que está ocasionando este custo pudesse ser solucionado. A representação quantitativa desse custo/ganho em se utilizar a qualidade é um fator que pode influenciar no empenho, na motivação e envolvimento com à implantação da qualidade, sobretudo para o pequeno empresário. 
Tabela 8.14 - Ocorrência das Causas de Insucesso

\begin{tabular}{|l|l|c|c|c|}
\hline & \multicolumn{1}{|c|}{ Causas de Insucesso } & \multicolumn{2}{|c|}{ Fatores de Insucesso } \\
\hline & \multicolumn{1}{|c|}{ O } & C & M \\
\hline 1 & Ausência de Foco no Consumidor & 2 & & \\
\hline 2 & Ausência de Planejamento & 3 & & \\
\hline 3 & Criação de uma estrutura interna paralela & 2 & & \\
\hline 4 & Não reconhecimento do corpo funcional pelas iniciativas da qualidade & 3 & & \\
\hline 5 & Dificuldade de utilização de ferramentas e técnicas & 3 & 4 & 4 \\
\hline 6 & Treinamento inadequado & & & \\
\hline 7 & Qualidade não é medida em termos financeiros & 7 & & \\
\hline 8 & Falta de envolvimento do pequeno proprietário & & 9 & \\
\hline 9 & Falta de envolvimento dos funcionários & & 5 & \\
\hline 10 & Falta de tempo do pequeno empresário & 3 & & \\
\hline 11 & Falta de tempo dos funcionários & 5 & & \\
\hline 12 & Resistências Internas & & 6 & \\
\hline 13 & Difícil adaptação a diferentes tipos de negócios & & & \\
\hline 14 & Falta de apoio do consultor & & & \\
\hline 15 & Deficiência de técnica de repasse da metodologia & & & 4 \\
\hline 16 & Ansiedade por Resultados & & 1 & \\
\hline 17 & Falta de envolvimento das pessoas-chave & 4 & & \\
\hline 18 & Falta de tempo das pessoas-chave & & & 2 \\
\hline 19 & Conteúdo do PSQT de difícil entendimento & & & 3 \\
\hline 20 & Tempo curto para a implantação do PSQT & 32 & 33 & $\mathbf{1 3}$ \\
\hline & Total & & & \\
\hline $\begin{array}{l}\text { Legenda dos Fatores de Insucesso } \\
\text { O - Organizacional C - Comportamental M - Metodológico }\end{array}$
\end{tabular}

Fonte: Elaboração Própria

Em relação a "falta de tempo dos funcionários" assim como "a falta de tempo das pessoaschave”, nas empresas pesquisadas, isto ocorreu principalmente no Bloco III, que coincidentemente foi implantado nos período de aumento de demanda da indústria calçadista (setembro a início de novembro). Alegou-se então que houve uma dificuldade de o funcionário conseguir conciliar suas atividades com as atividades do PSQT, acabando assim por priorizar a produção. Isto esbarra no fato de que as indústrias pesquisadas e as pequenas empresas de uma forma geral possuem uma estrutura muito enxuta que muitas vezes acaba acumulando um grande número ou volume de trabalho em uma só pessoa.

Já em relação à “falta de tempo dos pequenos empresários”, só em uma empresa o motivo alegado foi devido à priorização da produção, sendo que nas outras duas o motivo alegado foi a dificuldade em conciliar as atividades do Programa com outras atividades do empresário, como viagens, compromissos, que não poderiam ser delegados a uma outra pessoa da empresa, o que não deixa de ser também influenciado pela estrutura enxuta característica das pequenas empresas. 
A minimização das causas de insucesso do fator organizacional, que relaciona-se aos aspectos formais da organização com ações visando o coletivo, depende sobretudo da empresa, no estabelecimento de políticas, planos e estratégias que possam facilitar o processo de implantação do Programa. Amenizar as causas de insucesso associadas ao fator organizacional significa tomar medidas relacionadas aos meios formais (planos, políticas e estratégias) para que a implantação seja feita da melhor forma possível.

As causas comportamentais que apresentaram maior ocorrência, considerando as que foram apontadas em pelo menos cinco vezes, foram: "falta de envolvimento do pequeno empresário", "falta de envolvimento dos funcionários”, "falta de envolvimento das pessoas-chave” e "resistências internas", sendo comentadas a seguir.

A causa comportamental de maior ocorrência foi a "falta de envolvimento do pequeno empresário", seguida pela "falta de envolvimento das pessoas chave”, sendo importante ressaltar que essas duas causas foram as mais apontadas dentre as dez empresas pesquisadas, com ocorrência de 90\% e 80\% respectivamente. Ambas as causas têm influência significativa na implantação do PSQT, pois tanto o pequeno empresário como as pessoas-chave são elementos fundamentais para o sucesso da implantação do PSQT, sendo os responsáveis pelo repasse do programa na empresa. Assim, se ambos não se envolvem com o Programa é praticamente certo que a implantação não alcance bons resultados. Além do que, se os principais responsáveis não se envolvem é natural que os seus subordinados também não se envolvam, sentindo-se desmotivados.

Um ponto que deve ser destacado a respeito dessa questão é que a falta de envolvimento tanto do pequeno empresário, como das pessoas-chave e dos funcionários, ocorreram sobretudo, dentro das empresas pesquisada, no Bloco III, que foi o que apresentou piores resultados e níveis mais baixos de implantação em praticamente todas as empresas pesquisadas. Apenas dois pequenos empresários não se envolveram durante toda a implantação do Programa, pois não consideravam que sua participação fosse importante.

Pelo que foi observado nas empresas pesquisadas percebe-se que o não envolvimento tanto do proprietário como das pessoas-chave no Bloco III se deve por alguns fatores principais:

- o Bloco III é mais técnico, menos prático, de conteúdo mais elaborado, e as atividades de implantação dependem de muito empenho de grande dedicação por parte dos responsáveis pela implantação, e esse empenho muitas vezes não acontece pela falta de visão e de valorização dada ao Programa e/ou por considerarem suas atividades rotineiras mais importantes e deixarem a qualidade em segundo plano;

- os resultados do Bloco III são de longo prazo e não tão imediatos, como os do Bloco II, demorando a ser visualizados, o que muitas vezes dificulta o envolvimento. 
As resistências internas se deram sobretudo por problema de mudança de cultura, por não conseguir enxergar os benefícios em implantar o PSQT tanto em relação ao trabalho individual como da organização como um todo, o que ocorreu tanto por parte de funcionário dos níveis operacionais como em alguns caso por funcionários de gerência/diretoria.

A causa ansiedade por resultados teve uma representatividade baixa, só ocorrendo em uma empresa. Porém este fator, apesar de não ter uma influência significativa no insucesso do PSQT considerando as dez empresas pesquisadas, teve uma grande influência na empresa em que ocorreu, pois o proprietário da empresa, quando percebeu que os resultados do PSQT não seriam imediatos praticamente abandonou o Programa, e sua implantação acabou se desestruturando por falta de apoio.

Uma vez que o fator comportamental está ligado sobretudo ao caráter espontâneo na organização, originando-se dos comportamentos individuais e das relações interpessoais, pode-se dizer que a minimização da ocorrência das causas relacionadas a este fator depende basicamente de se trabalhar as pessoas dentro da empresa, da cultura da organização, da visão do empresário e dos funcionários em relação à qualidade, assim como a importância que a Gestão pela Qualidade Total tem para a organização que está implantando o Programa.

Já o fator metodológico, ligado à forma e conteúdo do Programa, teve baixa representatividade em relação às causas de insucesso do Programa. Assim, pode-se dizer que a estrutura do Programa é adequada para a pequena empresa, e que o insucesso na implantação do Programa não se deve pela metodologia do Programa ou ao apoio dado pelo Sebrae. É claro que o PSQT não é perfeito e deve ser continuamente revisto para que cada vez mais a implantação apresente bons resultados. A pesquisa realizada permitiu sugerir algumas alterações do conteúdo do Programa, que são apresentadas no capítulo seguinte, de considerações finais.

É importante destacar que a causa de insucesso “dificuldade de utilização de ferramentas” e técnicas por ter sido desdobrada tanto em fator organizacional, comportamental e metodológico acabou tendo sua importância ocultada, mas quando somada foi citada 11 vezes na pesquisa, o que pode ser considerado como bastante representativo.

Para reforçar o que foi dito até aqui é importante classificar também a avaliação dos consultores em relação às causas de insucesso do Programa Sebrae de Qualidade Total. A tabela 8.15 mostra o número de respostas dos três consultores entrevistados sobre as causas que eles consideravam como as mais relevantes no insucesso da implantação do PSQT.

Pode-se ver então que os fator organizacional e o comportamental foram os mais apontados pelos consultores, o que reforça os resultados encontrados na pesquisa, mesmo que a pergunta feita ao consultor tenha considerado a implantação do PSQT de uma forma geral, e não apenas nas 
empresas pesquisadas. A diferença entre o fator organizacional e o fator comportamental foi maior se comparada com a obtida na pesquisa nas empresas, mas deve-se levar em consideração que na avaliação dos consultores não foi levado em conta as causas observadas pela pesquisadora, que poderiam diminuir essa diferença entre os fatores

Tabela 8.15 - Causas de Insucesso: Avaliação dos Consultores

\begin{tabular}{|c|c|c|c|c|}
\hline & \multirow[b]{2}{*}{ Causas de Insucesso } & \multicolumn{3}{|c|}{ Fatores de Insucesso } \\
\hline & & $\mathbf{O}$ & $\mathbf{C}$ & $\mathbf{M}$ \\
\hline 1 & Ausência de Foco no Consumidor & 2 & & \\
\hline 2 & Ausência de Planejamento & 2 & & \\
\hline 3 & Criação de uma estrutura interna paralela & 2 & & \\
\hline 4 & Não reconhecimento do corpo funcional pelas iniciativas da qualidade & & & \\
\hline 5 & Dificuldade de utilização de ferramentas e técnicas & $1 *$ & $1^{*}$ & $1 *$ \\
\hline 6 & Treinamento inadequado & & & 1 \\
\hline 7 & Qualidade não é medida em termos financeiros & 2 & & \\
\hline 8 & Falta de envolvimento do pequeno proprietário & & 3 & \\
\hline 9 & Falta de envolvimento dos funcionários & & 3 & \\
\hline 10 & Falta de tempo do pequeno empresário & 3 & & \\
\hline 11 & Falta de tempo dos funcionários & 2 & & \\
\hline 12 & Resistências Internas & & 2 & \\
\hline 13 & Difícil adaptação a diferentes tipos de negócios & & & \\
\hline 14 & Falta de apoio do consultor & & & \\
\hline 15 & Deficiência de técnica de repasse da metodologia & & & 1 \\
\hline & Total & 14 & 9 & 3 \\
\hline & $\begin{array}{l}\text { enda dos Fatores de Insucesso } \\
\text { Organizacional } \quad \text { C - Comportamental } \quad \text { M - Metodológico } \\
\text { teve-se apenas uma resposta nessa causa, mas justifica-se colocá-la no } \\
\text { ter sido questionado ao consultor o motivo da ocorrência da causa, não } \\
\text { paradamente. }\end{array}$ & (1) & & $\begin{array}{l}\text { to de } \\
\text { ificá- }\end{array}$ \\
\hline
\end{tabular}




\section{CAPÍTULO 9}

\section{CONSIDERAÇÕES FINAIS}

Neste capítulo faz-se algumas considerações a respeito da pesquisa, assim como sugestões de futuros trabalhos a serem feitos ligados ao tema estudado. A pesquisa realizada permitiu chegar a conclusões importantes sobre o Programa Sebrae de Qualidade Total (PSQT), considerando sua implantação em pequenas empresas e as causas de insucesso desse.

A gestão da qualidade total (GQT) surge no ambiente empresarial como uma forma de auxiliar o alcance da competitividade pelas organizações, sendo os Programas de Implantação da Qualidade instrumentos de orientação para que a GQT seja estabelecida. Porém, tais Programas devem respeitar as peculiaridades de cada empresa na busca da implantação da qualidade.

O Sebrae, através do Programa Sebrae de Qualidade Total, busca implantar a Qualidade Total em Pequenas Empresas. Porém, como o Programa é padronizado e trabalhado em grupos, lidar com as peculiaridades desse tipo de organização e conseguir obter bons resultados com o PSQT é uma tarefa difícil, que muitas vezes não consegue ser cumprida.

A pesquisa foi feita em um grupo de indústrias do setor calçadista, onde as empresas não foram em sua totalidade treinadas no mesmo grupo, mas os grupos que elas participaram foram compostos de empresas do mesmo setor, o que propicia melhores resultados do Programa pois as empresas trocam vivências e experiências envolvendo assuntos comuns, facilitando o aprendizado dos participantes.

O nível de implantação do programa nas empresas pesquisada pode ser considerado bom em quase todos os casos, exceto em uma organização (Empresa I) que enfrentou um grande 
problema de mercado, precisou demitir pessoal e praticamente abandonou o programa no último Bloco, parando completamente com as ações de qualidade dentro da empresa.

Dentre as empresas pesquisadas percebe-se que a implantação apresentou melhores resultados nos dois primeiros módulos, sendo que o último apresentou, em todos os casos, níveis de implantação mais baixos que os dois primeiros.

Os motivos alegados pelas empresas pesquisadas são muito semelhantes: aumento de demanda, necessitando priorizar a produção, falta de envolvimento do proprietário e/ou das pessoas-chave e/ou dos funcionários e dificuldades em se utilizar ferramentas da qualidade. Faz-se as seguintes considerações a respeito dos motivos alegados:

- $\quad$ aumento de demanda, necessitando priorizar a produção: no caso da indústria do setor calçadista, realmente existe um aquecimento da demanda nos meses de setembro/outubro. Como em geral o PSQT se inicia no princípio do ano o Bloco III, que é mais técnico, coincide com este período. O Sebrae poderia fazer uma tentativa de iniciar o programa um pouco mais tarde, deixando o Bloco III para o início do ano, quando a produção é mais tranquila;

- $\quad$ falta de envolvimento do proprietário e/ou das pessoas-chave e/ou dos funcionários: podese perceber que a falta de envolvimento alegada deve-se ao fato de o Bloco III, por ser mais técnico e mais trabalhoso, necessita de um grande empenho de todos para padronizar os processos, analisá-los, implantar as ferramentas, e propor melhorias desses processos. Muitas vezes os funcionários não compreendem muito bem as ferramentas, sentem dificuldade em realizar as atividades etc, o que acaba prejudicando a correta implantação do Bloco.

- $\quad$ acredita-se que a dificuldade de implantação das ferramentas e técnicas do programa se dá em grande parte dos casos pelo fato de o nível de escolaridade dos funcionários das empresas pesquisadas, e do setor calçadista de uma forma geral, ser baixo (a própria forma de contratação, bastante informal, e o nível de instrução da mão-de-obra necessário para executar as atividades do setor calçadista contribuem para isso), o que realmente pode dificultar o aprendizado das técnicas e ferramentas instituídas no programa.

O Bloco II, D’Olho na Qualidade, foi o que apresentou melhores resultados e que teve, em geral, uma grande participação e colaboração dos funcionários para a execução das tarefas. Este Bloco é bem prático e envolvente, motivando o funcionário a executar as tarefas. Um outro ponto que contribui para a realização das atividades do D’Olho na Qualidade é que os resultados são 
visualizados de forma mais rápida, as contribuições se tornam mais evidentes em um período curto de tempo, o que já não acontece com o Bloco III.

Dentre as causas de insucesso do PSQT agrupadas em fator organizacional, comportamental e metodológico percebe-se o seguinte:

\section{A) Fator Organizacional:}

O fator organizacional apresentou um número a menos de ocorrência do que as causas relacionadas ao fator comportamental, tendo grande relevância no insucesso da implantação do PSQT.

As causas mais apontadas foram: "dificuldade em utilizar-se ferramentas e técnicas da qualidade”, já comentada anteriormente, a "qualidade não ser medida em termos financeiros”, que será comentada neste capítulo posteriormente, a "falta de tempo dos funcionários" e a "falta de tempo das pessoas-chave”.

A "falta de tempo dos funcionários", mencionada em cinco empresas, e a "falta de tempo das pessoas-chave", mencionada em quatro empresas, ocorreram sobretudo devido à necessidade de priorização da produção pela necessidade de atender a demanda.

De uma forma geral, a pequena empresa, por ser muito enxuta tem uma certa dificuldade em conciliar as atividades normais do trabalhador com alguma outra atividade extra, seja de qualidade ou outro tipo de treinamento, assim, muitas vezes, quando as atividades rotineiras acumulam-se, ou algum problema corre, necessitando de urgência em ser resolvido, os funcionários deparam-se com um acúmulo de atividades, deixando de lado as consideradas “não-prioritárias”.

\section{B) Fator Comportamental:}

As causas relacionadas a esse fator, de grande relevância no insucesso da implantação do PSQT, apresentaram quase o mesmo número de ocorrência das causas relacionadas ao fator organizacional nas empresas pesquisadas, tendo apenas uma ocorrência a mais. As ocorrências ficaram mais concentradas em determinadas causas, como: falta de envolvimento do pequeno empresário (90\% das empresas pesquisadas), falta de envolvimento das pessoas-chave ( $80 \%$ das empresas pesquisadas), resistências internas (60\% das empresas pesquisadas) e falta de envolvimento dos funcionários (50\% das empresas pesquisadas).

A "falta de envolvimento do pequeno empresário", foi a causa de maior ocorrência, podendo ser caracterizado de duas formas: o empresário foi totalmente ausente na implantação do programa ou o empresário demonstrou não estar envolvido em alguma parte da implantação, o que ocorreu sobretudo no Bloco III. 
A influência deste fator no insucesso da implantação do PSQT e dos Programas de Qualidade de uma forma geral já é fato conhecido e revelado na literatura.

A "falta de envolvimento das pessoas-chave" foi apontada em oito empresas e "falta de envolvimento dos funcionários” em cinco, sendo que a ocorrência desses fatores demonstrou ser predominante no Bloco III. Acredita-se que um fator está intimamente ligado ao outro, uma vez que as pessoas-chave são as responsáveis pelo repasse das atividades na empresa. Se elas não estão envolvidas e não dão o devido apoio aos funcionários para a realização das atividades, é natural que eles também não se envolvam.

Uma outra causa que também pode afetar o envolvimento tanto das pessoas-chave quanto dos funcionários é a ocorrência de resistências internas na organização, que foram apontadas em seis dentre as dez empresas pesquisadas. Essas resistências ocorreram em alguns casos por parte de funcionários (nível operacional) que se recusavam a participar das atividades do programa, tendo dificuldade em mudar a sua cultura e modo de trabalhar (empresas B, D, E, G) e em outros nos níveis mais altos da organização pelo sócio (empresa A), de acordo com o que foi relatado pelo consultor, e pelos diretores (empresa $\mathrm{H}$ ) que entraram na empresa na época em que o PSQT estava sendo implantado, se opondo à implantação desse e conseqüentemente não dando apoio aos subordinados para se dedicarem as tarefas do Programa.

No caso da resistência dos funcionários ela também pode ser prejudicial à implantação do Programa porque depende muito do trabalho em equipe e a não colaboração de um funcionário pode prejudicar o bom resultado da equipe como um todo.

Acredita-se que a minimização dos fatores comportamentais de insucesso ao PSQT são os fatores mais difíceis de serem solucionados porque dependem fundamentalmente da cultura da organização, da visão do empresário e dos funcionários em relação à qualidade, assim como a importância que a Gestão pela Qualidade Total tem para a organização que está implantando o programa.

\section{C) Fator Metodológico}

As causas de insucesso na implantação do PSQT, relacionadas ao fator metodológico foram as menos apontadas dentre as empresas pesquisadas. Das causas já apontadas na literatura, abordadas pela pesquisa, a única mencionada foi "deficiência de técnica de repasse da metodologia”, no que diz respeito à dificuldade do proprietário ou da pessoa responsável em repassar o conteúdo do programa na empresa em se expressar em público, em conseguir transmitir de forma didática e de fácil entendimento o conteúdo do Programa para os funcionários. 
Um dos consultores entrevistados até citou um exemplo de uma empresa em que em uma organização, quando o empresário falava nos repasses dos módulos, ele gaguejava bastante, prejudicando a compreensão do conteúdo do Programa. Por isso foi necessário a atuação do consultor de uma maneira mais próxima nos repasses.

Acredita-se que o fato da causa "treinamento inadequado", à realidade das pequenas empresas, não ter sido apontada em nenhuma empresa pesquisada pode ter ocorrido por terem sido feitas reformulações no Programa do Sebrae (a última versão passou a ter tópicos separados para indústria e comércio/serviços) e de as empresas pesquisadas terem participado de grupos de um mesmo setor, facilitando o aprendizado dos participantes.

Dentre as empresas pesquisadas, duas relataram que consideram o "tempo de implantação do PSQT curto”, fator não considerado inicialmente nas variáveis de pesquisa por não ter uma ocorrência frequente nos estudos já realizados.

Duas empresas relataram ter dificuldade na implantação de ferramentas e técnicas por considerarem o tempo curto para implantá-las, porém acredita-se que uma extensão maior de tempo para a implantação dessas não geraria melhores resultados e sim que se as dificuldades no aprendizado das ferramentas, cujos motivos já foram citados anteriormente, fossem menores, ou pudessem ser minimizadas o tempo seria suficiente.

Pode-se dizer então que em relação aos outros estudos já realizados a respeito do PSQT que as causas relacionadas ao fator metodológico tiveram menos representatividade no insucesso do Programa, o que pode ter acontecido pelo fato de o Sebrae ter feito reformulações metodológicas, aumentando as horas de consultoria e de treinamento, mudando a parte de indicadores do Bloco III para o Bloco I, reestruturando o Bloco II e acrescentando mais um módulo ao Bloco III, entre outras alterações.

\section{Outras Consideraç̧̃̃es:}

Dentre as empresas pesquisadas constatou-se uma série de benefícios alcançados com o PSQT, mas ao mesmo tempo percebe-se que exceto em três empresas, as demais não pretendem dar continuidade nas ações da qualidade na empresa. Assim, o PSQT acaba sendo deixado de lado e todo o trabalho e aprendizado obtido com a implantação se perdendo.

Acredita-se que algumas ocorrências podem ter influenciado na descontinuidade das ações de qualidade nas empresas pesquisadas:

- $\quad$ as empresas não têm como prioridade o investimento em treinamento (30\% não investem, $10 \%$ investem esporadicamente, $30 \%$ apenas para os níveis mais altos e apenas 30\% para toda a organização); 
- $\quad$ as empresas não têm como prática o repasse do que foi aprendido no PSQT para os funcionários novos (apenas 20\% das empresas pesquisadas repassam); assim a medida que os funcionários que participaram do treinamento vão saindo da empresa fica mais difícil manter a gestão da qualidade total na organização;

- $\quad$ a empresas não alcançam os resultados esperados com o PSQT, sentindo-se desmotivadas a retomá-lo ou a adotar qualquer outro tipo de ação que envolva a Gestão da Qualidade Total;

- $\quad$ a etapa de sustentação do programa ocorre em períodos muito próximos do término do Bloco III, não sendo suficiente para corrigir possíveis falhas e aí tentar auxiliar a empresa a implantar o que não foi conseguido no tempo de duração normal do programa, sendo que esta ocorrência pode ser considerado para as empresas treinadas pelo PSQT de uma forma geral, e não apenas nas abordadas pela pesquisa;

\section{Sugestões de melhoria ao Programa}

Em relação à minimização da ocorrência das causas relacionadas ao fator organizacional, de uma forma geral, sugere-se ao Sebrae, partindo de um conceito de melhoria contínua, que procure sempre buscar melhorias à concepção do Programa e que tais melhorias se atentem às peculiaridades das Pequenas Empresas, que são condições inerentes a este tipo de organização, e portanto difíceis de sofrer modificações. Tais melhorias devem ser pensadas não só em termos do conteúdo do Programa, em relação aos módulos e atividades relacionadas a cada um deles, como também na atuação do consultor do Programa às empresas participantes do PSQT.

Já em relação à minimização da ocorrência das causas relacionadas ao fator comportamental, também de uma forma geral, sugere-se ao Sebrae que reforce ainda mais a parte de sensibilização das empresas participantes do Programa, buscando mostrar não só causas de sucesso, como também causas de insucesso do Programa, o que poderia ser feito através de exemplos reais de empresas que obtiveram êxito e fracasso na implantação.

Nesta parte de sensibilização, um outro ponto a ser reforçado é que os resultados do Programa são de longo prazo, sendo importante que os empresários, pessoas-chave e funcionários estejam bem esclarecidos sobre o horizonte da realização dos objetivos e das dificuldades da caminhada na busca dos resultados.

As empresas deveriam realizar um diagnóstico para avaliar as reais necessidades em relação à qualidade total, antes da implantação do Programa, assim como pontos fracos dentro da empresa que poderiam prejudicar a implantação. Seria interessante que este diagnóstico fosse feito pelos consultores do PSQT, que já teriam um conhecimento prévio da empresa, podendo verificar de uma forma geral pontos a serem trabalhados e, se fosse preciso até mesmo aconselhar a empresa a 
implantar o Programa em um outro momento. Mesmo que isso signifique a perda da venda de um treinamento para o Sebrae, mas evitaria a ocorrência de mais um caso de fracasso na implantação do PSQT.

Para minimizar a ocorrência da causa "qualidade não é medida em termos financeiros", sugere-se que o Sebrae inclua no Programa um módulo sobre Custos da Qualidade, de preferência na parte inicial, Bloco I, buscando despertar atenção do proprietário a respeito do gasto que a empresa tem em não praticar a qualidade e comparar este gasto com o investimento que ela irá fazer para implantar o Programa. Para isso, é necessário um grande apoio do consultor do Programa, que deverá não só repassar a metodologia como acompanhar o levantamento e cálculo do referido custo.

Os custos da qualidade mostram as tendências, apontam desvios e fornecem os dados para uma melhor decisão. São indicadores pelos quais as gerências devem se orientar, para julgar que os especialistas buscam para melhorar a performance, procurando a diminuição dos custos totais, baixando progressivamente os custos das falhas e da avaliação, através de uma ótima dosagem dos gastos com a prevenção (MOSSO, 2001).

Algumas empresas citaram que com a implantação do Programa elas passaram a calcular os custos da qualidade, mas o programa não possui em seu conteúdo uma parte que explique como este cálculo pode ser feito. Não se tem conhecimento da forma como os empresários passaram a calcular este custo e se realmente ele está sendo calculado corretamente.

O custo da qualidade é inclusive citado, no material bibliográfico do PSQT, como parte componente do $10^{\circ}$ princípio da qualidade mencionado no quarto capítulo desta dissertação: que é denominado Não-aceitação de Erros, traduzindo-se da seguinte forma: não se conformar com o erro, definição do certo, atitude preventiva e custo da qualidade. Mas o custo da qualidade não é enfocado no programa.

Em se tratando do material didático do programa, sugere-se que a fita de vídeo do D’Olho na Qualidade poderia abordar uma empresa e não uma viagem de barco. Seria interessante até mesmo ser feito uma fita para cada tipo de setor: indústria, comércio e serviço.

O Sebrae poderia colocar mais pessoas dentro da empresa, estagiários, consultores júniores etc. para auxiliar o repasse do Bloco III, acompanhando mais de perto a implantação e apoiando mais diretamente os funcionários que apresentassem dificuldades na realização das atividades a eles designadas.

Sugere-se também a avaliação, pelo Sebrae, da necessidade de uma atuação mais próxima do consultor em todas as empresas. Assim, caso necessário o consultor poderia acompanhar mais de perto e auxiliar os repasses dentro da empresa, minimizando por exemplo deficiências na técnica de 
repasse da metodologia por parte do proprietário ou responsável pela implantação dentro da empresa.

Uma outra sugestão é o acompanhamento a longo prazo do PSQT, o que auxiliaria a correção das falhas ocorridas no Programa e daria uma folga maior para a implantação das atividades que deixaram de ser implantadas por questões de tempo. O Sebrae poderia fazer um levantamento ao final de cada Programa a respeito do interesse das empresas em participar desse acompanhamento. A forma de acompanhamento e o tempo de duração poderiam ser estabelecidos a partir de um estudo entre consultores e responsáveis pela qualidade dentro do Sebrae, procurando também buscar opiniões das empresas que já participaram do Programa, podendo ser um novo produto do Sebrae Nacional, que a empresa poderia optar por adquirir ou não ao final do PSQT. Este acompanhamento poderia ser feito em grupos ou individualmente, dependendo das necessidades, é claro, dos recursos que a empresa teria que arcar para obter este acompanhamento.

Mas, é importante ressaltar que, como colocou um dos consultores entrevistados, a etapa de sustentação, o que pode ser estendido para um acompanhamento a longo prazo, só dará resultados mediante a existência de três aspectos relacionados: grupo sensibilizado das vantagens do PSQT; visão madura dos líderes; e exigência dos funcionários quanto à continuidade do programa. O Sebrae pode contribuir para este acompanhamento, mas a empresa tem que estar ciente da importância dele e realizar ações e esforços para o alcance de bons resultados.

\section{Limitações da pesquisa realizada}

A pesquisa realizada limitou-se a um grupo de dez empresas, de um mesmo setor, sendo o seu foco de pesquisa relativamente estreito em relação ao número total de empresas que implantam o PSQT e que deixou de abordar os outros setores, comércio e serviço, podendo apresentar resultados bem diferentes em relação à indústria.

Uma outra limitação existente refere-se à extensão de tempo necessária para incluir mais empresas na pesquisa, dos setores de comércio e serviço, e também para aprofundar alguns pontos específicos relacionados às causas de insucesso, levantados através da pesquisa. O tempo necessário seria muito maior do que o que a pesquisadora teve para a realização de sua dissertação.

\section{Sugestões de pesquisas futuras}

Buscando então focar as lacunas que a pesquisa não teve condições de abordar, e que podem contribuir ainda mais para a compreensão das causas de insucesso do PSQT e consequentemente a melhoria dos resultados desse, coloca-se as seguintes sugestões de pesquisas futuras: 
- $\quad$ realização de um estudo considerando os fatores de insucesso pesquisados, mas enfocando apenas empresas do setor de serviço;

- $\quad$ realização de um estudo considerando os fatores de insucesso pesquisados, mas enfocando apenas empresas do setor de comércio;

- a partir dessas duas pesquisas poderia ser feita uma comparação entre os três setores: indústria, comércio e serviço;

- $\quad$ realização de um estudo sobre a influência do nível de instrução dos participantes do Programa e resultados alcançados com o mesmo;

- $\quad$ realização de um projeto piloto de acompanhamento a longo prazo do PSQT, com o apoio do Sebrae, em um grupo de empresas que implantaram o programa, verificando os resultados alcançados com este acompanhamento.;

- $\quad$ entender mais detalhadamente o foco de influência do proprietário e das pessoas-chave no insucesso do PSQT;

- $\quad$ realização de um estudo considerando o impacto regional nos resultados alcançados com o PSQT .

\section{Comentário Final}

Para finalizar coloca-se que, sem dúvida alguma, o PSQT é uma importante forma de auxílio para as pequenas empresas adotarem a Gestão pela Qualidade Total, as empresas conseguem benefícios com a implantação do PSQT e o Sebrae vem procurando melhorar o Programa desde que foi instituído objetivando o alcance de melhores resultados. Porém, o PSQT não deixa de ser uma metodologia pronta que procura trabalhar em grupos, sendo que por isso muitas vezes não consegue se adaptar às diferentes realidades das empresas.

O empenho da empresa e de todos os seus membros é fundamental para o alcance de bons resultados com o Programa, e muitas vezes as falhas são provenientes de falhas internas da organização, que o PSQT por si só não é capaz de resolver. Porém melhorias no PSQT ainda precisam ser feitas, valendo reforçar a necessidade do acompanhamento a longo prazo para assim consolidar a implantação do Programa. 


\section{BIBLIOGRAFIA}

\section{BIBLIOGRAFIA REFERENCIADA}

AlenCAR filHo, J. T. (1995). O Impacto de Programas de Qualidade Total em Micro e Pequenas Empresas: avaliação do Programa de Qualidade Total do Sebrae/ES. Rio de Janeiro. Dissertaação (Mestrado). Programa de Pós-Graduação em Engenharia de Produção, Pontifícia Universidade Católica do Rio de Janeiro.

BACKES, B. I. (1998). Altos e baixos, sucessos e fracassos nos Programas de Qualidade - por quê? In: XX ENCONTRO NACIONAL DE ENGENHARIA DE PRODUÇÃO. Universidade Federal Fluminense, Niterói - RJ.

BARÇANTE, L. C. (1998). Qualidade Total: uma visão brasileira: O impacto estratégico na universidade e na empresa. Rio de Janeiro, Campus.

BARRETO, R. A. et al (1997). Gestão de Unidades de Informação. Curitiba, Collecta.

BERVIAN, P. A.; CERVO, A. L. (1996). Metodologia Científica. São Paulo, Makron Books.

BOTOMÉ, S. P. (1997). Processos Comportamentais Básicos em Metodologia de Pesquisa: da delimitação do problema à coleta de dados. Chronos. Caxias do Sul, v. 30, n.1, p. 35-42, jan-jun.

BROCKA, B.; BROCKA, M. S. (1994). Gerenciamento da Qualidade Total: implementando TQM, passo a passo, através dos proessos e ferramentas recomendadas por Juran, Deming, Crosby e outros mestres. São Paulo, Makron Books.

CÂNDIDO, M. S. (1998). Gestão da Qualidade em Pequenas Empresas: uma contribuição aos modelos de implantação. Florianópolis. Dissertação (Mestrado). Programa de Pós-Graduação em Engenharia de Produção, Universidade Federal de Santa Catarina. 
CERQUEIRA NETO, E. P. (1992). Paradigmas da Qualidade. Rio de Janeiro, Imagem.

CERQUEIRA NETO, E. P. (1995). Ambiente da Qualidade Total. São Paulo, Pioneira.

CROSBY, P. B. (1993). A qualidade precisa ser bem sucedida. Revista Exame, v. 533, n. 12, p. 8991, dez.

CROSBY, P. B. (1985). Qualidade é investimento. Rio de Janeiro, José Olimpio.

CHER, R. (1991). A gerência das pequenas e médias empresas. São Paulo, Maltese.

DEMING, W. E. (1990). Qualidade: a revolução da administração. Rio de Janeiro, MarquesSaraiva.

DRUCKER, P. F. (1981). Prática de Administração de Empresas. São Paulo, Pioneira.

FEIGENBAUM, A. V. (1991). Total Quality Control. New York, Mc-Graw Hill.

FEIGENBAUM, A. V. (1997). Tendências, inovações e aspectos econômicos da qualidade. Conferência Internacional da Qualidade 1997. Rio de Janeiro, Qualitymark Editora.

FEIGENBAUM, A. V. (1998). The Future of Quality Management. http://www. qualitydigest.com/may98/html/futureq.html (17/01/2000)

GARVIN, D. A. (1992). Gerenciando a Qualidade: a visão estratégica e competitiva. Rio de Janeiro, Qualitymark.

GHOBADIAN, A; GALLEAR, D.N (1996). Total Quality Management in SMEs. International Journal of Management Science. Vol. 24, No. 1, pp. 83-106.

GONÇALVES, $\quad$ A. $\quad$ P. (2000). 10 Tendências na área da Qualidade. http://calidad.org/public/articles/911158900 alexis.htm (27/03)

HARRINGTON, H. J. (1997). Gerenciamento total da melhoria contínua. São Paulo, Makron Books.

ISHIKAWA, K. (1986). TQC, total quality control: estratégia e administração da qualidade. São Paulo, IMC Internacional Sistemas Educativos.

ISHIKAWA, K. (1993). Controle da qualidade total a maneira japonesa. Rio de Janeiro, Campus.

JURAN, J. M. (1993). Juran na Liderança pela Qualidade. São Paulo, Pioneira.

JURAN, J. M. (1995). A history of managing for quality in the United States - Part 2. http://www.qualitydigest.com/dec/hystoryo.html (13 jan 2000) 
JURAN, J. M. (1997). Qualidade no Século XXI. Prognósticos para o futuro da qualidade e uma análise de sua história no século XX, marcado pela busca da produtividade. HSM Management, v. 3, p. 96-104, julho-agosto.

LESSA, J. (1995). Qualidade Competitiva no Brasil. Transformando valores, atitudes e comportamentos na busca da Qualidade Total. Salvador, Casa da Qualidade.

LORENT, A. R. M; DEWHURST, F.; DALE, B. G. (1998). Total quality management: origins and evolution of the term. TQM Magazine, v. 10, n.5, p. 378-386.

LONGNECKER, J. G.; MOORE, C. W.;PETTY, J. W. (1997). Administração de Pequenas Empresas. São Paulo, Makron Books.

MAIN, J. (1995). Guerras pela Qualidade: os sucessos e fracassos da revolução da qualidade: Rio de Janeiro, Campus.

MARTINS, R. A. \& TOLEDO, J. C. (1998). Proposta de modelo para elaboração de programas de gestão para a qualidade total. Revista de Administração, v.33, n.2, p 52-59.

MIRANDA, R. L. (1994). Qualidade Total: rompendo as barreiras entre a teoria e a prática. São Paulo, Makron Books.

MORIYAMA, G. K. (2000). Obstáculos ao Sucesso Empresarial na Pequena Empresa: estudo dos fatores negligenciados pelo empreendedor e influentes no fracasso do negócio. São Carlos (Trabalho Iniciação Científica). Programa de Graduação em Engenharia de Produção, Escola de Engenharia de São Carlos - Universidade de São Paulo.

MOREIRA, K.C.S (2000). Implementação dos Princípios da Qualidade Total na Gestão de Recursos Humanos: estudo de caso. Florianópolis. Dissertação (Mestrado). Programa de PósGraduação em Engenharia de Produção, Universidade Federal de Santa Catarina

MOSSO, M. M. (2001). Introdução à Estratégia em Qualidade. Rio de Janeiro, ESC.

MOTTA, G. G. (2000). Fatores Condicionantes na Adoção de Métodos de Custeio em Pequenas Empresas. São Carlos. Dissertação (Mestrado). Programa de Pós Graduação em Engenharia de Produção, Escola de Engenharia de São Carlos - Universidade de São Paulo.

OISHI, M. ; LANDMANN, R.; TELMA, R. R. (1998). Programa de Qualidade: uma abordagem analítica em organizações de pequeno porte. In: XX ENCONTRO NACIONAL DE ENGENHARIA DE PRODUÇÃO. Universidade Federal Fluminense, Niterói - RJ.

OLIVEIRA, M. A. (1994). Mitos e realidades da qualidade no Brasil. São Paulo, Nobel.

OliVEIRA, M. A. L. (1998). A Pequena/Média Empresa e a Qualidade. http://www users.provider.com.br/qualitas/pme.htm. (02 mar 99)

ORTEGA, L. M. (1998). Impacto dos Programas de Qualidade sobre as Micro e Pequenas Empresas do Mato Grosso do Sul - MS. São Carlos. Dissertação (Mestrado). Programa de PósGraduação em Engenharia de Produção, Universidade Federal de São Carlos. 
PALADINI, E. P. Seleção Interativa de Ferramentas para a Qualidade Total. In: XIX ENCONTRO NACIONAL DE ENGENHARIA DE PRODUÇÃO. Gramado-RS, 1997.

PANIGAS, I. F. (1998). Dificuldades na Implantação de Programas da Qualidade nas Micro e Pequenas Empresas: uma análise do método SEBRAE. Dissertação (mestrado). Programa de Pós-Graduação em Administração, Faculdade de Ciências Econômicas, Universidade Federal do Rio Grande do Sul.

PINHEIRO, M. (1996). Gestão e Desempenho das Empresas de Pequeno Porte: uma abordagem conceitual e empírica. São Paulo. Tese (Doutorado). Programa de Pós-graduação em Administração, Faculdade de Economia, Administração e Contabilidade - Universidade de São Paulo.

PURI, S.C. (1994). Certificação ISO série 9000 e Gestão da Qualidade Total. Rio de Janeiro, Qualitymark.

RATTNER, H. et. al. (1985). Pequena Empresa: o comportamento empresarial na acumulação e na luta pela sobrevivência. São Paulo, Brasiliense, v. 1.

REGINA, J. B. (1999). A Implementação do Gerenciamento da Qualidade Total (TQM) Numa Empresa de Administração Pública Brasileira. Dissertação (Mestrado). Programa de Pósgraduação em Administração Faculdade de Economia, Administração e Contabilidade Universidade de São Paulo.

RESNIK, P. (1990). A bíblia da pequena empresa: como iniciar com segurança sua pequena empresa e ser muito bem sucedido. São Paulo, Mc Graw - Hill, Makron Books.

SANTINI et. al. (1998). Programa Gaúcho de Qualidade e Produtividade - PGQP: análise dos indicadores de desempenho de uma indústria de plásticos. In: XX Encontro Nacional de Engenharia de Produção. Universidade Federal Fluminense, Niterói - RJ.

SASHIKIN, M.; KISER, K.J (1994). Gestão da qualidade total na prática. Rio de Janeiro, Campus.

SEBRAE (1995a). Programa Sebrae de Qualidade Total para micro e pequenas empresas. Manual do Instrutor. Brasília, Ed. Sebrae.

SEBRAE (1995b).Projeto de Avaliação do Programa de Qualidade Total - Sebrae-MG. Belo Horizonte: Sebrae -MG.

SEBRAE (1997). Programa Sebrae de Qualidade Total para micro e pequenas empresas. Manual do Instrutor. Brasília, Ed. Sebrae.

SEBRAE (1998a). No Brasil as pequenas empresas sabem com quem contar./folder/

SEBRAE (1998b). Pesquisa Indicadores de Qualidade e Produtividade na Indústria Brasileira 1997. Rio de Janeiro.

SEBRAE (1999a). Fatores Condicionantes e Taxa de Mortalidade de Empresas. Brasília, Ed. Sebrae. 
SEBRAE (1999b). Programa Sebrae de Qualidade Total para micro e pequenas empresas. Guia do Empresário. Brasília, Ed. Sebrae.

SEBRAE (1999c). Programa Sebrae de Qualidade Total para micro e pequenas empresas. Manual do Instrutor. Brasília, Ed. Sebrae.

SEBRAE (2000a). As MPEs na economia. Estudos e Pesquisas. http://sebraesp.com.br (02 out 2000.).

SEBRAE(2000b). Onde estão as MPEs paulistas. http://sebraesp.com.br/sebrae/sebraenovo/pesquisa (02 mai 2000)

SEBRAE (2000c). Participação das MPEs no total de Pessoas Ocupadas nas Empresas Paulistas: 1995/1999. Sebrae-SP, Pesquisas Econômicas.

SOARES, A. C. S. (1999). Qualidade: estratégia de competitividade industrial - uma análise na indústria sul brasileira. Florianópolis. Dissertação (Mestrado). Programa de Pós-Graduação em Engenharia de Produção, Universidade Federal de Santa Catarina.

STEVAnATO, L. A. (1997). Um Estudo Sobre as Influências do Programa de Qualidade Sobre a Cultura da Organização. São Paulo. Dissertação (Mestrado). Programa de Mestrado em Administração de Empresas, Faculdade de Economia, Administração e Contabilidade, Universidade de São Paulo.

TAMIMI, N.; SEBASTIANELLI, R. (1998). The Barriers to Total Quality Management. Quality Progress, v. 31, n. 6, p. 57-60, jun.

TATIKONDA, L. V.; TATIKONDA, R. J. (1996). Top ten reasons your tqm effort is failing to improve profit. Production and Inventory Management Journal, third quarter, p. 5-9.

TAYLOR, W. A. (1997). Leadership Challenges for Smaller Organisations: self-perceptions of TQM implementation. International Journal of Management Science, v. 25, n. 5, p. 567-569.

TOLOVI JR., J. (1994). Por que os programas de qualidade falham? Revista de Administração de Empresas, v.34, n.6, p.6-11.

TRIVIÑOS, A. N. S. (1987). Introdução à Pesquisa em Ciências Sociais: a pesquisa qualitativa em educação. São Paulo, Atlas.

VALLE, B. M. (1995). Falhas dos programas de qualidade. Controle da qualidade, v.5, n.41, p. 3440.

WHITELEY, R. C. (1992). A empresa totalmente voltada para o cliente: do planejamento à ação. Rio de Janeiro, Campus.

WOOD JR., T.; URDAN, F.T. (1994) Gerenciamento da qualidade total: uma revisão crítica. Revista de Administração de Empresas, v.34, n.6, p.46-59.

ZIMMERER, T. W.; SCARBOROUGH, N. M. (1994). Essentials of Small Business Management. New York, Macmillan. 


\section{BIBLIOGRAFIA COMPLEMENTAR}

BROWN, M. G.; HITCHCOCK, D. E.; WILLARD, M. L. (1996). Por que o TQM falha e como evitar isso. São Paulo, Nobel.

FLÁVIO, R. ; FONSECA, J. L. A. (1995). A grande dimensão da pequena empresa: perspectivas de ação. Brasília, Ed. Sebrae.

FLEURY, M. T. L. (1993). Cultura da qualidade e mudança organizacional. Revista de Administração de Empresas, v.33, n. 2, p. 26-34.

MOSSO, M. M. (1998). Fatores Críticos na Estratégia de Implantação da Gestão da Qualidade Total. Niterói. Dissertação (Mestrado). Programa de Pós-Graduação em Administração. Universidade Federal Fluminense.

OLIVEIRA, M. A. L. (1994). Qualidade: desafio da pequena e média empresa. Fortaleza, Qualitymark.

PRADA, D. F.; MIGUEL, P. A. C.; FRANÇA,A. C. L. (1999). Práticas da gestão de pessoas no contexto da qualidade. Caderno de Pesquisas em Administração, v.1, n.10, p.13-22.

ROJO, F. J. F. (1998). Qualidade Total: uma nova era para os supermercados. Revista de Administração de Empresas, v. 38, n. 4, p. 26-36

SADAlla, L. O. B. (1998). Contribuições da Área de Recursos Humanos para a Gestão da Qualidade: um estudo de caso. São Carlos. Dissertação (Mestrado). Programa de PósGraduação em Engenharia de Produção, Escola de Engenharia de São Carlos - Universidade de São Paulo.

UNIVERSIDADE DE SÃO PAULO. Escola de Engenharia de São Carlos. Serviço de Biblioteca. (1996). Diretrizes para elaboração de dissertações e teses na EESC - USP. São Carlos 
APÊNDICES 


\section{UNIVERSIDADE DE SÃO PAULO ESCOLA DE ENGENHARIA DE SÃO CARLOS ENGENHARIA DE PRODUÇÃO}

APÊNDICE 1 - QUESTIONÁRIO DE CARACTERIZAÇÃO DA EMPRESA

A. Razão Social:

B. Nome Fantasia:

C. Endereço

R./Av.

$\mathbf{N}^{\circ}$ Compl. Bairro CEP

Cidade Telefone: $(\ldots)$ Fax: (_)

D. Tempo de Atividade: anos

E. Setor de Atuação:

\section{2- DADOS DOS SÓCIOS/PROPRIETÁRIOS}

Sócio 1)

$>\quad$ Nome:

$>\quad$ Data de Nascimento

$>\quad$ Formação Escolar:

$>\quad$ Participação Societária $\%$

$>\quad$ Possui experiência profissional anterior? $\square$ não $\square \operatorname{sim}$. Qual?

Sócio 2)

$>\quad$ Nome:

$>\quad$ Data de Nascimento

$>\quad$ Formação Escolar:

$>\quad$ Participação Societária $\%$

$>\quad$ Possui experiência profissional anterior? $\square$ não $\square \operatorname{sim}$. Qual? 
Existe parentesco entre os proprietários?

$\square$ não $\square$ sim. Qual?

\section{3 - ESTRUTURA DA EMPRESA}

A. Quais as relações de responsabilidade pelas atividades? (Desenhar o organograma)

B. Número de funcionários da empresa

\begin{tabular}{|l|l|}
\hline Sócios & \\
\hline Chefia & \\
\hline Administração & \\
\hline Operacional (chão-de-fábrica) & \\
\hline Total & \\
\hline
\end{tabular}

C. Qual o nível de escolaridade formal dos funcionários?

\begin{tabular}{|l|l|}
\hline Grau de Instrução & Número de Funcionários \\
\hline 1o. Grau Incompleto & \\
\hline 1o. Grau Completo & \\
\hline 2o. Grau Incompleto & \\
\hline 2o. Grau Completo & \\
\hline Superior Incompleto & \\
\hline Superior Completo & \\
\hline Pós-Graduação & \\
\hline
\end{tabular}

D. A empresa terceiriza serviços? $\square$ não $\square$ sim. Quais?

\section{E. Quantos e quais produtos a empresa produz?}


F. Os produtos são produzidos:

$\square$ Sob encomenda. Quais e em que percentual?

Para estoque. Quais e em que percentual?

G. Os equipamentos podem ser classificados de que forma?

Moderno: $\%$

\pm Moderno: $\%$

Obsoleto: $\%$

H. Organização do Trabalho

$\square$ automático (com força motriz sob supervisão humana).

$\square$ semi-automático (com força motriz e operação humana). $\%$

$\square$ ferramentas manuais (completa operação humana). $\%$ $\%$

\section{4 - CARACTERÍSTICAS MERCADOLÓGICAS}

\subsection{FORNECEDORES}

A. Quais são seus principais fornecedores, que porte possuem e onde se localizam?

B. A competição entre os fornecedores é acirrada? $\square$ sim $\square$ não

\subsection{CLIENTES}

A. Quais são seus principais clientes, que porte possuem e onde se localizam?

A competição entre os clientes é acirrada? $\square$ sim $\square$ não

\subsection{MERCADO DE ATUAÇÃo}

A. $\quad$ O mercado em que a empresa atua é competitivo? $\square$ muito $\square$ médio $\square$ pouco

B. Quais são seus principais concorrentes, que possuem e onde se localizam? 
C. Qual a posição da empresa no mercado em que atua? (market-share)

D. Qual a atuação da empresa com relação ao mercado geográfico?

$\square$ regional: $\% \quad \square$ nacional: $\% \square$ internacional: $\%$

\section{5 - ESTRATÉGIA}

A. Qual a principal estratégia adotada pela empresa? (custos, diferenciação, foco, etc.)

\section{6 - RECURSOS HUMANOS}

A. Como você classifica a remuneração dos funcionários em relação ao mercado? $\square$ maior $\square$ igual $\square$ menor

B. A empresa oferece benefícios aos funcionários? Se sim, quais?

C. A empresa investe em treinamento? Se sim, em que níveis organizacionais?

D. Qual é a taxa de rotatividade e de absenteísmo dos funcionários? 


\section{7 - INFORMATIZAÇÃO}

A. A empresa é informatizada? $\square$ sim $\square$ não (vá para o item 8)

B. Os equipamentos estão ligados em rede? $\square$ sim $\square$ não

C. Utiliza a Internet? $\square \operatorname{sim} \quad \square$ não

D. Quais aplicativos utiliza?

\section{8 - SITUAÇÃO FINANCEIRA}

\section{A. Faturamento}

1997:

1998:

1999:

2000:

B. A empresa enfrenta problemas com inadimplência? $\square$ sim $\square$ não

C. Há falta de capital de giro? $\square \operatorname{sim} \quad \square$ não

\section{9 - HISTÓRICO DA EMPRESA}

(Data de fundação, como a empresa foi concebida e com qual objetivo, relatar se houve algum processo sucessório na empresa, qual a situação atual da empresa hoje - houve mudança de enfoque?) 


\section{UNIVERSIDADE DE SÃO PAULO ESCOLA DE ENGENHARIA DE SÃO CARLOS ENGENHARIA DE PRODUÇÃO}

\section{APÊNDICE 2 - QUESTIONÁRIO (Proprietário/pessoa-chave)}

Empresa:

Entrevistado:

Cargo:

Início da Implantação do PSQT:

Término da Implantação do PSQT:

Nome do consultor:

\section{Qualidade Total e PSQT}

\subsection{Qual é o seu entendimento do que vem a ser Qualidade Total?}

( ) Processos padronizados e sistematizados ( ) Atender as necessidades dos clientes

( ) Melhoria contínua de processos

( ) Ausência de defeitos nos produtos

( ) Outros. Especificar:

1.2 Qual o seu entendimento do que vem a ser um Programa de Qualidade Total?

( ) Introdução/ aprendizado de técnicas e ferramentas da qualidade （ ) Não respondeu

( ) Orientação para atender as necessidades do cliente ( ) Aprimoramento de processos/ técnicas

( ) Outros. Especificar:

1.3 Quais são os principais objetivos de um Programa de Qualidade Total?
( ) Mudanças na estrutura, atendimento e cultura
( ) Enfocar o cliente
( ) Recursos Humanos
( ) Melhoria de processos
( ) Orientação/Compreensão sobre a GQT
( ) Outros. Especificar: 
1.4 O que mais influenciou a empresa a implantar o Programa Sebrae de Qualidade Total?
( ) Dinâmica da economia
( ) Mercado
( ) Alterações de tecnologia
( ) Adaptação
( ) Recursos Humanos
( ) Mídia
( ) Outros. Especificar :

1.5 Você acredita que a empresa entrou no PSQT no momento certo?
( ) Sim
( ) Não. Por quê?

1.6 O que a empresa buscava quando procurou o PSQT?
( ) Crescimento organizado
( ) Compreensão e entendimento da GQT
( ) Sobrevivência e adaptação da empresa
( ) Satisfação do cliente
( ) Maior rentabilidade
( ) Melhoria trabalho/relacionamento dos Recursos Humanos
( ) Outros. Especificar:

\subsection{Como a empresa teve conhecimento do PSQT?}
( ) Sebrae
( ) Mídia
( ) Outras empresas
( ) Outros. Especificar

1.8 Foi feito algum diagnóstico na empresa antes da implantação do PSQT, buscando avaliar as necessidades da empresa em relação à qualidade?

( ) sim ( ) não

\section{FORMA DE ADMINISTRAÇÃO DA EMPRESA E CICLO DE INFORMAÇÕES}

\subsection{Estilo de Gerência}
( ) centralizadora
( ) descentralizadora
( ) controle direto
( ) autonomia
( ) outros:

2.2 A participação dos funcionários na tomada de decisões relevantes é considerada importante?
( ) $\operatorname{sim}$
( ) não. Por quê? 


\subsection{Quanto ela é exercida na empresa?}

( ) não é exercida ( ) às vezes ( ) na maioria das decisões

\subsection{Como se dá o processo de tomada de decisão na sua empresa?}

( ) o dirigente é responsável pela maior parte das decisões

( ) os funcionários intermediários tem poder de decisão

( ) a decisão é delegada a todos os níveis, nas devidas proporções

( ) outros:

\subsection{Que atividades de caráter participativo são exercidas?}
( ) programas de sugestões individuais
( ) equipes de melhorias de processos
( ) equipes para solução de problemas
( ) canal aberto de comunicação
( ) outros:

2.6 Em relação ao fluxo de informação na empresa:

\begin{tabular}{|c|c|}
\hline De cima p/ baixo & De baixo para cima \\
\hline ( ) ) alta difusão & ( ) alta difusão \\
\hline ( ) média difusão & ( ) média difusão \\
\hline ( ) baixa difusão & ( ) baixa difusão \\
\hline ( ) não sabe & ( ) não sabe \\
\hline
\end{tabular}

\subsection{A disseminação de informações é considerada (pela gerência/diretoria):}
( ) de elevada importância
( ) de média importância
( ) de baixa importância
( ) não é considerada importante

\subsection{Tipo de informação divulgada aos funcionários de produção:}
( ) evolução das vendas
( ) evolução dos índices de qualidade
( ) rentabilidade da empresa
( ) desempenho individual ou de equipe
( ) evolução dos índices de produtividade
( ) outros:

\subsection{Fator determinante a não divulgação de certas informações:}

( ) informação de caráter estratégico

( ) falta de confiança nos funcionários

( ) funcionários não compreendem a informação 
( ) não há necessidade de os funcionários saberem

( ) outros:

3. IMPLANTAÇÃO DAS ATIVIDADES RELATIVAS AO PROGRAMA

3.1 Quem foi o principal responsável pela implantação do PSQT na empresa?

( ) proprietário ( ) outro. Quem?

3.2 Quem foram as pessoas - chave do programa (citar nome e cargo) ? Eles ainda trabalham na empresa?

3.3. Quantos funcionários foram treinados? Quantos ainda trabalham na empresa?

3.4 O empresário participou de todas as reuniões do PSQT?

( ) $\operatorname{sim}$ ( ) não. Por quê?

3.5 Qual foi o nível de envolvimento do proprietário da empresa durante a implantação do PSQT?

( ) alto ( ) médio ( ) baixo ( ) não se envolveu

3.6 Qual foi o nível de envolvimento das pessoas - chave durante a implantação do PSQT?

( ) alto ( ) médio ( ) baixo ( ) não se envolveu

3.7 Qual foi o nível de envolvimento dos funcionários da empresa durante a implantação do PSQT?

( ) alto ( ) médio ( ) baixo ( ) não se envolveu

3.8 O PSQT foi repassado para os funcionários de baixa escolaridade?

( ) sim ( ) não. Por quê? 
3.9 A empresa reconheceu o corpo funcional pelas iniciativas da qualidade?

( ) não （ ) sim. De que forma?

3.10 Houve resistência dos funcionários em relação à implantação do PSQT?

( ) não ( ) sim. Por quê?

3.11 Em relação à responsabilidade pela qualidade:

( ) foi disseminada a todos ( ) foi delegada a um departamento/ equipe de trabalho

( ) foi delegada a um único funcionário ( ) outra. Especificar

3.12Os conceitos e princípios da qualidade foram repassados e assimilados pelos funcionários?

( ) sim, foram repassados e assimilados ( ) repassados mas assimilados parcialmente

( ) repassados mas não assimilados ～（ ） não foram repassados

3.13 A missão e política da qualidade foram elaborados e disseminados por toda a empresa?
( ) elaborados e disseminados
( ) elaborados mas disseminados parcialmente
( ) elaborados mas não assimilados
( ) não foram elaborados

3.14 Foram elaborados os instrumentos de pesquisa de satisfação de clientes?

( ) sim ( ) não. Por quê?

Eles foram implantados?

( ) $\operatorname{sim}$ ( ) não. Por quê?

3.15 A empresa estabeleceu indicadores de desempenho?

( ) sim. Quais?

\begin{tabular}{|l|l|l|}
\hline Indicadores de Qualidade & Indicadores de Produtividade & Indicadores Financeiros \\
\hline ( ) satisfação de clientes & ( ) mão-de-obra & ( ) liquidez seca \\
\hline ( ) defeitos da produção & ( ) produção média & ( ) margem bruta \\
\hline ( ) qualidade das vendas & ( ) faturamento médio & ( ) margem de contribuição \\
\hline ( ) reclamação de clientes & ( ) atendimento médio & ( ) margem líquida \\
\hline
\end{tabular}




\begin{tabular}{|l|l|l|}
\hline $\begin{array}{c}\text { ( ) cumprimento prazos na } \\
\text { produção }\end{array}$ & $\begin{array}{c}\text { ( ) endividamento de longo } \\
\text { prazo }\end{array}$ \\
\hline Indicadores de Pessoal & $\begin{array}{c}\text { ( ) rentabilidade patrimônio } \\
\text { liquido }\end{array}$ \\
\hline $\begin{array}{c}\text { ( ) taxa de rotatividade } \\
\text { ) índice de treinamento de } \\
\text { pessoal }\end{array}$ & & \\
\hline
\end{tabular}

( ) não. Por quê?

\subsection{Todas as etapas do D'Olho na Qualidade foram implantadas?}

( ) $\operatorname{sim}$ ( ) não.

Se não, quais não foram implantadas. Por quê?

\subsection{Os processos da empresa foram identificados e padronizados?}
( ) $\operatorname{sim}$
( ) parcialmente. Por quê?
( ) não. Por quê?

( ) falta de persistência e apoio dos responsáveis pelo repasse das ferramentas

( ) falta de tempo dos funcionários ( ) desmotivação dos funcionários

( ) falta de apoio do consultor ( ) outras.

Quais?

\subsection{Houve dificuldades na implantação das ferramentas?}

( ) não

( ) sim. Quais? ( ) falta de persistência e apoio dos responsáveis pelo repasse das ferramentas
( )falta de preparo dos funcionários
( ) desmotivação dos funcionários
( ) complexidade das ferramentas
( ) tempo curto para implantação 

( ) falta de apoio do consultor
( ) outras. Quais?

4 Práticas gerenciais (antes, durante e após a implantação do PSQT).

4.1 A empresa utiliza a prática de especificar os materiais e serviços que são comprados?

\begin{tabular}{|l|l|l|}
\hline Antes & Durante & Depois \\
\hline ( ) não utilizava & ( ) não utilizou & ( ) não utiliza \\
\hline ( ) em implantação & ( ) em implantação & ( ) em implantação \\
\hline ( ) baixa utilização & ( ) baixa utilização & ( ) baixa utilização \\
\hline ( ) utilizava & ( ) utilizou & ( ) utiliza \\
\hline ( ) não respondeu/não sabe & ( ) não respondeu/não sabe & ( ) não respondeu/não sabe \\
\hline
\end{tabular}

4.2 A empresa utiliza o método de registrar de forma organizada, os materiais e serviços comprados?

\begin{tabular}{|l|l|l|}
\hline Antes & Durante & Depois \\
\hline ( ) não utilizava & ( ) não utilizou & ( ) não utiliza \\
\hline ( ) em implantação & ( ) em implantação & ( ) em implantação \\
\hline ( ) baixa utilização & ( ) baixa utilização & ( ) baixa utilizção \\
\hline ( ) utilizava & ( ) utilizou & ( ) utiliza \\
\hline ( ) não respondeu/não sabe & ( ) não respondeu/não sabe & ( ) não respondeu/não sabe \\
\hline
\end{tabular}

4.3 A empresa utiliza o processo de estabelecer com seus fornecedores critérios adotados para aceitar ou não os materiais e serviços adquiridos?

\begin{tabular}{|l|l|l|}
\hline Antes & Durante & Depois \\
\hline ( ) não utilizava & ( ) não utilizou & ( ) não utiliza \\
\hline ( ) em implantação & ( ) em implantação & ( ) em implantação \\
\hline ( ) baixa utilização & ( ) baixa utilização & ( ) baixa utilização \\
\hline ( ) utilizava & ( ) utilizou & ( ) utiliza \\
\hline ( ) não respondeu/não sabe & ( ) não respondeu/não sabe & ( ) não respondeu/não sabe \\
\hline
\end{tabular}

4.4 A empresa pesquisa informações a respeito das necessidades e expectativas dos clientes?

\begin{tabular}{|l|l|l|}
\hline Antes & Durante & Depois \\
\hline ( ) não pesquisava & ( ) não pesquisou & ( ) não pesquisa \\
\hline ( ) em implantação & ( ) em implantação & ( ) em implantação \\
\hline ( ) muito pouco & ( ) muito pouco & ( ) muito pouco \\
\hline ( ) pesquisa & ( ) pesquisou & ( ) pesquisa \\
\hline ( ) não respondeu/não sabe & ( ) não respondeu/não sabe & ( ) não respondeu/não sabe \\
\hline
\end{tabular}

Se utiliza, de que forma é feita a pesquisa? 
4.5 A empresa calcula os custos da qualidade?

\begin{tabular}{|l|l|l|}
\hline Antes & Durante & Depois \\
\hline ( ) não & ( ) não & ( ) não \\
\hline ( ) em implantação & ( ) em implantação & ( ) em implantação \\
\hline ( ) sim & ( ) sim & ( ) sim \\
\hline ( ) não sabe & ( ) não sabe & ( ) não sabe \\
\hline
\end{tabular}

4.6 Como você avalia a empresa no que diz respeito ao ambiente de trabalho em relação à: limpeza, iluminação, ruídos, arejamento etc.

\begin{tabular}{|l|l|}
\hline Antes & Depois \\
\hline ( ) péssimo & ( ) péssimo \\
\hline ( ) regular & ( ) regular \\
\hline ( ) bom & ( ) bom \\
\hline ( ) excelente & ( ) excelente \\
\hline ( ) não respondeu/não sabe & ( ) não respondeu/não sabe \\
\hline
\end{tabular}

4.7 Os empregados da produção participam da solução de problemas ou de atividades de melhoria do produto ou processo de fabricação?

\begin{tabular}{|l|l|l|}
\hline Antes & Durante & Depois \\
\hline ( ) não participavam & ( ) não participaram & ( ) não participam \\
\hline ( ) participavam pouco & ( ) participaram pouco & ( ) participam pouco \\
\hline ( ) participavam & ( ) participaram & ( ) participam \\
\hline ( ) não respondeu/não sabe & ( ) não respondeu/não sabe & ( ) não respondeu/não sabe \\
\hline
\end{tabular}

\subsection{Planejamento estratégico}

\begin{tabular}{|l|l|l|}
\hline Antes & Durante & Depois \\
\hline ( ) era instituído & ( ) foi instituído & ( ) instituído \\
\hline ( ) não era instituído & ( ) não foi instituído & ( ) não instituído \\
\hline ( ) não sabe & ( ) não sabe & ( ) não sabe \\
\hline
\end{tabular}

Caso o planejamento estratégico seja feito pela empresa, quem participa de sua elaboração?

\section{Resultados/sugestões de melhoria}

\subsection{Em relação ao retorno financeiro da empresa com a implantação do PSQT:}
( ) houve retorno financeiro
( ) não sofreu alteração
( ) retorno será a longo prazo
( ) não sabe dizer

\subsection{Em relação à qualidade do processo, após a implantação do PSQT:}

índice de perdas: ( ) diminuiu ( ) aumentou ( ) não sofreu alteração （ ) nr índice de retrabalho: ( ) diminuiu ( ) aumentou ( ) não sofreu alteração （ ) nr custos da qualidade: ( ) diminuiu ( ) aumentou ( ) não sofreu alteração （ ) nr 
5.3 Em relação à qualidade do produto, após a implantação do PSQT:

reclamação de clientes: ( ) diminuiu ( ) aumentou ( ) não sofreu alteração （ ) nr devolução de produtos: ( ) diminuiu ( ) aumentou ( ) não sofreu alteração ( ) nr confiança do cliente ao produto: ( ) diminuiu （） aumentou （ ） não sofreu alteração （ ) nr imagem do produto no mercado: ( ) melhorou ( ) piorou ( ) não sofreu alteração （ ) nr

\subsection{Em relação aos funcionários:}

produtividade: ( ) diminuiu ( ) aumentou ( ) ñalterou ( ) nr participação/envolvimento com a qualidade: ( ) diminuiu ( ) aumentou ( ) ñ alterou ( ) nr motivação no trabalho: ( ) diminuiu ( ) aumentou ( ) ñ alterou ( ) $\mathrm{nr}$ número de funcionários: ( ) diminuiu ( ) aumentou ( ) ñ alterou ( ) nr

\subsection{Em relação ao mercado:}

participação no mercado: ( ) diminuiu ( ) aumentou ( ) ñ alterou ( ) nr abriu novos mercados: ( ) sim ( ) não ( ) nr

5.6Em relação ao volume de vendas: ( ) diminuiu （ ）aumentou ( ) ñ alterou （ ）nr 5.7 Em relação aos clientes:

número de clientes: ( ) diminuiu ( ) aumentou ( ) ñ alterou ( ) nr satisfação dos clientes: ( ) diminuiu ( ) aumentou ( ) ñ alterou ( ) nr exigência dos clientes - produto: ( ) diminuiu ( ) aumentou ( ) ñ alterou （ ) nr

\subsection{Como você avalia os resultados do PSQT em relação às expectativas iniciais?}

( ) atendeu totalmente ( ) atendeu parcialmente ( ) não atendeu Caso não tenha atendido total ou parcialmente comentar os motivos:

5.9 A utilização de ferramentas da qualidade trouxe algum benefício para a empresa?

( ) sim. Quais? （ ) não. Por quê? 
5.10 Atualmente a empresa utiliza alguma ferramenta da qualidade?

( ) não. Por quê? （ ) sim. Quais?

5.11 Como você avalia os seguintes pontos do PSQT:

a) treinamento repassado em sala de aula

( ) ótimo ( ) satisfatório ( ) deixou a desejar. Por quê?

b) adequação do conteúdo do material utilizado às necessidades das MP'es:

( ) ótimo ( ) satisfatório ( ) deixou a desejar. Por quê?

c) qualidade técnica do material utilizado

( ) ótimo ( ) satisfatório ( ) deixou a desejar. Por quê?

d) apoio do Sebrae

( ) ótimo ( ) satisfatório ( ) deixou a desejar. Por quê?

e) tempo de duração do programa

( ) suficiente para implantar todas as tarefas do Programa ( ) muito curto

( ) muito extenso ( ) não sabe 
( ) ótimo ( ) satisfatório （ ) deixou a desejar. Por quê? Como poderia melhorar?

5.12 A empresa repassa os conhecimentos adquiridos com o PSQT aos funcionários novos? ( ) sim. De que forma? （ ) não.

5.13 Atualmente como a cultura da empresa se apresenta em relação à qualidade?

( ) pouco desenvolvida ( )muito desenvolvida ( ) em desenvolvimento ( ) não sabe

5.14 A empresa adota ou planeja adotar alguma iniciativa em prol da qualidade?

( ) sim. Qual?

( )não.

5.15 Outras críticas e sugestões de melhoria ao PSQT: 


\section{UNIVERSIDADE DE SÃO PAULO ESCOLA DE ENGENHARIA DE SÃO CARLOS ENGENHARIA DE PRODUÇÃO}

\section{APÊNDICE 3 - QUESTIONÁRIO (Funcionários treinados no PSQT)}

Empresa:

Entrevistado:

Cargo:

1 QUALIDADE TOTAL e PSQT

1.1 Qual é o seu entendimento do que vem a ser Qualidade Total?

( ) Processos padronizados e sistematizados ( ) Atender as necessidades dos clientes

( ) Melhoria contínua de processos

( ) Ausência de defeitos nos produtos

( ) Outros. Especificar:

1.2 Qual o seu entendimento do que vem a ser um Programa de Qualidade Total?

( ) Introdução/ aprendizado de técnicas e ferramentas da qualidade （ ) Não respondeu

( ) Orientação para atender as necessidades do cliente ( ) Aprimoramento de processos/ técnicas

( ) Outros. Especificar:

\section{IMPLANTAÇÃO DAS ATIVIDADES RELATIVAS AO PROGRAMA}

2.1 Como você avalia o envolvimento do proprietário como PSQT durante a implantação?

( ) alto ( ) médio ( ) baixo ( ) não se envolveu

2.2 Como você avalia o seu nível de envolvimento com o PSQT na empresa durante a implantação?

( ) alto ( ) médio ( ) baixo ( ) não se envolveu

2.3 A empresa reconheceu o seu trabalho pelas iniciativas da qualidade?

( ) não ( ) sim. De que forma? 
2.4 Os conceitos e princípios da qualidade foram repassados? Você assimilou-os?
( ) sim, foram repassados e assimilados
( ) repassados mas assimilados parcialmente
( ) repassados mas não assimilados
( ) não foram repassados

2.5 A missão e política da qualidade foram elaborados e disseminados por toda a empresa?
( ) elaborados e disseminados
( ) elaborados mas disseminados parcialmente
( ) elaborados mas não assimilados
( ) não foram elaborados

2.6 Você participou da elaboração da missão e política da qualidade?
( ) $\operatorname{sim}$
( ) não

2.7 Você participou da elaboração de indicadores de desempenho?
( ) a empresa não elaborou indicadores
( ) $\operatorname{sim}$
( ) não. Por quê?

2.8 Você participou de todas as etapas do D’Olho na qualidade?

( ) sim ( ) não . Por quê?

2.9 Você sentiu dificuldades em assimilar o repasse das ferramentas da qualidade?
( ) não, foram de fácil assimilação
( ) sim, em algumas delas
( ) sim, em grande parte delas
( ) sim, em todas

Se sentiu dificuldade, quais foram os motivos? 
2.10 De uma forma geral como você avalia o cumprimento das tarefas que lhe foram atribuídas durante a implantação do Programa?

\begin{tabular}{|l|l|l|}
\hline Bloco I & Bloco II & Bloco III \\
\hline ( ) realizou todas & ( ) realizou todas & ( ) realizou todas \\
\hline ( ) realizou grande parte & ( ) realizou grande parte & ( ) realizou grande parte \\
\hline ( ) realizou poucas & ( ) realizou poucas & ( ) realizou poucas \\
\hline ( ) não realizou & ( ) não realizou & ( ) não realizou \\
\hline
\end{tabular}

2.11 Como você avalia o repasse das atividades do PSQT, pelos facilitadores, na empresa?
( ) ótimo
( ) satisfatório
( ) deixou a desejar. Por quê?

2.12 Quais foram as principais motivos para a não implantação das atividades do Programa?

( ) todas foram implantadas

( ) dificuldade em conciliar as atividades do PSQT com a rotina de trabalho

( ) falta de apoio do proprietário ( ) falta de apoio dos facilitadores

( ) falta de apoio consultor ( ) metodologia do programa de difícil entendimento

( ) desmotivação ( ) falha no repasse das atividades

( ) $\mathrm{nr} \quad$ ( ) outras. Quais?

2.13 Quais os principais benefícios que o Programa Sebrae de Qualidade Total gerou para o seu trabalho?

( ) nenhum

( ) passou a preocupar-se em executar suas atividades com qualidade

( ) conscientização do que é qualidade

( ) preocupação com o cliente interno/ externo

( ) outras. Quais? 
2.14 No seu ponto de vista, quais os principais benefícios que o Programa Sebrae de Qualidade Total trouxe para a empresa?

( ) nenhum

( funcionários passaram a preocupar-se em executar suas atividades com qualidade

( ) conscientização do que é qualidade

( ) preocupação com o cliente interno/ externo

( ) aumento de produtividade

( ) redução de custos

( ) outras. Quais?

2.15 Atualmente você aplica os conceitos e princípios da qualidade em seu trabalho?

( ) $\operatorname{sim}$ ( ) não. Por quê?

2.16 Atualmente você utiliza alguma ferramenta da qualidade em seu trabalho?

( ) sim. Qual (is)?

( ) não. Por quê?

2.17 Outras críticas e sugestões de melhoria ao PSQT: 


\section{UNIVERSIDADE DE SÃO PAULO ESCOLA DE ENGENHARIA DE SÃO CARLOS ENGENHARIA DE PRODUÇÃO}

APÊNDICE 4 - QUESTIONÁRIO (Consultor)

Consultor:

Há quanto tempo trabalha como facilitador do PSQT?

1. O que mais influencia as pequenas empresas a implantar o PSQT? (se pertinente marque mais de uma alternativa)
( ) Dinâmica da economia
( ) Mercado
( ) Alterações de tecnologia
( ) Adaptação
( ) Recursos Humanos
( ) Mídia
( ) Outros. Especificar:

2. O que as pequenas empresas buscam com a implantação do PSQT? (se pertinente marque mais de uma alternativa)
( ) Crescimento organizado
( ) Compreensão e entendimento da GQT
( ) Sobrevivência e adaptação da empresa
( ) Satisfação do cliente
( ) Maior rentabilidade
( ) Melhoria relacionamento dos recursos humanos
( ) Outros. Especificar:

3. Quais os principais benefícios que as pequenas empresas obtêm com a implantação do PSQT? (se pertinente marque mais de uma alternativa)
( ) abertura de mercado
( ) redução de custos
( ) ganhos de competitividade
( ) melhoria satisfação do cliente
( ) ganhos de produtividade
( ) maior envolvimento e participação dos recursos humanos
( ) Outros. Especificar: 
4. Você acredita que a Pesquisa Nossa Empresa Trabalha com Qualidade Total feita no início da implantação do PSQT consegue avaliar as reais necessidades da empresa em relação à Gestão da Qualidade Total?

( ) $\operatorname{sim}$

( )não. Por quê? Como as necessidades da empresa em relação à GQT poderiam ser melhor avaliadas?

5. Em relação ao prazo de implantação do Programa, você considera:

( ) suficiente para implantação das atividades e tarefas na empresa

( ) insuficiente para implantação das atividades e tarefas na empresa. Como poderia melhorar?

6. Em relação ao número de horas de consultoria:

( ) baixo ( ) adequado ( ) alto

Comentários:

7. Você acredita que o apoio do consultor ao pequeno empresário na implantação do PSQT poderia melhorar? Se sim, de que forma?

8. Como você avalia a metodologia do PSQT?

( ) muito simples （ ) adequada ao público-alvo (pequena empresa) $\quad$ ( ) muito complexa

Comentários: 
9. Em relação a qualidade do material didático:

apostilas: ( ) baixa ( ) satisfatória ( ) alta

fitas de vídeo: ( ) baixa ( ) satisfatória ( ) alta

cartazes: ( ) baixa ( ) satisfatória ( ) alta

Comentários:

10. Em relação à duração dos módulos repassados em sala de aula:

( ) muito extensos ( ) adequados ( ) muito curtos

Comentários:

11. Em relação aos casos práticos apresentados durante os módulos, você considera:

número de casos: ( ) excesso （ ) quantidade suficiente （ ) quantidade insuficiente

adequação: $\quad(\quad$ ) adequados à realidade das PE's $\quad$ ( ) inadequados à realidade das

PE's

Comentários:

12. No seu ponto de vista o PSQT quando trabalhado setorialmente apresenta melhores resultados do que quando trabalhado com empresas de diferentes setores em um mesmo grupo? ( ) sim.Comentar ( ) não. Comentar

13. Em relação às atividades de Implantação do PSQT, como você classifica, de uma forma geral, o nível de implantação dessas nas empresas participantes do Programa?

$1-80 \%$ a $100 \%$ das empresas conseguem implantar

2 - $60 \%$ a $79 \%$ das empresas conseguem implantar

3 - $40 \%$ a $59 \%$ das empresas conseguem implantar

$4-20 \%$ a $39 \%$ das empresas conseguem implantar

5 - $0 \%$ a $19 \%$ das empresas conseguem implantar 


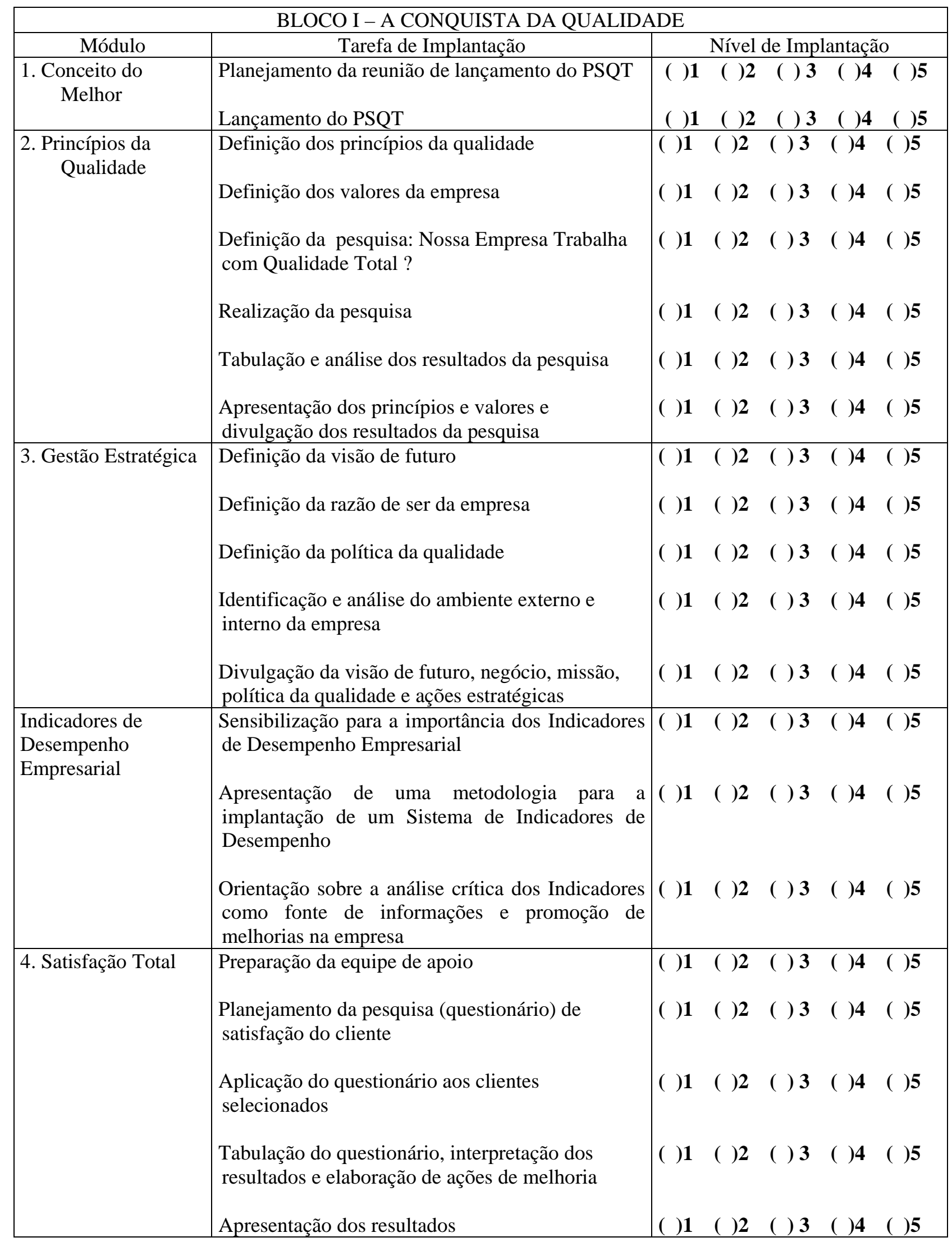




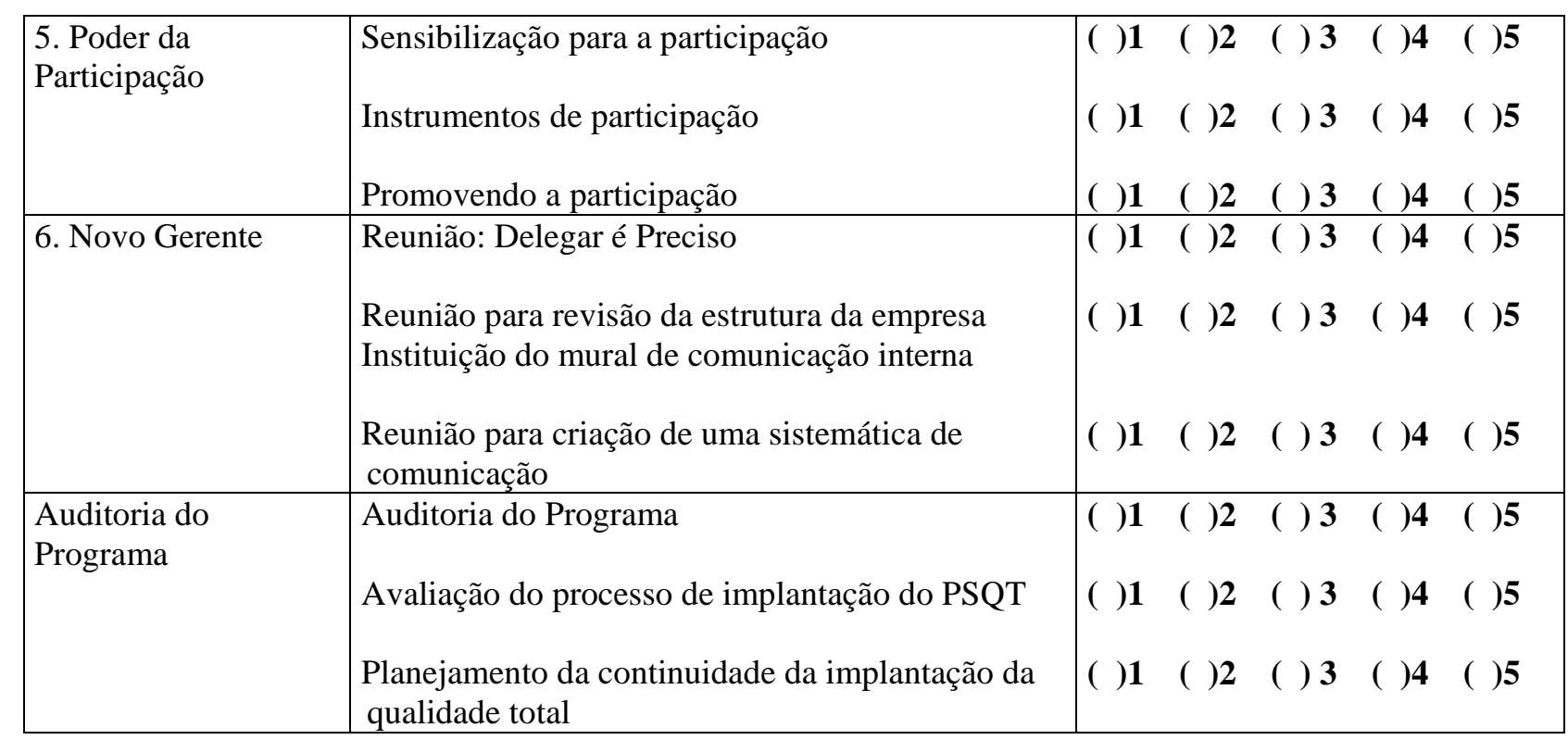

\begin{tabular}{|c|c|c|}
\hline \multicolumn{3}{|c|}{ BLOCO II - D-OLHO NA QUALIDADE } \\
\hline Módulo & Tarefa de Implantação & Nível de Implantação \\
\hline $\begin{array}{l}\text { 1. Eliminando o } \\
\text { Desperdício }\end{array}$ & Lançamento do D-Olho & 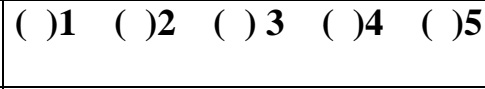 \\
\hline 2. Descarte e & Executando o Descarte & $\begin{array}{llllll}() 1 & (\text { )2 } & \text { ( ) } 3 & \text { ( ) } 4 & \text { ( )5 }\end{array}$ \\
\hline & Executando a Organização & 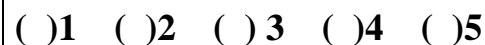 \\
\hline 3. Limpeza, Higiene e & Executando a Limpeza & 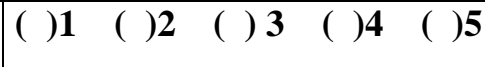 \\
\hline & Executando a Organização & ( ) $3 \quad($ ) $4 \quad($ )5 \\
\hline & Executando a Ordem Mantida & $\begin{array}{llllll}() & 1 & (\text { ) } & \text { ( ) } 3 & \text { ( ) } 4 & \text { ( )5 }\end{array}$ \\
\hline $\begin{array}{l}\text { 4. Manutenção e } \\
\text { Auditoria do }\end{array}$ & Auditoria do Programa & 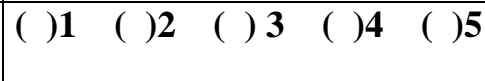 \\
\hline Programa & Avaliação do processo de implantação do PSQT & 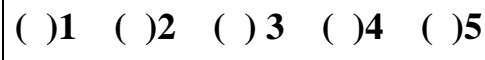 \\
\hline & $\begin{array}{l}\text { Planejamento da continuidade da implantação da } \\
\text { qualidade total }\end{array}$ & 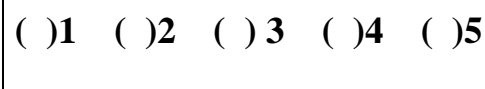 \\
\hline
\end{tabular}

\begin{tabular}{|c|c|c|}
\hline \multicolumn{3}{|c|}{ BLOCO III - MELHORIA DE PROCESSOS } \\
\hline \multirow{5}{*}{$\begin{array}{l}\text { Módulo } \\
\text { 1. Gerenciando } \\
\text { Processos }\end{array}$} & Tarefa de Implantação & Nível de Implantação \\
\hline & $\begin{array}{l}\text { Planejamento da reunião de introdução aos } \\
\text { conceitos de gerenciamento de processos }\end{array}$ & 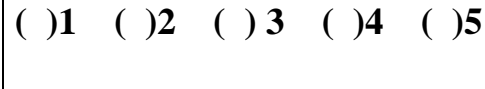 \\
\hline & $\begin{array}{l}\text { Disseminação dos conceitos de gerenciamento de } \\
\text { processos e cadeia cliente-fornecedor interno }\end{array}$ & 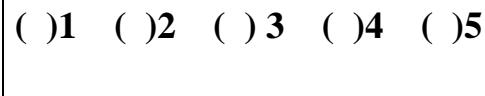 \\
\hline & $\begin{array}{l}\text { Preparação da equipe de apoio para identificar e } \\
\text { estabelecer os processos e a cadeia cliente- } \\
\text { fornecedor interno da empresa }\end{array}$ & 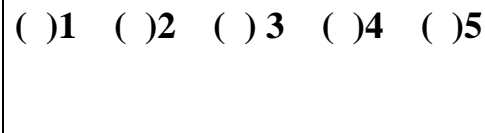 \\
\hline & Definição da cadeia cliente-fornecedor interno & 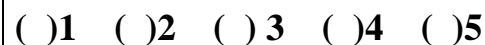 \\
\hline
\end{tabular}




\begin{tabular}{|c|c|c|}
\hline $\begin{array}{l}\text { 2. Garantia da } \\
\text { Qualidade }\end{array}$ & $\begin{array}{l}\text { Sensibilização para documentação dos processos } \\
\text { Reunião sobre Garantia da Qualidade } \\
\text { Elaboração dos procedimentos }\end{array}$ & $\begin{array}{lllll}(\text { )1 } & \text { ( )2 } & \text { ( ) } 3 & \text { ( )4 } & \text { ( )5 } \\
(\text { )1 } & \text { ( )2 } & \text { ( ) } 3 & \text { ( )4 } & \text { ( )5 } \\
(\text { ) } 1 & \text { ( )2 } & \text { ( ) } 3 & \text { ( ) } 4 & \text { ( )5 }\end{array}$ \\
\hline 3. Análise e Melhoria & $\begin{array}{l}\text { Identificação de problemas } \\
\text { Aplicação do MAMP } \\
\text { Analisando permanentemente os processos }\end{array}$ & 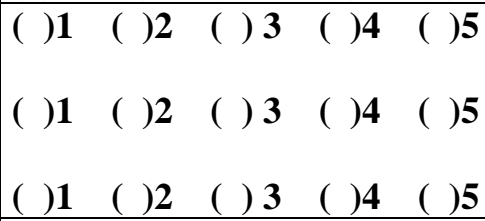 \\
\hline Auditoria & $\begin{array}{l}\text { Auditoria do Programa } \\
\text { Avaliação do processo de implantação do PSQT } \\
\text { Planejamento da continuidade da implantação da } \\
\text { qualidade total }\end{array}$ & $\left(\begin{array}{lllll}(\text { )1 } & \text { ( )2 } & \text { ( ) } 3 & (\text { ) } 4 & (\text { ) } 5 \\
(\text { )1 } & \text { ( )2 } & \text { ( ) } 3 & \text { ( )4 } & \text { ( )5 } \\
(\text { )1 } & (\text { ) } 2 & \text { ( ) } 3 & (\text { ) } 4 & (\text { ) } 5\end{array}\right.$ \\
\hline
\end{tabular}

14. Como você avalia a etapa de sustentação do Programa?

\begin{tabular}{|l|}
\hline \\
\hline \\
\hline
\end{tabular}

15. Você acredita que seria viável o acompanhamento a longo prazo pelo Sebrae do Gerenciamento da Qualidade Total nas empresas que implantaram o PSQT? Se sim, de que forma poderia ser feito? Se não, porque?

16. Quais os principais fatores que levam as empresas à não implantarem o PSQT? (Assinale os que acha relevante)

\begin{tabular}{|l|l|}
\hline Ausência de foco no consumidor & \\
\hline Ausência de planejamento & \\
\hline Criação de uma estrutura interna (da qualidade) paralela & \\
\hline Não reconhecimento do corpo funcional pelas iniciativas da qualidade & \\
\hline Dificuldade de utilização de ferramentas e técnicas da qualidade & \\
\hline Treinamento inadequado à realidade da empresa & \\
\hline Qualidade não é medida em termos financeiros & \\
\hline Falta de envolvimento do pequeno empresário & \\
\hline Falta de um processo de diagnóstico & \\
\hline
\end{tabular}




\begin{tabular}{|l|l|}
\hline Falta de envolvimento dos funcionários & \\
\hline Falta de tempo do pequeno empresário & \\
\hline Falta de tempo dos funcionários & \\
\hline Resistências Internas & \\
\hline Difícil adaptação do Programa a diferentes tipos de negócios & \\
\hline Falta de apoio do consultor & \\
\hline $\begin{array}{l}\text { Deficiência de técnica de repasse da metodologia (pelo (s) responsável } \\
\text { (is) na implantação dentro da empresa) }\end{array}$ & \\
\hline
\end{tabular}

\section{( ) Outros. Quais?}

17. Comentar a implantação do PSQT nas seguintes empresas que você atuou como consultor:

A, B, C, D: observar as seguintes questões abaixo

$\Rightarrow$ conseguiu implantar todas as atividades e tarefas do Programa? Se sim, quais fatores contribuíram para isso?

$\Rightarrow$ não implantou ou implantou parcialmente? Por quê, quais os fatores/ dificuldades enfrentadas que levaram a não implantação)?

$\Rightarrow$ se possível quantificar percentualmente o nível de implantação em cada um dos blocos.

$\Rightarrow$ você ainda mantêm contato/ exerce alguma atividade nessas empresas?

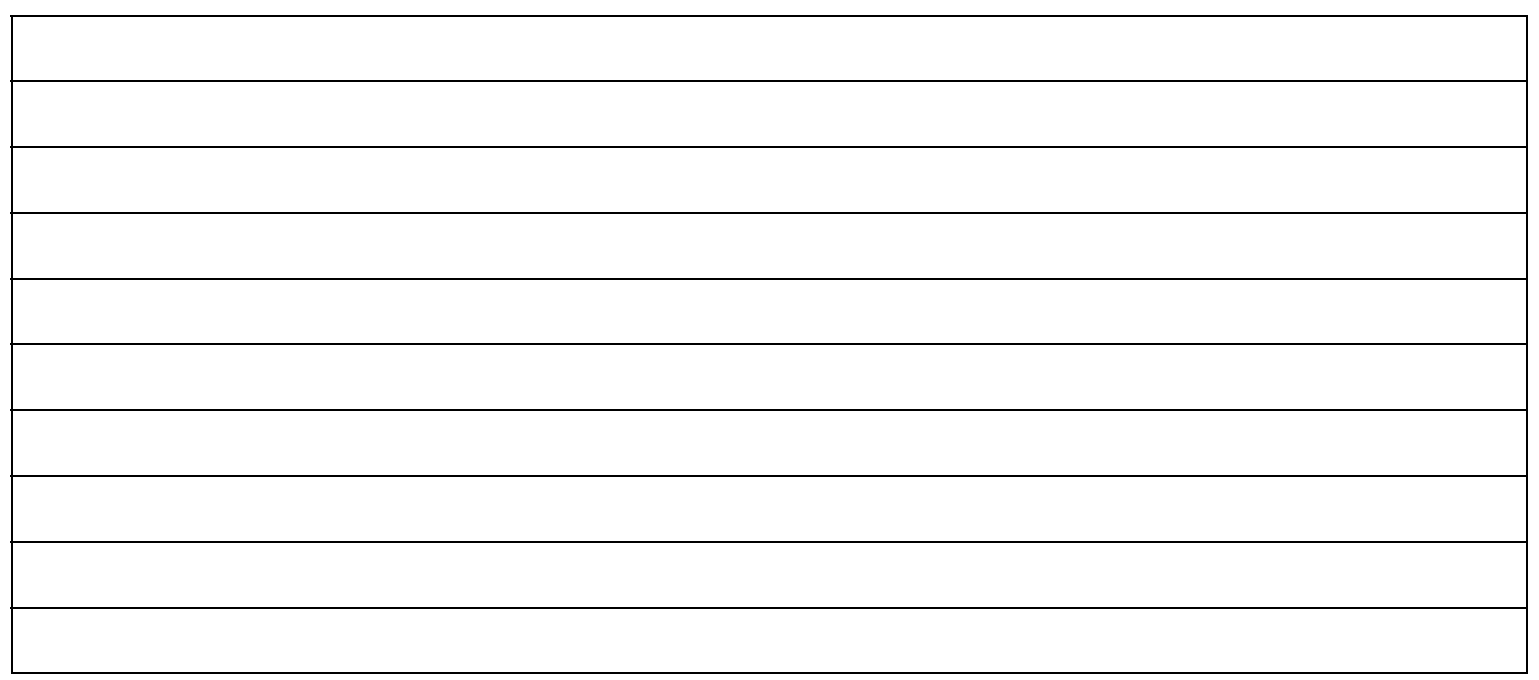




\section{APÊNDICE 5 - INFORMAÇÕES OBTIDAS ATRAVÉS DA ANÁLISE DOCUMENTAL}

Para a realização da análise documental foram consultados 36 (trinta e seis) formulários, elaborados pelo Sebrae, preenchidos pelas pessoas da empresa que participaram do PSQT. Deve-se ressaltar que os formulários não eram separados por empresa participante e sim por grupo. Dessa forma foram analisados os formulários dos grupos que as empresas que foram pesquisadas participaram, selecionando os questionários das pequenas indústrias, levando então em consideração opiniões de funcionários de empresas que não participaram da pesquisa, uma vez que não foi possível fazer a separação dos questionários.

Os formulários analisados continham os seguintes tópicos: o curso; o facilitador; o material didático; e os participantes. Os dados coletados nos formulários podem ser apresentados de acordo com os gráficos demonstrados nos tópicos 1, 2, .3 e 4 a seguir, atentando para a correspondência da legenda dos gráficos da seguinte forma:

(1) Discorda totalmente;

(2) Discorda parcialmente;

(3) Discorda;

(4) Concorda parcialmente;

(5) Concorda e

(6) Concorda totalmente.

\section{0 curso}

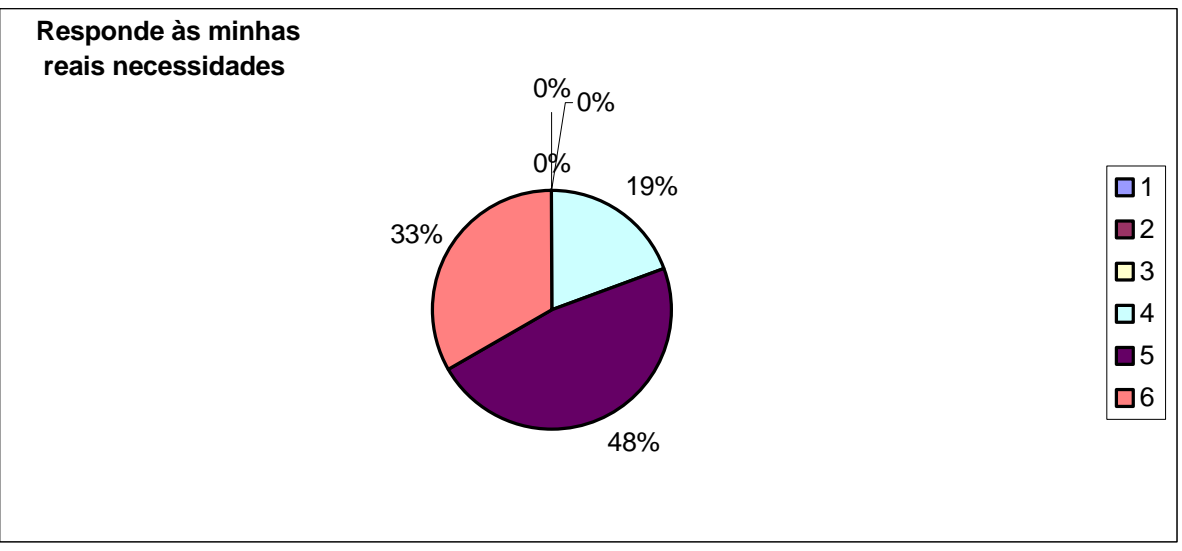

Figura 1: Resposta às necessidades 


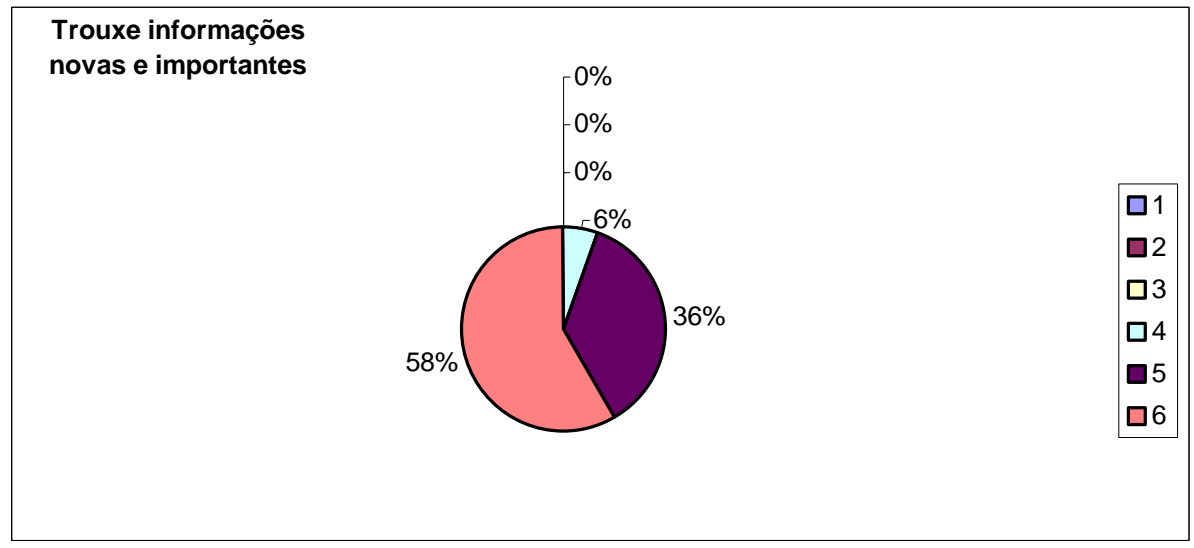

Figura 2: Informações Agregadas

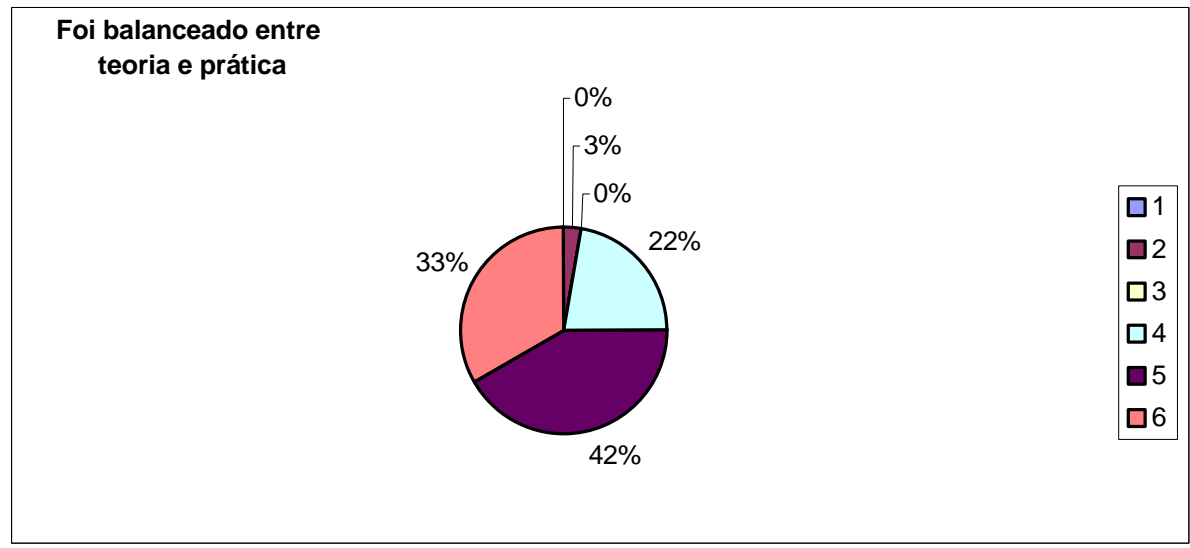

Figura 3: Balanceamento entre teoria e prática

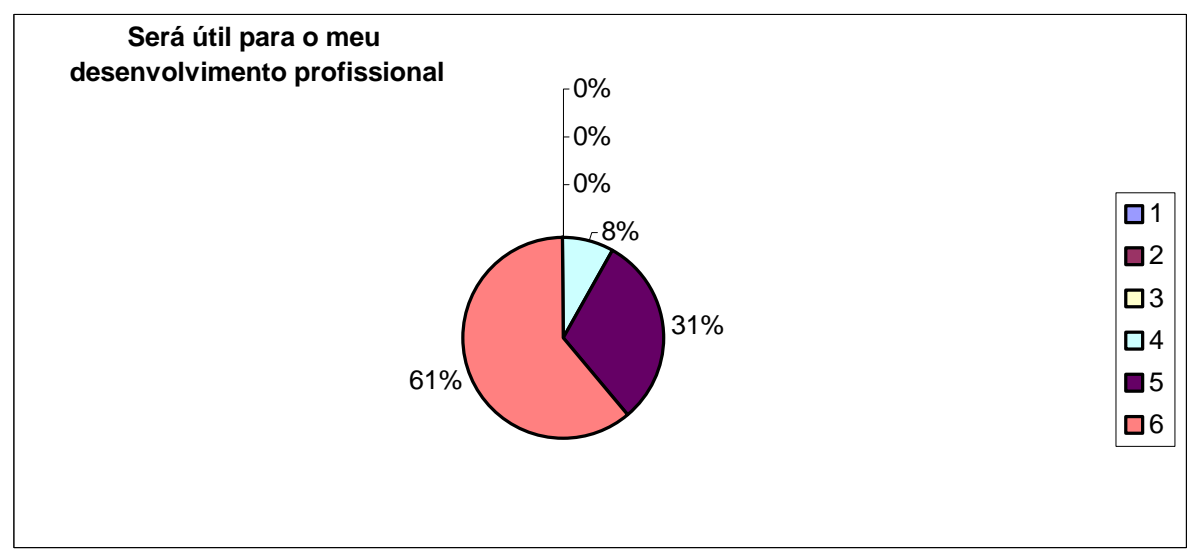

Figura 4: Utilidade para o desenvolvimento profissional 
O tempo de duração foi suficiente para todas as atividades

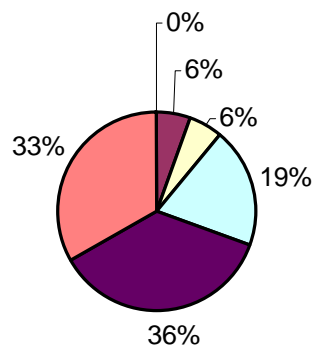

Figura 5: Tempo de Duração X Atividades

Possibilitou gerenciar a minha

própria aprendizagem

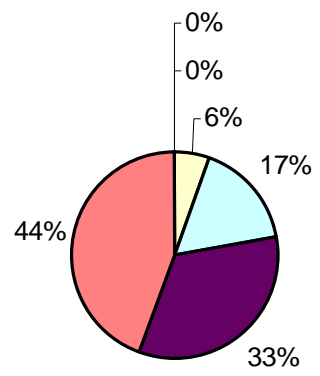

Figura 6: Gerenciamento da aprendizagem

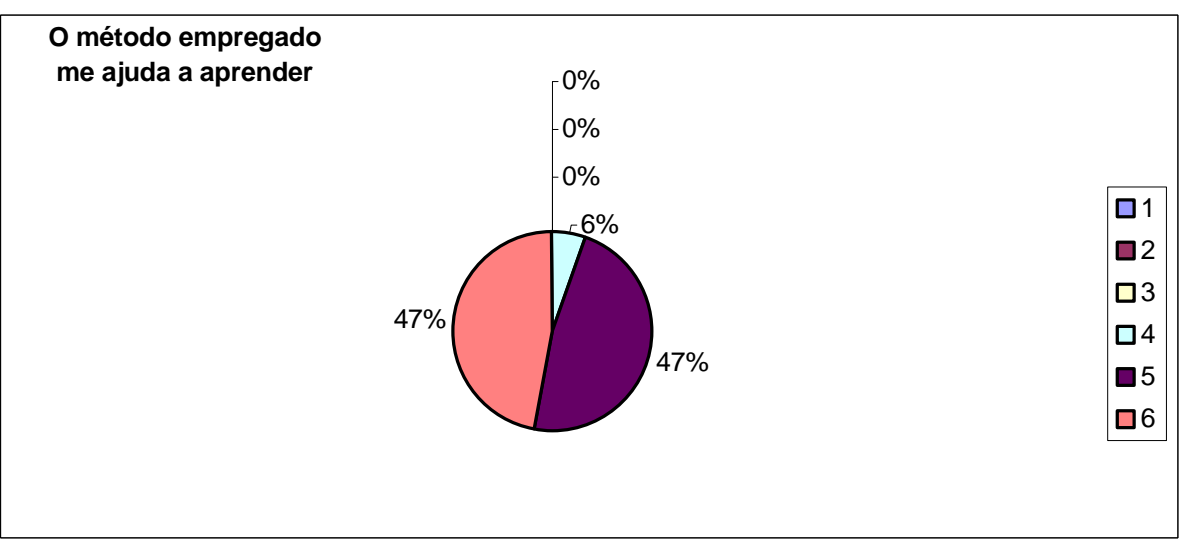

Figura 7: Método X Aprendizado 


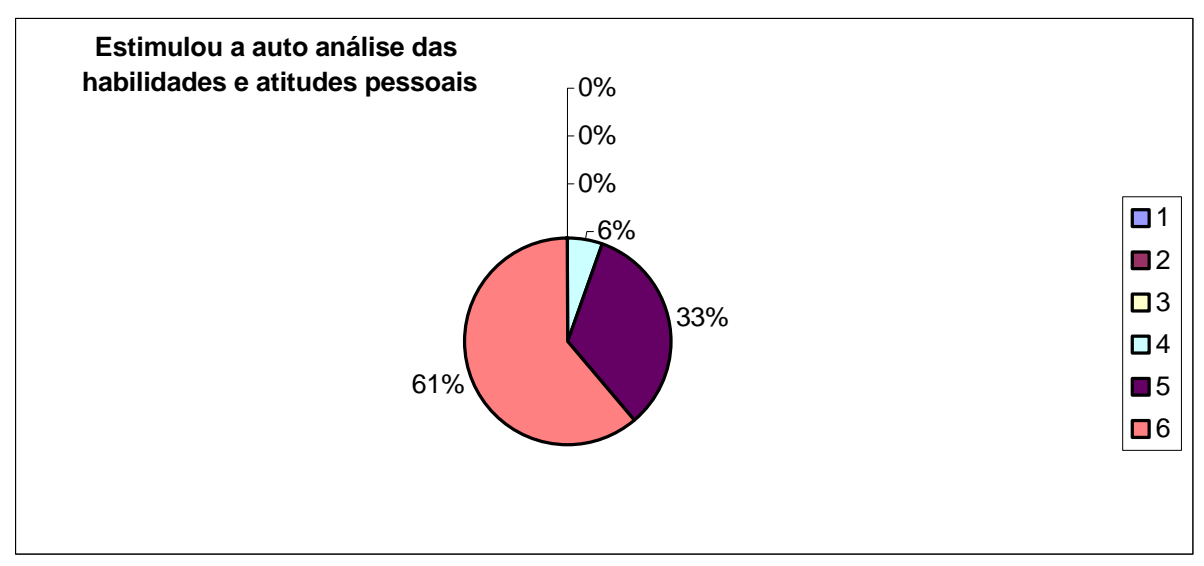

Figura 8: Auto análise

Pelas respostas obtidas pode-se verificar que o Programa contribuiu para a parte comportamental, para a percepção das pessoas em relação à qualidade, o que também pode ser verificado pelas respostas obtidas nos questionários aplicados na pesquisa de campo e com os estudos já realizados anteriormente, específicos do PSQT.

Um outro ponto a se considerar é que o curso foi avaliado como bem balanceado entre teoria e prática em grandes partes das respostas, o que também coincide com as respostas obtidas na pesquisa de campo.

O tempo de duração foi considerado suficiente para a implantação das atividades em 69\% das respostas. Das empresas pesquisadas apenas metade considerou o tempo suficiente para a implantação do PSQT, havendo uma diferença, em termos percentuais, de 19\%. O tempo de duração curto foi um fator citado como causa de insucesso do programa em apenas um estudo, dos cinco específicos do programa.

Os seguintes comentários feitos nos questionários reforçam a contribuição do PSQT em termos comportamentais:

$>$ O curso é bom tem possibilidade de promover uma evolução pessoal e profissional dos participantes na medida em que resgata valores e permite o progresso de cada um;

Mudei muito o modo de pensar e agir. 


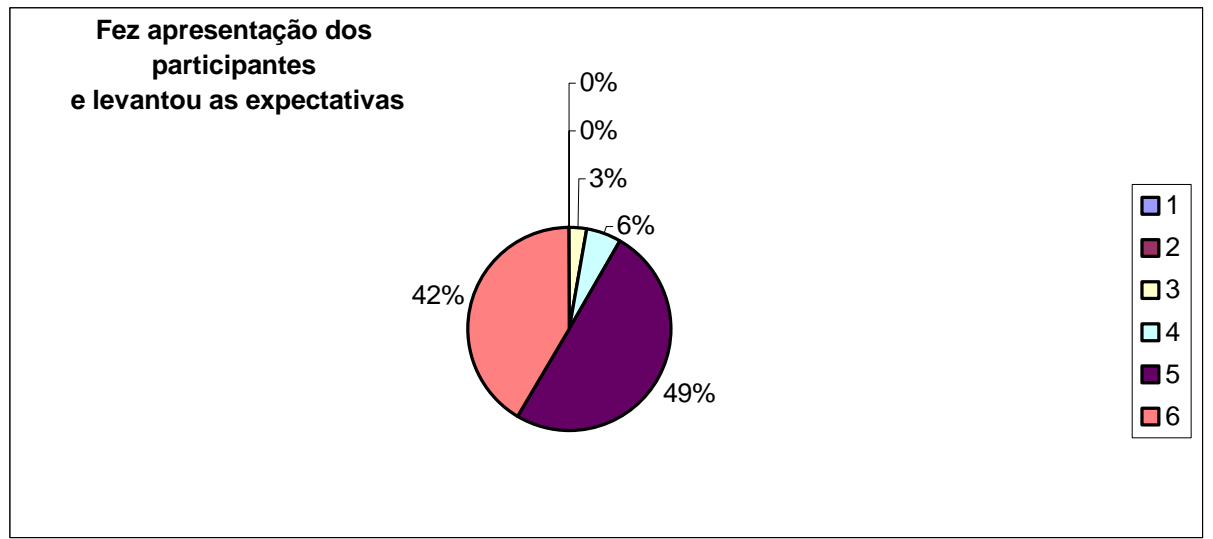

Figura 9: Apresentação e levantamento de expectativas

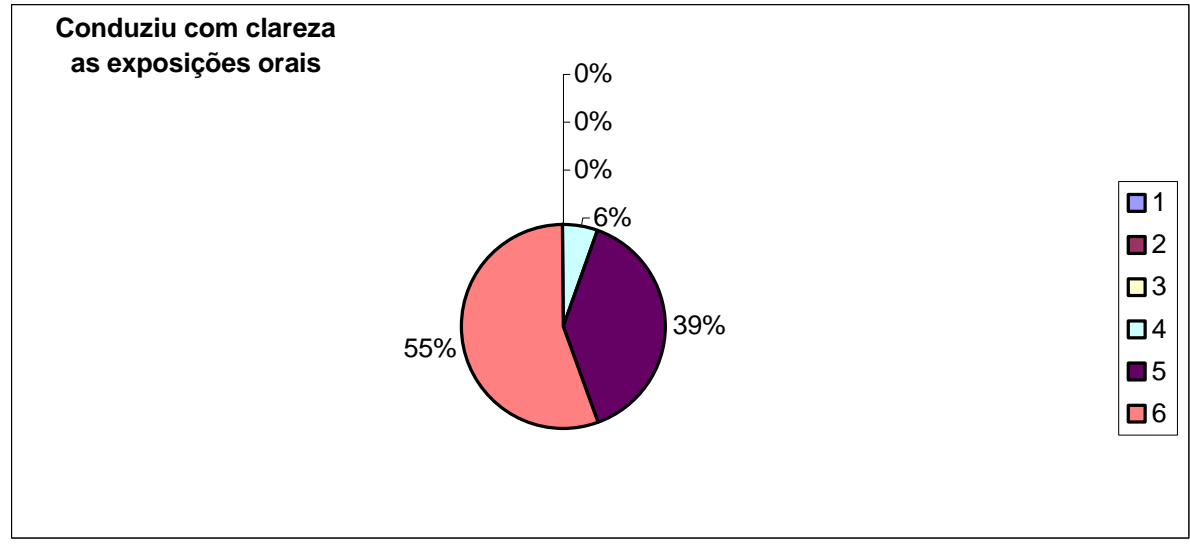

Figura 10: Clareza nas exposições

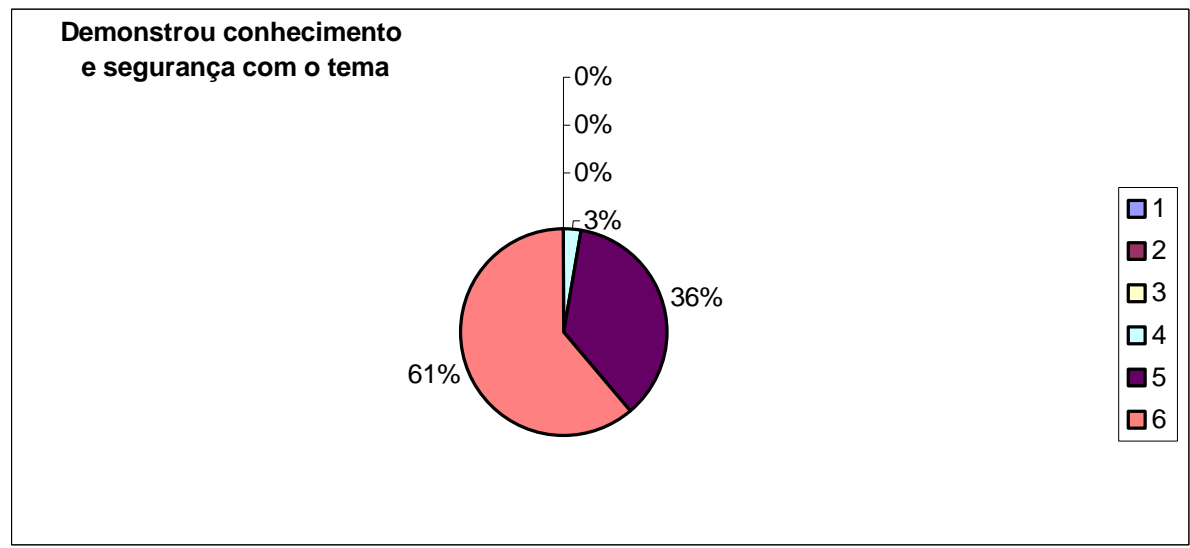

Figura 11: Conhecimento e segurança 
Bom relacionamento

com os participantes

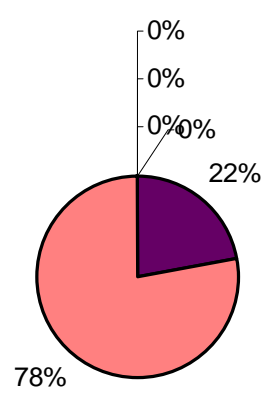

Figura 12: Relacionamento com os participantes

Cumpriu o programa por inteiro

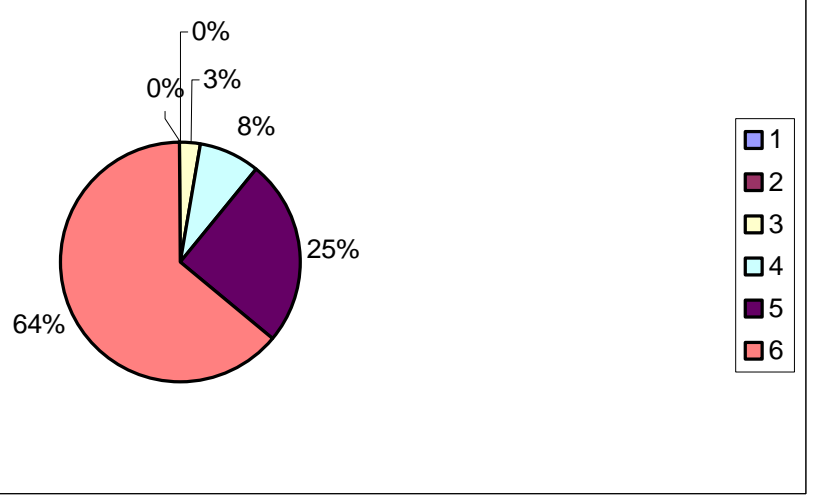

Figura 13: Cumprimento do programa

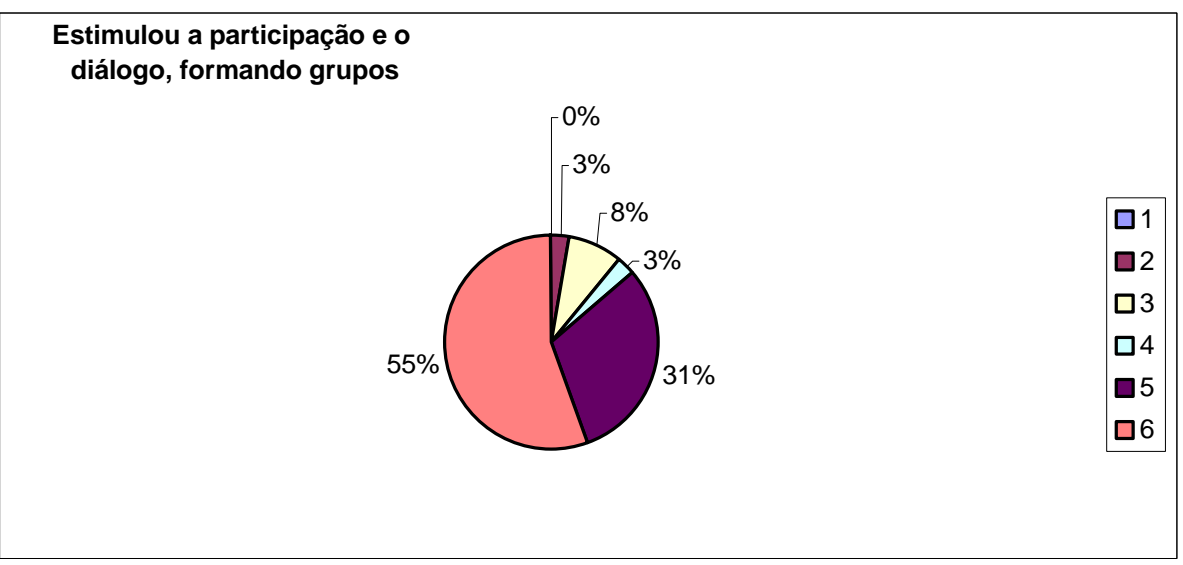

Figura 14: Estímulo à participação 


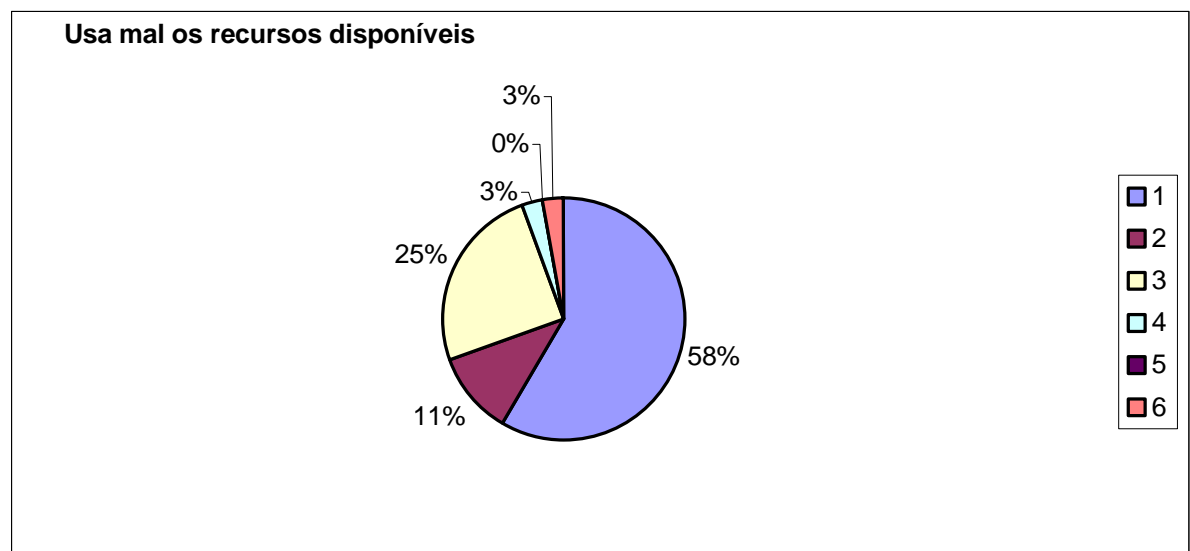

Figura 15: Utilização dos recursos

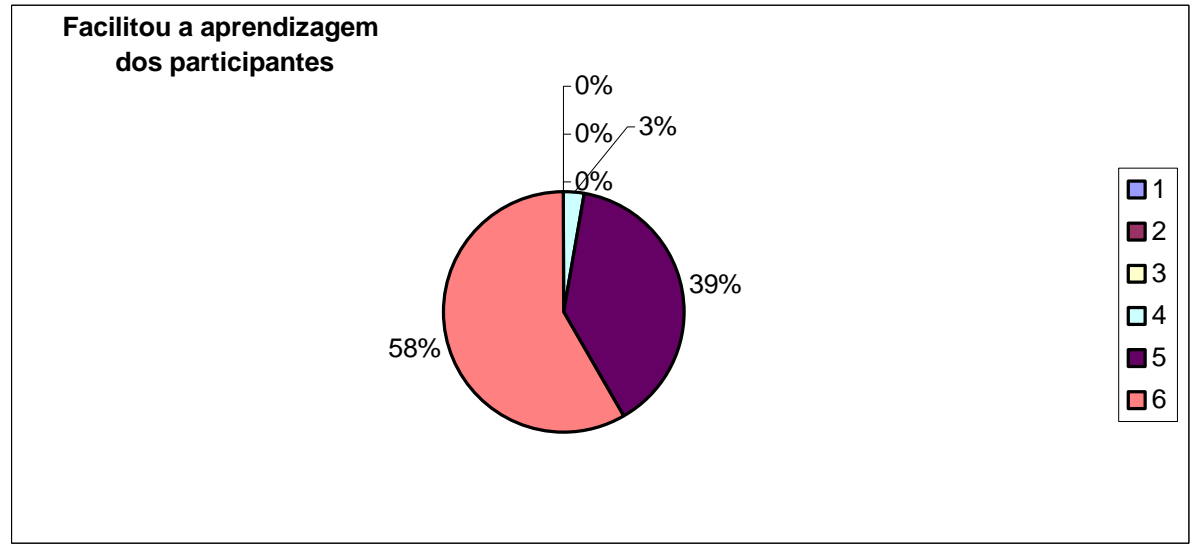

Figura 16: Aprendizagem dos participantes

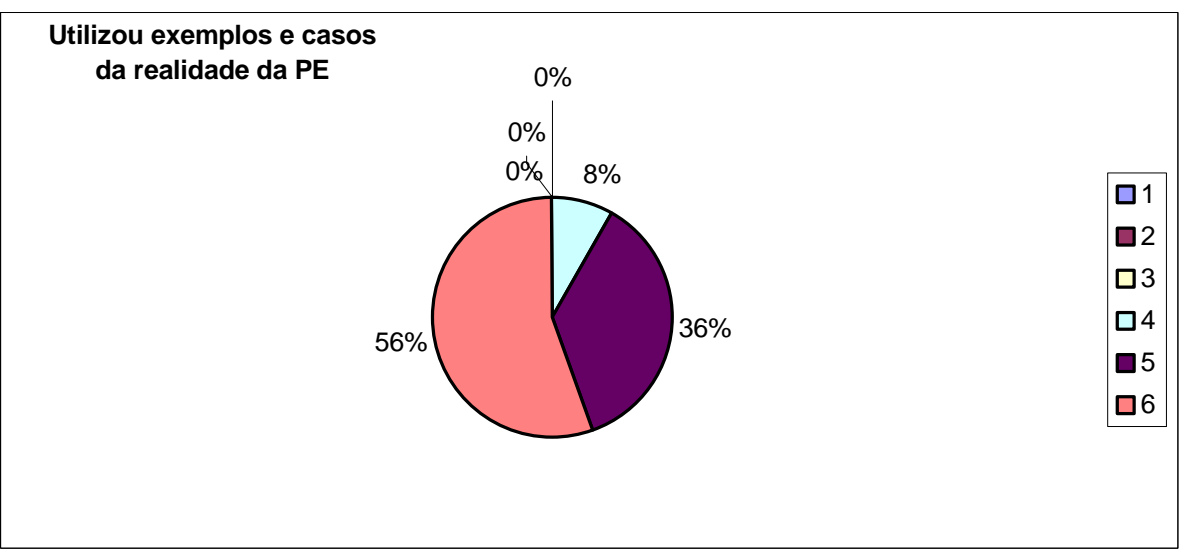

Figura 17: Utilização de exemplos 


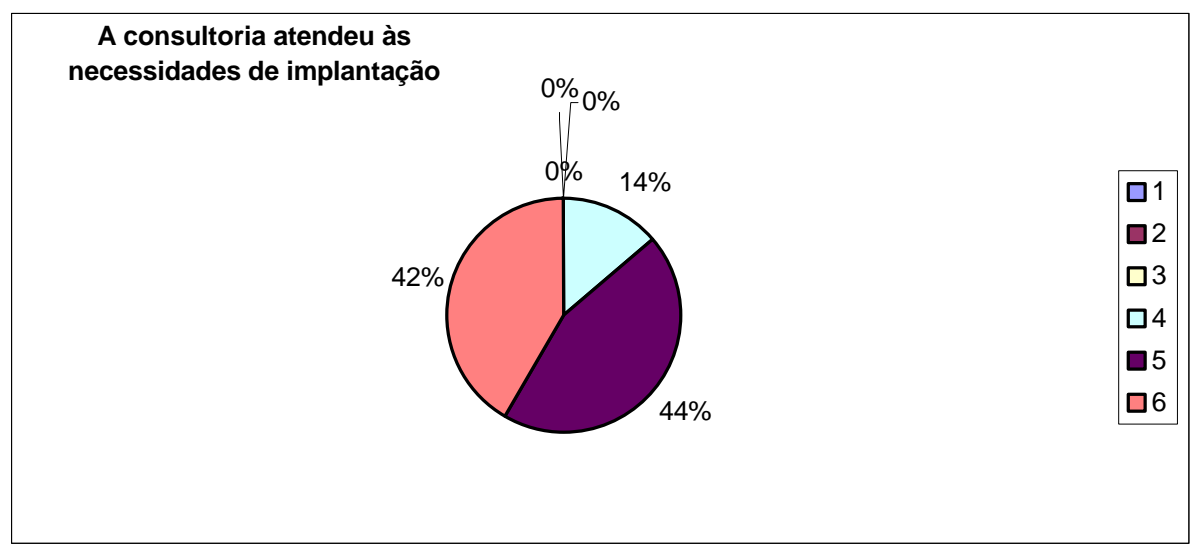

Figura 18: Atendimento às necessidades de implantação

Assim como na pesquisa de campo realizada, o trabalho do consultor e apoio dado pelo às empresas treinadas foi bem avaliado, o que diverge dos resultados encontrados nos estudos já realizados a respeito do PSQT, citados na revisão bibliográfica. Dos cinco estudos pesquisados três apontaram como fator de insucesso do Programa a falta de acompanhamento dos consultores.

\section{0 material didático}

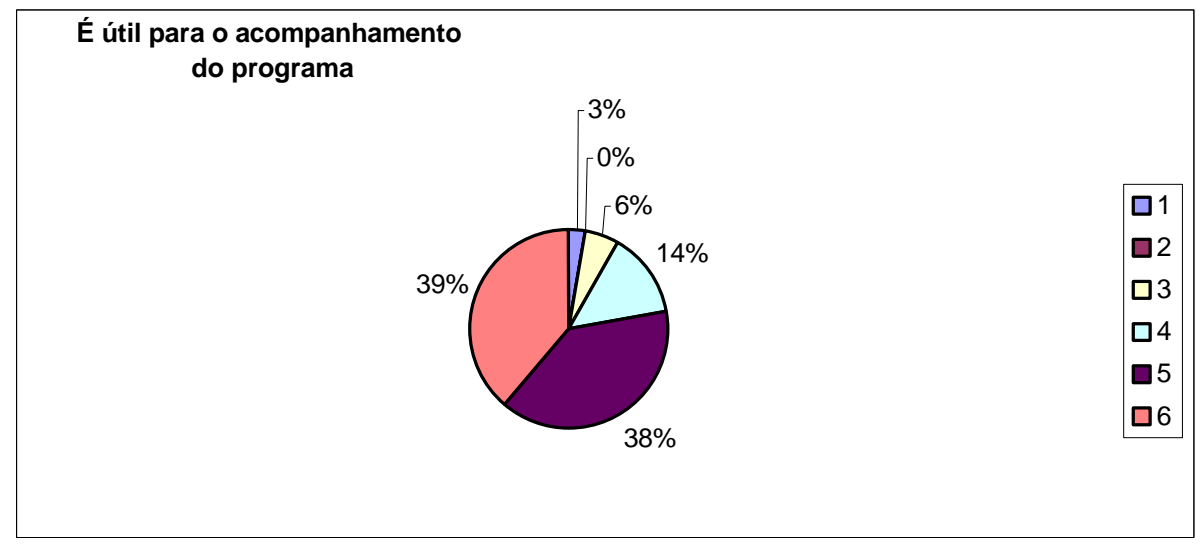

Figura 19: Utilidade para acompanhamento do programa 


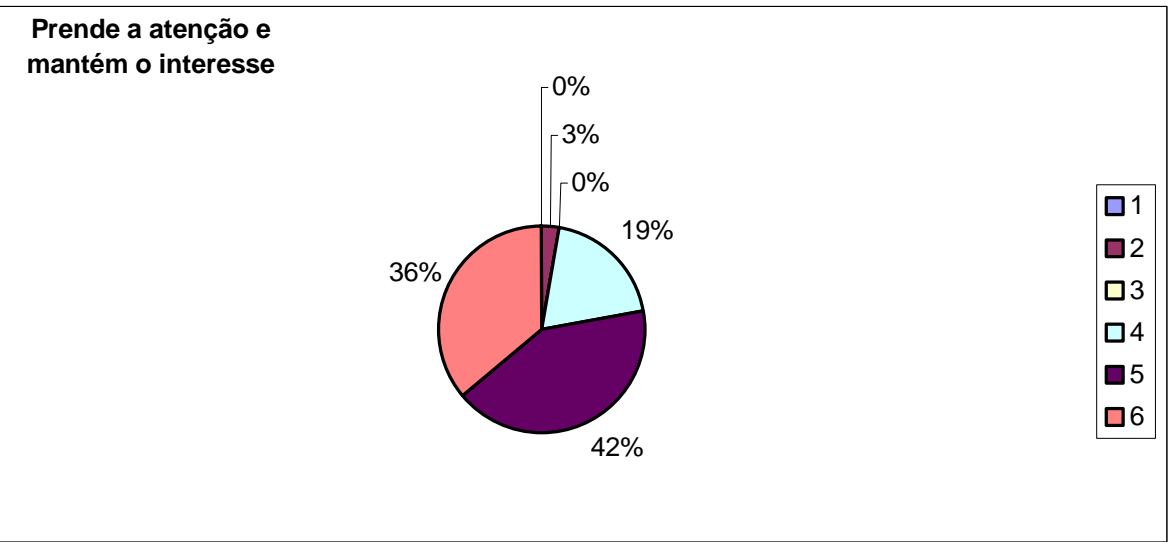

Figura 20: Atenção e interesse

É de fácil leitura e o vocabulário é adequado para o entendimento

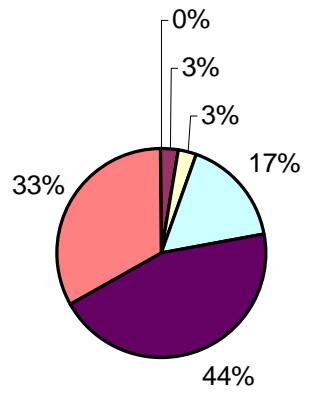

Figura 21: Facilidade de leitura e adequação do vocabulário

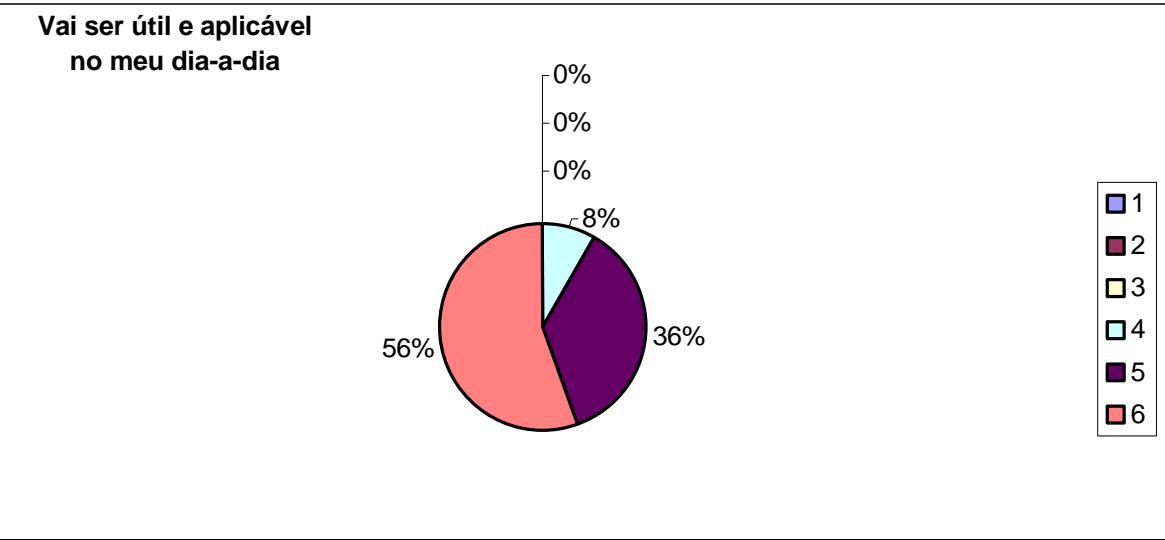

Figura 22: Aplicação no dia-a-dia 


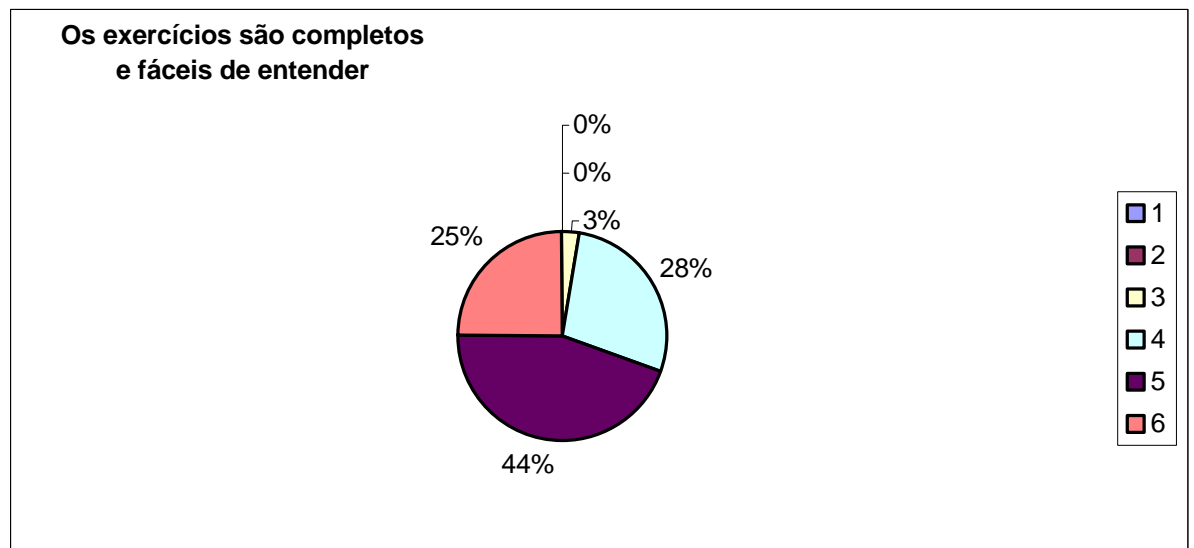

Figura 23: Conteúdo e facilidade de entendimento

O material didático também foi bem avaliado, assim como na pesquisa de campo feita. Um ponto negativo a respeito do material levantado foi o seguinte: a apostila deveria ser de melhor qualidade, pois desgruda.

\section{Os participantes}

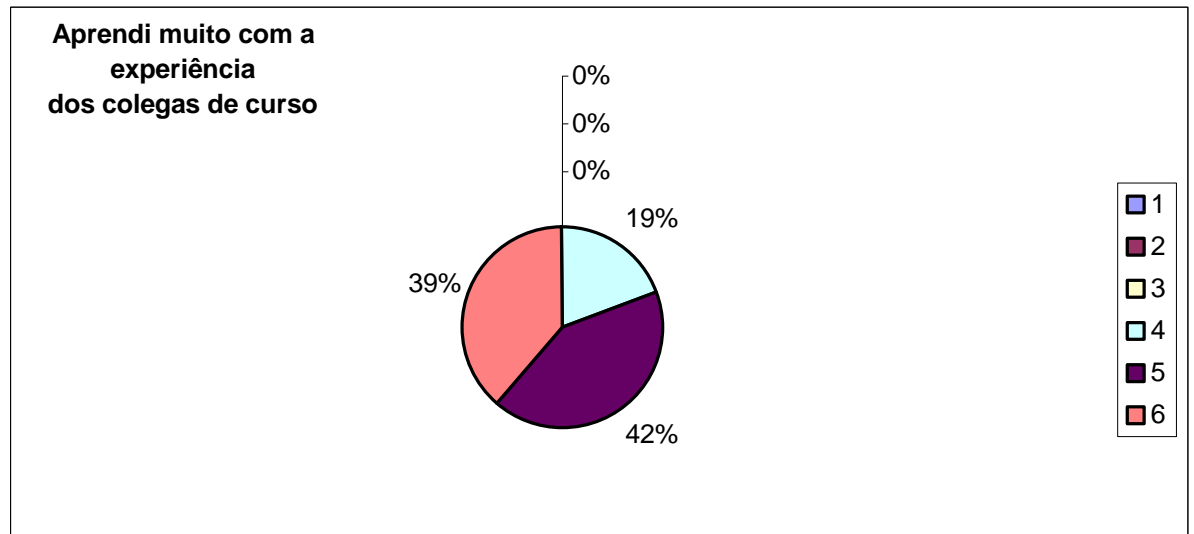

Figura 24: Aprendizagem através da troca de experiências 


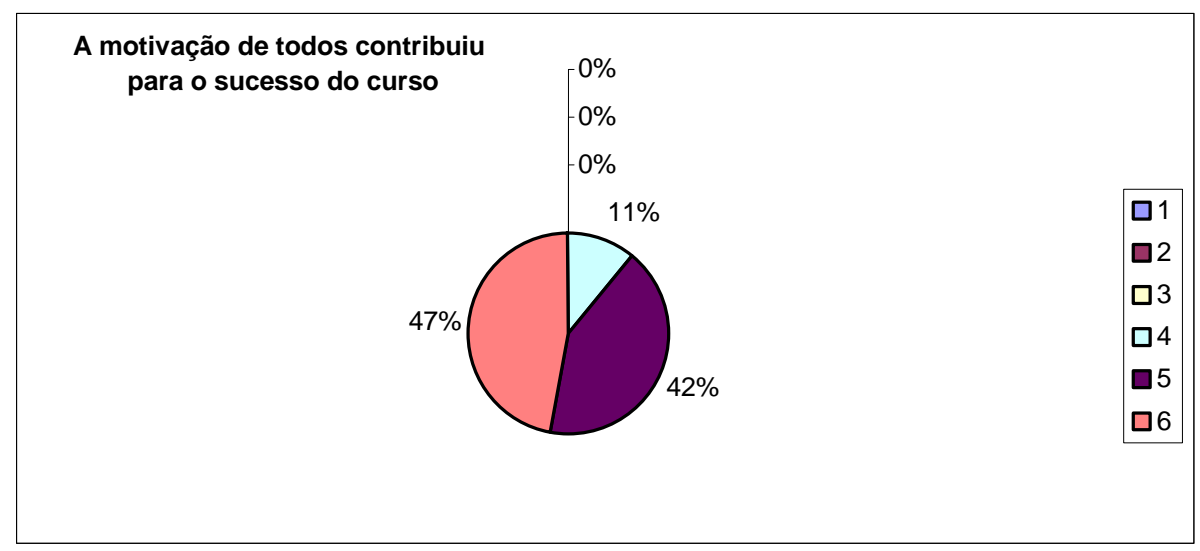

Figura 25: Motivação

Contribuí pouco para o trabalho do meu grupo

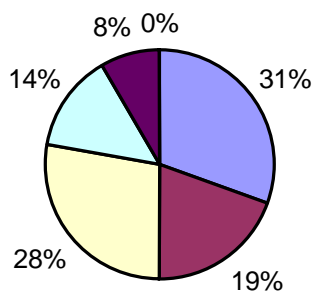

Figura 26: Contribuição ao grupo

Quem tinha grupo bom aprendeu bem

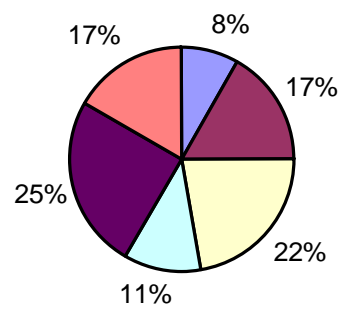

Figura 27: Aprendizado X qualidade do grupo 


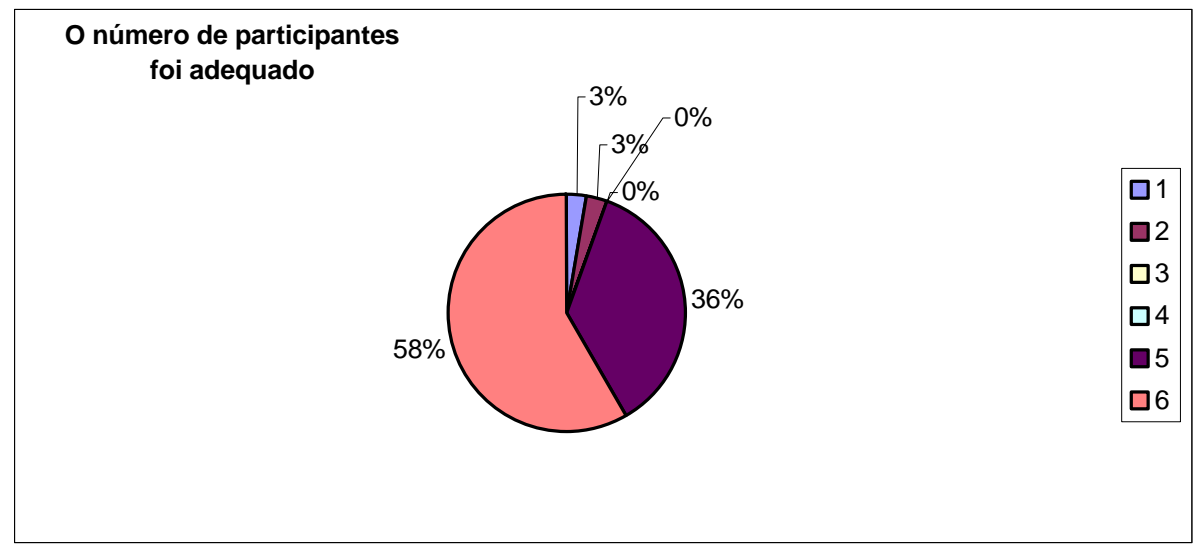

Figura 28: Número de participantes

A avaliação do quesito participantes, através dos formulários, demonstra que o PSQT auxilia a melhoria do trabalho em equipe, revelando um aprendizado dos participantes através da troca de experiências entre eles. Esta avaliação, reforça a contribuição do PSQT para a parte comportamental da empresa treinada.

$>$ O curso contribuiu muito para uma melhoria da comunicação entre pessoas de diferentes níveis hierárquicos, quebrando tabus principalmente entre os funcionários do chão de fábrica e da administração;

> Gostei do curso porque ajudou a somar conhecimentos a respeito do gerenciamento participativo, melhorando o relacionamento diário com meus colegas de trabalho, ouvindo e avaliando opiniões de todos. Também houve uma grande melhoria da produtividade e qualidade de nossos produtos;

$>$ O PSQT facilitou o relacionamento com as pessoas, as responsabilidades foram melhor distribuídas.

\section{Sugestões feitas nos formulários:}

Seria interessante que a cada 2 reuniões fosse entregue a cada multiplicador/pessoa-chave um questionário para resposta em casa, forçando a leitura da apostila. Seria uma espécie de prova com consulta;

$>$ Levar o grupo para conhecer uma indústria que já fez o PSQT;

$>$ Pegar exemplos teóricos da indústria calçadista;

$>$ Com relação ao repasse sugiro algo mais participativo entre os membros da empresa;

$>$ Reuniões semanais trariam melhor aproveitamento;

> Os módulos repassados em sala de aula deveriam ter uma menor duração e serem mais freqüentes; 


\section{APÊNDICE 6 - NÍVEL DE IMPLANTAÇÃO DAS TAREFAS DO PSQT POR BLOCO}

Os gráficos a seguir, representam as informações levantadas através da pesquisa feita com três consultores do PSQT. Os dados representados referem-se ao percentual de implantação das tarefas dos Blocos I, II e III (considerando empresas treinadas no PSQT de uma forma geral, e não somente as participantes da pesquisa) de acordo com a seguinte escala:

1) $80 \%$ a $100 \%$ das empresas conseguem implantar a tarefa

2) $60 \%$ a $79 \%$ das empresas conseguem implantar a tarefa

3) $40 \%$ a $59 \%$ das empresas conseguem implantar a tarefa

4) $20 \%$ a $39 \%$ das empresas conseguem implantar a tarefa

5) $0 \%$ a $19 \%$ das empresas conseguem implantar a tarefa

\section{Bloco I}

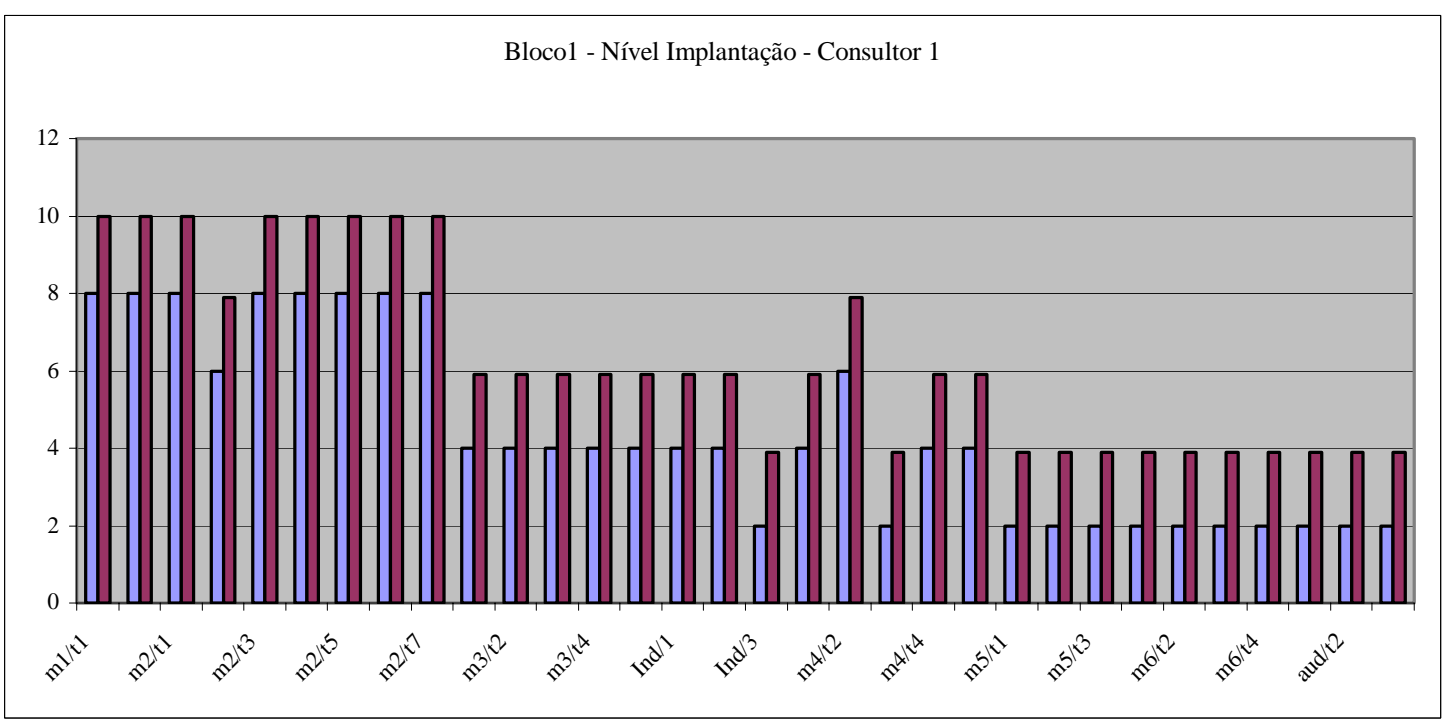

Figura 1: Nível de Implantação Bloco I - Consultor 1 


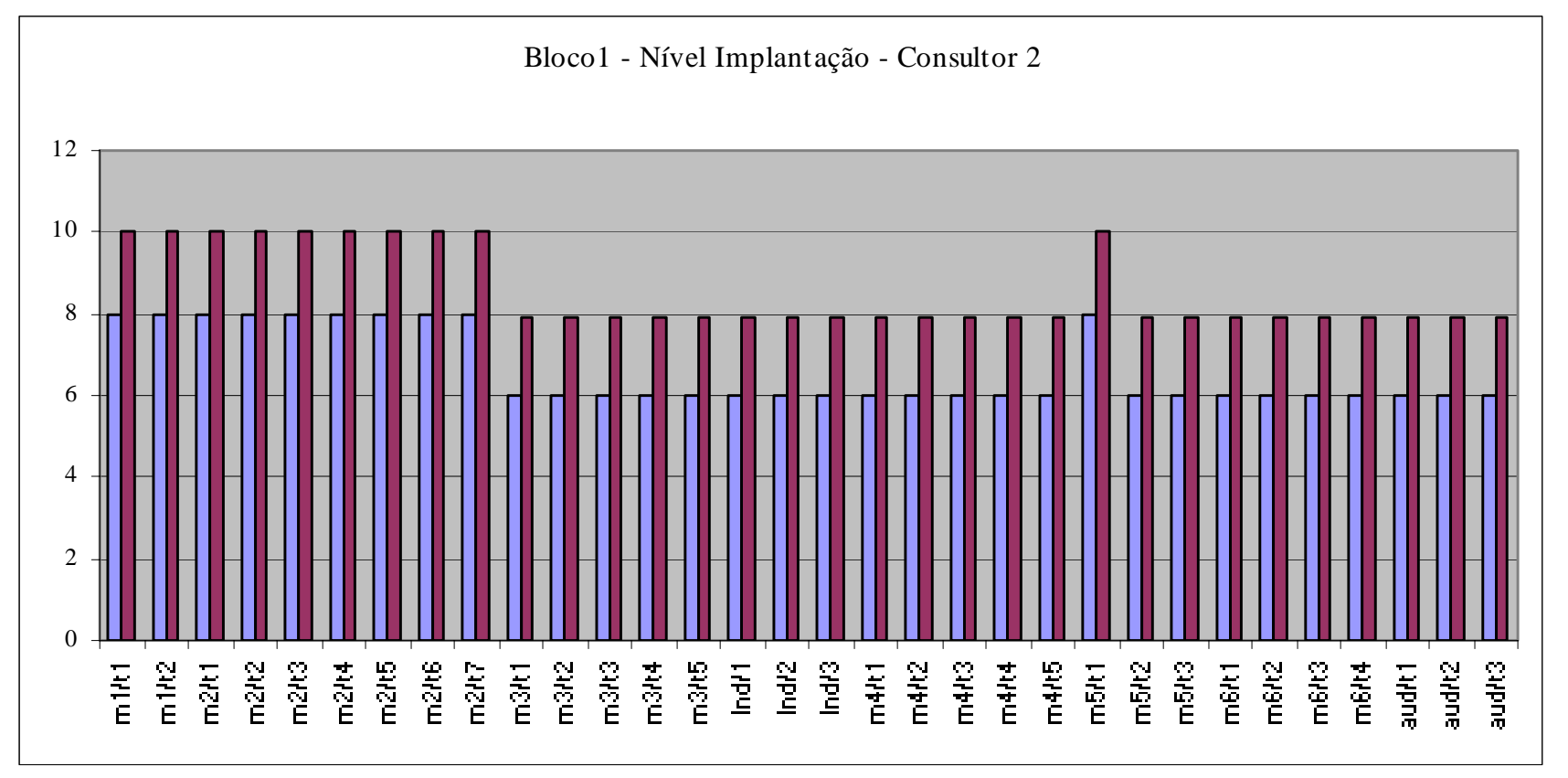

Figura 2 - Nível de Implantação Bloco I - Consultor 2

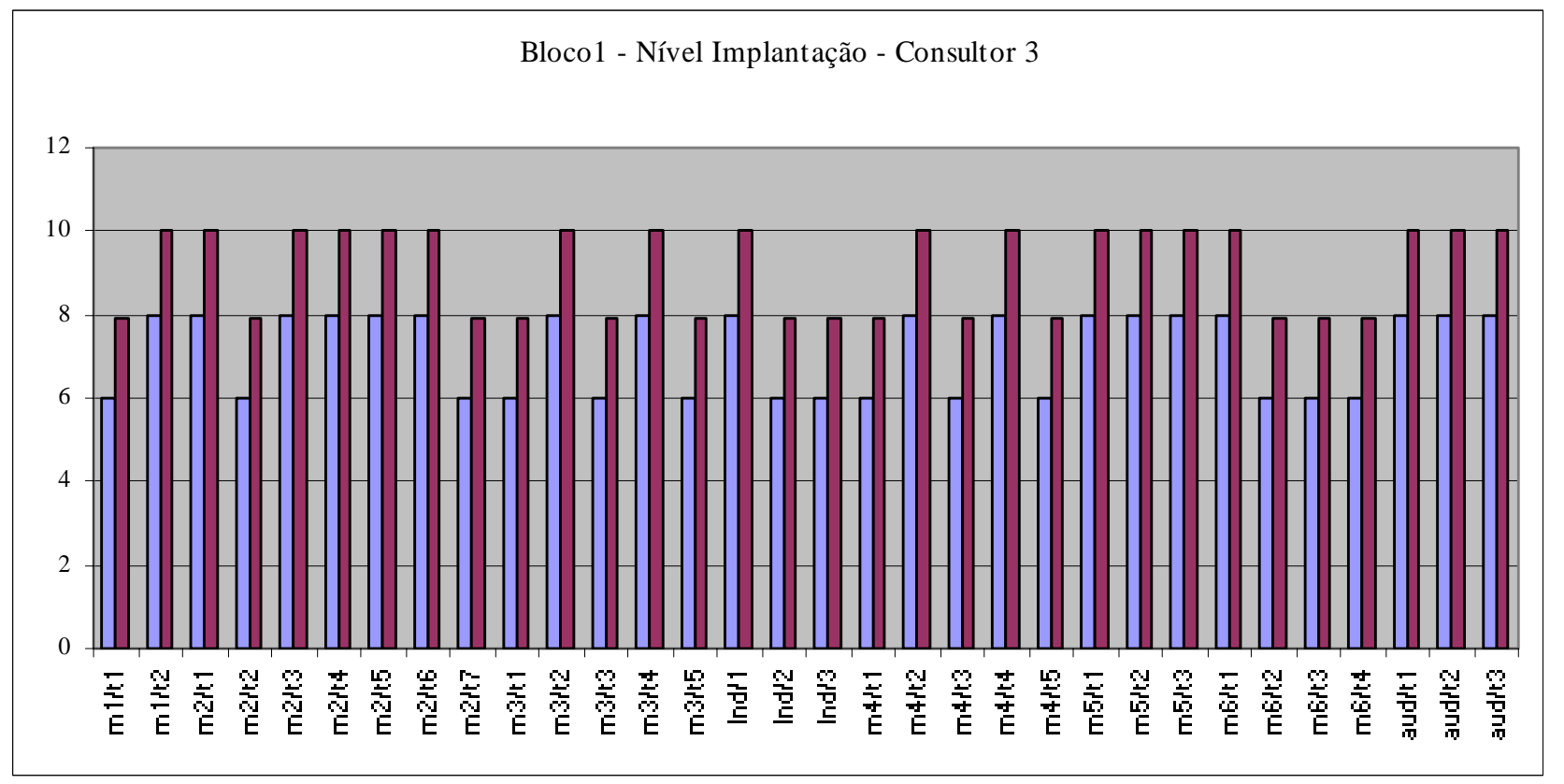

Figura.3: Nível de Implantação Bloco I - Consultor 3 


\section{Bloco II}

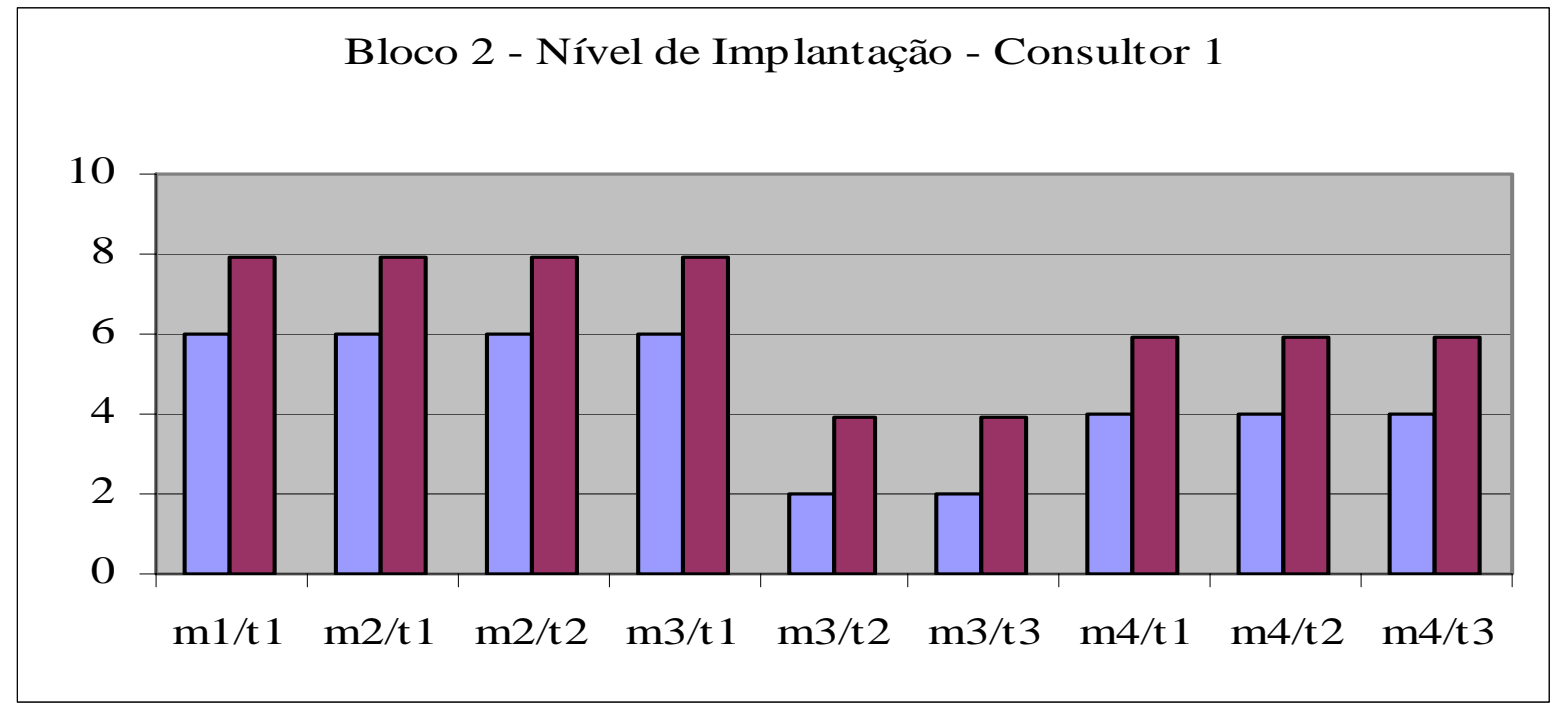

Figura 4: Nível de Implantação Bloco II - Consultor 1

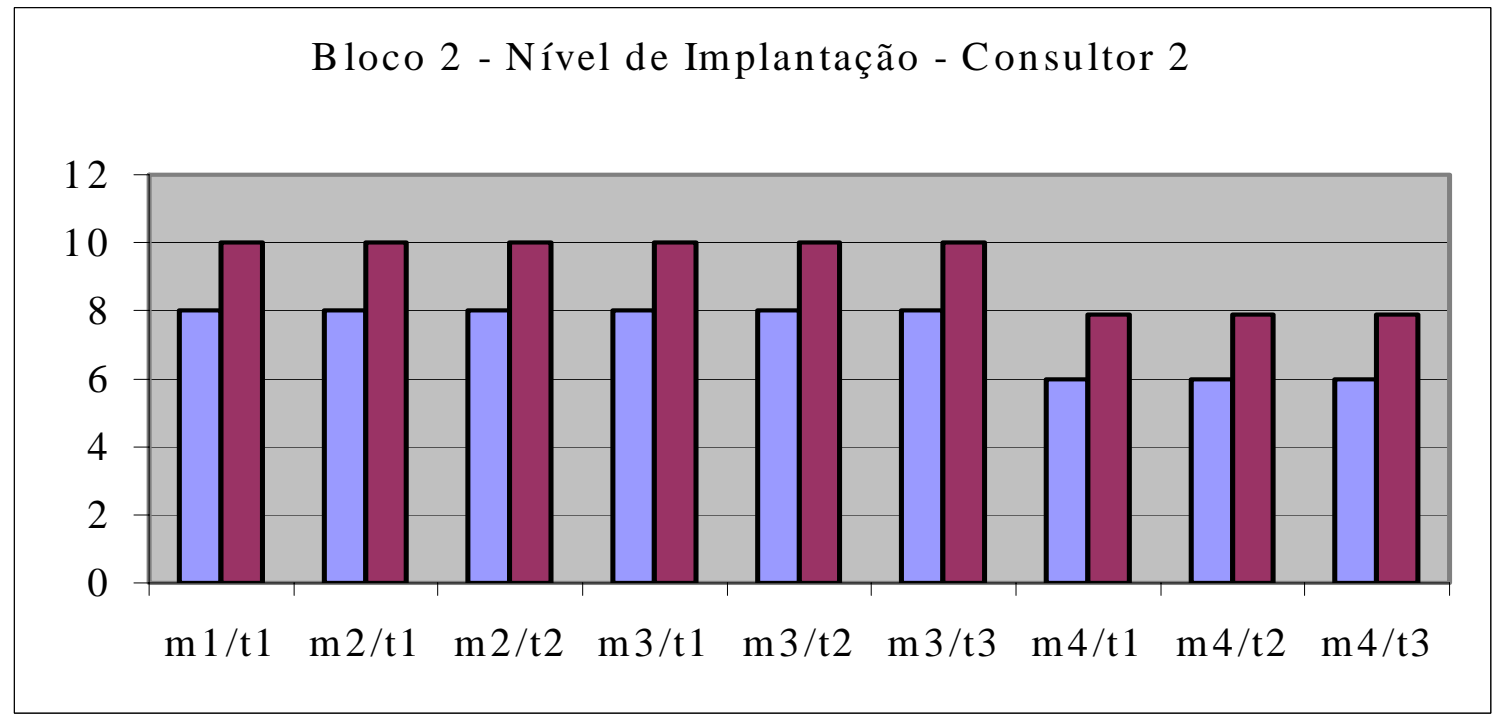

Figura 5: Nível de Implantação Bloco II - Consultor 2 


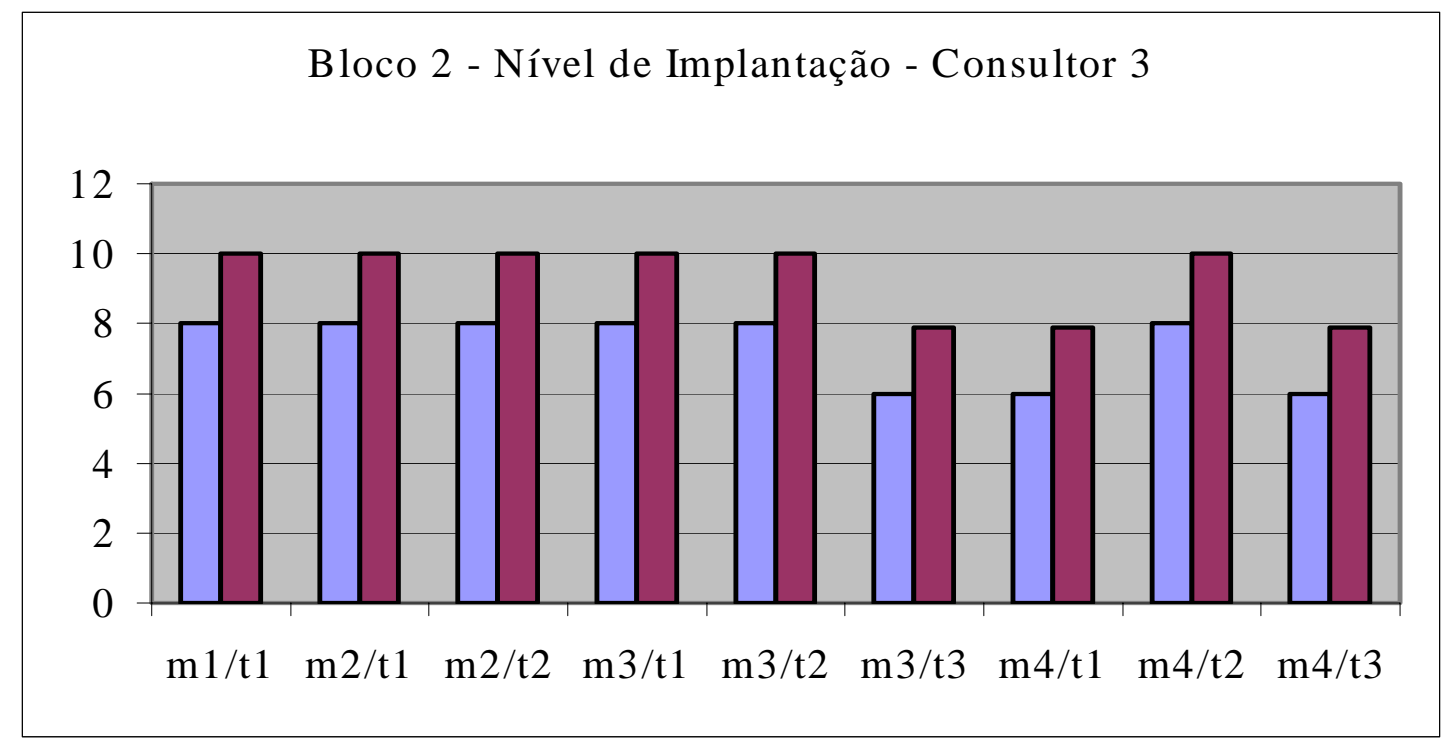

Figura 6: Nível de Implantação Bloco II - Consultor 3

\section{Bloco III}

Bloco 3 - Nível de Implantação - Consultor 1

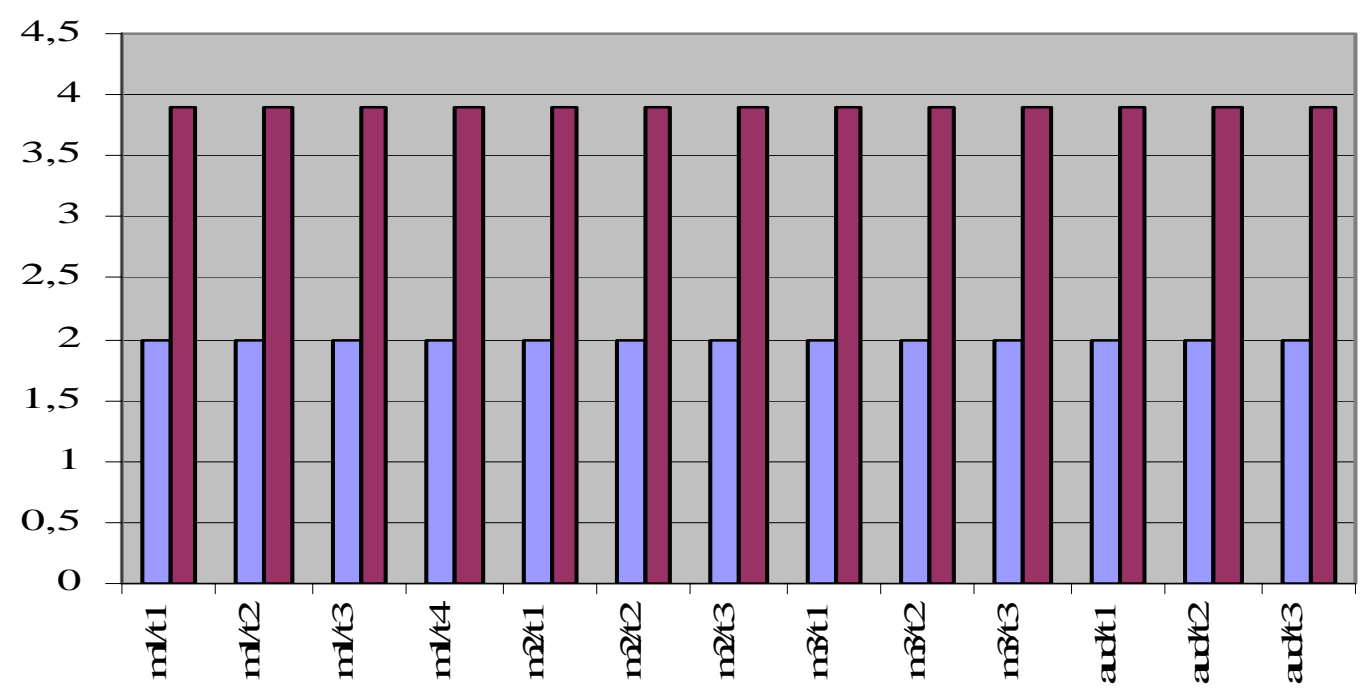

Figura 7: Nível de Implantação Bloco III - Consultor 1 


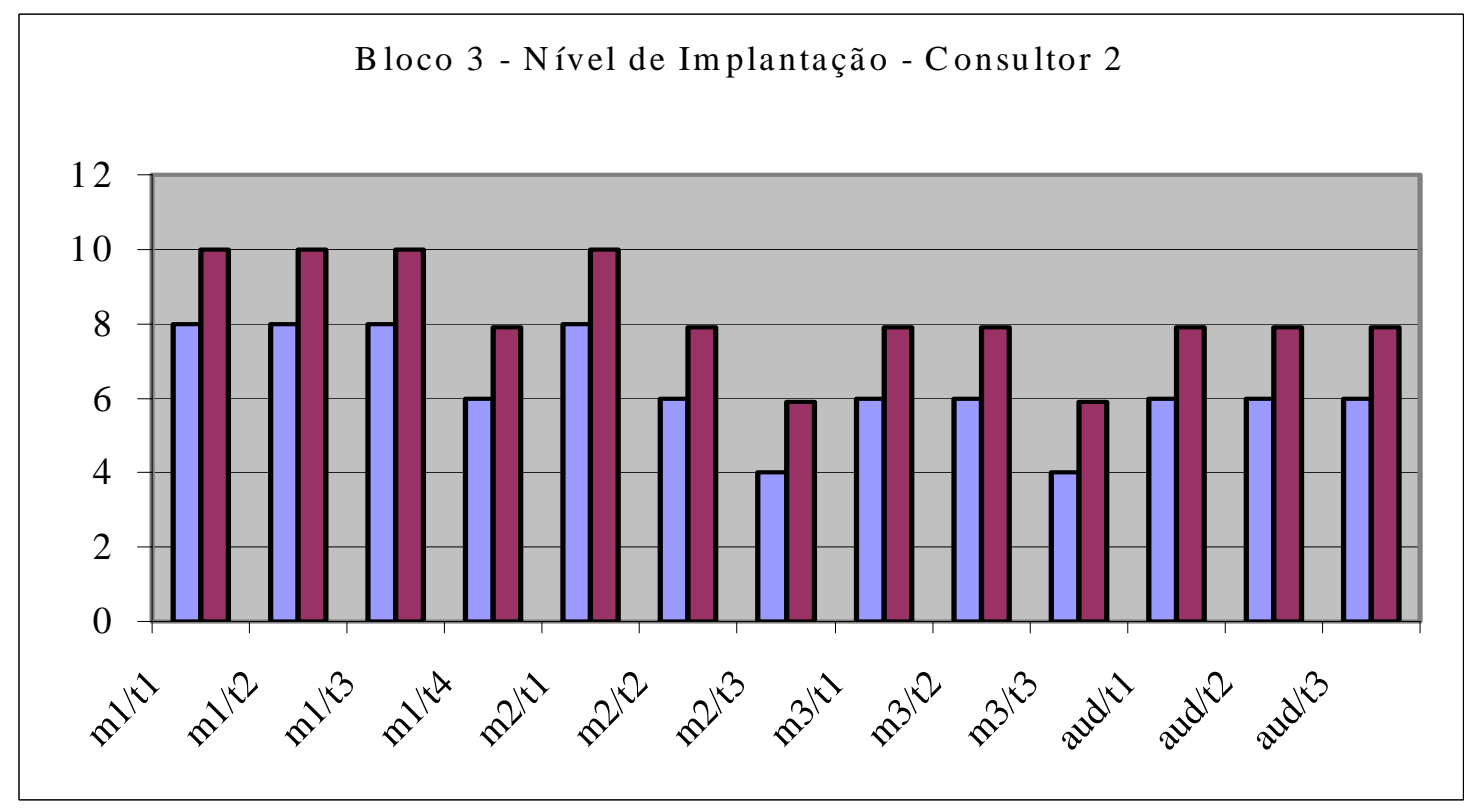

Figura 8: Nível de Implantação Bloco III - Consultor 2

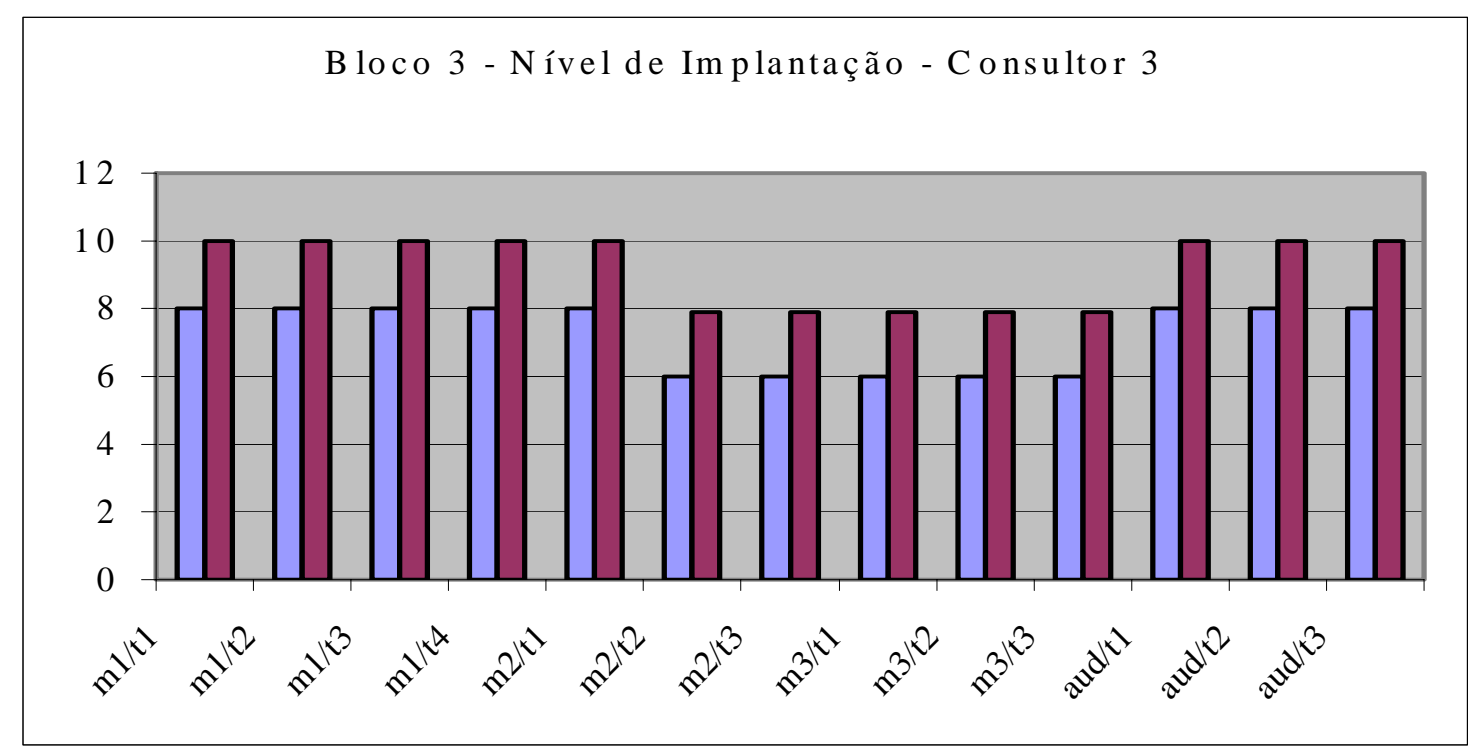

Figura 9: Nível de Implantação Bloco III - Consultor 3

Pode-se visualizar através dos gráficos apresentados três visões diferentes:

- consultor 1, apresenta resultados mais céticos a respeito da implantação do Programa, demonstrando níveis mais baixos de implantação pelas empresas das tarefas em todos os 
blocos, em comparação com os outros consultores; a diferença maior é encontrada no Bloco III. O consultor 1 apresenta níveis baixos de implantação até mesmo no Bloco I, que de acordo com os resultados encontrados na pesquisa de campo realizada e na revisão bibliográfica apresenta, de uma forma geral, níves de implantação elevados.

- consultor 2, apresenta resultados intermediários, demonstrando níveis de implantação medianos, de uma forma geral;

- consultor 3, apresenta resultados mais otimistas em relação ao nível de implantação pelas empresas das tarefas, o que ocorre até mesmo no Bloco III, que de acordo com os resultados encontrados na pesquisa de campo realizada e na revisão bibliográfica é o Bloco que demonstra níveis de implantação baixos. 